Uma abordagem de desenvolvimento de linha de produtos com uma arquitetura orientada a serviços 

SERVIÇO DE PÓS-GRADUAÇÃO DO ICMC-USP

Data de Depósito: 30 de novembro de 2009

Assinatura:

\title{
Uma abordagem de desenvolvimento de linha de produtos com arquitetura orientada a serviços
}

\author{
Paulo Gabriel Gadelha Queiroz
}

Orientadora: Profa. Dra. Rosana Teresinha Vaccare Braga

Dissertação apresentada ao Instituto de Ciências Matemáticas e de Computação - ICMC/USP, como parte dos requisitos para obtenção do título de Mestre em Ciências de Computação e Matemática Computacional. 

A Deus, por me dar oportunidade, capacidade e vontade para realizar este trabalho.

A toda minha família, em especial, meus pais Amélia e Paulo, meus avós Rita e Pedro e meus irmãos Pedro, Davi e Rebeca. Não existem palavras suficientes para expressar o quanto amo, admiro e tenho orgulho de vocês.

À Professora Dra. Rosana Teresinha Vaccare Braga, pela amizade, conselhos, conhecimento e confiança na orientação deste trabalho.

À Professora Dra. Renata P. M. Fortes e ao Prof. Dr. Antonio Francisco do Prado, pelas sugestões apresentadas no exame geral de qualificação.

Aos professores tanto da graduação quanto do mestrado que contribuíram para minha formação. Em especial, à Professora Dra. Rossana Andrade, à Professora Dra. Cláudia Linhares, ao Professor Dr. Riverson Rios, ao Professor Dr. Joaquim Bento que foram fonte de inspiração durante a minha graduação e ao Professor Dr. Paulo C. Masiero, que sempre deu apóio ao meu trabalho.

A todas as minhas amigas, amantes, paixões e amores que estiveram do meu lado e me fizeram bem mais feliz, ou não. Em especial, a Ana Karinne que sempre apoiou minhas decisões, confiou em mim e participou das principais escolhas que me trouxeram aqui.

Aos amigos do LABES/USP, pelo companheirismo, pela hora do café, pelo futebol e pelos churrascos: Andrezinho, Brunão, Calvo, Cascão, Camila, Casão, Chan, Daga, David, Diogo, Digão, DJ D', Edson, Endo, Erika, Fabis, Frotinha, japa, KLB, Lenon, Logan, Marcelo, Maria, Nerso, Otávio, Paula Donegan, Pio, pikaxu, puiuna, Plúcio, Rafael, Rodolfo, rumus, tibum, tiozão, Vânia. Obrigado a todos!

Aos amigos e companheiros de rep que fizeram da minha estadia em São Carlos um momento bem mais divertido, agradável e prazeroso: beira, caca, calcinho, cabeção, Cyntia, etzinho, mada, Marcella Letícia, marquito, maycuzim, miel, mobilis, pablito, petinho, ricardim, van, tobinha, Viça e Xunim. Provavelmente esqueci de alguém, mas com certeza todos estão gravados em minhas melhores lembranças

Aos amigos de Fortaleza, por, apesar da minha ausência, ainda serem meus amigos.

Aos professores e funcionários do ICMC, pelo constante auxílio, disposição e atenção. 
A todas as pessoas que contribuíram de alguma forma para a realização deste trabalho.

Ao CNPQ, pelo apoio financeiro. 
"Há três coisas na vida que nunca voltam: a flecha lançada, a palavra pronunciada e a oportunidade perdida. Por isso, viva como se fosse o último dia, dance como se ninguém o olhasse e ame como se nunca sofrera por amor."(Provérbio Chinês + Paulo Gabriel) 

$\begin{array}{ll}\text { Abstract } & \text { Xv }\end{array}$

1 Introdução $\quad 1$

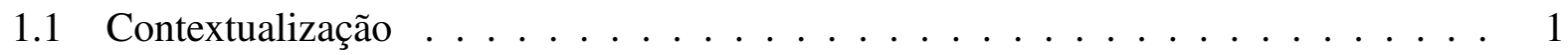

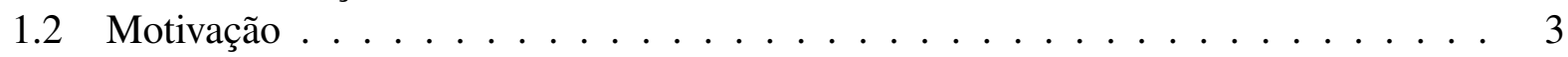

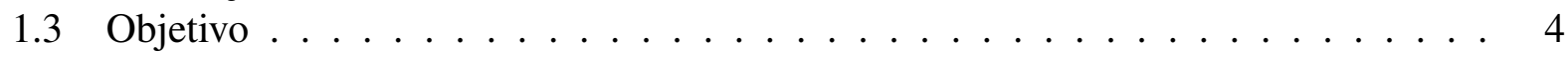

1.4 Organização . . . . . . . . . . . . . . . . . . . . 4

2 Fundamentação Teórica $\quad 7$

2.1 Considerações Iniciais $\ldots \ldots \ldots \ldots \ldots$

2.2 Linha de Produto . . . . . . . . . . . . . . . . . . . . 7

2.2.1 Abordagens para Desenvolvimento de LPS . . . . . . . . . . . . . . . . . 9

2.2.2 Variabilidades em Linhas de Produtos . . . . . . . . . . . . . . . . 16

2.3 Geradores de Aplicações . . . . . . . . . . . . . . . . . . . . . . . . 17

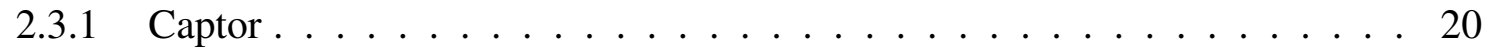

2.4 Arquitetura Orientada a Serviços . . . . . . . . . . . . . . . . . . 21

2.4.1 Arquitetura de software . . . . . . . . . . . . . . 21

2.4 .2 SOA: definição . . . . . . . . . . . . . . . . . . 22

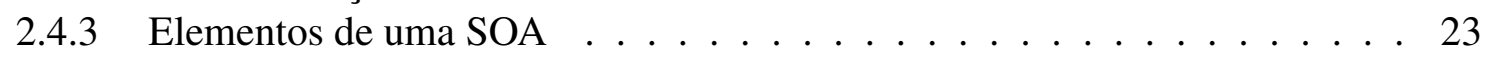

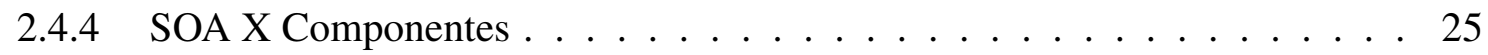

2.4.5 Classificação de Serviços . . . . . . . . . . . . . . . . . . . 26

2.4.6 SOA e os Web Services . . . . . . . . . . . . . . . . . . 27

2.4.7 Principais Padrões Usados pelos Web Services . . . . . . . . . . . . . . . . 28

2.4 .8 Processos de Negócios . . . . . . . . . . . . . . . . . . 32

2.5 Considerações Finais . . . . . . . . . . . . . . . . . . . . . . . 44

3 Trabalhos Relacionados $\quad 45$

3.1 Considerações Iniciais . . . . . . . . . . . . . . . . . . . . . . . . . . . . . . 45

3.2 Engenharia de Linhas de Produtos para Web Services e UML . . . . . . . . . . . 46

3.3 Uma Abordagem para o Desenvolvimento de Linhas de Produto Orientada a Serviço 48

3.4 Família de Processos de Negócios . . . . . . . . . . . . . . . . . . . 48

3.5 Um Método de Modelagem de Variabilidades para Serviços Adaptáveis . . . . . . 51

3.6 Abordagem para o Desenvolvimento de Populações de Famílias de Produtos . . . . 51 
3.7 Um Processo de Desenvolvimento de Aplicações Web baseado em Serviços . . . . 52

3.8 Considerações Finais . . . . . . . . . . . . . . . . . . . 53

4 Abordagem SoProL-WS $\quad \mathbf{5 5}$

4.1 Considerações Iniciais . . . . . . . . . . . . . . . . . . . 55

4.2 Caracterização da Abordagem . . . . . . . . . . . . . . . . . 56

4.3 Visão Geral do Domínio de Leilões Web . . . . . . . . . . . . . . . . . . . . . 58

4.4 Princípios Adotados para o Desenvolvimento da LPS . . . . . . . . . . . . . . . 59

4.5 Engenharia de Domínio . . . . . . . . . . . . . . . . . . 6 61

4.6 Atividades de Requisitos . . . . . . . . . . . . . . . . . . . . 63

4.6.1 Elicitação dos Requisitos . . . . . . . . . . . . . . . . . . . . . . 64

4.6.2 Identificação dos Processos de Negócio e suas Variabilidades . . . . . . . . 66

4.6.3 Modelagem de Casos de Uso . . . . . . . . . . . . . . . . . . . . . . . 69

4.6.4 Modelagem de Características . . . . . . . . . . . . . . . . . . 72

4.7 Atividades de Análise e Projeto . . . . . . . . . . . . . . . . . . . . . . . 74

4.7.1 Modelagem estática . . . . . . . . . . . . . . . . 75

4.7.2 Identificação dos Web Services . . . . . . . . . . . . . . . . 75

4.7.3 Modelagem de Navegação de Interface . . . . . . . . . . . . . . . . 79

4.7.4 Diagrama de Comunicação . . . . . . . . . . . . . . . . . . 80

4.7 .5 Projeto de Classes . . . . . . . . . . . . . . . . . . . . 81

4.7.6 Definição da Arquitetura . . . . . . . . . . . . . . . . . . . . 83

4.7 .7 Projeto de Banco de Dados . . . . . . . . . . . . . . . . . . . 84

4.8 Implementação . . . . . . . . . . . . . . . . . . . . . . . . 85

4.8.1 Definição do Ambiente de Desenvolvimento . . . . . . . . . . . . . 85

4.8 .2 Implementação . . . . . . . . . . . . . . . . . . . 86

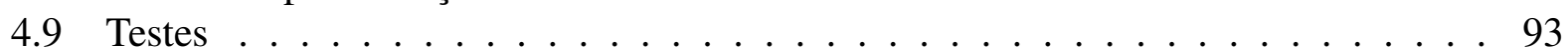

4.10 Manual para Geração dos Membros da LPS . . . . . . . . . . . . . . . 93

4.11 Engenheria de Aplicações . . . . . . . . . . . . . . . . . . . . . 93

4.12 Considerações Finais . . . . . . . . . . . . . . . . . . . . . . 94

5 Configuração do Captor-AO e Engenharia de Domínio 95

5.1 Considerações Iniciais . . . . . . . . . . . . . . . . . . . . . 95

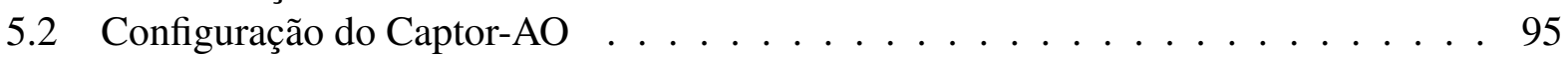

5.2 .1 Definição da LMA . . . . . . . . . . . . . . . . . . . . . . 97

5.2 .2 Criação dos Gabaritos . . . . . . . . . . . . . . . . . 98

5.2.3 Definição do Arquivo de Mapeamento de Transformação de Gabaritos . 100

5.2.4 Definição dos Arquivos de Pré e Pós-processamento . . . . . . . . . . . . . 101

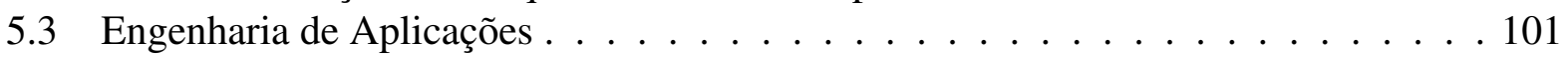

5.4 Considerações Finais . . . . . . . . . . . . . . . . . . . 106

6 Conclusão $\quad 107$

6.1 Contribuições . . . . . . . . . . . . . . . . . . . . 107

6.2 Dificuldades e Limitações . . . . . . . . . . . . . . . . . . . . . . . . . . . . 108

6.3 Trabalhos Futuros . . . . . . . . . . . . . . . . . . . . . 109 


\section{Lista de Figuras}

2.1 Estrutura do Processo de Análise de Características comuns de FAST (adaptada de Gimenes e Travassos (2002)). . . . . . . . . . . . . . . . . . . . . . 10

2.2 Visão geral da abordagem PuLSE para Linha de Produtos (adaptada de Bayer et al. (1999)). . . . . . . . . . . . . . . . . . . . . 12

2.3 Atividades essenciais de uma LPS (adaptada de Software Engineering Institute (SEI) (2007)) . . . . . . . . . . . . . . . . . . . . 13

2.4 Processo de engenharia de linhas de produtos evolucionário (adaptada de Gomaa (2004)) . . . . . . . . . . . . . . . . . . . . 14

2.5 Exemplo de modelo de características (adaptado de Gomaa (2004)). . . . . . . . . 17

2.6 Utilização de um gerador de aplicações (adaptado de Cleaveland (1988)). . . . . . 18

2.7 Arquitetura do Captor (adaptado de Shimabukuro Junior (2006)). . . . . . . . . . . 21

2.8 Colaborações em uma SOA (adaptado de Papazoglou e van den Heuvel (2007)). . . 24

2.9 Elementos de uma SOA (adaptado de Krafzig et al. (2004)). . . . . . . . . . . . . 25

2.10 Principais tecnologias para implementação de uma SOA (adaptado de Merson

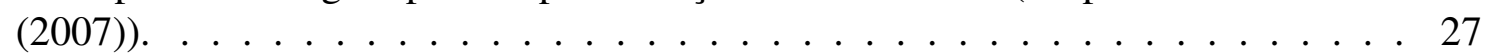

2.11 Coreografia de serviços $($ Endo, 2007) . . . . . . . . . . . . . . . . 33

2.12 Orquestração de serviços (adaptado de Endo (2007)). . . . . . . . . . . . . . . . 34

2.13 Inicialização do processo BPEL no ambiente de desenvolvimento. . . . . . . . . . . 42

2.14 Processo BPEL completo em modo visual. . . . . . . . . . . . . . . . . 43

2.15 Chamada ao processo de negócio. . . . . . . . . . . . . . . . . 43

2.16 Resultado da chamada. . . . . . . . . . . . . . . . . . . . . 44

3.1 Diagrama de Colaboração - Reserva de quarto (adaptada de Gomaa e Saleh (2005)). 46

3.2 Diagrama de Atividades - Reserva de quarto (adaptada de Gomaa e Saleh (2005)). . 47

3.3 Exemplos de interfaces de web services (adaptada de Gomaa e Saleh (2005)). . . . 47

3.4 Estágios de desenvolvimento de famílias de processos de negócios (adaptado de Ye et al. (2007)). . . . . . . . . . . . . . . . . . . . . . . 49

3.5 Exemplo de mapeamento de um diagrama de características A para um diagrama de classes B (Zaupa, 2007) . . . . . . . . . . . . . . . . . 53

4.1 Legenda BPMN. . . . . . . . . . . . . . . . . . . . . 58

4.2 Visão Geral da Abordagem SoProL-WS. . . . . . . . . . . . . . . . . . 58

4.3 Tipos de Leilões (Ré, 2002). . . . . . . . . . . . . . . . . . . . . . 60

4.4 Conjunto de artefatos gerados em cada atividade da abordagem SoProL-WS. . . . . 63

4.5 Diagrama de atividades dos sites: Mercado Livre e Milan Leilões. . . . . . . . . . 68 
4.6 Diagrama de atividades unificado com as variabilidades. . . . . . . . . . . . 68

4.7 Diagrama com os principais casos de uso da LP . . . . . . . . . . . . . . . . 71

4.8 Relação entre casos de uso e características. . . . . . . . . . . . . . . . . 73

4.9 Modelo hierarquico de características do núcleo da LPS de leilões Web. . . . . . . 74

4.10 Modelo hierarquico de características das variabilidades da LPS de leilões Web. . . 74

4.11 Modelo conceitual da LP. . . . . . . . . . . . . . . . . . . . . 76

4.12 Definição de alguns serviços da LPS de leilões Web. . . . . . . . . . . . . 79

4.13 Algumas telas da LPS de leilões Web com suas interações. . . . . . . . . . . . . . 80

4.14 Diagrama de comunicação da GUI VisualizarR. . . . . . . . . . . . . . . . . 81

4.15 Projeto do serviço participante. . . . . . . . . . . . . . . . . 83

4.16 Projeto arquitetural em alto nível. . . . . . . . . . . . . . . . . . . 84

4.17 Estrutura de pacote dos WS e da camada de visão da LPS de leilões Web. . . . . 87

4.18 Passos para a criação do WS . . . . . . . . . . . . . . . . . . . . 90

5.1 Configuração de um domínio no Captor-AO . . . . . . . . . . . . . . . . . . . 96

5.2 Relação entre os artefatos usados na configuração e uso do Captor-AO. . . . . . . . 97

5.3 Estrutura hierárquica dos formulários. . . . . . . . . . . . . . . . . . 98

5.4 Configuração do ponto de variação Tipo de Leilão. . . . . . . . . . . . . . . . . . 98

5.5 Escolha das característica para a aplicação alvo. . . . . . . . . . . . . . . 102

5.6 Exibição do log de geração do código XML . . . . . . . . . . . . . . . . . . . . . 102

5.7 GUI gerada pela transformação dos gabaritos feita pelo Captor-AO. . . . . . . . . 105 


\section{Lista de Tabelas}

2.1 Elementos WSDL. . . . . . . . . . . . . . . . . . . . 31

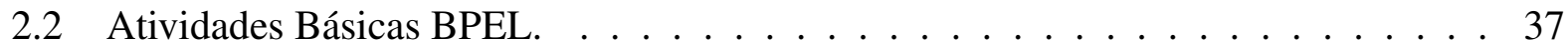

2.3 Atividades Estruturadas BPEL. . . . . . . . . . . . . . . . . . 37

3.1 Passos para o mapeamento de diagrama de características em diagrama de classes. . 52

3.2 Principais contribuições das abordagens apresentadas. . . . . . . . . . . . . . . 54

4.1 Requisitos Funcionais. . . . . . . . . . . . . . . . . . . . . 66

4.2 Tabela de mapeamento entre os casos de uso e os requisitos. . . . . . . . . . . . 70

4.3 Requisitos Funcionais. . . . . . . . . . . . . . . . . . . . . . 80

4.4 Avaliação das Ferramentas. . . . . . . . . . . . . . . . . . . . . . . 86

4.5 Requisitos Funcionais. . . . . . . . . . . . . . . . . . . . . . . . . 94

5.1 Avaliação das Ferramentas. . . . . . . . . . . . . . . . . . . . . . . . 98 



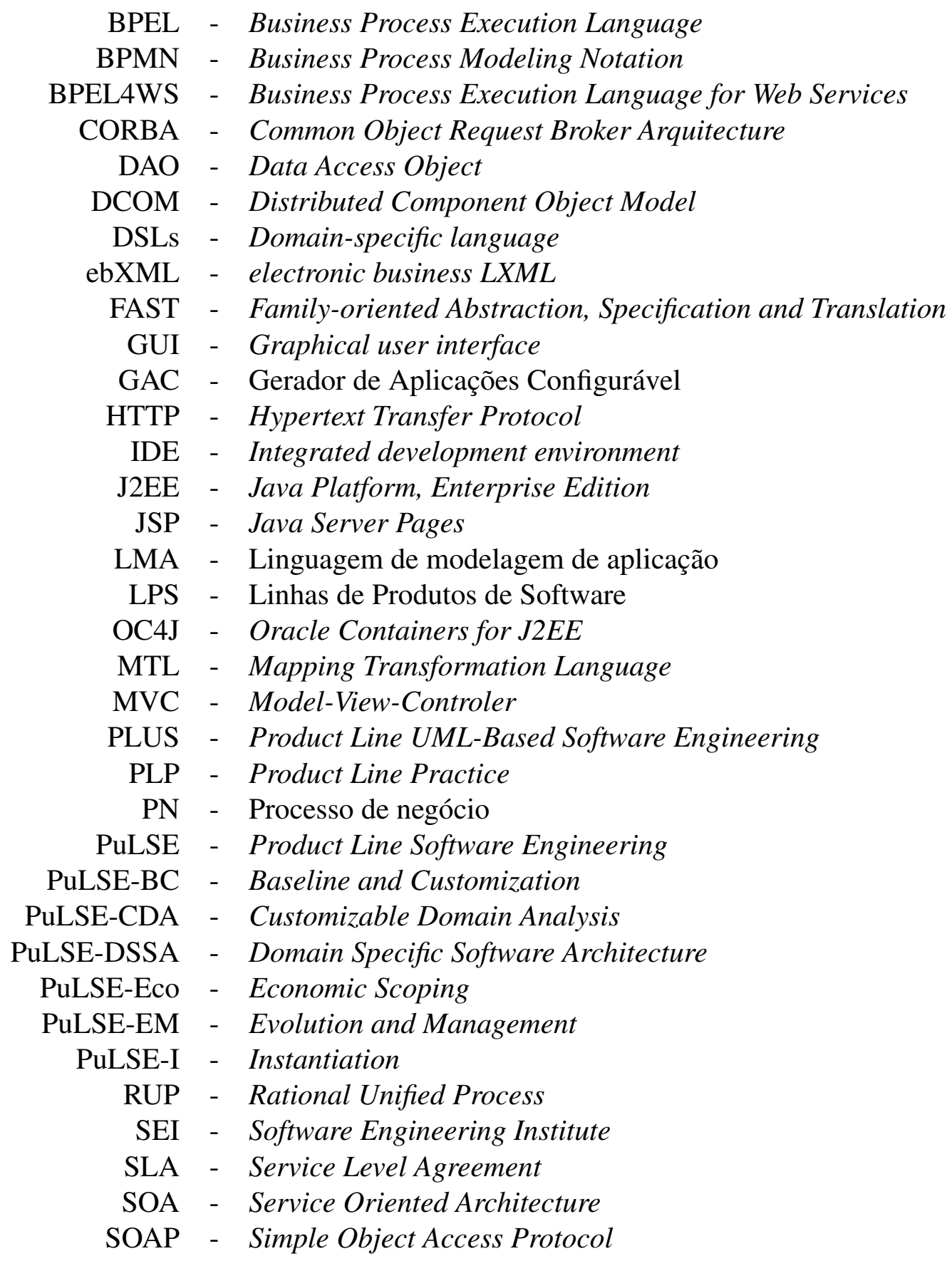


SOPLA - Service-oriente product-line architecture

SoProL-WS - Software Product Line-Web Services

TO - transfer Object

UDDI - Universal Description, Discovery, and Integration

UML - Unified Modeling Language

URI - Uniform Resource Identifier

USDP - Unified Software Development Process

W3C's - Web Services Architecture Working Group

WIDE-PL - Waterloo Informatics Development Environment-Product Line

WS - Web services

WS-BPEL - Web services Business Process Execution Language

WSCI - Web Service Choreography Interface

WSDL - Web Service Description Language

WSRF - Web Service Resource Framework

XML - Extensible Markup Language

XSL - Extensible Stylesheet Language

XPath - XML Path Language 
Inha de produtos de software (LPS) corresponde a uma das mais bem sucedidas formas de reúso, pois permite a reutilização de requisitos e arquitetura. Embora o desenvolvimento, manutenção e evolução de uma LPS ainda possua um custo alto quando comparado ao desenvolvimento de sistemas únicos (single systems), um lucro significativo pode ser obtido com a venda de diversos produtos derivados da LPS. No projeto de uma LPS analisa-se os sistemas coletivamente, ou seja, o domínio. Geradores de aplicações são ferramentas capazes de gerar artefatos a partir de uma especificação, e no caso de se ter a especificação de um domínio, é possível gerar aplicações para esse domínio. Web services representam uma tecnologia promissora para disponibilização de serviços na Web e desenvolvimento de software com arquitetura flexível e de fácil manutenção. Neste trabalho é proposta uma abordagem de desenvolvimento de linha de produtos com arquitetura orientada a serviços, na qual a geração de produtos é apoiada por um gerador de aplicações. A abordagem chama-se SoProL-WS e possui o objetivo de reduzir os custos e prazos de desenvolvimento da LPS e facilitar a sua manutenção, evolução e derivação de seus membros. SoProLWS apresenta as atividades e artefatos necessários para partir dos requisitos da LPS, projetar, implementar, configurar um gerador de aplicações e gerar seus membros a partir do gerador ou por meio de uma configuração manual. Além disso, é apresentado um estudo de caso com o desenvolvimento de uma linha de produtos de leilões Web seguindo os passos da abordagem, bem como são discutidas as alternativas de projeto relevantes para esse tipo de desenvolvimento. 

oftware product lines (SPL) is a successful reuse technique that fosters requirements and architecture reuse. Although SPL costs with development, maintenance and evolution increases when compared to single system development, significant profit can be obtained by selling many products derived from SPL. In a SPL project, systems are analised collectively like a domain. Application generators are tools capable of generating artifacts based on an specification, in case of a domain specification, it is possible to generate applications in this domain. Web services represent a technology to make services available over a network and to develop a flexible and adaptable software architecture. This work presents an approach, called SoProL-WS, to develop SPL using service oriented architecture, where product derivation is supported by an applicator generator. The aim of this approach is to enhance flexibility, reuse and consequently decrease SPL development costs. In addition, this work presents a case study where SoProL-WS is applied to develop a Web auctions SPL. 


\subsection{Contextualização}

A engenharia de software tem progredido de modo a criar ou evoluir técnicas e métodos para o desenvolvimento de software com qualidade e de forma mais rápida, para cumprir os prazos e metas dos projetos. Um dos fatores que nos leva a atingir essas metas é o foco no reúso durante o processo de desenvolvimento de software (Krueger, 1992). A reutilização de requisitos, arquitetura e outros artefatos em níveis altos de abstração mostra-se mais eficiente em comparação às técnicas que focam em código. Uma técnica promissora para esse tipo de reúso são as linhas de produtos de software (LPS) (Gomaa, 2004).

Uma LPS consiste de um conjunto de sistemas de software que compartilham características comuns e gerenciadas e que satisfazem a uma necessidade específica de um segmento particular de mercado, sendo desenvolvidas a partir de um conjunto comum de ativos centrais, de forma sistemática (Clements e Northrop, 2001). Os produtos de uma LPS distinguem-se, uns dos outros, em termos de características (features), que são abstrações essenciais entendidas por clientes e desenvolvedores (Kang et al., 2002).

O desenvolvimento de uma linha de produtos exige mais esforço do que o desenvolvimento de um sistema único tradicional (single system), uma vez que linhas de produtos exigem duas fases de desenvolvimento. A primeira fase é chamada de engenharia de domínio e nela são desenvolvidos uma série de artefatos genéricos para os produtos da linha. A segunda fase é conhecida como engenharia de aplicações e utiliza os artefatos desenvolvidos na engenharia de domínio para montar os produtos da linha. Embora tenha maior custo, torna-se vantajoso desenvolver uma LPS quando 
o ganho é potencialmente maior analisando-se os sistemas coletivamente, ao invés de analisálos em separado, ou seja, quando os sistemas apresentam mais características em comum do que características que os distinguem (Parnas, 1978).

Uma LPS possui pontos de variação, que são locais em que uma variação pode ocorrer. A instância de um ponto de variação é uma característica variante, que identifica uma única opção de um ponto de variação e diferencia um produto de outros. Existem diversas técnicas para o projeto de uma LPS, como a utilização de frameworks (Weiss e Lai, 2004), aspectos (Pacios, 2007), componentes (Gomaa, 2004; Atkinson et al., 2002), serviços (Gomaa e Saleh, 2005) ou possivelmente alguma combinação dessas técnicas.

Os geradores de aplicações são ferramentas capazes de gerar artefatos a partir de uma especificação em alto nível. Entre os artefatos que podem ser gerados têm-se os segmentos de código, subrotinas, sistemas de software, entre outros. O objetivo dos geradores de aplicações é maximizar a automatização do desenvolvimento de aplicações (Cleaveland, 1988; Czarnecki et al., 2002). Uma vez que durante o desenvolvimento de linhas de produtos geram-se artefatos genéricos para um certo domínio, pode-se utilizar geradores de aplicações para a derivação dos sistemas alvo (membros) da LPS. Entre os geradores de aplicações destacam-se os geradores de aplicações configuráveis (GAC), que podem ser adaptados para geração de artefatos em diferentes domínios.

Uma das técnicas ainda pouco abordadas em LPS é a utilização de serviços. Um serviço é a implementação de uma funcionalidade de negócios bem definida, que pode ser utilizada por clientes em diferentes aplicações e processos de negócio. Um serviço possui uma interface pública, com ênfase em interoperabilidade, disponibilidade e pode se ligar dinamicamente com outros serviços. Clientes, nesse caso, podem ser tanto aplicações de usuário final (por exemplo, páginas Web ou aplicações desktop) quanto outros módulos de aplicações de processos negócios (por exemplo, outros serviços) (Mahmoud, 2005). Um web service (serviço Web) é um tipo de serviço independente de plataforma que está disponível na Web e pode ser utilizado por meio de protocolos baseados em XML (Extensible Markup Language) (W3C, 2008).

Uma arquitetura orientada a serviços (SOA) é um estilo arquitetural para a construção de aplicações de software que utilizam serviços disponíveis em uma rede (Mahmoud, 2005). Uma SOA básica não trata apenas de serviços. Ela é um relacionamento entre três tipos de participantes: o provedor de serviços, o repositório de serviços e o solicitante de serviços (cliente). As operações envolvem publicação, busca e ligação (Papazoglou, 2003). Web services representam uma das tecnologias capazes de implementar uma SOA. Em princípio, um serviço assemelha-se a um componente, contudo o serviço possui uma série de características que o tornam diferenciados, como a forma de comunicação entre eles, o tipo de acoplamento, de interface, de invocação, de reúso, entre outros.

Os web services podem ser requisitados de forma independente ou podem ser agrupados em colaborações conhecidas como processos de negócios. Um processo de negócios é um fluxo de atividades progressivas, no qual cada atividade representa o trabalho de uma pessoa, um sistema 
interno ou o processo de uma empresa parceira, para atingir algum objetivo empresarial (Ye et al., 2007). Essas atividades são tipicamente implementadas como operações de um serviço.

O uso de SOA no desenvolvimento de LPSs pode trazer diversos benefícios ao seu projeto, como a possibilidade de utilizar serviços existentes na Web, disponibilizar na Web os serviços construídos para a LPS, projetar arquiteturas flexíveis, gerar produtos pela composição de serviços e até a possibilidade de alterar os membros da linha em tempo de execução.

\subsection{Motivação}

Facilmente identifica-se em empresas de um mesmo segmento ou domínio, produtos de software com grande semelhança mas que apresentam alguma variabilidade, o que nos leva a visualizálos como uma linha de produtos. Com o uso da abordagem de LPS pode-se aumentar o reúso por intermédio do reaproveitamento de requisitos e arquitetura e reduzir os custos de produção quando são desenvolvidos diversos sistemas a partir desta mesma linha de produtos. Existem diversas abordagens de desenvolvimento de LPS e elas possuem duas vertentes. A primeira possui foco na engenharia de domínio, na qual investe-se a maior parte dos recursos no projeto da linha, que na maioria dos casos é baseada em componentes. Exemplos de autores nessa linha são Gomaa (2004) e Clements e Northrop (2001). A outra vertente foca na engenharia de aplicação e possui o objetivo de automatizar essa fase, o que consiste de uma abordagem menos flexível, uma vez que incorporar mudanças resulta na necessidade de mudar a forma de gerar as aplicações. Weiss e Lai (2004) são exemplos de autores que seguem essa linha.

Web services (WS) tem recebido, recentemente, grande atenção da academia, indústria e órgãos de padronização (Chou et al., 2006; Barros et al., 2005; Endrei et al., 2004; Gomaa e Saleh, 2005; van Gurp e Savolainen, 2006; Krafzig et al., 2004; W3C, 2002b; OASIS, 2007). Como a principal forma de realização de SOA, os web services oferecem formas para realizar arquiteturas com baixo acoplamento, soluções de interoperabilidade entre sistemas com plataformas heterogêneas, possibilidade de alteração de aplicações em tempo de execução, entre outros benefícios. Como o uso de web services e SOA continua a crescer, as linhas de produtos deveriam tirar vantagem dos benefícios alcançados com o uso dessa tecnologia. Para isso, deveriam ser elaborados métodos que possibilitem a análise, projeto, implementação e manutenção de linhas de produtos baseadas em web services. Entre os poucos trabalhos relacionados encontrados pelo autor desta dissertação até o momento de sua escrita, está a abordagem de desenvolvimento de LPS baseada em WS proposta por Gomaa e Saleh (2005). Entretanto, ela não apresenta detalhes sobre como definir os serviços, como identificar variabilidade em processos de negócios, como gerenciar os dados das diversas aplicações geradas ou como montar os produtos na engenharia de aplicação.

Portanto, a motivação deste trabalho é apresentar um método de desenvolvimento de LPS com uma arquitetura orientada a serviços baseada em WS, que permita o desenvolvimento bem sucedido, com flexibilidade, facilidade de manutenção e que apresente detalhes de como derivar seus 
membros na fase de engenharia de aplicação, preenchendo as principais lacunas deixadas pelas abordagens existentes.

\subsection{Objetivo}

Um dos objetivos deste trabalho é propor uma abordagem de desenvolvimento de LPS que possua um projeto arquitetural baseado em serviços e use um gerador de aplicações configurável (GAC) para a derivação dos membros da linha. O objetivo dessa abordagem é produzir LPSs de forma mais rápida por meio da união das duas vertentes de desenvolvimento apresentadas nas Seção 1.2, com a flexibilidade proporcionada pela utilização de web services, e facilidades para a geração de produtos derivados por intermédio da utilização de um gerador de aplicações. Esta abordagem também visa preencher as lacunas deixadas pelas abordagens apresentadas no Capítulo 3 , pois trata dos problemas essenciais desse tipo de desenvolvimento.

Outro objetivo desta dissertação é investigar questões relacionadas ao projeto de LPS com uma arquitetura orientada a serviços, ou seja, pesquisar diferentes alternativas de projetos de serviços e projetos de processos de negócios para projetar e implementar as variabilidades da LPS. Pretende-se também investigar a geração de produtos da LPS por meio da utilização de um gerador de aplicações para automatizar a fase de engenharia de aplicações. Nesse caso, o gerador é responsável por adicionar as chamadas aos serviços ou processos de negócios nas classes que recebem requisições, bem como configurar as interfaces do usuário que devem estar presentes no sistema alvo (membro) da LPS. Utiliza-se para isso o gerador de aplicações Captor-AO (de Freitas Pereira Júnior, 2006), desenvolvido no ICMC como extensão do gerador Captor (Shimabukuro Junior, 2006).

Para analisar essas questões e avaliar as propostas feitas, é utilizada uma linha de produtos para leilões Web como estudo de caso. Os principais passos do desenvolvimento dessa LPS são detalhados e, com isto, pretende-se investigar o desenvolvimento de LPSs com SOA e ter softwares orientados a serviços que possam apoiar outras pesquisas.

\subsection{Organização}

No Capítulo 2, apresenta-se os conceitos sobre LPS, geradores de aplicações e SOA. São apresentadas as principais abordagens para o desenvolvimento de LPS, conceito e modelagem de variabilidades, geradores de aplicações, estrutura de uma SOA, paradigmas para composição de web services e suas abordagens, além de apresentar as tecnologias usadas por WS. No Capítulo 3, fazse um levantamento dos trabalhos relacionados que apresentam técnicas e abordagens objetivando unir os conceitos de LPS e SOA. No Capítulo 4, apresenta-se uma visão geral da abordagem proposta que recebeu o nome de SoProL-WS. Adicionalmente, apresenta-se suas contribuições em relação a outras abordagens, suas atividades e artefatos gerados em cada etapa do desenvolvi- 
mento, com o seu respectivo exemplo aplicado ao estudo de caso de leilões Web. No Capítulo 5, apresenta-se a configuração da LPS de leilões Web no gerador de aplicações Captor-AO, bem como sua aplicação na engenharia de aplicação da LPS. Por fim, no Capítulo 6, as conclusões deste trabalho são apresentadas, destacando-se as principais contribuições, dificuldades e limitações encontradas, além de sugestões de trabalhos futuros. 



\section{Fundamentação Teórica}

\subsection{Considerações Iniciais}

Neste capítulo, são apresentados os conceitos relevantes para a pesquisa realizada, tais como linha de produtos, geradores de aplicações, arquitetura orientada a serviços (SOA), web services e composição de web services.

O capítulo está organizado da seguinte forma. Na Seção 2.2, são explicados os conceitos de linha de produtos, destacando-se seus objetivos, vantagens de uso, tratamento de variabilidades e uma visão geral das principais abordagens de desenvolvimento. Na Seção 2.3, apresenta-se o conceito de geradores de aplicações, que podem ser usados, entre outras coisas, para geração automática de produtos da LPS. Na Seção 2.4, é feita uma introdução a SOA, com a apresentação de uma classificação para os serviços, além da definição dos web services e processos de negócio, destacando-se a tecnologia WS-BPEL para composição de serviços. Na Seção 2.5, faz-se uma conclusão sobre os tópicos apresentados no capítulo.

\subsection{Linha de Produto}

Linha de Produtos de Software (LPS), também conhecida como família de produtos, corresponde a um conjunto de sistemas de software que compartilham características comuns e gerenciadas e que satisfazem a uma necessidade específica de um segmento particular de mercado, sendo desenvolvidas a partir de um conjunto comum de ativos centrais, de forma sistemática (Clements e Northrop, 2001). Uma linha de produtos é representada por produtos que, embora possuam 
requisitos em comum, ao mesmo tempo exibem variabilidade significativa nos requisitos (Griss, 2000).

Essa técnica de desenvolvimento de software tem como objetivo o desenvolvimento em larga escala. No desenvolvimento de uma linha de produtos, são reconhecidas as semelhanças e variabilidades de um conjunto de software em um certo domínio e é então executada uma engenharia de domínio em que são produzidos artefatos comuns (núcleo) aos produtos da linha, de tal forma que os membros (produtos de software) da linha, por meio de uma engenharia de aplicação, possam ser desenvolvidos a partir dos artefatos do núcleo, adicionando-se ou não artefatos que implementam as partes variáveis dos produtos da linha. Esta técnica permite que grande parte dos requisitos e da arquitetura seja reusada, uma vez que pode-se tirar vantagem de suas características comuns e variabilidades previstas e evitar o esforço redundante no desenvolvimento de cada software independente. Como exemplos de partes variáveis (variabilidades) em LPS pode-se citar: o sistema operacional ao qual elas se destinam; funcionalidades presentes ou não nos produtos da linha; funcionalidades presentes em produtos da linha mas com diferença na sua implementação ou no seu uso.

No desenvolvimento de uma LPS, é projetada uma arquitetura do sistema de modo a atender as necessidades de todo o conjunto de produtos e fornecer um contexto no qual outros recursos, tais como código e testes, possam ser desenvolvidos com flexibilidade o suficiente para satisfazer os produtos e serem facilmente adicionados à linha.

As técnicas de linha de produtos são usadas amplamente na indústria automotiva, aeronáutica e eletrônica. Tem-se por exemplo a linha de produtos que representa a família de aviões da Airbus, representada pelos modelos A-318, A-319, A-320 e A-321. São aeronaves com 100 a 220 lugares, movidas por linhas de produtos de motores com linhas de produtos de equipamentos de controle $\mathrm{e}$ navegação (Clements e Northrop, 2001).

No âmbito de linha de produtos de software, Clements e Northrop (2001) citam diversas empresas que adotaram essa abordagem com grande sucesso. Em decorrência do aumento do interesse em LPS, muitos trabalhos recentes, principalmente com software para dispositivos móveis e para sistemas embarcados, estão explorando as possibilidades da utilização dessa abordagem. Alguns fabricantes de celulares mantém, entre outras, uma LPS para o menu de seus celulares. Existe um núcleo que está presente no modelo mais simples e que vai ganhando variabilidades em outros modelos mais complexos.

Ao contrário dos métodos convencionais de desenvolvimento de software que desenvolvem seus produtos de forma manual como uma arte, a engenharia de software de linha de produtos preocupa-se com a industrialização do processo de desenvolvimento. Essa industrialização inclui o aprendizado da configuração e montagem de componentes para a produção de produtos similares, integração e automação do processo de produção, desenvolvimento de ferramentas que configuram e automatizam tarefas repetitivas, melhoramento das relações entre clientes e fornecedores para a redução de riscos, automação da produção de variantes dos produtos, distribuição da produção 
entre os diferentes fornecedores e padronização de processos (Greenfield e Short, 2003; Weiss e Lai, 2004).

Vários artefatos são implementados para satisfazer as possíveis funcionalidades de um produto da linha. Um determinado produto é composto utilizando-se artefatos dos diversos tipos de funcionalidades. As diferentes escolhas de artefatos podem fazer com que dois produtos tenham funcionalidades diferentes ou as mesmas funcionalidades com características diferentes. Custo e tempo de desenvolvimento são diminuídos, já que o esforço de desenvolvimento para qualquer produto sozinho é largamente distribuído para vários recursos reusáveis, cujo custo é distribuído a todos os membros da linha de produtos. Com essas técnicas, uma organização pode atingir níveis mais elevados de produtividade e construir sistemas sob demanda de forma mais eficaz (Shimabukuro Junior, 2006).

O benefício chave do uso de LPS resulta do compartilhamento da implementação de artefatos em múltiplos produtos, levando em geral a um menor custo de desenvolvimento e manutenção. Contudo, atingir esses benefícios na prática não é trivial. Uma grande dificuldade é a escolha da abordagem correta para o desenvolvimento da LPS. Uma escolha errada pode levar a vários problemas (Bosch, 2004). Os principais problemas e um framework de decisão para resolver esses problemas podem ser encontrados em Bosch (2004).

\subsubsection{Abordagens para Desenvolvimento de LPS}

Existem diversas abordagens para o desenvolvimento de LPS propostas na literatura. Como foi citado anteriormente, a escolha da técnica que melhor se adapta a cada caso é um passo fundamental para o sucesso no desenvolvimento da LPS. Nas subseções seguintes são apresentadas algumas das técnicas mais conhecidas e bem sucedidas.

\section{Abordagem Fast}

A abordagem FAST(Family-oriented Abstraction, Specification and Translation) (Ardis e Weiss, 1997)) foi desenvolvida pela Lucent Technologies na década de 90 e ainda continua em uso (Weiss e Lai, 2004). Essa estratégia foca no investimento em produção de facilidades para a família de produtos e é organizada em três subprocessos. O primeiro consiste em identificar famílias de produtos que compensam o investimento. Quando uma família de produtos é identificada, é feita uma análise econômica para estabelecer se vale a pena investir nessa família, ou seja, o investimento em produzir facilidades para a família é compensado por intermédio do lucro gerado pela produção de um conjunto de membros, com a expectativa de que a velocidade e variedade na produção possam garantir uma vantagem competitiva. O segundo subprocesso tem o propósito de investir em facilidades para a produção rápida de membros da família. É então feito um investimento em processos, ferramentas e recursos para criação rápida de membros da família. O terceiro subprocesso visa usar essas facilidades criadas no segundo subprocesso para produzir membros da família rapidamente (Weiss e Lai, 2004). 
A abordagem FAST utiliza a análise de características comuns como um passo inicial. Ela consiste de algumas reuniões com especialistas de um certo domínio, com a presença de um moderador e é organizada em fases, cada qual com objetivos específicos (Ardis e Weiss, 1997). Como resultado dessas reuniões é produzido um documento conhecido como análise de características comuns, organizada em cinco estágios: preparação, planejamento, análise, quantificação e revisão externa. Na Figura 2.1 apresenta-se a estrutura do processo de análise de características comuns de FAST. Na fase de preparação, o moderador assegura que todos os recursos necessários estão disponíveis. Nas outras quatro fases são realizadas as atividades apresentas na figura em forma de retângulos menores.

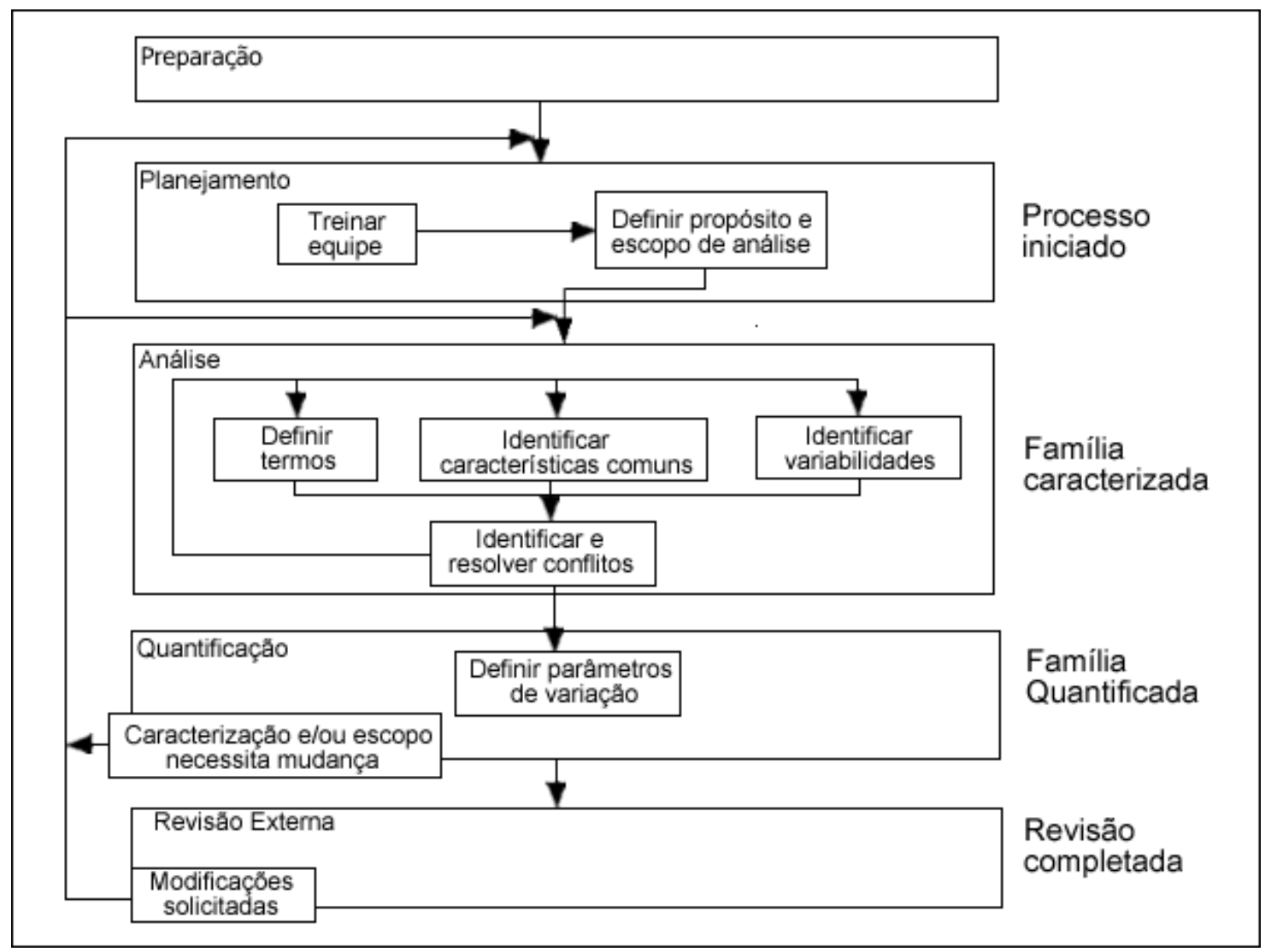

Figura 2.1: Estrutura do Processo de Análise de Características comuns de FAST (adaptada de Gimenes e Travassos (2002)).

\section{Abordagem PuLSE}

PuLSE(Product Line Software Engineering) (Bayer et al., 1999) é uma metodologia cujas fases são fortemente centradas no produto. Ela é articulada em torno de três elementos principais: as fases de desenvolvimento, os componentes técnicos e os componentes de suporte (Bayer et al., 1999). Os componentes são customizáveis para atender melhor a diferentes situações e contextos (Bayer et al., 2000a).

Bayer et al. (1999) apresentam as seguintes fases de desenvolvimento: 
- Inicialização: é o ponto de partida da iniciativa e tem a customização do PuLSE como resultado.

- Construção da infra-estrutura: corresponde à definição do escopo, modelagem e arquitetura da infra-estrutura da linha.

- Uso da infra-estrutura: uso da infra-estrutura para criar os membros da linha.

- Evolução e gerenciamento: envolve a evolução da infra-estrutura e o seu gerenciamento ao longo do tempo.

Os componentes técnicos fornecem o apoio técnico necessário para executar as atividades em cada fase do desenvolvimento (Knauber et al., 2000). Knauber et al. (2000) e Bayer et al. (1999) apresentam e definem os seguintes componentes técnicos:

- Customização: também conhecido como PuLSE-BC (do inglês Baseline and Customization), descreve como o PuLSE é inicializado, ou seja, como os outros componentes técnicos são customizados de acordo com o ambiente específico.

- Escopo: também conhecido como PuLSE-Eco (do inglês Economic Scoping), é utilizado para identificação de escopo para um membro da linha de produto.

- Modelagem: também conhecido como PuLSE-CDA (do inglês Customizable Domain Analysis), contém análise de domínio e elaboração do modelo de decisão que será utilizado para a criação da arquitetura da linha de produto. Esse modelo contém um conjunto estruturado de decisões. Cada decisão corresponde a uma variabilidade de um produto da linha junto com um conjunto de soluções para essa variabilidade.

- Arquitetura: também conhecido como PuLSE-DSSA (do inglês Domain Specific Software Architecture), apóia à definição da arquitetura específica de domínio, o que implica no desenvolvimento incremental da estrutura da linha de produto guiada por cenários. Cada cenário pode representar requisitos funcionais ou descrever aspectos qualitativos independentes do domínio.

- Instanciação: também conhecido como PuLSE-I (do inglês Instantiation), executa a instanciação do produto na fase que o utiliza.

- Evolução e gerenciamento: também conhecido como PuLSE-EM (do inglês Evolution and Management), lida com o gerenciamento de configuração e questões relacionadas à evolução do produto.

Os componentes de suporte fornecem diretrizes para o apoio aos outros componentes, são eles (Bayer et al., 2000b): 
- Pontos de entrada de projeto: personalizam PuLSE para tipos maiores de projeto.

- Escala de maturidade: usada para avaliar a qualidade de aplicação do processo PuLSE em empresas com o objetivo de identificar e melhorar os pontos fracos.

- Questões organizacionais: configuração e manutenção da estrutura da organização para apoiar o desenvolvimento e gerenciamento de linha de produtos.

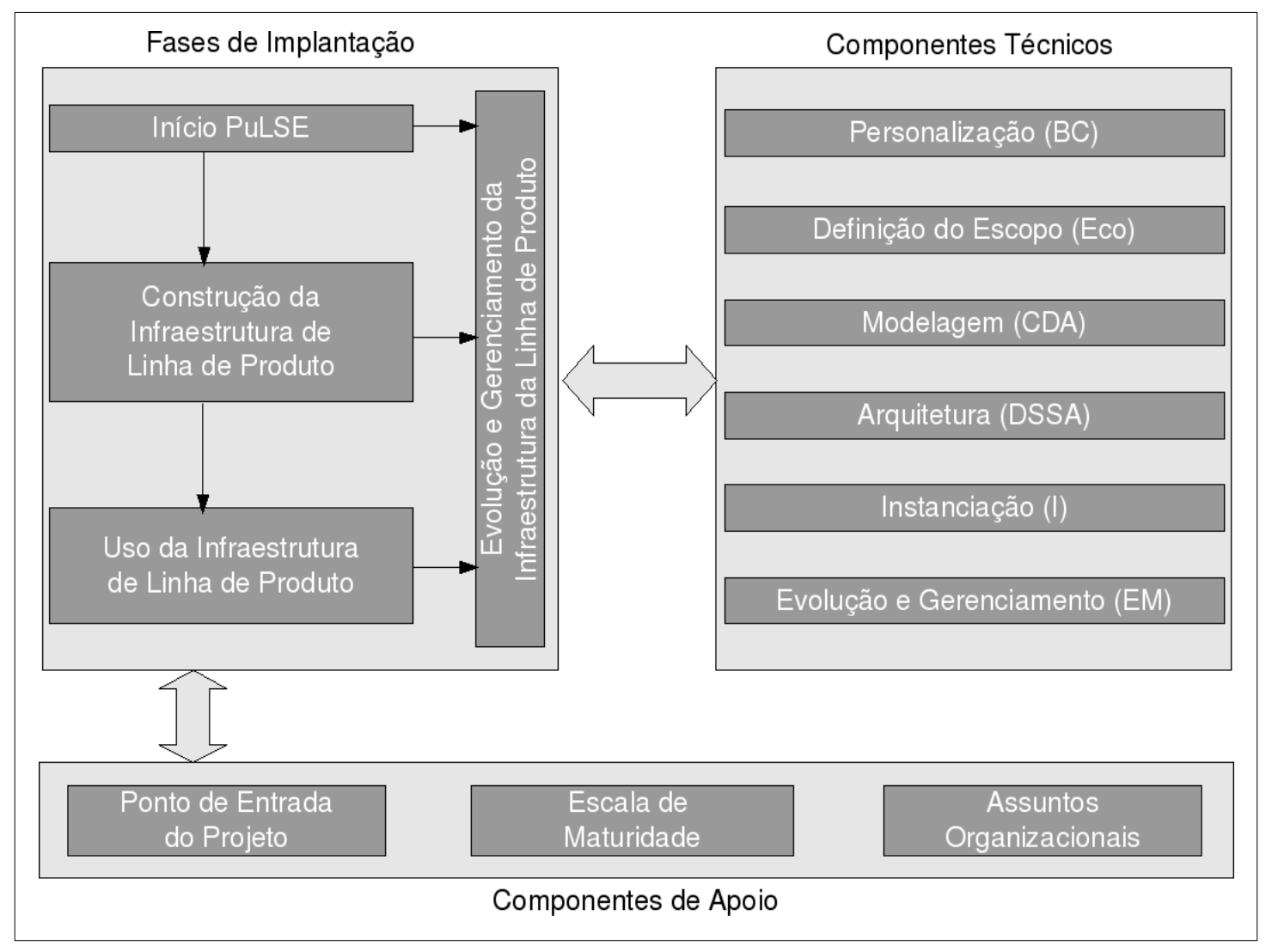

Figura 2.2: Visão geral da abordagem PuLSE para Linha de Produtos (adaptada de Bayer et al. (1999)).

Na Figura 2.2 são apresentadas as fases e os componentes da abordagem PuLSE. Observe como os componentes de suporte fornecem uma base para os outros componentes e como os componentes técnicos são usados ao longo das fases de implantação da LPS.

\section{Abordagem PLP}

A abordagem PLP (Product Line Practice) é uma estratégia para desenvolvimento de linha de produtos desenvolvida pelo SEI ( Software Engineering Institute). Ela é exposta em um documento Web para o apoio à comunidade de software. Cada versão representa uma tentativa incremental de compilar as últimas informações sobre práticas bem sucedidas em LPS (Software Engineering Institute (SEI), 2007). 


\section{Desenvolvimento de Linha de Produto}

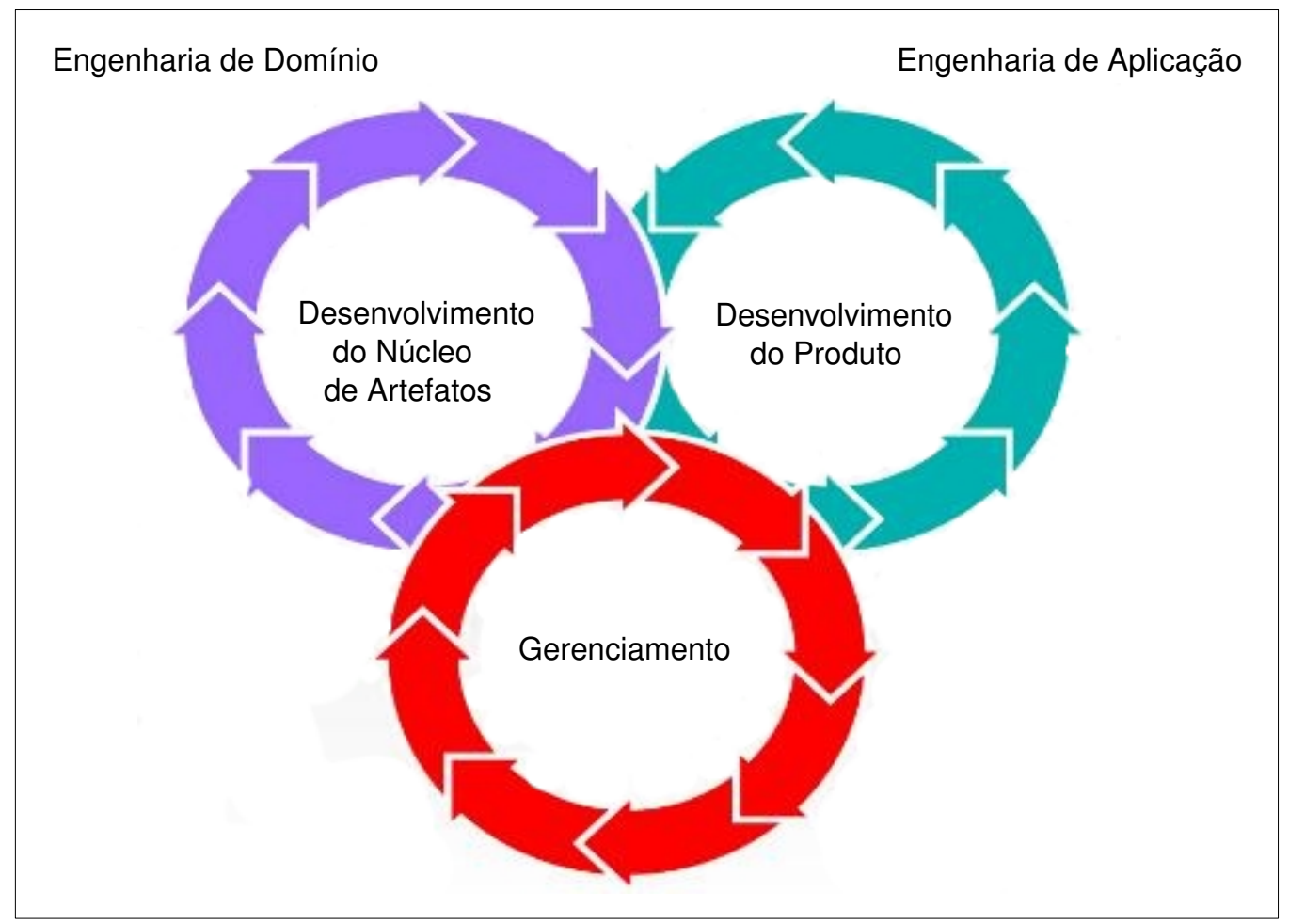

Figura 2.3: Atividades essenciais de uma LPS (adaptada de Software Engineering Institute (SEI) (2007)).

A iniciativa PLP estabelece três atividades essenciais para o desenvolvimento de linha de produtos: o desenvolvimento do núcleo de artefatos , também conhecido como engenharia de domínio; o desenvolvimento do produto, também conhecido como engenharia de aplicação; e o gerenciamento da LPS (Software Engineering Institute (SEI), 2007). Na Figura 2.3, são ilustradas essas atividades. Destaca-se a relação entre elas, que são iterativas e estão altamente interligadas, conforme é indicado pelas flechas rotativas que se entrecortam. A atividade de desenvolvimento do núcleo de artefatos pode passar por revisões ou inclusões de novos artefatos, na medida em que produtos são desenvolvidos, assim como novos produtos podem ser gerados, conforme são realizadas mudanças no núcleo de artefatos. Essas duas atividades são influenciadas pela atividade de gerenciamento.

A abordagem PLP define um conjunto de áreas de trabalho menores e mais gerenciáveis com o objetivo de realizar essas atividades essenciais.

\section{Abordagem Plus}

A abordagem Product Line UML-Based Software Engineering (PLUS) (Gomaa, 2004) estende os métodos de modelagem de sistemas únicos baseados em Unified Modeling Language (UML) (Object Management Group (OMG), 2007) para tratar linha de produto de software (Gomaa, 
2004). Ela é baseada no processo de desenvolvimento de sistemas conhecido como Unified Software Development Process (USDP) (Jacobson et al., 1999), também chamado de Rational Unified Process (RUP). Cada fase do PLUS corresponde a um workflow do USDP com o mesmo nome. O principal objetivo do PLUS é modelar explicitamente as características comuns e variáveis de uma LPS.

Gomaa (2004) faz uma divisão das atividades de requisitos, análise e projeto para a linha de produtos. As atividades de requisitos são divididas em: definição do escopo da LPS, modelagem de casos de uso e modelagem de características. As atividades de análise são divididas em: modelagem estática, construção de objetos, modelagem dinâmica, modelagem de máquina de estados finitos e análise de dependência de características/classes. As atividades de projeto correspondem ao projeto da arquitetura da LPS baseado em padrões arquiteturais.

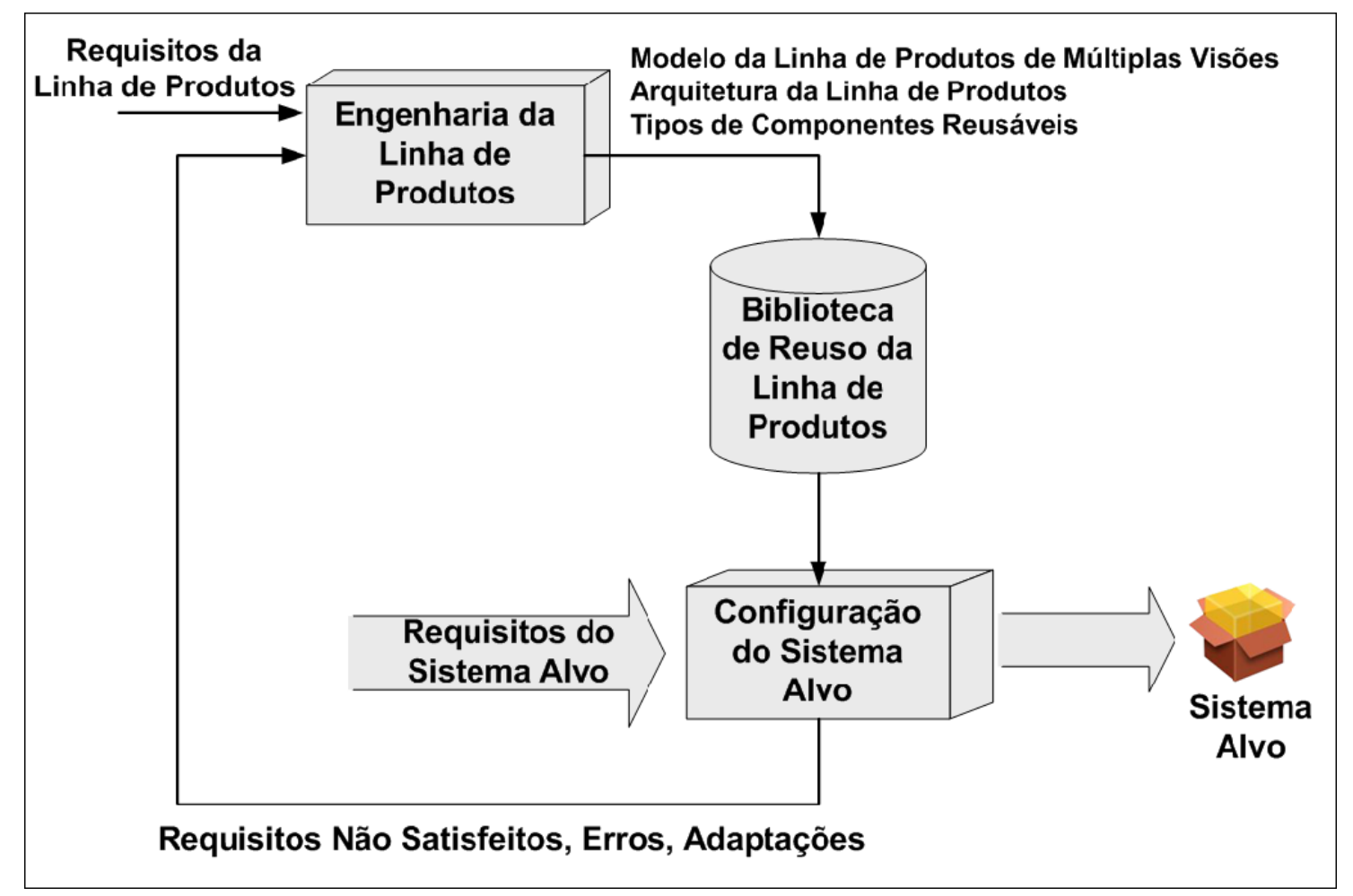

Figura 2.4: Processo de engenharia de linhas de produtos evolucionário (adaptada de Gomaa (2004))

Essa abordagem utiliza o processo de engenharia de linha de produtos evolucionário, que consiste de dois processos principais: a engenharia da linha de produto, representada por modelos de múltiplas visões da linha; e a configuração do sistema alvo, que é a configuração de um membro da LPS, onde o usuário seleciona as características desejadas para o esse sistema (Gomaa, 2004). Na Figura 2.4 ilustra-se esse processo.

As variações adicionadas em relação ao desenvolvimento de sistemas comuns são:

- Modelagem de casos de uso: são definidos três tipos de casos de uso. Os casos de uso do tipo kernel (núcleo) são aqueles presentes em todos os membros da linha. Os casos de uso 
do tipo optional (opcional) são aqueles presentes em somente alguns membros da linha. Os casos de uso do tipo alternative (alternativo) são aqueles que possuem diferentes versões requeridas por diferentes membros da linha. Adiciona-se a noção de pontos de variação, que é a localização, no caso de uso, dos pontos onde a mudança pode ocorrer.

- Análise de características: as características são analisadas como obrigatórias ou opcionais, que de forma semelhante aos casos de uso compreendem as características comuns a todos os membros da linha e as características comuns a alguns mas não todos os membros da linha, respectivamente. Existem ainda as características do tipo alternativa, que definem um grupo de características, no qual deve existir uma seleção de uma delas para estar presente em um membro da família e as características do tipo parametrizadas, que definem parâmetros da LPS cujo valor precisa ser definido em tempo de configuração do sistema e ainda, duas características que são sempre necessárias juntas, são chamadas de mutualmente inclusivas.

- Diagrama de classes: é adaptado para diferenciar as propriedades de reúso das classes da LPS. Nesse sentido, as classes podem ser do tipo núcleo, opcional ou variante. As que são usadas por todos os membros da linha são chamadas de classes do núcleo. As classes usadas por alguns mas não todos os membros da linha são chamadas de classes opcionais. As classes que apresentam diferentes versões em diferentes membros da linha são chamadas de classes variantes.

- Diagrama de comunicação: torna-se necessário realizar a modelagem dinâmica para todos os casos de uso, independentemente de sua categoria, para determinar que objetos são necessários para cada caso de uso e como eles interagem entre si. Os diagramas de comunicação também são categorizados como opcionais, alternativos ou núcleo.

- Máquinas de estado finito: cada variante deve ser modelada com seu próprio statechart.

- Existência da modelagem de dependência características/classes: mostra a relação existente entre as características e as classes, ou seja, mostra quais classes são necessárias para implementar determinada característica.

Nos diagramas usados, ocorre a introdução dos estereótipos para diferenciar entre os diferentes tipos de casos de uso, de classes ou de objetos. Os estereótipos usados são: $<<$ kernel $>>,<<$ optional $>>,<<$ alternative $>>$ ou $<<$ variant $>>$. O modelo de características para LPS é detalhado na Seção 2.2.2.

\section{Outras abordagens}

Existem ainda outras abordagens importantes para o desenvolvimento de LPS. Embora elas apresentem alguma semelhança, cada abordagem foca em um dos problemas específicos do desenvolvimento de LPS. Essas abordagens são: 
- Abordagem Synthesis: foi a predecessora da abordagem FAST (Ardis e Weiss, 1997). Foi elaborada pelo Software Productivity Consortium e descreve uma metodologia para construção de sistemas de software representando instâncias de uma família de sistemas que possuem descrições similares (Gimenes e Travassos, 2002).

- Abordagem kobrA: é uma abordagem de desenvolvimento de LPS que usa UML e componentes na implementação da linha (Atkinson et al., 2002).

Essas são as principais abordagens para o desenvolvimento de linha de produtos, cada uma delas tem um foco maior em alguma fase do desenvolvimento, possuindo seus pontos positivos e negativos.

\subsubsection{Variabilidades em Linhas de Produtos}

Variabilidade é a habilidade de mudar ou customizar um sistema. Melhorar a variabilidade em um sistema implica facilitar a realização de certos tipos de mudança. Em LPS, a arquitetura de um sistema real é fixada cedo, contudo os detalhes de implementação de um produto são atrasadas até a implementação. Refere-se a essas decisões atrasadas como pontos de variação (Gurp et al., 2001).

Segundo Gurp et al. (2001), as variabilidades podem ser pensadas como uma mudança no conjunto de características correspondentes. O conceito de features (característica) surgiu na engenharia de domínio. Uma feature é uma característica de um produto que usuários e clientes vêem como importante na descrição e distinção entre membros de uma linha de produtos (Griss, 2000).

Segundo Gomaa (2004), as variabilidades podem ser modeladas com o uso de parametrização, herança ou information hiding. A técnica a ser utilizada depende do nível de flexibilidade desejado para a linha de produtos. Em geral, na implementação de uma LPS, mais de uma dessas técnicas é utilizada.

\section{Modelo de Features para LPS}

Para apoiar o desenvolvimento de LPS, deve-se elaborar o modelo de características (Kang et al., 1990), que é uma representação hierárquica para capturar os relacionamentos estruturais entre as características de um domínio de aplicação. Existem três tipos de relacionamentos distintos entre as características: composição, generalização e implementado-por. Além disso, em uma composição, as características podem ser opcionais, obrigatórias ou alternativas (Kang et al., 1998).

As características relacionadas podem ser agrupadas e classificadas de acordo com Gomaa (2004) como:

- At least one of feature group: no mínimo uma característica do grupo deve ser selecionada.. 
- Exactly one of feature group: uma e somente uma característica pode ser selecionada de um grupo.

- Zero or more of feature group: nenhuma ou mais características podem ser selecionadas de um grupo.

- zero or one of feature group: nenhuma ou uma característica pode ser selecionadas de um grupo.

Na Figura 2.5, apresenta-se um exemplo de diagrama de características para uma LPS de hotel. Destaca-se que essa LPS possui as seguintes características e grupos de características: Uma característica comum, núcleo do hotel; Um grupo de características do tipo Zero or more of feature group, Opções hotel, que depende do núcleo do hotel; Um grupo de características do tipo Exactly one of feature group, alternativas do hotel, que consiste de dois grupos de características alternativas; dois grupos alternativos do tipo Zero or more of feature group, hotel Convencional e hotel Residencial, que são disponíveis para seleção.

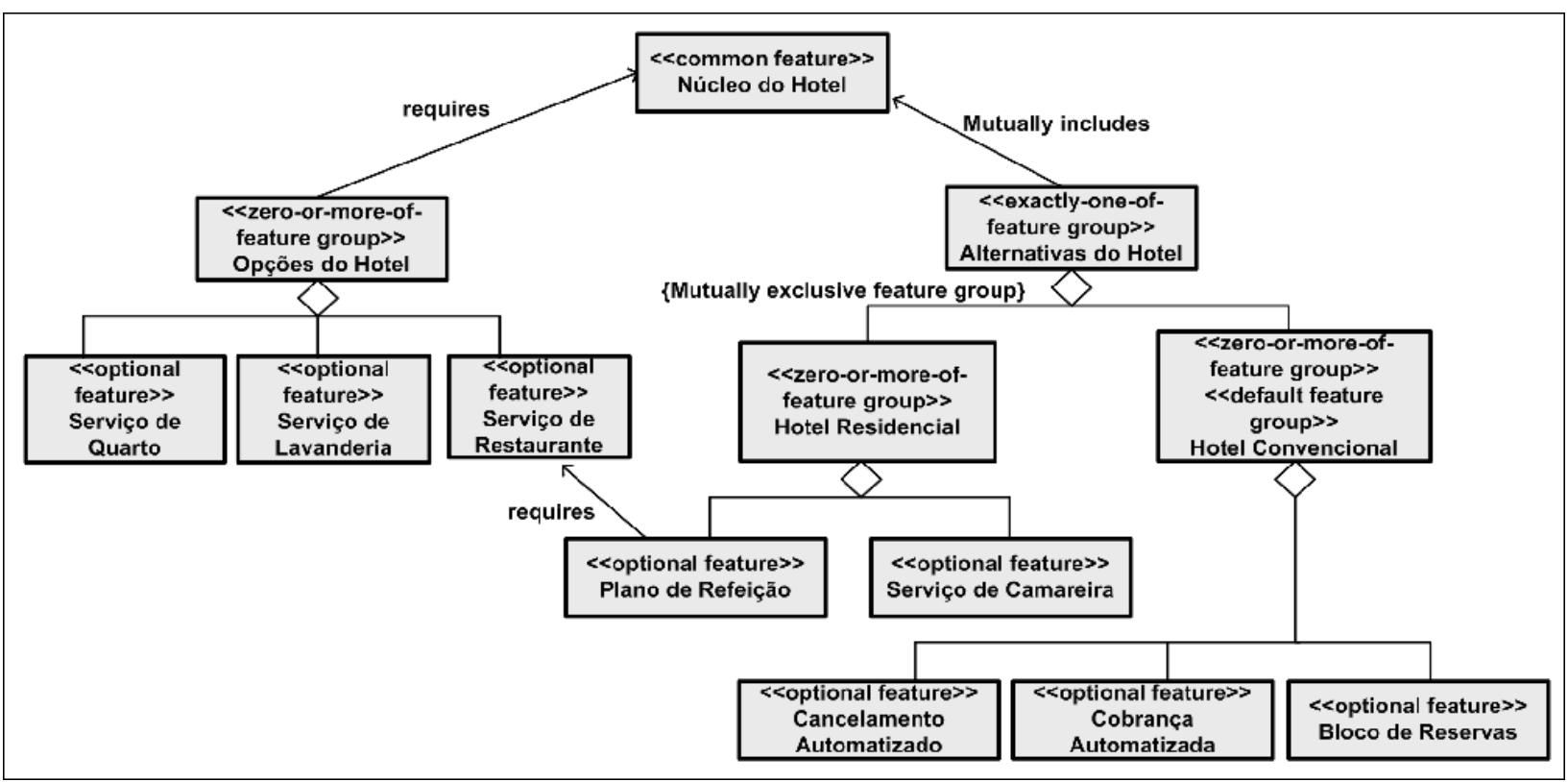

Figura 2.5: Exemplo de modelo de características (adaptado de Gomaa (2004)).

\subsection{Geradores de Aplicações}

Geradores de aplicações são ferramentas capazes de gerar artefatos a partir de uma especificação. A especificação descreve o problema ou tarefa a ser feita pelo artefato. Essa especificação pode ter a forma de um diálogo interativo, onde o usuário seleciona as opções desejadas a partir de uma série de menus, pode aparecer de uma forma gráfica, onde o usuário edita um diagrama ou pode ser escrita em alguma linguagem. Os artefatos gerados pelo gerador de aplicações podem 
ser segmentos de código, subrotinas, sistemas de software, entre outros. Geradores de aplicações tem como objetivo maximizar a automação do desenvolvimento de aplicações por meio do uso de software customizado reusável (Cleaveland, 1988; Czarnecki et al., 2002).

Pode-se dizer que um gerador de aplicações funciona de forma semelhante a um compilador, traduzindo as informações em alto nível para implementação de baixo nível. Alguns tipos são compiladores para linguagens de programação específicas de domínios (DSLs), esse termo é usado para descrever linguagens de programação para tarefas especializadas. Embora os compiladores possam ser vistos como geradores, a pesquisa e prática em geradores de aplicações foca em diferentes problemas daqueles tratados por compiladores, tais como transformação de programas (Smaragdakis e Batory, 2000). Sempre que for necessário modificar o produto, basta alterar as especificações de entrada e executá-las novamente no gerador de aplicação.

Na Figura 2.6 apresenta-se o processo de desenvolvimento de uma aplicação ou código utilizando um gerador de aplicações típico. Os quadrados representam arquivos e as elipses representam programas executáveis. O processo inicia-se com uma especificação que é submetida ao gerador de aplicação. O gerador transforma essa especificação em um programa ou código por exemplo. Esse programa passa por um compilador de sua linguagem específica, que gera o executável. A aplicação gerada recebe entradas, processa e gera uma saída correspondente.

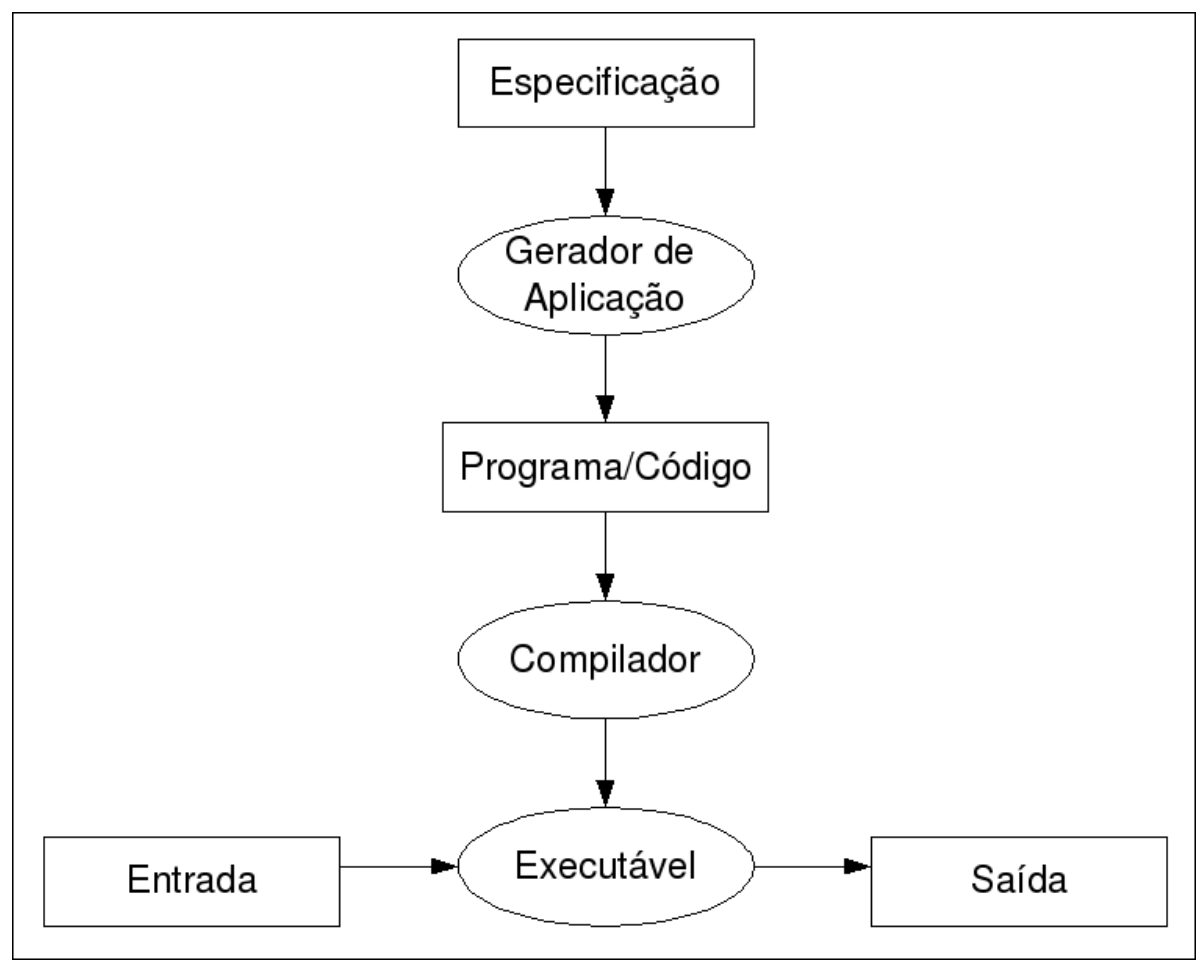

Figura 2.6: Utilização de um gerador de aplicações (adaptado de Cleaveland (1988)).

Cleaveland (1988) levantou um conjunto de vantagens e desvantagens do uso de geradores de aplicação. Vantagens:

- Permitem fácil customização e reúso de um projeto de software genérico. 
- Por meio da automatização do projeto do sistema, podem aumentar significativamente a produtividade durante o desenvolvimento e manutenção.

- A entrada para um gerador de aplicações é mais fácil de ler, escrever e alterar do que a entrada para um sistema convencional de codificação.

- Possibilita a redução de erros de programação, permitindo que os projetistas se concentrem nos erros de especificação.

- Possibilita a geração e manutenção de aplicações por usuários que não sabem programar.

- Facilita o teste e prototipação de especificações alternativas.

- Facilita a padronização da implementação. O gerador pode criar interfaces padronizadas ou gerar saídas formatadas.

Desvantagens:

- Um único gerador de aplicações pode ser usado efetivamente somente em alguns tipos de aplicação em um dado domínio (Jarzabek, 1995; Cleaveland, 1988)

- São difíceis de construir.

- É difícil reconhecer quando podem ser usados, e geralmente, esse reconhecimento ocorre em fases avançadas do desenvolvimento.

Um dos principais problemas dos geradores é que podem ser usados efetivamente somente em alguns tipos de aplicação (Cleaveland, 1988). Para minimizar esse problema, foram criados os geradores de aplicação configuráveis (GAC). Os GACs são geradores que podem ser adaptados para trabalharem com diferentes domínios. Um GAC configurado para um certo domínio deve apresentar as mesmas características de um gerador de aplicação específico, ou seja, receber uma especificação, armazená-la em meio persistente, permitir a edição e re-edição dessa especificação, validá-la e transformá-la em artefatos de software. A configuração de um GAC pode ser uma atividade menos custosa do que a construção de um gerador de aplicações específico (Shimabukuro Junior, 2006). Seção 2.3.1, apresenta-se o um gerador de aplicação configurável.

Para construir um gerador de aplicações é necessário ter conhecimento sobre o domínio da aplicação. Cleaveland (1988) destacou sete etapas necessárias para o desenvolvimento de um gerador de aplicações:

1. Reconhecimento de domínios, iniciado na maioria dos casos por meio do reconhecimento de padrões (Cleaveland, 1988).

2. Definição das fronteiras do domínio. 
3. Definição do modelo subjacente.

4. Definição das partes fixas e variantes.

5. Definição da especificação de entrada.

6. Definição dos produtos.

7. Implementação do gerador.

\subsubsection{Captor}

O Captor (Shimabukuro Junior, 2006) é um GAC que possui o objetivo de facilitar a geração de artefatos de software em diferentes domínios. Entre os artefatos que o captor pode gerar estão: código, documentação e testes. Esse gerador permite a definição de domínios com diferentes arquitetura de software.

O Captor possui quatro módulos, conforme é mostrado na Figura 2.7. O módulo de gerenciamento de projetos é responsável por fazer a criação, manutenção e a remoção de projetos. $\mathrm{O}$ módulo de gerenciamento de domínio cria uma estrutura de dados para representar o domínio escolhido pelo usuário para ser usada pelos outros módulos do gerador. O módulo de gerenciamento de interface apresenta as janelas para o usuário. Por fim, o módulo de transformação de gabaritos gera os artefatos. O Captor se baseia em arquivos XML e gabaritos XSL para realizar a configuração para domínios específicos.

Para utilizar o Captor corretamente é necessário seguir os seguintes passos:

- especificar a linguagem de modelagem de aplicação (LMA) em um conjunto de formulários organizados hierarquicamente em forma de árvore;

- criar gabaritos para cada artefato que deve ser gerado;

- fornecer um arquivo de mapeamento de transformação de gabaritos baseado na MTL (Mapping Transformation Language) definida por Shimabukuro Junior (2006);

- Configuração do captor e da ferramenta Ant (Davidson et al., 2009) para realização de pré e pós-processamentos específicos nos artefatos gerados.

O Captor foi posteriormente atualizado para permitir a geração de software que utilize mais de um domínio. A nova versão do Captor é chamada de Captor-AO (de Freitas Pereira Júnior, 2006), pois utiliza aspectos para a composição dos domínios. Com o Captor-AO, o engenheiro de aplicações pode utilizar um domínio principal, chamado de domínio base, e opcionalmente mais alguns domínios transversais compatíveis com o domínio base escolhido para compor as aplicações. Além dessa possibilidade de composição de aplicações com mais de um domínio o Captor-AO incorporou diversas melhorias relacionadas a usabilidade do Captor. 


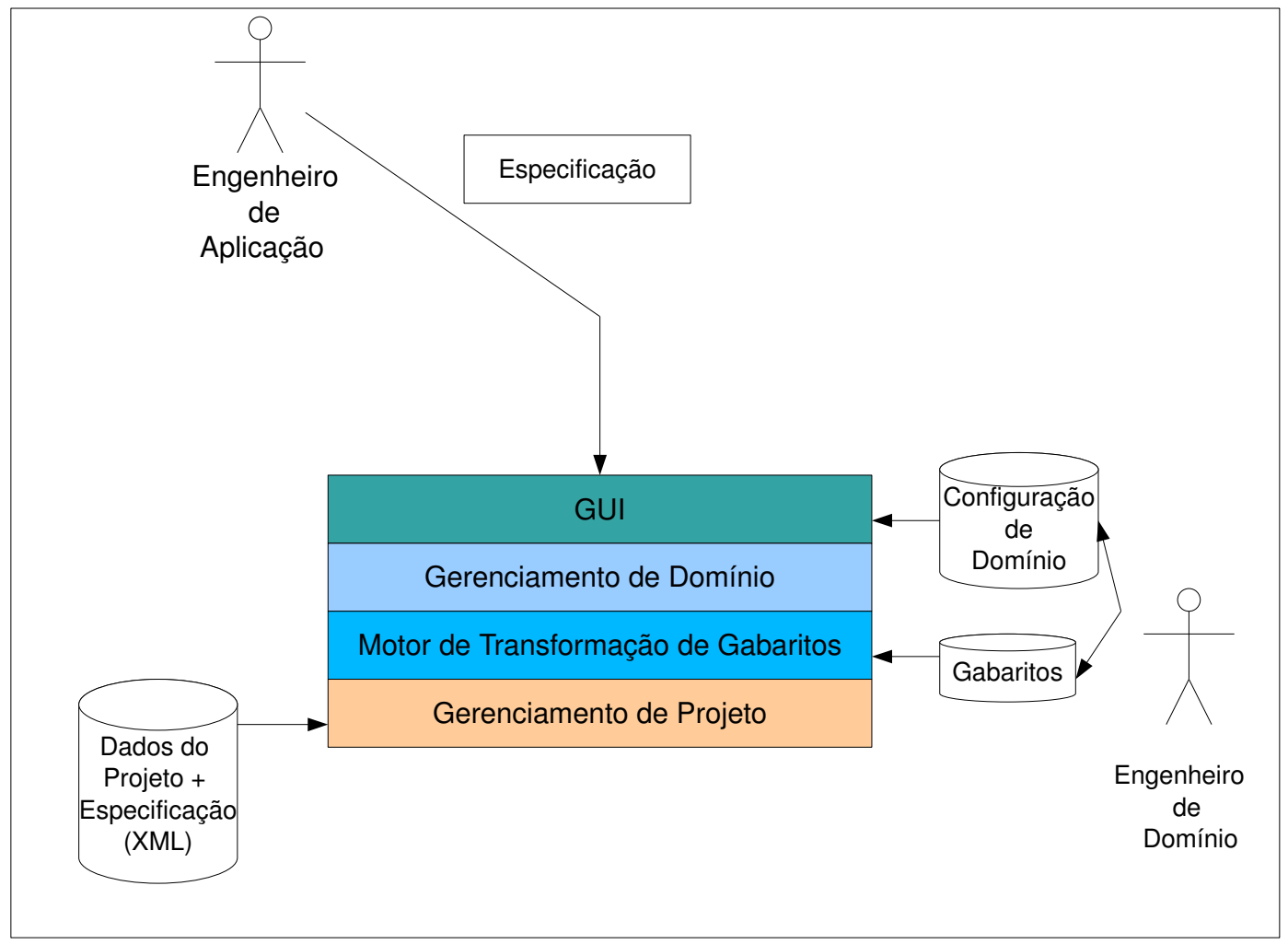

Figura 2.7: Arquitetura do Captor (adaptado de Shimabukuro Junior (2006)).

\subsection{Arquitetura Orientada a Serviços}

\subsubsection{Arquitetura de software}

O desenvolvimento de sistemas de informação empresarial tem sofrido de falta de agilidade e ineficiência. Tendo em vista que as empresas dependem fortemente do seu backbone de tecnologia da informação, que os sistemas são fortemente ligados à organização, aos processos e modelos de negócios das empresas e que esses mudam constantemente no mundo globalizado, seja por mudanças nas leis, fusões de empresas, alterações nos processos para aumentar competitividade ou mesmo em decorrência de mudança no comando, os sistemas de informação devem acompanhar essas mudanças da forma mais rápida possível. Essa velocidade não tem sido alcançada, pois esses sistemas são compostos por um grande número de subsistemas com complexas dependências cruzadas, o que aumenta a dificuldade de manutenção. Além disso, o número de usuários é potencialmente grande, o que gera um grande número de requisitos conflitantes e não precisos. Pode-se perceber que a tecnologia de desenvolvimento utilizada atualmente não está adaptada a conviver e aceitar que as mudanças são algo natural de um sistema de software (Krafzig et al., 2004; Baresi et al., 2006).

A arquitetura de um sistema de software preocupa-se com a decomposição em alto nível do sistema nos seus componentes principais. Existem três propósitos para uma definição explícita de uma arquitetura de software: permite uma avaliação antecipada e projeto dos atributos de qualidade 
de um sistema de software; representa um artefato concreto que pode ser usado para discussões com e entre as partes envolvidas no sistema; define os componentes arquiteturais e suas interações, o que facilita o reúso de forma geral (Bosch, 2000).

Para aumentar a velocidade de manutenção do software, ele precisa de uma arquitetura, que atenda aos seguintes requisitos: simplicidade, flexibilidade, manutenibilidade, reusabilidade e desacoplamento de funcionalidade e tecnologia (Krafzig et al., 2004; Komoda, 2006).

A comunidade de desenvolvedores de software não chegou a uma definição unânime de arquitetura de software (Baragry e Reed, 1998). A literatura nos apresenta diversas definições de arquitetura, das quais esse trabalho adotará, a partir desse ponto, a definição de Bass et al. (2003), por se tratar de uma definição com muitas citações na literatura e adequar-se ao contexto deste trabalho. Segundo Bass et al. (2003), Arquitetura de software de um programa ou sistema de computação é a estrutura ou estruturas do sistema, que compreende os elementos de software, as propriedades visíveis externamente desses elementos e as relações entre eles.

\subsubsection{SOA: definição}

Arquiteturas de software têm evoluído de estáticas, monolíticas e centralizadas, para dinâmicas, modulares e distribuídas (Baresi et al., 2006). SOA pode ajudar a atingir esses objetivos de projeto (Krafzig et al., 2004). Liegl (2007) acredita que SOA é a solução para uma maior flexibilidade e maior velocidade de adaptação para os novos cenários de negócio.

Uma SOA é um estilo arquitetural para a construção de aplicações de software que utilizam serviços disponíveis em uma rede (Mahmoud, 2005). SOA não é uma arquitetura, mas sim um padrão arquitetural do qual uma infinidade de arquiteturas podem ser derivadas, algumas boas, outras ruins (Lewis et al., 2007).

Um serviço é a implementação de uma funcionalidade de negócios bem definida, que pode ser utilizada por clientes em diferentes aplicações e processos de negócios. Um serviço possui uma interface pública, com ênfase em interoperabilidade, disponibilidade e pode se ligar dinamicamente com outros serviços. Clientes, nesse caso, podem ser tanto aplicações de usuário final (por exemplo, páginas Web ou aplicações desktop) quanto outros módulos de aplicações de processos negócios (por exemplo, outros serviços) (Mahmoud, 2005). Os serviços permitem que as empresas exponham suas competências principais em termos de programação, na da Internet (ou Intranet), com o uso de linguagens e protocolos baseados em XML (W3C, 2008), implementadas via interfaces auto-descritivas que usam padrões abertos (Papazoglou, 2003).

Papazoglou et al. (2005) se referem a SOA como uma maneira lógica de projetar sistemas de informação para prover serviços tanto para aplicações de usuário final quanto para outros serviços distribuídos na rede, por meio de interfaces publicáveis e acessíveis. Com isso, a interoperabilidade é um dos princípios mais importantes das SOAs (Mahmoud, 2005). As SOAs vêm ganhando importância à medida que surgem novas tecnologias para o desenvolvimento de sistemas de soft- 
ware, e existe uma necessidade de interoperabilidade entre os sistemas desenvolvidos sob essas diferentes tecnologias, incluindo a integração com sistemas legados.

Vale ressaltar que o desenvolvimento de software orientado a serviços ainda não possui uma abordagem consolidada para projeto e desenvolvimento de serviços (Engenharia Orientada a Serviços). Um dos maiores desafios no desenvolvimento de sistemas orientados a serviços é o fornecimento de metodologias que apóiem a especificação e o projeto de composição de serviços (Papazoglou et al., 2005; Papazoglou e van den Heuvel, 2007). Entre outros, Endrei et al. (2004) e Zaupa (2007) buscam preencher esta lacuna.

As SOAs não são conceitos novos. A idéia de serviços pode ser observada em tecnologias já consolidadas e com um tempo maior de vida como, por exemplo, Common Object Request Broker Arquitecture (CORBA) (Siegel, 2000) e Distributed Component Object Model (DCOM) (Thai, 1999), mesmo que parcialmente (Endrei et al., 2004). Os principais pontos que têm chamado a atenção dos desenvolvedores para SOA são algumas características inerentes desse estilo arquitetural: baixo acoplamento, granularidade em nível de negócio, independência de protocolo e transparência de localização.

\subsubsection{Elementos de uma SOA}

Uma SOA básica não trata apenas de serviços. Ela é um relacionamento entre três tipos de participantes: o provedor de serviços, o repositório de serviços e o solicitante de serviços (cliente). As operações envolvem publicação, busca e ligação (Papazoglou, 2003). Os provedores de serviços inscrevem seus serviços em registros públicos. Esse registro é usado pelos consumidores para encontrar serviços que satisfazem a um determinado critério. Se o registro possui esse serviço, ele fornece ao consumidor o contrato e o endereço para o serviço desejado (Mahmoud, 2005).

Na Figura 2.8 pode-se observar as colaborações realizadas entre esses participantes. O Fornecedor de Serviços, que contém a implementação das funcionalidades do serviço e sua descrição (incluindo a descrição da interface disponível) publica essa descrição no repositório de serviços. Essa publicação do serviço permite ao Cliente localizá-lo e solicitá-lo ao Fornecedor, que estabelece a conexão e se encarrega de executar as funcionalidades, inclusive fazendo a distribuição de chamadas internas, se necessárias.

O serviço de rastreamento fornecido por uma empresa de transportes pode ser usado para ilustrar as colaborações entre os componentes de uma SOA. Uma empresa de transporte de cargas A, representada pelo Fornecedor de Serviços da Figura 2.8, fornece um serviço online para rastreamento de produtos entregues por ela. Esta empresa então publica seu serviço em um localizador de serviços representado na Figura 2.8 como o Registro de Serviços, que vai então possuir todas as informações necessárias para acessar esse serviço. Caso alguma empresa B, representada na Figura 2.8 pelo Cliente de Serviços, pretenda montar, por exemplo, um portal de rastreamento de cargas, ela pode consultar o localizador de serviços, e encontrar, entre outros, o serviço de rastreamento 


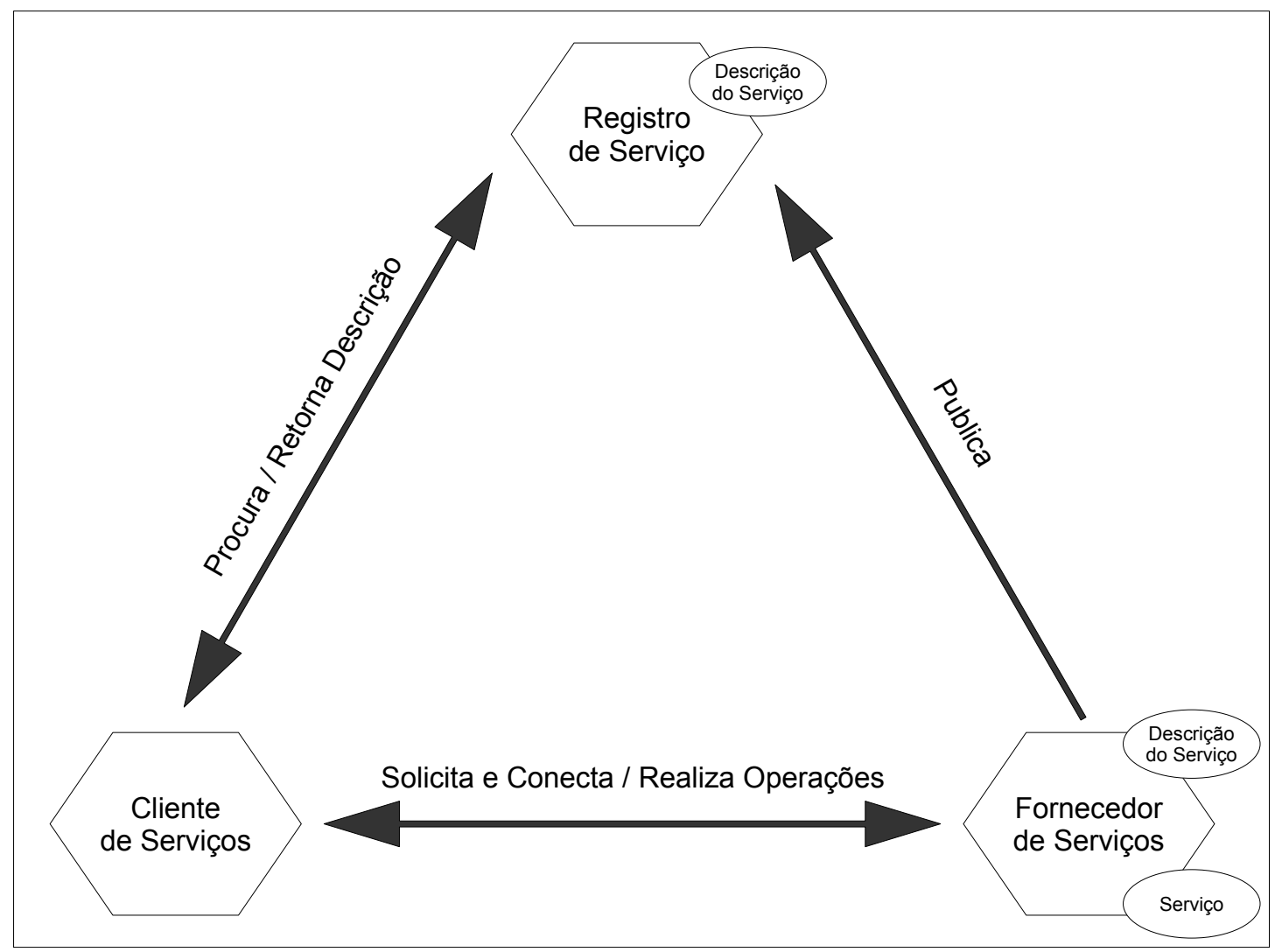

Figura 2.8: Colaborações em uma SOA (adaptado de Papazoglou e van den Heuvel (2007)).

de cargas fornecido pela empresa A. O localizador de serviços fornecerá todas as informações necessárias para que a empresa B possa consumir o serviço fornecido pela empresa A.

Krafzig et al. (2004) identificam quatro componentes em uma SOA : aplication frontend, que é responsável por iniciar os processos de negócios; o serviço, que representa uma funcionalidade de negócio, possui uma interface, um contrato e a sua implementação (essa implementação pode possuir lógica de negócios, dados ou ambos); o repositório de serviços, que armazena os contratos de serviços para que possam ser buscados; e o service bus que conecta a application frontend e os serviços. Na Figura 2.9 ilustra-se a hierarquia e relação desses componentes.

A aplication frontend é a parte ativa de uma SOA, ela inicia e controla todas as atividades, não necessariamente interage com o usuário final, pode delegar responsabilidades para um ou mais serviços e sempre inicia um processo de negócio e recebe seus resultados (Krafzig et al., 2004).

Um serviço tipicamente encapsula funcionalidades de negócios de alto nível. Ele possui: um contrato que provê uma especificação do seu propósito, funcionalidade, restrições e uso; uma interface que expõe as funcionalidades dos serviços para os clientes, que faz parte do contrato do serviço e geralmente é representada fisicamente por um service stub; e uma implementação que fisicamente provê a lógica de negócios requerida, os dados apropriados ou ambos (Krafzig et al., 2004). 


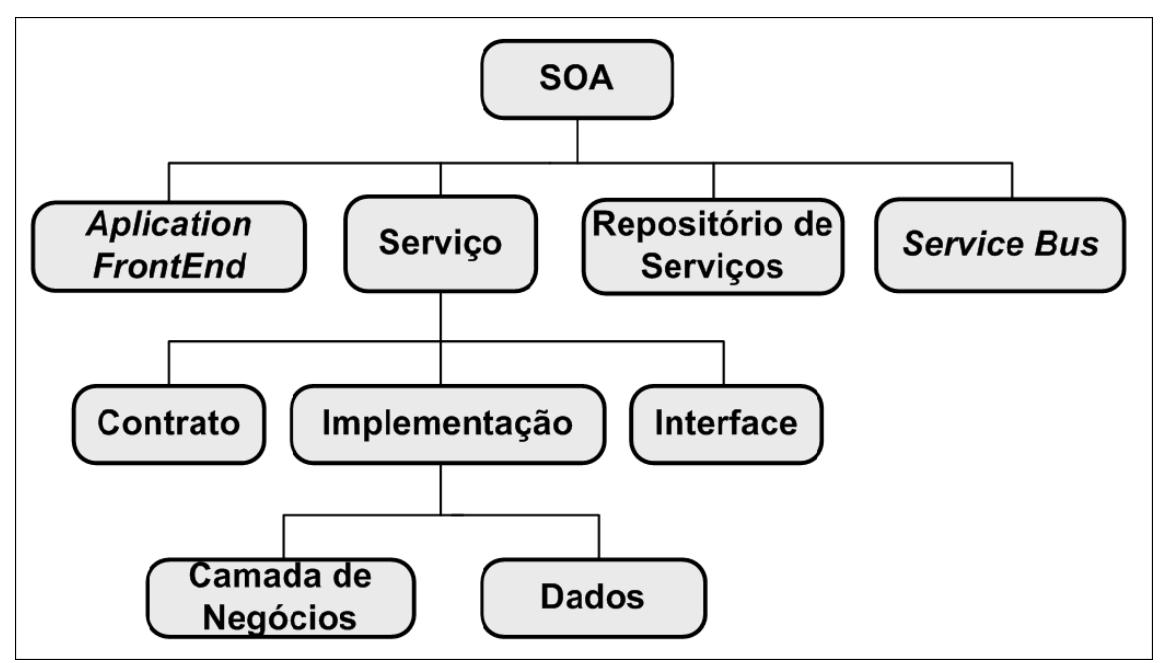

Figura 2.9: Elementos de uma SOA (adaptado de Krafzig et al. (2004)).

O repositório de serviços provê facilidades para descobrir serviços e adquirir todas as informações necessárias para usá-los. Além das informações contidas no contrato do serviço, pode oferecer: localização física, informações sobre o provedor, pessoas para contato, restrições técnicas, entre outras. É importante destacar que é possível construir uma SOA e atingir muitos de seus benefícios sem o uso do repositório de serviço (Krafzig et al., 2004).

O service bus é o centro para a integração de diferentes tipos de serviços por meio de mensagens, manipulação de eventos e gerenciamento de performance de negócios (Luo et al., 2005). Ele conecta todos os participantes de uma SOA, não é composto necessariamente por uma única tecnologia, engloba uma variedade de produtos e conceitos de comunicação e provê serviços técnicos como logging, auditoria, segurança, entre outros.

\subsubsection{SOA X Componentes}

Embora serviços possam, em primeira vista, se parecer com componentes, pois pretendem ser blocos de construção que coletivamente representam ambientes de aplicações, eles possuem um conjunto de características únicas. Entre essas características pode-se citar a completa autonomia que um serviço tem dos outros, isso significa que cada serviço é responsável pelo seu próprio domínio, o que limita seu escopo a uma função específica de negócios. Essa abordagem resulta na criação de unidades de funcionalidades de negócio isoladas e fracamente ligadas por um framework. Além disso, a lógica de negócios que os serviços encapsulam são independentes de plataforma ou tecnologia (Erl, 2005).

Papazoglou et al. (2005) destacam que componentes e serviços diferem no tipo de comunicação, tipo de acoplamento, tipo de interface, tipo de invocação, tipo de request brokering, e ainda, durante o desenvolvimento, eles diferem fundamentalmente na forma como abordam flexibilidade e reusabilidade. Enquanto os serviços estão sujeitos a contínuas manutenções, aumento de escopo, 
performance e oferecem a possibilidade de seleção dinâmica de serviços, o uso de componentes instalados não permite o mesmo tipo de reúso e dinamicidade.

\subsubsection{Classificação de Serviços}

É possível identificar diferentes tipos de serviços, que podem ser classificados de acordo com a sua função, complexidade ou categoria de reúso. Conhecer os diferentes tipos de serviços pode ser muito útil, principalmente nas seguintes situações: ao estimar custos e prazos de desenvolvimento, uma vez que alguns tipos de serviços requerem mais esforço de programação e prazo que outros; ao separar segmentos de código com diferentes características de reúso, uma vez que mesmo com o uso de serviços podem existir partes de código que podem ser reusadas por vários projetos e outras específicas de um único projeto; ao escolher a melhor estratégia de implementação, uma vez que diferentes tipos de serviços necessitam de diferentes estratégias de implementação; durante o gerenciamento de mudanças, pois é importante separar a lógica de negócios que é freqüentemente exposta a mudanças, daquela que é mais estável (Krafzig et al., 2004).

Krafzig et al. (2004) classificam os serviços em:

- Serviços básicos: correspondem ao fundamento de uma SOA, podem ser centrados em dados, conter lógica de negócios ou ambos e são basicamente servidores em uma SOA.

- Serviços intermediários: podem ser clientes ou servidores em uma SOA, não possuem estado, fazem a ponte entre tecnologias inconsistentes e geralmente são específicos de cada projeto.

- Serviços centrados em processo: encapsula o conhecimento do processo de negócio da organização, podem ser clientes ou servidores em uma SOA, separam a lógica de processo da lógica de negócios e correspondem ao tipo mais sofisticado de serviços.

- Serviços de empresa pública: provê interfaces para integração entre empresas, granularidade alta, exige uma maior segurança e robustez. As operações de um serviço público geralmente são controladas por um Service Level Agreement (SLA)

Uma SOA pode ser dividida em quatro camadas, a saber: camada empresarial, camada de processo, camada intermediária e camada básica. Os tipos de serviços: público, centrados em processo, intermediários e básico se encaixam respectivamente nessas camadas (Krafzig et al., 2004).

Existe outra classificação para os serviços, conhecida como modelos de serviços. Nessa classificação, os serviços podem ser: utilitários, de negócios, controladores, proxy, wrapper, de coordenação para transações atômicas, processos ou coordenadores para atividades de negócios. É possível encontrar um paralelo entre as duas classificações: Os serviços utilitários e de negócios correspondem aos serviços básicos; serviços controladores, de coordenação para transações 
atômicas, de processos e coordenadores para atividades de negócios correspondem aos serviços centrados em processo; proxy e wrapper correspondem aos serviços intermediários (Erl, 2005). Por considerar que a classificação de Krafzig et al. (2004) atende bem aos requisitos listados no início da seção, este trabalho a toma como base.

\subsubsection{SOA e os Web Services}

Como já foi visto, SOA é um estilo arquitetural. Nesse contexto, tem-se os web services como uma tecnologia usada para implementar SOA. Os web services utilizam a infra-estrutura da Web para disponibilizar funcionalidades de negócios sob forma de serviços.

O Web Services Architecture Working Group (representa um subgrupo do W3C's) chegou à seguinte definição de web service: "Um web service é uma aplicação de software identificada por uma URI, cujas interfaces e ligações são capazes de serem definidas, descritas e descobertas como artefatos XML. Um web service possibilita interações diretas com outros agentes de software por meio de mensagens baseadas em XML trocadas via protocolos da Internet. Um web service pode ser acessado por qualquer cliente capaz de fazer invocações SOAP. Contudo, os WSs são tipicamente acessados por motores BPEL, portais, e/ou aplicações (Sun Microsystems, 2004).

Na Figura 2.10 são apresentadas as principais tecnologias para implementação de uma SOA. Em particular tem-se os web services, que tem como base WSDL, UDDI, SOAP e HTTP.

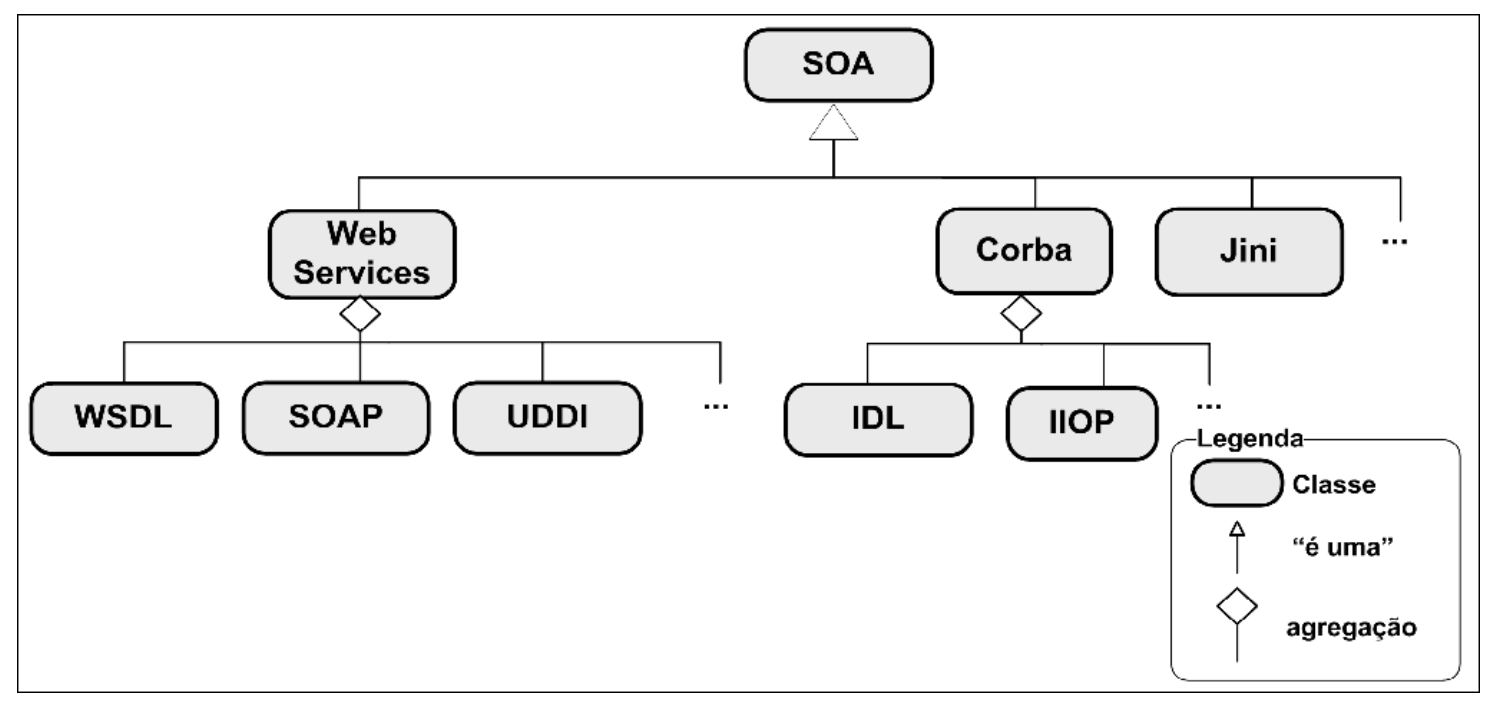

Figura 2.10: Principais tecnologias para implementação de uma SOA (adaptado de Merson (2007)).

Algumas das principais características dos web services são (Endrei et al., 2004):

- Auto-contidos: cada web service é a implementação de uma funcionalidade de negócios bem definida e pode ser usada por outros serviços de forma independente.

- Auto-descritos: os web services só precisam conhecer o formato e o conteúdo das mensagens de resposta e requisição e o formato viaja com a mensagem. 
- Modulares: tecnologias como Java Platform, Enterprise Edition (J2EE) (Sun Microsystems, 2008) e CORBA, podem ser usadas para implementar web services.

- Podem ser publicados, localizados e invocados na rede: os padrões usados para isto são: UDDI, WSDL e SOAP.

- São independentes de linguagem: a comunicação entre web services necessita apenas de um WSDL para definição da interface e do serviço, e de um protocolo de rede. Não dependem da linguagem de implementação do web service.

- São baseados em padrões abertos: a base para o uso de web services é o XML e o HTTP.

- São dinâmicos: com o uso WSDL e UDDI, a descrição e descoberta de web services pode ser automatizada.

- Podem ser compostos por outros web services: web services simples podem ser agregados por alguns mais complexos ou fazer chamadas a outros web services de uma camada mais baixa.

Para que os web services sejam consumidos, é preciso que ocorra a ligação do cliente com o web service desejado. Essa ligação pode ser estática ou dinâmica. A ligação estática é também conhecida como development-time binding e ocorre quando a descoberta e a ligação propriamente dita do cliente com o web service ocorre quando o cliente é implementado. Para isso é necessário um conhecimento prévio da assinatura das operações do serviço, do protocolo do serviço e da localização física do serviço. A ligação dinâmica é também conhecida como runtime binding e ocorre quando a ligação ocorre em tempo de execução e, para isso, é necessário o uso do repositório de serviços. A ligação dinâmica ainda pode ser de três tipos: dinâmica com busca por nome, dinâmica com busca por propriedade e dinâmica com descoberta baseada em reflexão. Nos dois primeiros casos é preciso conhecer a definição do serviço em tempo de execução. O terceiro caso é o mais complexo pois necessita da implantação de um mecanismo de reflexão no cliente para descobrir dinamicamente a semântica e o formato de requisições válidas (Krafzig et al., 2004).

O principal objetivo do uso de web services é atingir interoperabilidade universal entre aplicações usando padrões Web. Web services possuem um baixo acoplamento para permitir integração flexível de sistemas heterogêneos em uma variedade de domínios, tais como negócio-paraconsumidor, negócio-para-negócio e integração de aplicações empresariais (OASIS, 2007).

\subsubsection{Principais Padrões Usados pelos Web Services}

Os web services usam um conjunto de padrões consolidados, abertos e baseados em XML para executar as funcionalidades de negócios e montar arquiteturas orientadas a serviços. Os WSs são baseados em quatro padrões principais: XML, WSDL, SOAP e UDDI, descritos a seguir. 


\section{XML}

Extensible Markup Language (XML)(W3C, 2008) é uma linguagem de marcação de dados baseada em tags, que oferece um padrão para descrever dados estruturados de modo a facilitar a declaração do conteúdo.

XML transformou-se no padrão de fato para descrever dados trocados na WEB. Uma tag XML identifica as informações em um documento e também identifica a estrutura da informação. Visto que os documentos XML precisam ser bem formados e estar de acordo com seu esquema associado, é relativamente fácil processar documentos XML. Como resultado, XML foi adotada como a linguagem dos dados para web services (Sun Microsystems, 2005).

A Listagem 2.1 apresenta um exemplo de documento XML. A primeira linha do documento é uma declaração XML e deve ser sempre incluída, pois define a versão XML do documento. A segunda linha define o primeiro elemento do documento, o elemento raiz (nó raiz), definido pela tag <exemplo>. As quatro linhas seguintes definem quatro elementos filhos do nó raiz (<nome>, $<$ profissao $>$, <localTrabalho $>$ e < orientadora $>$ ), cada elemento é fechado por uma tag de mesmo nome antecedida por uma barra invertida. A última linha define o fim do elemento raiz.

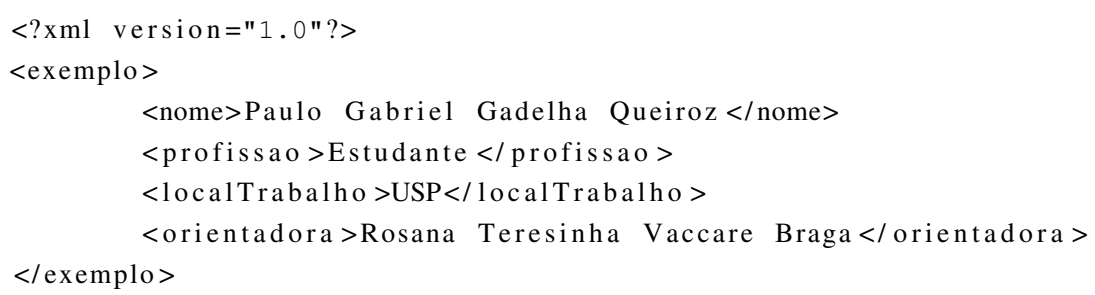

Listagem 2.1: Exemplo de documento XML.

\section{SOAP}

Simple Object Access Protocol (SOAP) (W3C, 2004) é um protocolo que define o formato das mensagens que são trocadas entre clientes e fornecedores de serviços.

Embora exista um consenso de que o uso de XML é uma forma efetiva de troca de dados, ela não é suficiente para a troca de dados na WEB. O objetivo do SOAP é ser um protocolo para formatar o documento XML, de tal forma que a parte que está recebendo a mensagem saiba o que contém na parte principal da mensagem e quais partes correspondem a informações ou instruções adicionais (Sun Microsystems, 2005).

Uma mensagem SOAP possui obrigatoriamente um envelope SOAP e um corpo, podendo possuir ainda um cabeçalho. O envelope funciona como um recipiente para todos os elementos da mensagem e ainda pode especificar um namespace XML e um estilo de codificação. O namespace XML especifica os nomes que podem ser usados na mensagem SOAP. Deve-se notar que os mesmos nomes podem ser usados em diferentes itens, desde que os nomes estejam em diferentes namespaces. O estilo de codificação identifica os tipos de dados reconhecidos pela mensagem SOAP. Visto que uma mensagem SOAP passa por diferentes nós desde a sua origem até encontrar o 
destino correspondente, esses nós podem adicionar um cabeçalho à mensagem para indicar algum processamento adicional ou operações de segurança feitos na mensagem. O corpo da mensagem contém a sua parte principal, ou seja, aquilo que é direcionado ao destinatário da mensagem. É importante destacar que as mensagens SOAP são independentes de plataforma e de sistema operacional e podem ser transportadas por uma variedade de protocolos de comunicação, tais como HTTP ou SMTP (Sun Microsystems, 2005).

A Listagem 2.2 apresenta um exemplo de mensagem SOAP contendo os itens obrigatórios, envelope e corpo. A primeira linha define o envelope SOAP por meio da tag <env:Envelope> . A segunda linha contém o corpo da mensagem definido pela tag <env:Body>. O corpo possui um alerta definido pela tag $<\mathrm{m}$ :alert $>$. O alerta possui uma mensagem definida pela tag $<\mathrm{m}$ :msg $>$ na linha 4. As duas últimas linhas da mensagem encerram o corpo e o envelope da mensagem SOAP.

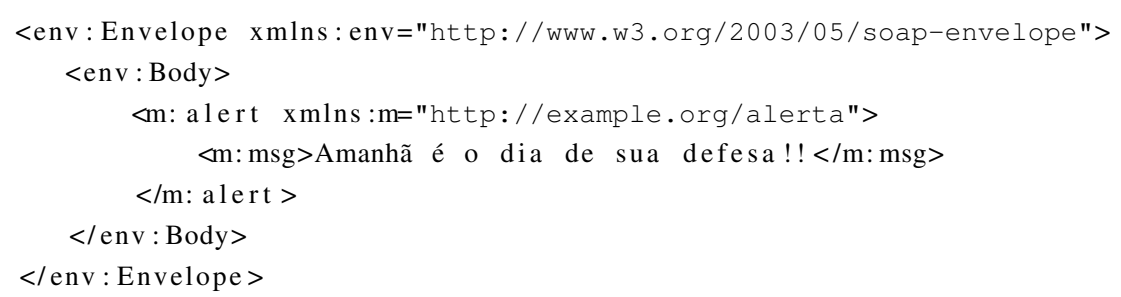

Listagem 2.2: Exemplo de mensagem SOAP.

\section{WSDL}

Web Service Description Language (WSDL) (W3C, 2001) é uma linguagem utilizada para descrever os web services, permitindo a utilização de um serviço ou a integração entre serviços. Utiliza XML como base e descreve quatro partes de dados: interfaces, tipos de dados, o protocolo de transporte a ser utilizado e o endereço do serviço.

Para obter a descrição do WS, o cliente precisa encontrar seu documento WSDL. Os principais lugares para encontrar o WSDL de um WS são os repositórios de serviços, que podem ser registros UDDI (OASIS UDDI Specification Technical Committee, 2007) ou registro/repositório ebXML (OASIS, 2006). Em um cenário típico, um serviço é desenvolvido e registrado. A entrada do registro inclui, entre outros, um ponteiro para o documento WSDL do serviço. Um programador utiliza a informação da interface contida no documento WSDL para construir a chamada apropriada para o uso do serviço (Sun Microsystems, 2005).

WSDL é um formato XML que descreve web services como uma coleção de endpoints ou ports capazes de trocar mensagens. O documento define as ações que o WS pode executar e os dados transmitidos de uma forma abstrata. Messages correspondem à descrição abstrata dos dados transmitidos e porttype representam uma coleção abstrata de operações. O protocolo de rede e a especificação do formato das mensagens para um porttype em particular constitui um binding. Uma porta é definida por uma associação de um endereço de rede com um binding. Uma coleção de ports define um serviço. Na Tabela 2.1 apresenta-se um resumo com os elementos do WSDL e uma breve descrição de sua função. 
Tabela 2.1: Elementos WSDL.

\begin{tabular}{|l|l|}
\hline Elemento & Função \\
\hline Types & Utilizado para a definição de tipos de dados. \\
\hline Message & Apresenta uma descrição abstrata dos dados transmitidos. \\
\hline Operation & Descrição abstrata de uma ação oferecida pelo WS. \\
\hline Port Type & Descreve um conjunto abstrato de operações oferecidas por um ou mais endpoints. \\
\hline Binding & Especifica o protocolo concreto e um formato para um port type em particular. \\
\hline Port & Um único endpoint definido pela combinação de um binding e um endereço de rede. \\
\hline Service & Uma coleção de enpoints relacionados. \\
\hline
\end{tabular}

A Listagem 2.3 apresenta alguns trechos de um documento WSDL que descreve um web service chamado TemperaturaWS. O web service descrito realiza uma operação, retorna a temperatura de uma cidade passada como parâmetro. Pode-se observar na listagem que um documento WSDL utiliza os elementos apresentados na Tabela 2.1 para a definição do web service. A tag <types $>$ define os tipos de dados de entrada (String) e os tipos de dados de retorno (double) utilizados nas operações do WS. A tag <message> descreve os dados transmitidos (TemperaturaWSPortTypetemperaturaAmbiente e TemperaturaWSPortType-temperaturaAmbienteResposta) conforme os tipos definidos na tag <types $>$. A tag < port type $>$ define as operações (temperaturaAmbiente), por meio de um conjunto de tags <operations>, do WS. A tag <binding > define o protocolo a ser utilizado (SOAP) e a especificação do formato das mensagens (literal). Um serviço definido pela tag < service > possui uma coleção de <ports >, no exemplo apresentado na listagem, possui apenas uma, e esta define uma associação de um endereço de rede (http://143.107.183.148:8888/temp/TempWSSoapHttpPort) com um binding (TemperaturaWSSoapHttp).

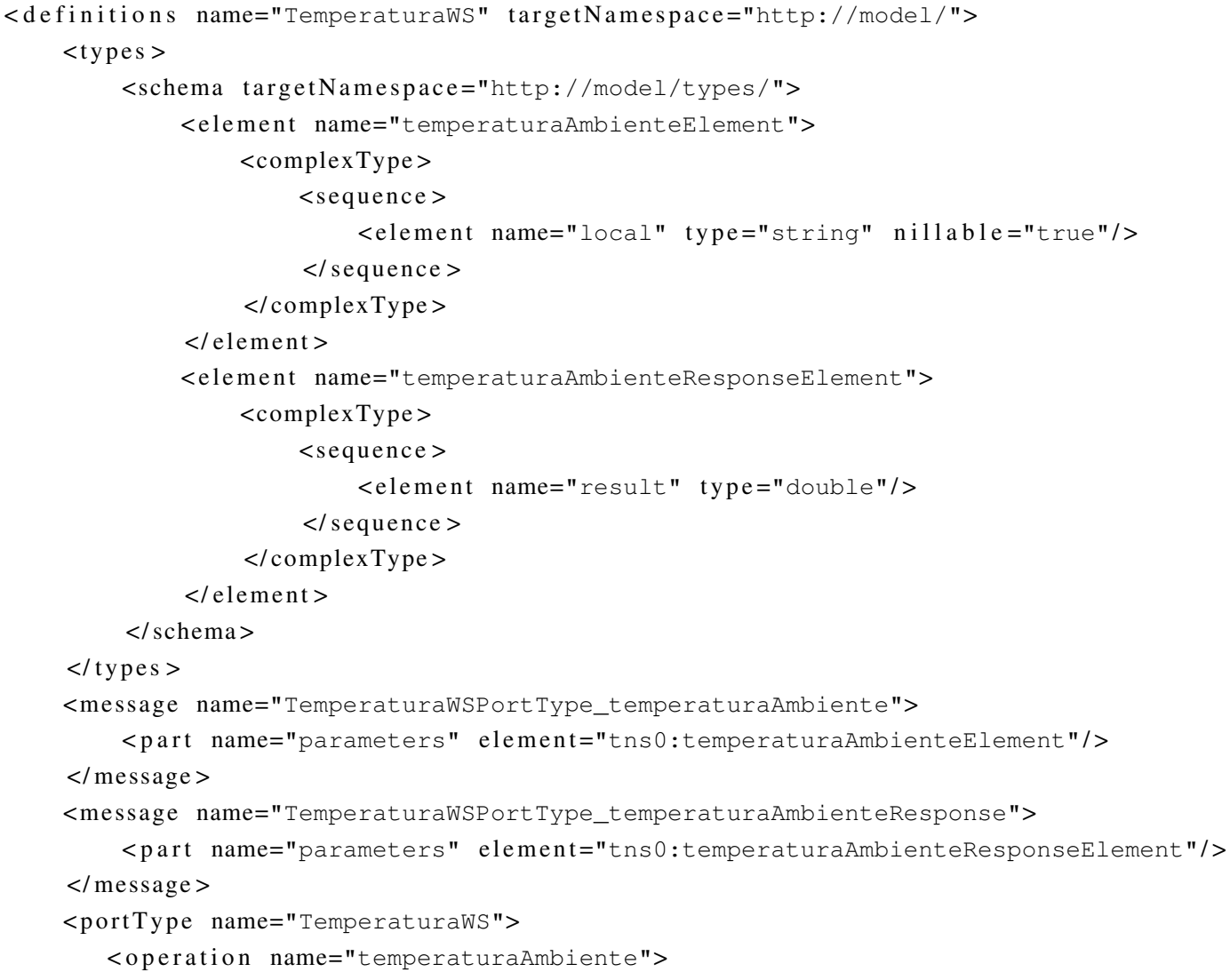




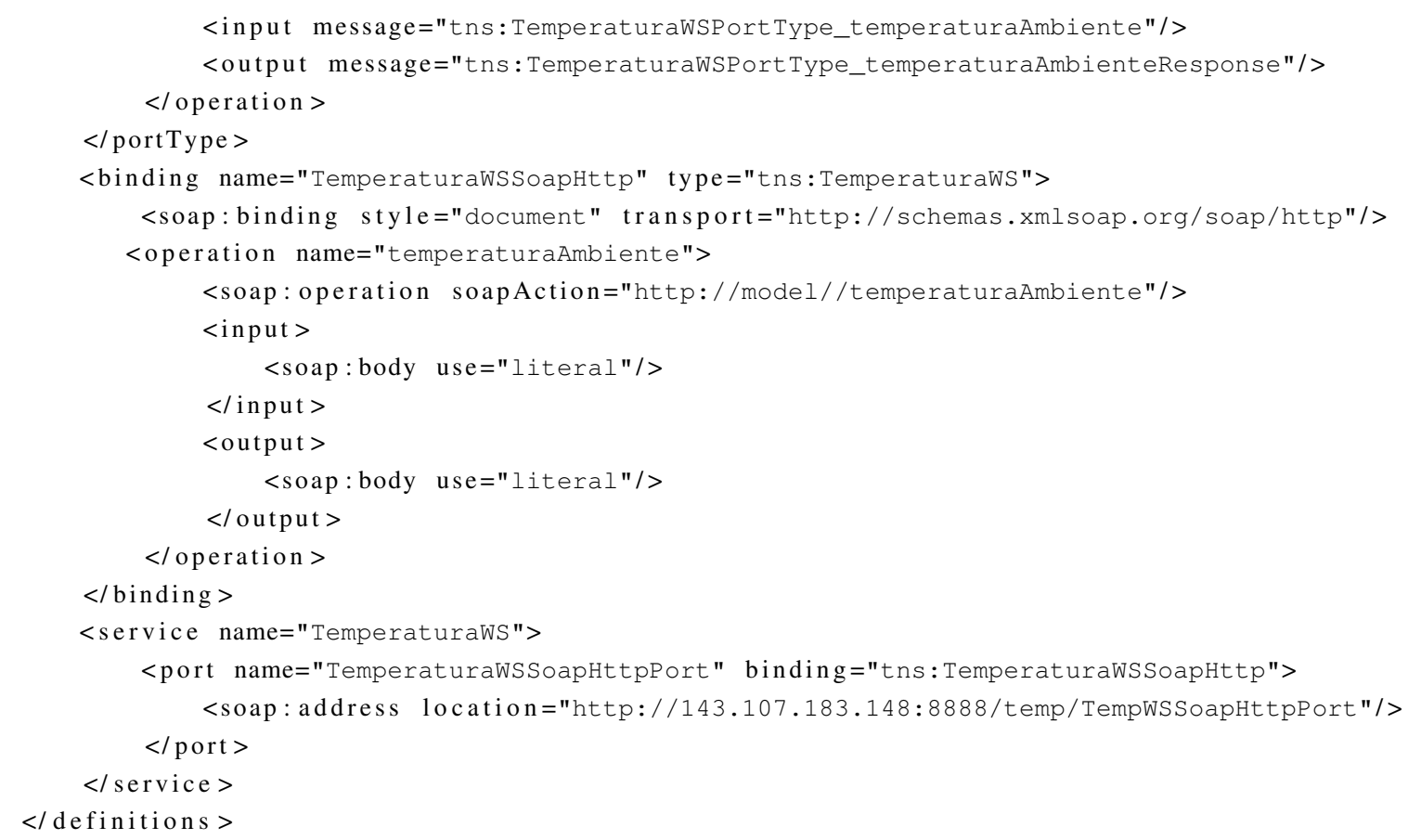

Listagem 2.3: Exemplo de documento WSDL.

UDDI

Universal Description, Discovery, and Integration (UDDI) é um padrão que define a estrutura e o conteúdo dos repositórios de serviços, possibilitando a publicação, descoberta e invocação de serviços (OASIS UDDI Specification Technical Committee, 2007).

O registro UDDI possui informações sobre os serviços, tais como o nome, uma breve descrição do que faz, o endereço para acesso, a descrição de sua interface e ainda permite descrever as finalidades desses WSs. Um registro UDDI funciona de forma semelhante às páginas amarelas de um catálogo telefônico. Sua capacidade de descrição se dá por intermédio da utilização de palavras-chave e pequenas tags de descrição, possibilitando que se informe a todos o que o WS oferece. UDDI é uma poderosa ferramenta para desenvolvedores (consumidores) que buscam serviços que atendam suas necessidades (Sun Microsystems, 2005).

\subsubsection{Processos de Negócios}

Os web services disponibilizados por várias organizações podem ser interconectados para implementar colaborações entre empresas (Xiaoqiang e Jun, 2006), e essas colaborações podem ser vistas como processos de negócio. Um processo de negócios é um fluxo de atividades progressivas, no qual cada atividade representa o trabalho de uma pessoa, um sistema interno ou o processo de uma empresa parceira, para atingir algum objetivo empresarial (Ye et al., 2007). Note que essas atividades são tipicamente implementadas como serviços. Os processos são compostos por operações fornecidas pelos web services, que podem ser aninhados ou seqüenciados de acordo 
com os requisitos de negócios (Endrei et al., 2004). Serviços distribuídos heterogêneos devem ser integrados para completar a execução de um processo de negócio (Laliwala et al., 2006).

A execução de processos de negócios por meio da composição de serviços pode acontecer basicamente por meio de dois paradigmas detalhados a seguir.

\section{Coreografia}

A coreografia descreve a relação entre os serviços de uma forma colaborativa, sem a presença de um coordenador central, conforme ilustra-se na Figura 2.11. Um modelo de coreografia descreve a colaboração entre um conjunto de serviços para atingir um objetivo comum, capturando as interações de uma perspectiva global e tratando todos os serviços participantes de forma igual (Barros et al., 2005). As interações globais podem ser: troca de mensagens públicas; regras de interação; e acordos entre dois ou mais serviços (Xiaoqiang e Jun, 2006). É importante salientar que a coreografia não descreve ações internas de serviços participantes que não resultem em um efeito externamente visível, tais como computação interna ou transformações de dados (Barros et al., 2005). A Web Service Choreography Interface(WSCI) (W3C, 2002a) é uma das linguagens para implementação de coreografia de serviços. Ela é uma linguagem de descrição de interface baseada em XML, que descreve o fluxo de mensagens trocadas pelos web services participantes de interações coreografadas com outros serviços (Deng et al., 2007).

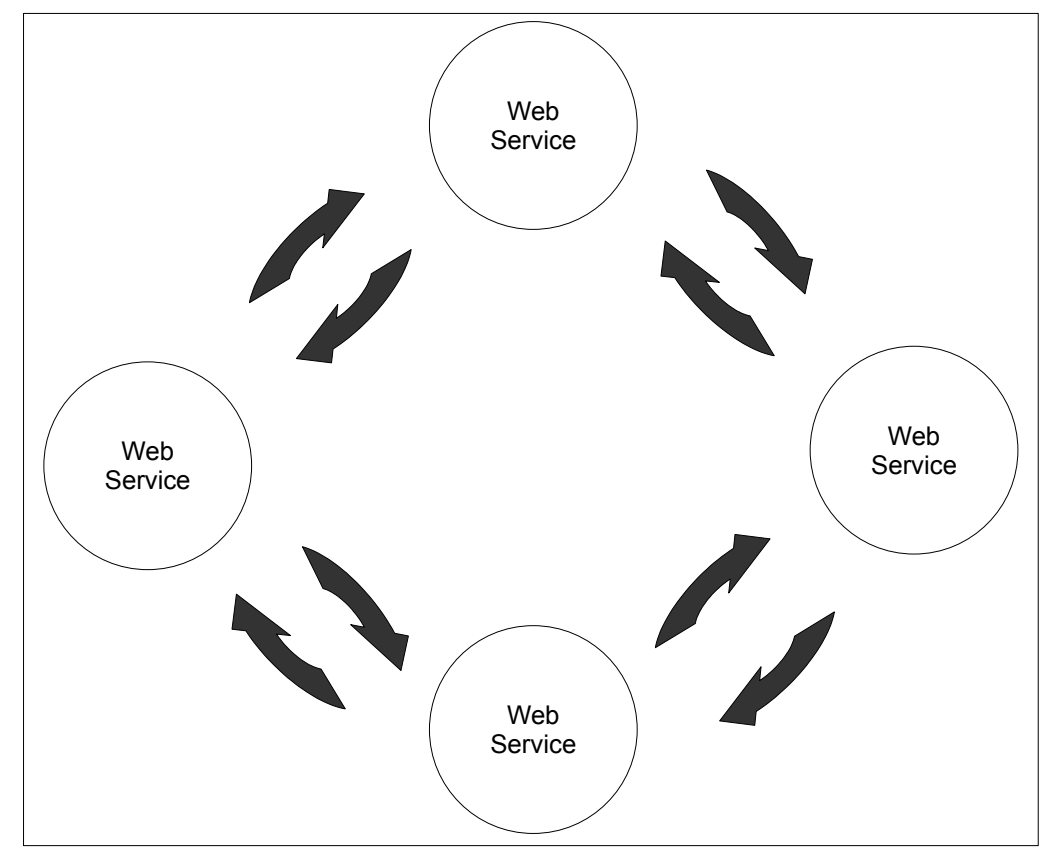

Figura 2.11: Coreografia de serviços (Endo, 2007).

\section{Orquestração}

Orquestração é um paradigma para composição de serviços no qual existe a presença um coordenador central. Esse coordenador gerencia a interação entre os serviços e realiza operações ou 
adaptações nos dados trocados entre eles, quando necessário. Ela permite uma forma de interação mais sofisticada entre os participantes da colaboração (Deng et al., 2007). Business Process Execution Language for Web Services (BPEL4WS) (Andrews et al., 2003) está se tornando um padrão industrial para modelagem de processos de negócios baseados em web services (Martens et al., 2006).

Na Figura 2.12 representa-se uma orquestração de serviços, com destaque para o coordenador central, que é responsável por realizar chamadas a serviços ou algum processamento interno que seja necessário.

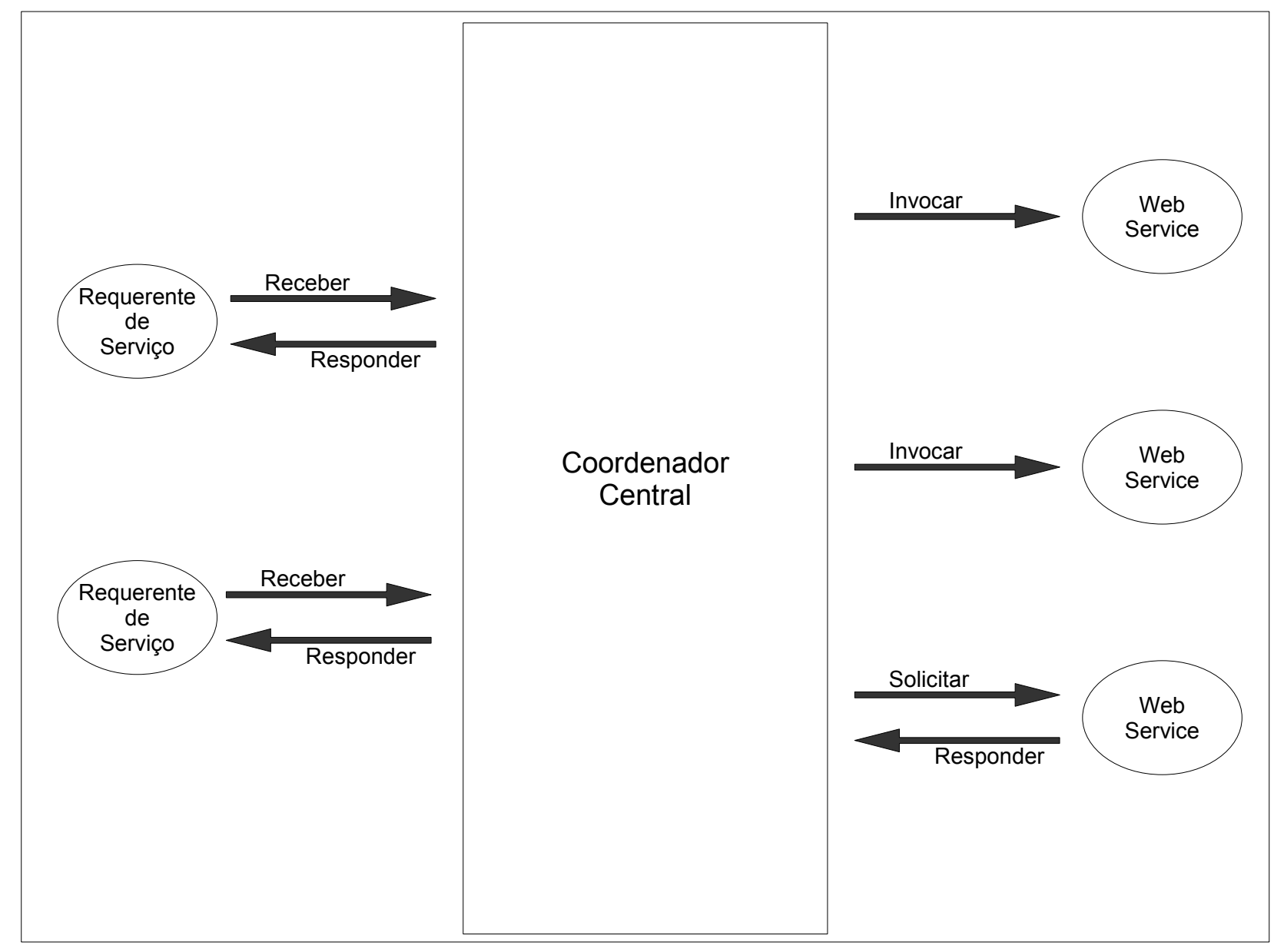

Figura 2.12: Orquestração de serviços (adaptado de Endo (2007)).

Processos de negócios podem ser descritos de duas formas: Processos de negócios executáveis ou Protocolos de negócios. Processos de negócio executáveis modelam o comportamento atual dos participantes em uma interação de negócios. Protocolos de negócios, em contraste, usam descrições de processos que especificam o comportamento das mensagens trocadas que são mutuamente visíveis por cada parte envolvida no protocolo, sem revelar seu comportamento interno. BPEL4WS foi projetada para modelar ambas as formas de descrever processos de negócios. BPEL4WS fornece uma linguagem para a especificação formal dos processos de negócios e das interações dos protocolos de negócios. Por esse motivo, estende o modelo de interação de web services e permite 
que apóiem transações de negócios. WS-BPEL 2.0 (Web Services Business Process Execution Language) é uma revisão do original BPEL4WS 1.0 e 1.1.

Um processo BPEL é um contêiner onde pode-se declarar relações com parceiros externos, declarações para processamento de dados, manipuladores com objetivos diversos, e principalmente, as atividades a serem executadas. No topo, o contêiner do processo tem um par de atributos, isto é, um nome e uma declaração de namespace, ambos obrigatórios.

O processo de negócio BPEL oferece a possibilidade de agregar web services e definir a lógica de negócios entre cada uma dessas interações de serviços. É dito que BPEL orquestra essas interações de web services. Cada interação com um serviço pode ser vista como uma comunicação com um parceiro de negócio. A interação é descrita com a ajuda dos partner links. Partner links são instâncias de conectores tipados que especificam as port types do WSDL que o processo oferece e que requer de um parceiro. Cada partner link é caracterizado por um partner link type e um role name. Essa informação identifica a funcionalidade que deve ser oferecida pelo processo de negócio e pelo serviço parceiro. Para mudar o estado do processo por meio da alteração do conteúdo de variáveis utiliza-se a linguagem de expressão XPath (W3C, 1999).

O principal bloco dos processos BPEL são as atividades, que podem ser de dois tipos: as atividades estruturadas, que podem conter outras atividades ou definir a lógica de negócio entre elas; e as atividades básicas, que apenas executam seu propósito (como receber mensagens de um parceiro, ou manipular dados) e não podem definir nenhuma outra lógica contendo outras atividades.

Em BPEL, as atividades básicas com o propósito de receber e fornecer mensagens, de e para web services parceiros são: receive activity, reply activity, e invoke activity. O propósito da receive activity é receber mensagens de um parceiro externo. Para utilizá-la é necessário especificar o partner link, a operação do web service parceiro e a variável (ou o conjunto de variáveis) que carrega o dado desejado que será recebido do parceiro. Uma receive activity deve ter uma reply activity associada caso seja usada para fornecer um operação WSDL do tipo receber-responder, conforme pode ser observado na Figura 2.12. Uma reply activity pode retornar dados normais, ou pode retornar dados de erros. Nesse caso, é necessário especificar um atributo adicional para erros nesse tipo de atividade. Esse atributo é usado para determinar o correspondente erro WSDL. A terceira atividade relativa a comunicação entre web services é a invoke activity, que é usada para chamar um web service fornecido por um parceiro. Para utilizá-la deve-se especificar um partner link e uma operação do web service a ser chamada.

Em WSDL 1.1 existem múltiplos tipos de operações. Duas delas são apoiadas por BPEL: one-way operations e request-response operations. Uma invoke activity pode chamar tanto uma one-way operation e depois continuar com a lógica do processo de negócio sem esperar a resposta do parceiro, quanto uma request-response operation que bloqueia o processo ou parte dele até que receba a resposta do serviço parceiro. Os dois tipos de operações podem ser observados na Figura 2.12. Se a operação invocada é do tipo request-response operation, é necessário fornecer variáveis 
de entrada e saída. No caso de invocar uma one-way operation, basta especificar uma variável de entrada.

BPEL oferece maneiras de estruturar a lógica de negócio de acordo com suas necessidades. Se for necessário executar um conjunto de atividades em uma ordem seqüencial, pode-se usar uma atividade sequence. Ou seja, uma sequence activity é usada para definir uma coleção de atividades que é executada seqüencialmente em ordem léxica.

Outra atividade usada para estruturar a lógica de negócios é a atividade if-else. Essa construção é conhecida das linguagens tradicionais de programação. Ela permite selecionar exatamente um tipo de atividade a partir de um dado conjunto de alternativas. Para cada escolha, o comportamento é definido pela verificação de uma condição. Quando ela é verdadeira, a opção associada é executada, caso contrário um caminho alternativo é tomado. Assim como em todas as expressões em BPEL, pode-se usar expressões XPath para formular as condições. Observe que somente o primeiro caminho que satisfaz a condição é executado. Se nenhuma alternativa for verdadeira, uma escolha padrão pode ser especificada usando o else.

BPEL oferece três atividades que permitem a execução repetitiva de uma parte de lógica de negócio. Uma delas é a atividade while, que permite a execução de uma atividade filha tantas vezes quando a condição seja avaliada como verdadeira. A condição é especificada na atividade while e é avaliada no começo de cada iteração, o que significa que o corpo da atividade pode não ser executado nenhuma vez. A atividade repeatUntil possui a diferença de que o corpo da atividade é executado pelo menos uma vez, dado que a condição é avaliada no fim de cada iteração. A terceira atividade desse grupo de atividades de repetição é a atividade forEach. No seu comportamento padrão, faz iterações seqüenciais $\mathrm{N}$ vezes sobre um dado conjunto de atividades.

Com o propósito de permitir a execução de operações em paralelo, BPEL oferece a atividade flow. Condições de transição oferecem mecanismo para separar o fluxo de controle baseado em certas condições. Contudo, deve-se oferecer um mecanismo para junta-los novamente. Esse mecanismo são as condições de junção. Elas são associadas com as atividades, usualmente se a atividade tem algum link de entrada.

BPEL oferece a atividade assign, que permite a execução de uma ou mais cópias de dados em variáveis. Cada cópia deve especificar a variável de origem e de destino. BPEL ainda oferece o conceito de manipuladores de erros. Um manipulador pode ser ligado a um escopo, um processo ou a uma atividade invoke.

Nas Tabelas 2.2 e 2.3 são apresentados resumos das funcionalidades das atividades básicas e estruturadas de BPEL, respectivamente.

Embora WS-BPEL e WSCI estejam sendo mais usados que outros padrões na orquestração e coreografia de serviços, respectivamente, outras iniciativas estão sendo pesquisadas na área, tais como: utilização de statecharts (Zeng et al., 2003), redes de petri (Hamadi e Benatallah, 2003) e mais recentemente utilização de redes de petri coloridas (Deng et al., 2007), entre outros. 
Tabela 2.2: Atividades Básicas BPEL.

\begin{tabular}{|l|l|}
\hline Atividade Básica & Função \\
\hline Invoke & Invoca um web service. \\
\hline Reply & Envia uma mensagem de resposta a um cliente. \\
\hline Receive & Recebe uma mensagem de um cliente. \\
\hline Assign & Comando de atribuição. \\
\hline Throw & Usado para sinalizar explicitamente uma falha interna. \\
\hline Wait & Especifica um tempo de espera. \\
\hline Empty & Atividade que não tem nenhum efeito. \\
\hline Rethrow & Utilizado para lançar novamente uma falha que foi capturada. \\
\hline
\end{tabular}

Tabela 2.3: Atividades Estruturadas BPEL.

\begin{tabular}{|l|l|}
\hline Atividade Estruturada & Função \\
\hline Sequence & Atividades dentro do sequence são executadas seqüencialmente. \\
\hline If & Fornece estrutura para desvio condicional. \\
\hline While & Fornece estrutura para execução iterativa (laços). \\
\hline RepeatUntil & Fornece estrutura para execução iterativa (é executado ao menos uma vez). \\
\hline Pick & $\begin{array}{l}\text { Permite associar ações a determinados eventos (recebimento de mensagens, condições } \\
\text { temporais). }\end{array}$ \\
\hline Flow & Atividades dentro do flow são executados em paralelo. \\
\hline ForEach & Fornece estrutura para execução iterativa contada. \\
\hline
\end{tabular}

\section{Composição de Web Services - Exemplo de uso do BPEL}

Com o propósito de ilustrar o uso de BPEL, foi proposto o seguinte problema: informar a temperatura em uma certa localidade na unidade graus Celsius. No cenário ideal, seria encontrado um serviço que resolve esse problema, contudo foram encontrados dois serviços que se aproximam da resolução do problema. O primeiro serviço oferece uma operação que retorna a temperatura de uma certa localidade em Fahrenheit. O uso desse único serviço não atende completamente os requisitos do problema. O segundo serviço encontrado oferece duas operações: a primeira converte um valor de temperatura em graus Celsius para Fahrenheit; a segunda converte uma temperatura descrita em Fahrenheit para Celsius. A solução encontrada para atender os requisitos do problema é fazer uma composição desses dois web services. As interfaces WSDL desses dois serviços são apresentadas nas Listagens 2.4 e 2.5. Destacam-se: as definições das operações, delimitadas pelas tags porttype; e as definições dos endpoints, delimitados pelas tags service e ports. As ports e portypes definidas serão utilizadas para executar as atividades invoke do BPEL.

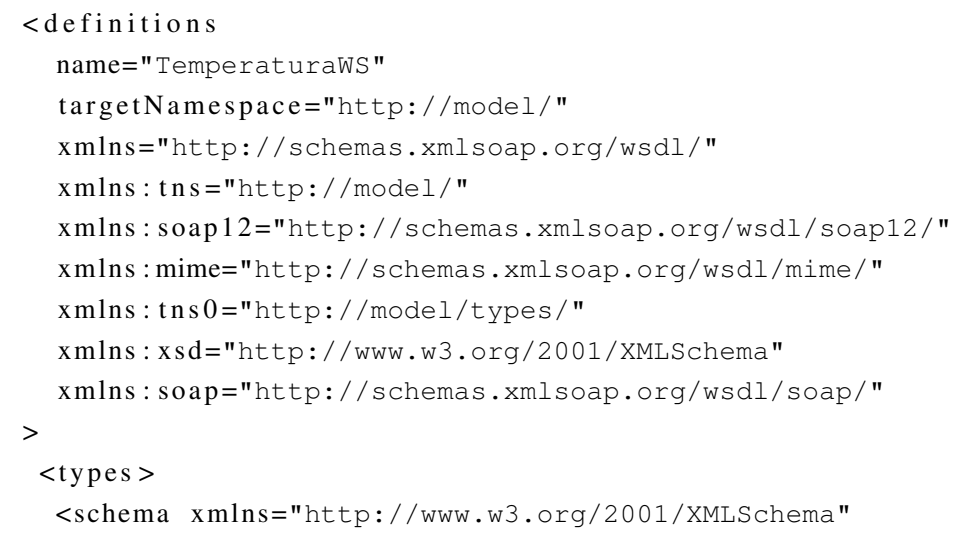


targetNamespace $=$ "http: //model/types $/ "$ elementFormDefault="qualified"

xmlns: tns="http://model/types/" xmlns: wsdl="http://schemas.xmlsoap.org/wsdl/"

xmlns: xsi="http://www.w3.org/2001/XMLSchema-instance"

xmlns : soap 11-enc="http://schemas. xmlsoap.org/soap/encoding/">

$<$ element name="temperaturaAmbienteElement">

$<$ complexType $>$

$<$ sequence $>$

<element name="local" type="string" nillable="true"/>

$</$ sequence $>$

$</$ complex Type $>$

$</$ element $>$

$<$ element name="temperaturaAmbienteResponseElement ">

$<$ complexType $>$

$<$ sequence $>$

$<$ element name $=$ "result" type $=$ "double"/>

$</$ sequence $>$

$</$ complexType $>$

$</$ element $>$

$</$ schema $>$

$</$ types $>$

$<$ message name="TemperaturaWSPortType_temperaturaAmbiente" $>$

<part name="parameters" element="tns0:temperaturaAmbienteElement"/>

$</$ message $>$

$<$ message name="TemperaturaWSPortType_temperaturaAmbienteResponse">

$<$ part name="parameters" element="tns0:temperaturaAmbienteResponseElement"/>

$</$ message $>$

$<$ portType name="TemperaturaWS">

$<$ operation name="temperaturaAmbiente">

<input message="tns: TemperaturaWSPortType_temperaturaAmbiente"/>

<output message="tns: TemperaturaWSPortType_temperaturaAmbienteResponse"/>

$</$ operation $>$

$</$ portType $>$

$<$ binding name="TemperaturaWSSoapHttp" type="tns: TemperaturaWS">

<soap:binding style="document" transport="http://schemas.xmlsoap.org/soap/http"/>

$<$ operation name="temperaturaAmbiente">

<soap: operation soapAction="http://model//temperaturaAmbiente"/>

$<$ input $>$

$<$ soap: body use="literal"/>

$<$ input $>$

$<$ output $>$

$<$ soap: body use="literal"/>

$</$ output $>$

$</$ operation $>$

$</$ binding $>$

$<$ service name="TemperaturaWS">

<port name="TemperaturaWSSoapHttpPort" binding="tns:TemperaturaWSSoapHttp">

$<$ soap : address

location="http: //143.107.183.148:8888/apptestews-Model-context-root/TemperaturaWSSoapHttpPort"/> $</$ port $>$

$</$ service $>$

$</$ definitions $>$

Listagem 2.4: WSDL do primeiro WS.

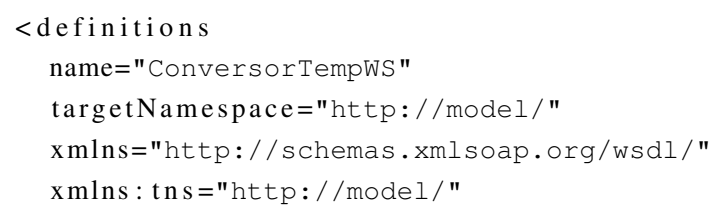


8

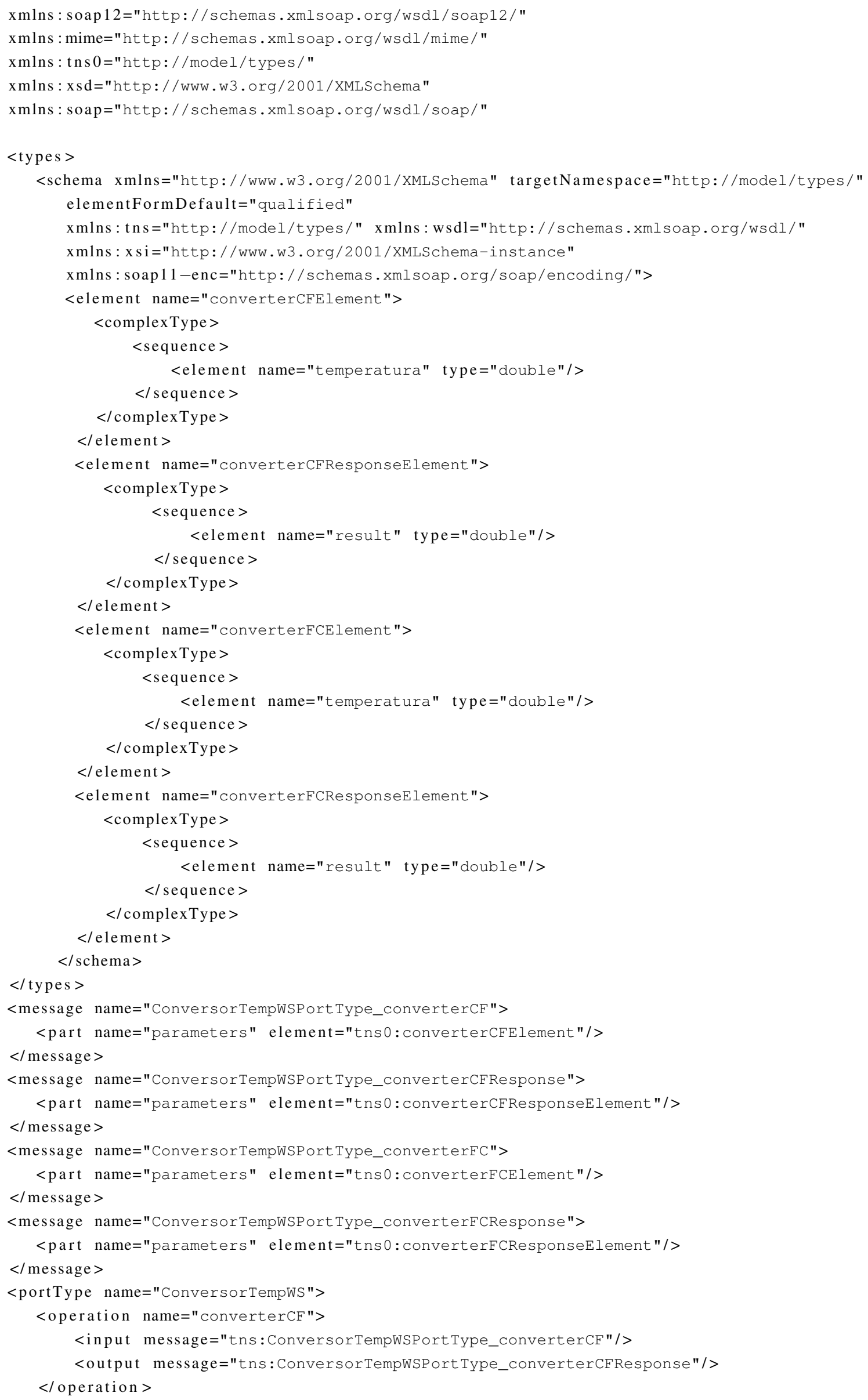




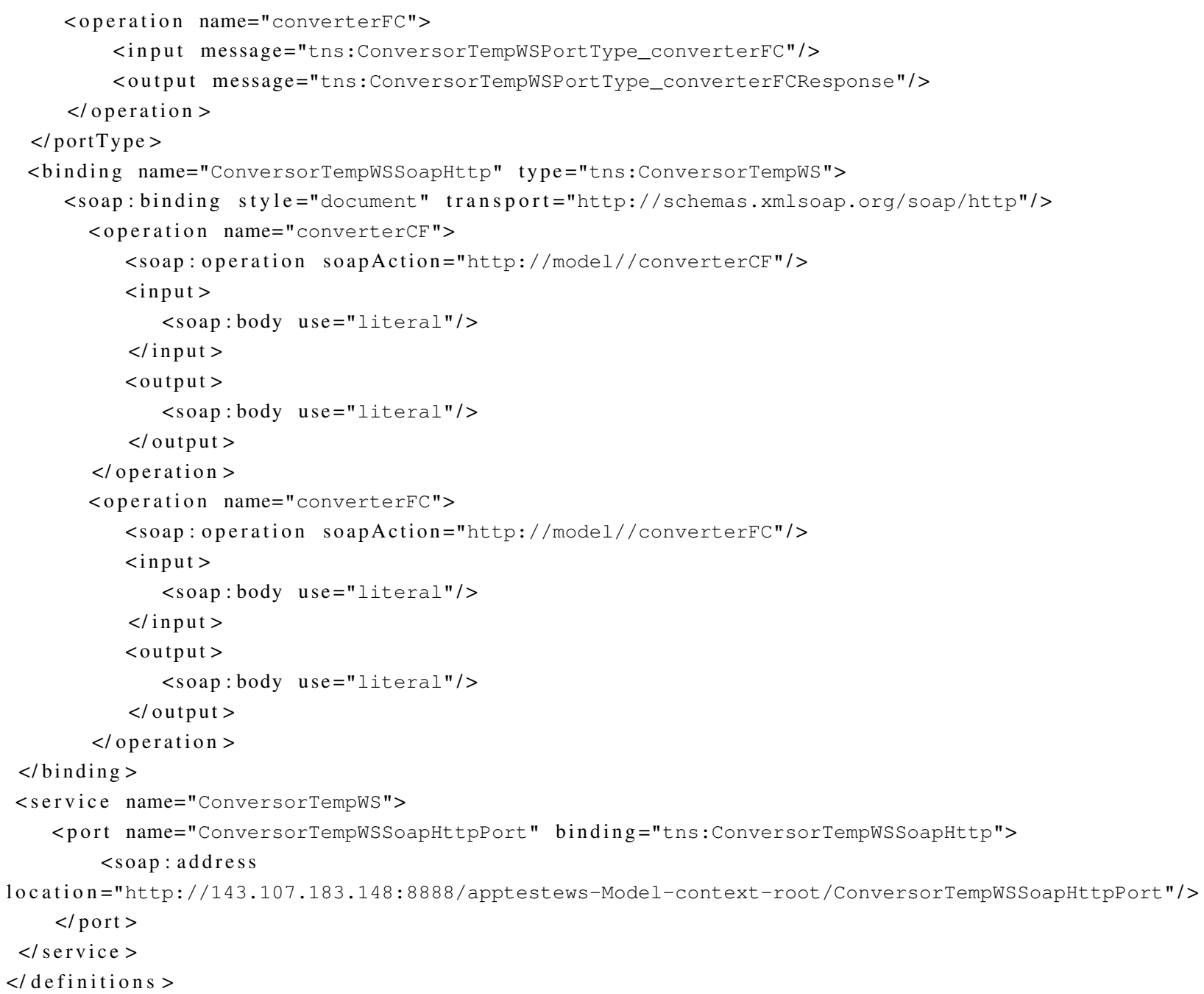

Listagem 2.5: WSDL do segundo WS.

A linguagem utilizada para a composição é o WS-BPEL e a IDE utilizada é o JDEVELOPER (Oracle, 2009c) com o servidor de aplicações OC4J e facilidades para apoiar o uso de BPEL. O problema exige a chamada a dois web services e a manipulação do resultado dessas chamadas. Em BPEL, conforme apresentado na Subseção 2.4.8, realiza-se a chamada a web services por meio de atividades invoke e deve-se armazenar o resultado dessas operações utilizando atividades copy.

A IDE permite a criação de um processo BPEL inicial que consiste de uma entrada e uma saída. Na Figura 2.13 apresenta-se uma visão geral da IDE utilizada e esse processo de negócio inicial. A IDE apresenta o conjunto de atividades BPEL no seu canto superior direito. A inserção de atividades é feita arrastando a atividade e levando para o local desejado.

O primeiro passo para a resolução do problema é criar uma atividade invoke e configurá-la para chamar o primeiro serviço. Em seguida é necessário criar uma operação assign para copiar a variável de entrada (receiveInput) para o parâmetro recebido pelo web service. Essa operação de cópia é chamada de cidade, conforme pode ser visto na Figura 2.14. Em seguida é realizada a segunda operação invoke que chama a operação de conversão de Fahrenheit para Celcios do segundo serviço. Nesse ponto é necessário criar duas atividades assign: a primeira copiará o valor 
retornado pela chamada ao primeiro web service para o parâmetro de entrada do segundo web service; A segunda copiará o valor retornado pelo chamada ao segundo web service para a variável de saída (replyOutput). Essas operações de cópia são chamadas de TempF e TempC conforme pode ser visto na Figura 2.14, que apresenta o resultado visual final dessa composição de web service. Maiores detalhes sobre a utilização do ambiente podem ser encontradas em (Oracle, 2009b).

Essa representação visual gera o código BPEL apresentado na Listagem 2.6. Destaca-se a definição dos partner links e variáveis (variables) e a seqüência definida pela tag sequence name= "main".

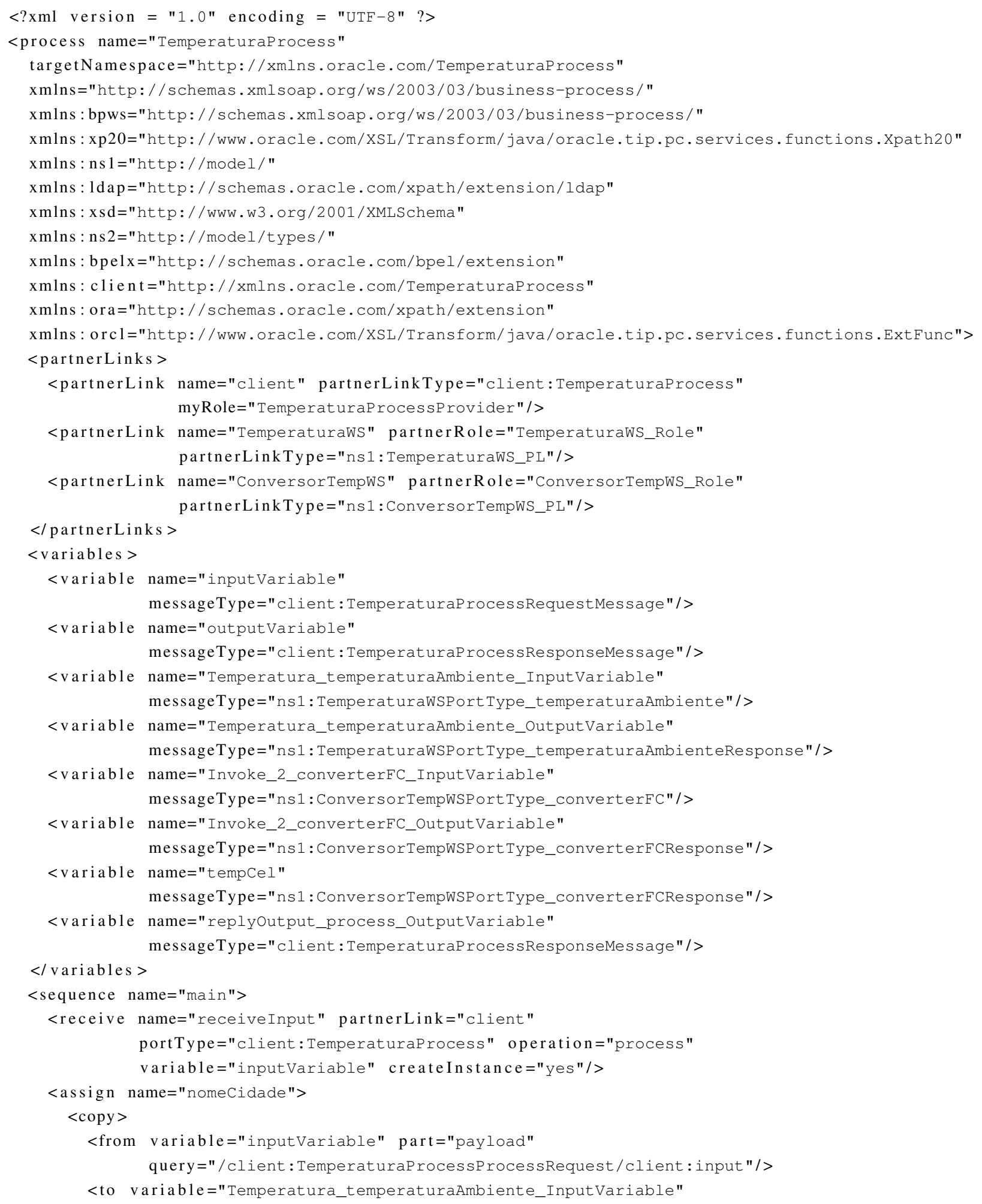


part="parameters" $</$ copy $>$

query ="/ns2: temperaturaAmbienteElement/ns2: local"/>

$</$ assign $>$

<invoke name="Temperatura" partnerLink="TemperaturaWS"

portType="ns1: TemperaturaWS" operation="temperaturaAmbiente"

in putVariable=" Temperatura_temperaturaAmbiente_InputVariable"

ou tputVariable=" Temperatura_temperaturaAmbiente_OutputVariable"/>

<assign name="tempFah">

$<\operatorname{copy}>$

$<$ from variable="Temperatura_temperaturaAmbiente_OutputVariable" part = "parameters"

query=" /ns2: temperaturaAmbienteResponseElement/ns2:result"/>

<to variable="Invoke_2_converterFC_InputVariable" part="parameters" query $=" /$ ns2 : converterFCElement/ns2: temperatura"/>

$</$ copy $>$

$</$ assign $>$

<invoke name="ConversorTemp" partnerLink="ConversorTempWS" portType="ns1: ConversorTempWS" operation="converterFC" inputVariable="Invoke_2_converterFC_InputVariable" outputVariable $="$ tempCel"/>

$<$ assign name="tempFinal">

$<$ copy $>$

$<$ from variable="tempCel" part="parameters"

query="/ns2: converterFCResponseElement/ns2:result"/>

$<$ to variable="outputVariable" part="payload"

query=" /client: TemperaturaProcessProcessResponse/client:result"/>

$</ \operatorname{copy}>$

$</$ assign $>$

$<$ reply name="replyoutput" partnerLink="client"

portType="client : TemperaturaProcess" operation="process"

variable="replyOutput_process_OutputVariable"/>

$</$ sequence $>$

$</$ process $>$

Listagem 2.6: Código BPEL para o problema da temperatura.

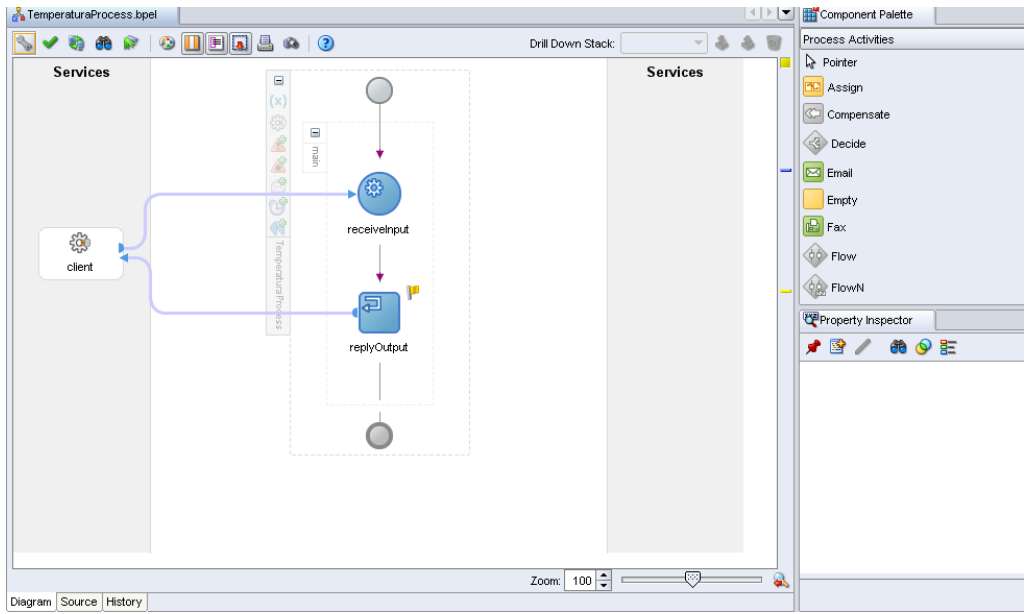

Figura 2.13: Inicialização do processo BPEL no ambiente de desenvolvimento. 


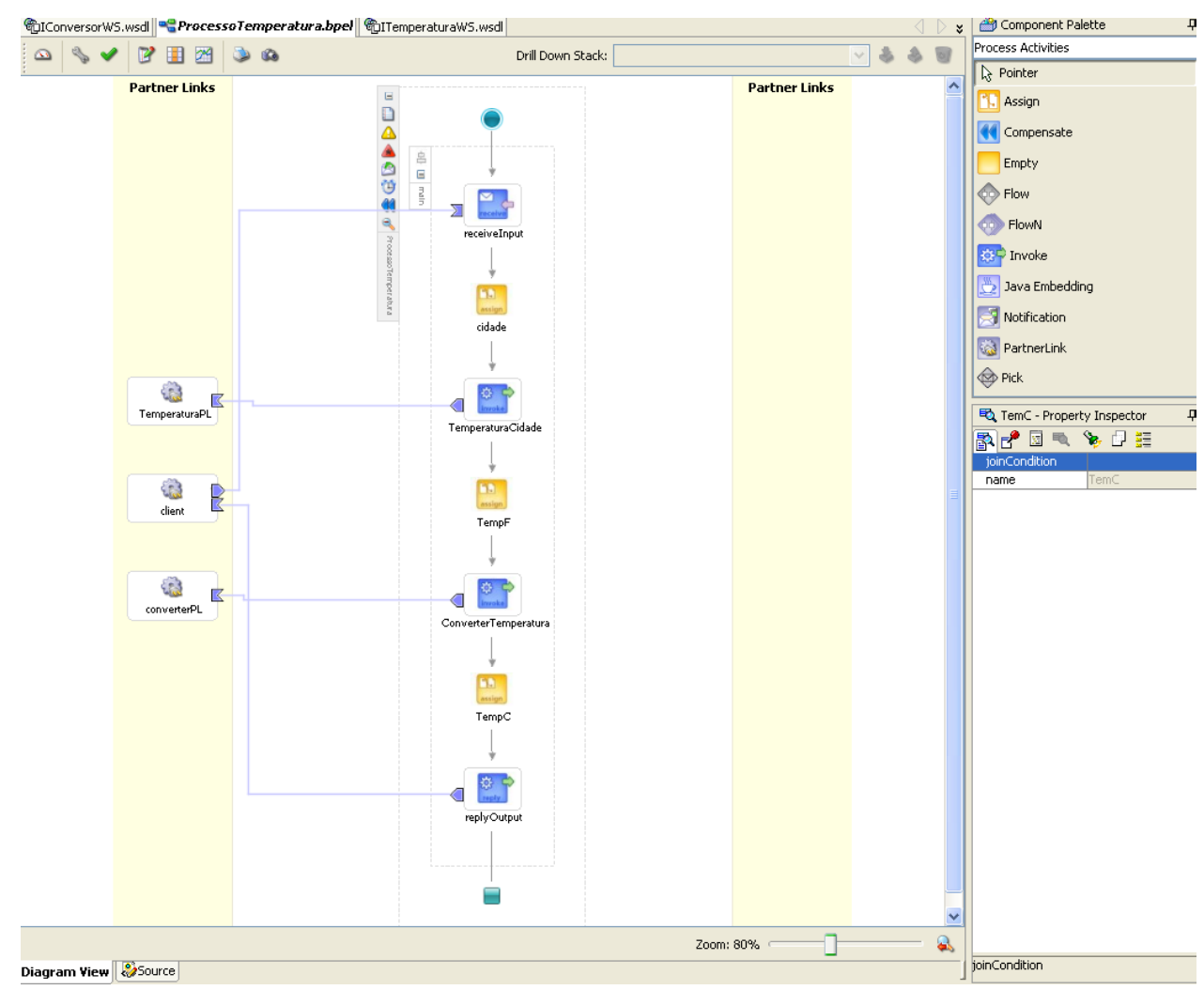

Figura 2.14: Processo BPEL completo em modo visual.

Nas Figuras 2.15 e 2.16 são mostrados a chamada e o resultado da execução desse processo de negócio. Na chamada, passa-se como parâmetro a cidade de Fortaleza e recebe-se como resultado a temperatura de $32^{\circ}$ Celsius.

Gerenciar $\quad$\begin{tabular}{l|l} 
Iniciar \\
Testando este Processo BPEL
\end{tabular} Descritor
Iniciando um teste da instância
Para criar um novo 'teste' da instância deste Processo BPEL, preencha este form e clique no botão 'Publicar Mensagem XML'.
ProcessoTemperaturaProcessRequest input Fortalezal

$\square$ Salvar como entrada default

$\square$ Adicionar propriedades de cabeçalho de mensagem opcionais

$\square$ Executar teste de stress

Publicar Mensagem XML

Figura 2.15: Chamada ao processo de negócio. 


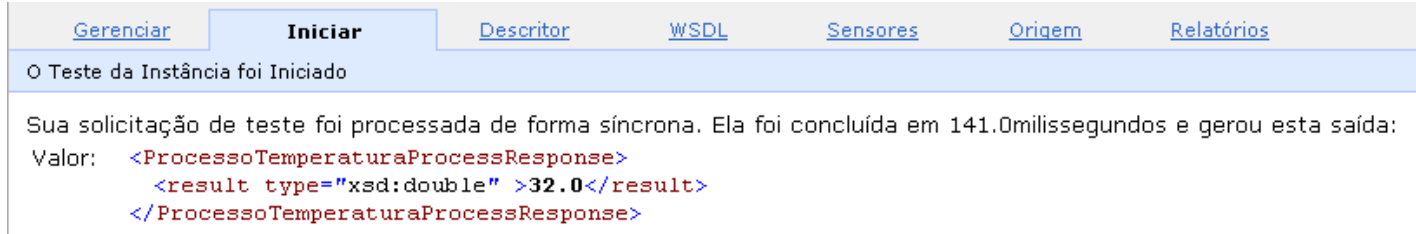

Figura 2.16: Resultado da chamada.

\subsection{Considerações Finais}

Neste capítulo, foram apresentados os conceitos de linha de produtos com suas principais abordagens de desenvolvimento, variabilidades, arquitetura de software, SOA, web services e composição de WS.

LPS constitui uma das principais formas de reúso, pois é utilizada quando os sistemas em estudo possuem mais características comuns do que características distintas, permitindo o reúso em diferentes níveis de abstração como requisitos, arquitetura e código. Existem diversos métodos de desenvolvimento de LPS que dividem o processo de forma semelhante, contudo cada método possui o foco em uma parte do desenvolvimento: seja na engenharia de domínio ou na engenharia de aplicações. Portanto, procura-se adaptar essas linhas de pesquisa para conseguir eficiência tanto na engenharia de domínio quanto na engenharia de aplicações.

Dos métodos apresentados, destaca-se o PLUS pois utiliza UML para a descrição dos modelos de múltiplas visões da linha e é baseado no processo unificado. Embora forneça modelos detalhados para a engenharia de domínio da linha, é superficial em termos de engenharia de aplicações, onde considera-se a utilização de outro método em conjunto para melhorar essa etapa do desenvolvimento de uma LPS. Para esse outro método, considera-se o uso do FAST, no qual durante a engenharia de domínio é desenvolvido um ambiente para geração dos membros da família a partir de sua especificação e é definido um processo para produção dos membros usando esse ambiente.

Foram apresentados ainda os conceitos de SOA e as formas de composição de serviços. Coreografia de serviços é uma técnica onde os serviços colaboram entre si sem a necessidade de algum coordenador central. É uma técnica em estudo e ainda não está madura para uso em larga escala. A composição por orquestração exige a presença de um coordenador central e apresenta-se como um padrão de fato da indústria, por esse motivo é utilizada para compor os serviços da LPS de leilões Web.

No próximo capítulo, são apresentadas algumas abordagens encontradas na literatura que combinam as técnicas de linha de produtos e SOA. 


\section{Trabalhos Relacionados}

\subsection{Considerações Iniciais}

Conforme discutido no Capítulo 1, diversos trabalhos tem sido feitos para investigar o uso de SOA em Linhas de Produtos ou investigar a utilização de técnicas de LPS para desenvolver software orientado a serviços. Assim, este capítulo apresenta algumas técnicas e abordagens que combinam LPS e SOA.

O capítulo está organizado da seguinte forma. Na Seção 3.2, é apresentado um método de desenvolvimento de linha de produtos baseada em web services proposto por Gomaa e Saleh (2005). $\mathrm{Na}$ Seção 3.3, é apresentada uma outra abordagem de desenvolvimento de linha de produtos baseado em serviço proposta por Lee et al. (2008). Na Seção 3.4, é apresentada a noção de famílias de processos de negócios proposta por Ye et al. (2007). Na Seção 3.5, é apresentada uma classificação de variabilidades em SOA e um método de modelagem dessas variabilidades proposto por Chang e Kim (2007). Na Seção 3.6, é apresentada uma abordagem que trata de populações de famílias de produtos proposta por van Gurp e Savolainen (2006). Na Seção 3.7, é apresentada uma abordagem que utiliza técnicas de linhas de produto para o desenvolvimento de sistemas Web baseado em serviços proposto por Zaupa (2007). Na Seção 3.8, são apresentadas as considerações finais do capítulo e uma tabela resumindo as contribuições dessas abordagens que são mais relevantes para este trabalho de mestrado. 


\subsection{Engenharia de Linhas de Produtos para Web Servi- ces e UML}

Gomaa e Saleh (2005) apresentam uma abordagem de desenvolvimento de LPS baseada em web services adaptada a partir do método PLUS(2.2.2.4). Ela usa UML, uma vez que esta provê maiores facilidades para entender e gerenciar variabilidades em linhas de produtos por meio de diferentes perspectivas. Com o uso da notação da UML, a visão dos requisitos funcionais é representada pelos casos de uso, a visão do modelo estático se dá pelo modelo de classes e a visão do modelo dinâmico é feita por meio do modelo de colaboração e o modelo de statechart. Para atender a uma necessidade especial de linhas de produtos, um outro diagrama que não pertence a UML precisa ser adicionado: o diagrama de features(2.2.3), que descreve as características comuns e variantes de uma linha de produtos.

A primeira diferença em relação ao PLUS ocorre durante a elaboração dos diagramas de colaboração, no qual deve-se adicionar os estereótipos $<<$ web services $>>$ e $<<$ user interface $>>$ para os componentes que serão web services e Interface gráfica, respectivamente (Gomaa e Saleh, 2005). Conforme mostra-se na Figura 3.1, em um exemplo de reserva de quarto em uma linha de produtos de um hotel, observa-se o uso de uma Interface gráfica (ReservaQuarto), dois web services do tipo núcleo (CreditoWS e DisponivelWS) e um web service do tipo variante (ReservaQuartoWS).

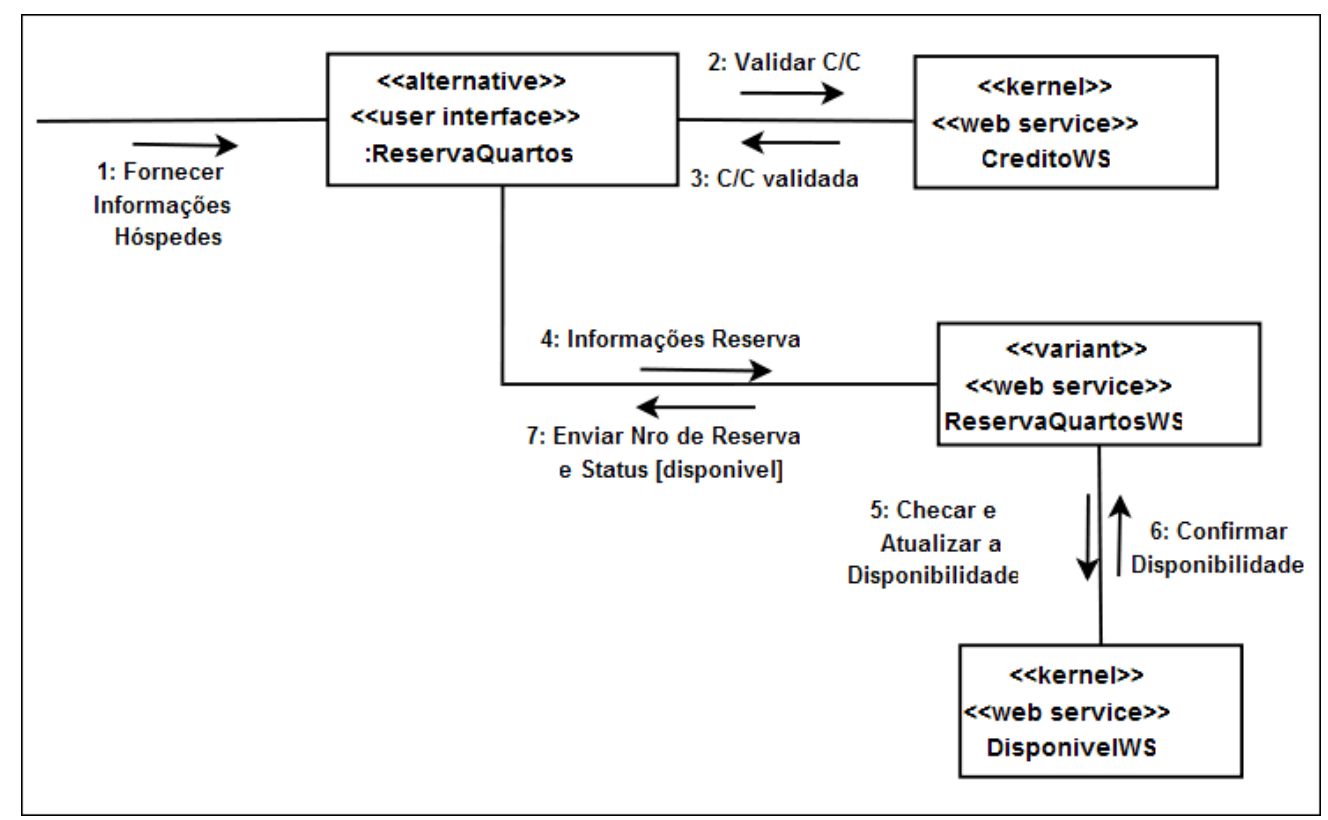

Figura 3.1: Diagrama de Colaboração - Reserva de quarto (adaptada de Gomaa e Saleh (2005)).

A próxima mudança no método envolve o diagrama de atividades, que descreve o workflow de cada ação iniciada pelo usuário. Esses workflows têm duas tarefas principais: invocar web services ou outras interfaces. Na Figura 3.2 são ilustradas essas mudanças para o evento de reserva de 
quarto, no exemplo de linha de produtos de um hotel. Destacam-se as chamadas aos web services ReservaQuartoWS, CreditoWS e DisponivelWS.

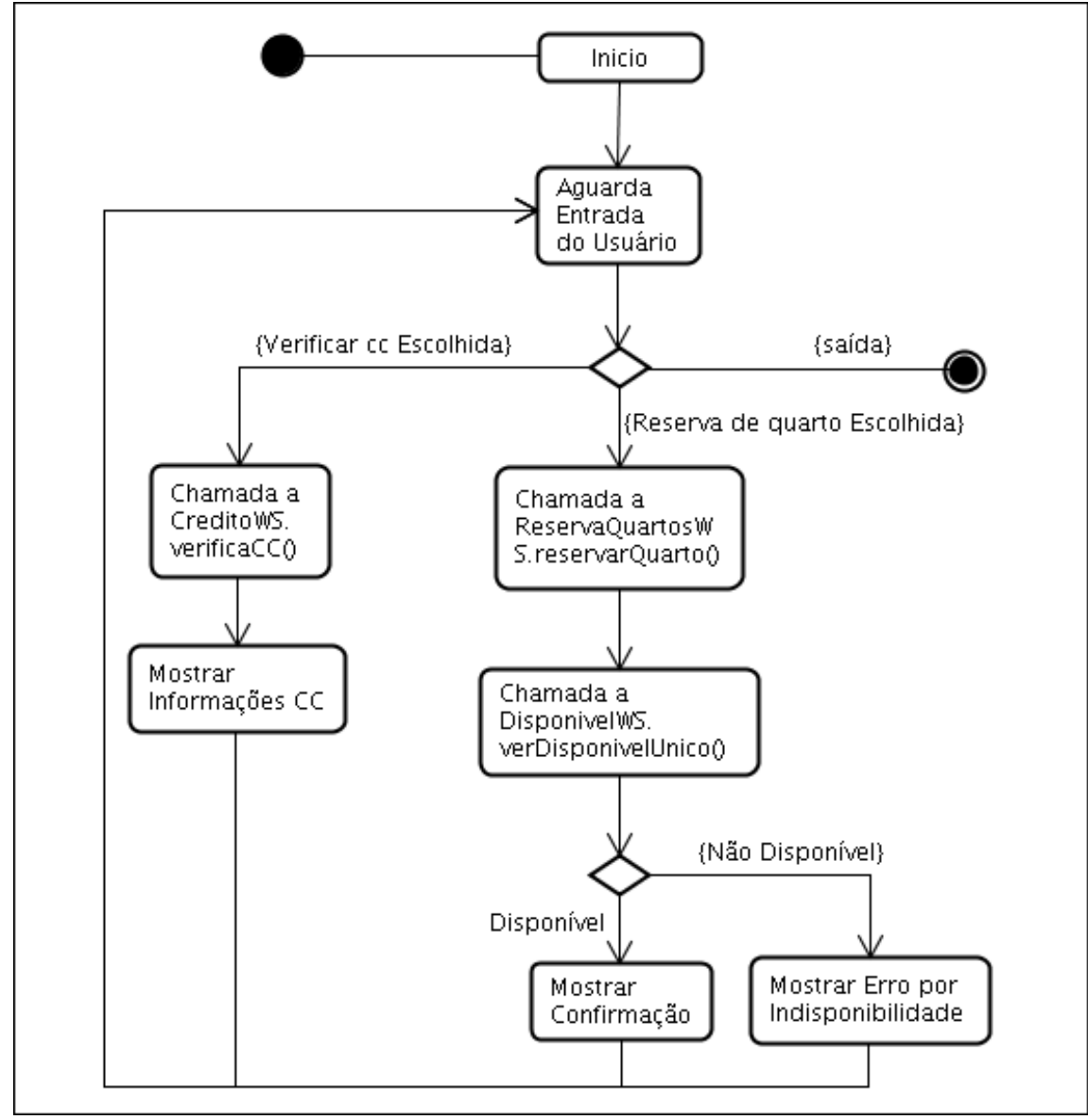

Figura 3.2: Diagrama de Atividades - Reserva de quarto (adaptada de Gomaa e Saleh (2005)).

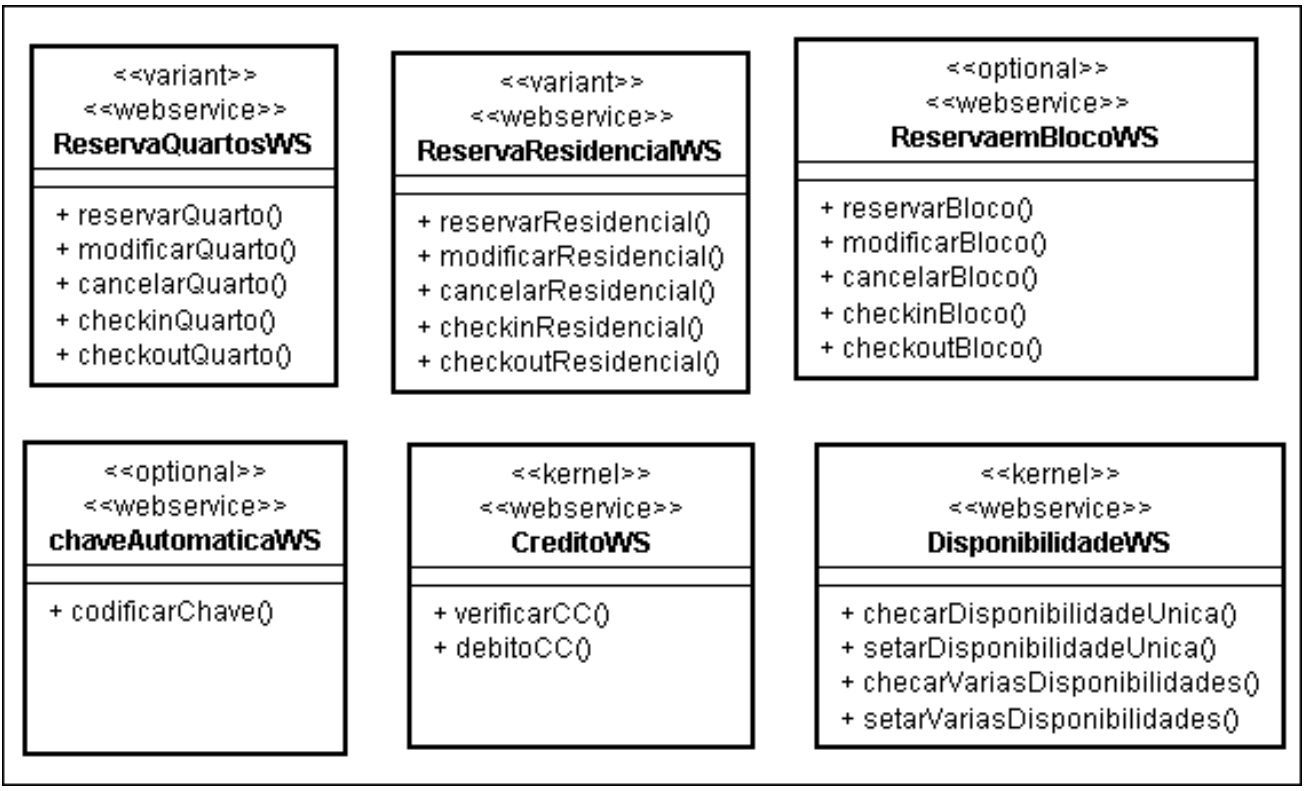

Figura 3.3: Exemplos de interfaces de web services (adaptada de Gomaa e Saleh (2005)). 
Por fim, deve-se projetar os web wervices. Este projeto se dá por meio do projeto da interface, que consiste nos métodos disponibilizados pelo web service aos seus usuários. Na Figura 3.3 são apresentadas as interfaces dos principais web services em uma linha de produtos de um hotel. Destaca-se o uso do estereótipo $<<$ web services $>>$ nas definições das interfaces dos web services.

\subsection{Uma Abordagem para o Desenvolvimento de Linhas de Produto Orientada a Serviço}

Lee et al. (2008) apresentam uma abordagem de desenvolvimento de linha de produtos orientada a serviço que, entre outras coisas, ajuda os desenvolvedores a identificar serviços com o grau certo de granularidade. Os autores desse trabalho classificam os serviços em atômicos, moleculares e orquestrativos. Os serviços atômicos são a maioria dos serviços de baixo nível e podem ser agrupados em serviços mais robustos chamados de moleculares, que formam o bloco de construção básica dos membros da família e são mais reusáveis. Os serviços orquestrativos são serviços de alto nível especificados por workflows.

Esse trabalho apresenta o conceito de feature binding unit, que consiste de service features, que representam as principais funcionalidades de um sistema e podem ser adicionadas ou removidas como uma unidade de serviço. Os autores propõem o uso das feature binding units como uma forma de identificar os serviços candidatos com a granularidade adequada, ou seja, serviços reusáveis. O primeiro passo para identificar os serviços é separar as service features em dois grupos: comportamentais (workflow) e computacionais (tarefas). As características computacionais são utilizadas para identificação dos serviços moleculares com base nas orientações que definem um serviço molecular, que deve ser:

- auto-contido (controle e computação locais);

- sem estado do ponto de vista do usuário;

- oferecido com pré e pós condições;

- representante de um domínio de serviço específico.

O item mais difícil a ser analisado é o último, pois exige o julgamento profissional de um especialista de domínio.

\subsection{Família de Processos de Negócios}

Ye et al. (2007) apresentam uma abordagem com foco nos processos de negócios. Um vez que um sistema de informação está ligado aos processos de negócios das empresas, e esses processos 
de negócios mudam constantemente, os sistemas passam por uma necessidade de mudança muito grande, e essa mudança deve acontecer com alta velocidade.

SOA surgiu como uma arquitetura de software flexível para possibilitar que essas mudanças nos requisitos sejam refletidas rapidamente no software, mas mesmo assim, ainda precisam ser usados outros artifícios para que a velocidade dessas mudanças atendam à demanda das empresas. Neste sentido, essa abordagem propõe a aplicação de técnicas de linhas de produtos em processos de negócios orientados a serviços. Essa abordagem foi chamada de Service-oriented product-line architecture (SOPLA). A SOPLA é usada no desenvolvimento de famílias de processos de negócio (Ye et al., 2007).

A abordagem SOPLA apresenta um ângulo de visão diferente da abordagem anterior. Enquanto PLUS++ propunha a implementação de uma linha de produtos cujos componentes eram web services, esta abordagem foca na análise do software existente, implementado com o uso de serviços, para identificar variabilidades nos processos de negócios que regem essa interação entre os serviços.

O desenvolvimento de famílias de processos de negócios com o uso de SOPLA possui três estágios: Engenharia de domínio, transformação e engenharia de processos de negócio. Na Figura 3.4 são ilustrados esses estágios.

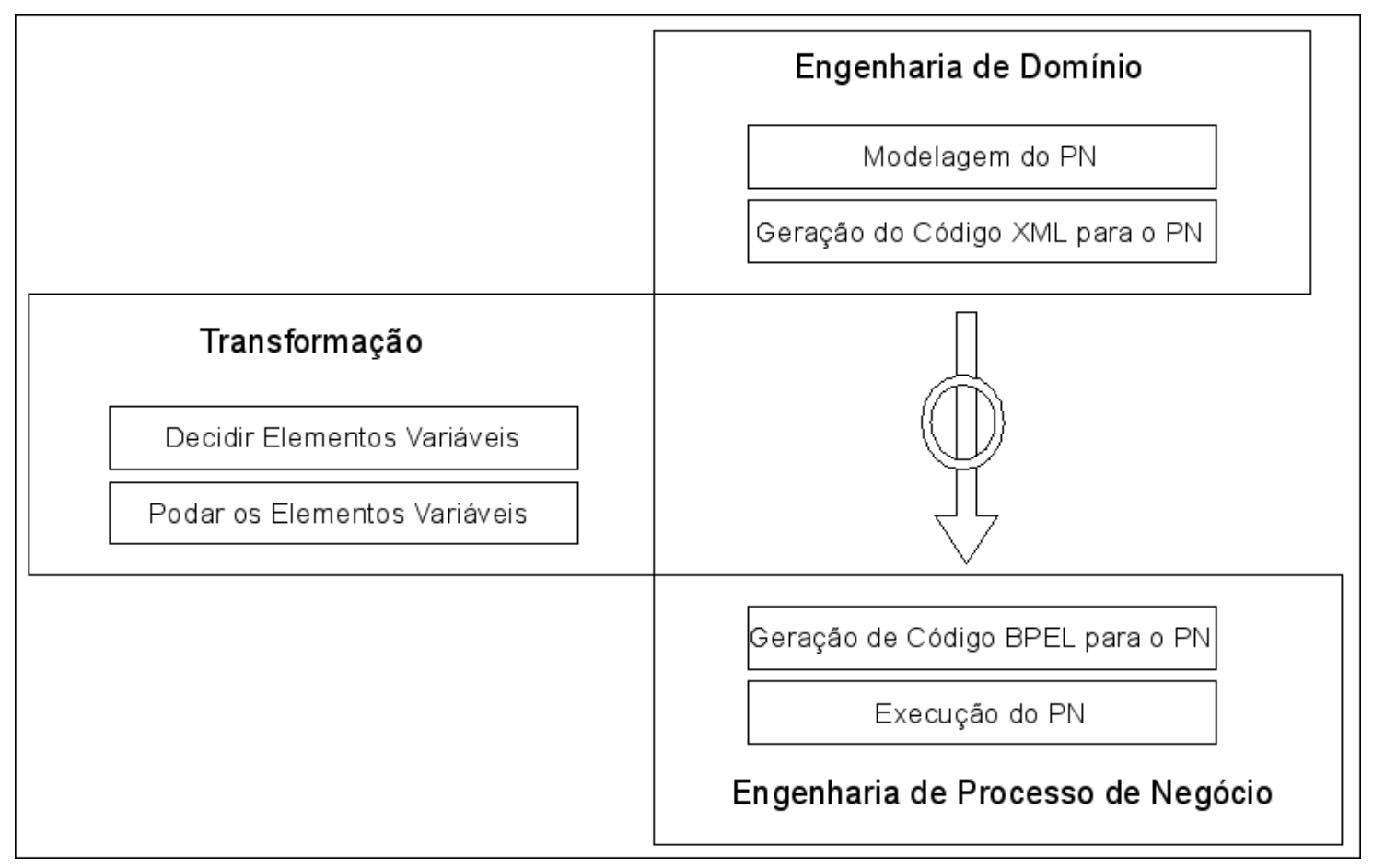

Figura 3.4: Estágios de desenvolvimento de famílias de processos de negócios (adaptado de Ye et al. (2007)).

O estágio de engenharia de domínio consiste na modelagem dos processos de negócios variáveis e da geração do código XML para eles. Isto é feito por meio da identificação de variabilidades 
e partes comuns entre os processos de negócios. Ye et al. (2007) definem quatro tipos de variabilidades de processos de negócios:

- Atividades de negócios comuns: devem ser incluídas em todos os processos de negócios. Fazem parte do núcleo da linha.

- Atividades de negócios comuns incluindo variabilidades: as atividades são comuns a todos os processos de negócios mas com variações em alguns processos.

- Atividades de negócios opcionais: essas atividades podem ou não ser incorporadas em um processo de negócios.

- Atividades de negócios opcionais incluindo variabilidades: são atividades de negócios opcionais, mas que apresentam variabilidades entre elas.

Pode-se ainda identificar três tipos de variações internas em atividades de negócios: Variações de dados, variações de gateway e variações de eventos. As variações de dados são variabilidades dos parâmetros de uma atividade de negócios, como por exemplo valores de entrada e saída. As variações de gateway representam as variabilidades dos processos condicionais entre as atividades de negócios. As variações de eventos são aquelas variabilidades nos eventos de mensagens ou de tempo entre as atividades de negócios.

Geralmente um modelo de processos de negócios é representando por intermédio do diagrama de atividades da UML ou a da Business Process Modeling Notation (BPMN) (Ouyang et al., 2006). Deve-se ainda adicionar algumas informações a esses diagramas referentes às variabilidades: o ponto no qual a variação pode ocorrer, as variantes que podem ser ligadas ao ponto de variação e propriedades da variabilidade (tipo de variabilidade, cardinalidade da variação, relação das variações e etc.). Para documentar as variações do modelo de processos de negócios, o autor criou uma linguagem baseada em XML, que ao fim do processo de desenvolvimento pode ser usada para gerar o código XML para a execução individual de processos de negócios.

O estágio de transformação é aquele responsável por decidir quais elementos variáveis entrarão no processo de negócios e por cortar os elementos não selecionados. A decisão pode ser executada de duas formas: seleção ou configuração. A seleção determina quando uma atividade de negócio com uma variabilidade comum ou opcional é selecionada ou não. A configuração envolve a configuração de parâmetros ou mensagens em atividades de negócios com variabilidades internas como: variação de dados, de gateway ou de evento/tempo.

O estágio final consiste da transformação do diagrama de atividades ou BPMN em um modelo de processo de negócios como o BPEL. A conversão de BPMN em BPEL pode ser feita por vários métodos apresentados na literatura (Ouyang et al., 2009; Dikmans, 2008). 


\subsection{Um Método de Modelagem de Variabilidades para Ser- viços Adaptáveis}

A partir de uma comparação entre as formas de reúso obtidas com LP e SOA, Chang e Kim (2007) procuram aplicar elementos de linha de produtos para tratar variabilidades em SOA. Esse trabalho apresenta uma classificação das variabilidades em SOA e um método de modelagem de variabilidades.

Chang e Kim (2007) apresentam quatro tipos de variabilidades em SOA: variabilidades de workflow, que são as variações no workflow do processo de negócio, ou seja, os serviços utilizados no processo de negócio podem ser alternativos ou opcionais para cada usuário do processo; variabilidades de composição, que representam as variações dos diferentes serviços com interfaces que atendem aos requisitos funcionais, mas que possuem implementações diferentes com atributos de qualidade distintos; variabilidades de interface, que ocorrem quando as interfaces do serviços apresentam diferenças entre si; e, variabilidades de lógica, que ocorre quando os serviços representam lógica de negócios que variam de acordo com o serviço requisitado.

Os artefatos de SOA que representam workflows, composições e interfaces são diferentes daqueles para software convencional, contudo a lógica de negócios é a mesma do modelo baseado em componentes. Por isso, esse trabalho propõe representações por meio de esquemas XML para três tipos de variabilidades: variabilidades de workflow, variabilidades de composição e variabilidades de interface.

\subsection{Abordagem para o Desenvolvimento de Populações de Famílias de Produtos}

van Gurp e Savolainen (2006) apresentam uma técnica e um processo para serem usados na implementação de características variantes em arquitetura de grades de web services. Os autores tiram proveito da grande capacidade dos web services como tecnologia de integração, seja para software de diferentes vendedores ou para integração de sistemas legados, e propõem seu uso para integração de produtos de famílias de produtos para criar uma população de famílias de produtos.

Para atingir tal fim, são usados service grids, que combinam web services e computação em grade. Um service grid é um sistema de software distribuído que consiste de sistemas de software desenvolvidos independentemente, cujo único aspecto em comum é que podem ser acessados como um web service (van Gurp e Savolainen, 2006).

O objetivo principal dessa abordagem é apresentar técnicas para a realização de variabilidades em populações de famílias de produtos usando service grids. Uma população de produtos consiste de múltiplas famílias de produtos desenvolvidas independentemente que precisam ser integradas. Embora essa abordagem foque no uso de técnicas no desenvolvimento de populações de famílias 
de produtos, essas técnicas podem ser estendidas para implementar variabilidades em linhas de produtos com arquitetura orientada a serviço.

\subsection{Um Processo de Desenvolvimento de Aplicações Web baseado em Serviços}

Zaupa (2007) apresentam um ambiente de desenvolvimento chamado WIDE-PL e um processo de desenvolvimento de aplicações Web baseado em serviços chamado ADESE, no qual utilizam técnicas de linha de produtos ao longo do desenvolvimento. As atividades propostas pelo processo são: definir o domínio da aplicação; modelar serviços com base nos conceitos de modelo de características de linha de produtos; instanciar o modelo de características; mapear o modelo instanciado para um correspondente diagrama de classes; implementar os serviços a partir do diagrama de classes; e, gerar aplicações com base nos serviços definidos.

Uma das contribuições deste trabalho é fornecer um método de mapeamento do modelo de características de um serviço para seu respectivo diagrama de classes. Para cada serviço definido deve-se refinar seu diagrama de características e seguir as regras definidas por Zaupa (2007) conforme apresenta-se na Tabela 3.1.

Tabela 3.1: Passos para o mapeamento de diagrama de características em diagrama de classes.

\begin{tabular}{|l|l|}
\hline Etapa & Procedimento \\
\hline Identificar classes & Criar uma classe para cada característica não "folha" do modelo de características. \\
\hline $\begin{array}{l}\text { Identificar relaciona- } \\
\text { mentos }\end{array}$ & $\begin{array}{l}\text { Adicionar o relacionamento de agregação entre as classes que tem relacionamento no } \\
\text { modelo de características, sendo que a classe agregadora é a classe que, no relaciona- } \\
\text { mento, tem nível mais alto no modelo de características. }\end{array}$ \\
\hline $\begin{array}{l}\text { Identificar operações e } \\
\text { atributos }\end{array}$ & $\begin{array}{l}\text { Transformar as características "folhas" do modelo de características em operações ou } \\
\text { atributos das classes já criadas, sendo que cada característica "folha" que será trans- } \\
\text { formada em operação ou atributo deverá ser incluída na classe que representa sua } \\
\text { respectiva característica de nível mais alto no modelo de características. }\end{array}$ \\
\hline $\begin{array}{l}\text { Identificar operações } \\
\text { da classe principal }\end{array}$ & $\begin{array}{l}\text { A característica raiz do modelo de características é a classe principal do diagrama de } \\
\text { classes e as operações incluídas nesta classe serão as operações convertidas em ope- } \\
\text { rações do serviço. Assim, caso alguma outra classe do diagrama contenha operações } \\
\text { que devam ser operações do serviço, estas operações deverão ser incluídas na classe } \\
\text { principal, e na implementação, as operações contidas na classe principal deverão fazer } \\
\text { a invocação da operação original nas outras classes. }\end{array}$ \\
\hline $\begin{array}{l}\text { Incluir operações e atri- } \\
\text { butos auxiliares }\end{array}$ & $\begin{array}{l}\text { operações e atributos adicionais como os casos das operações get e set podem ser in- } \\
\text { cluídos no diagrama para auxiliarem posteriormente na execução de alguma operação } \\
\text { do serviço. }\end{array}$ \\
\hline
\end{tabular}

Na Figura 3.5, mostra-se um exemplo de uso dessas regras para transformar o diagrama de características do serviço de calendário no seu respectivo diagrama de classes. 


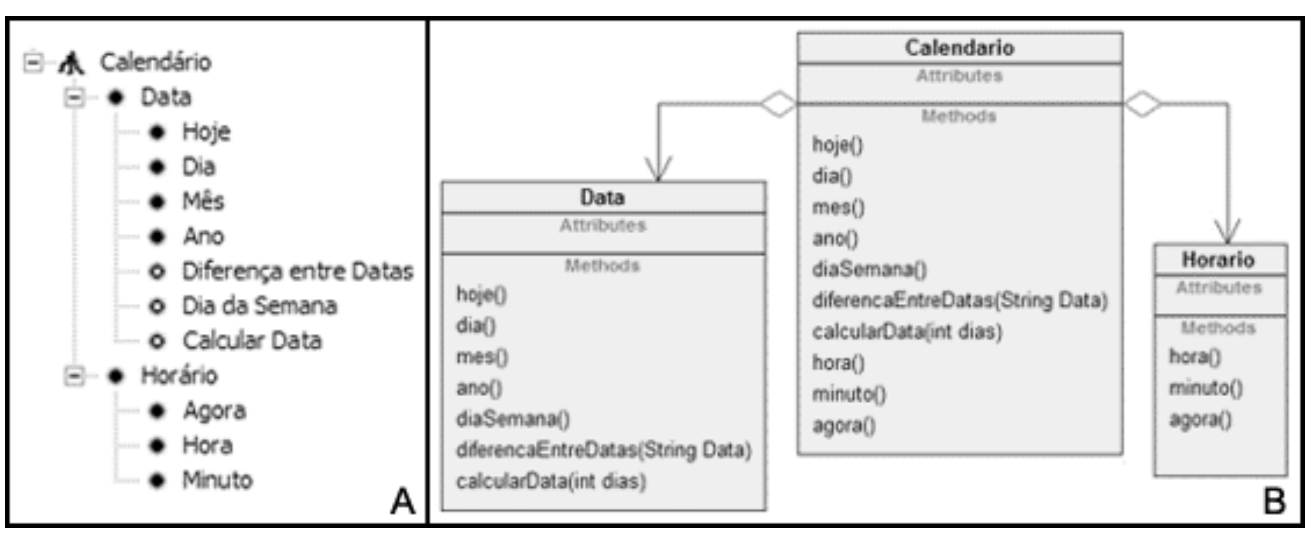

Figura 3.5: Exemplo de mapeamento de um diagrama de características A para um diagrama de classes B (Zaupa, 2007).

\subsection{Considerações Finais}

Neste capítulo foram apresentadas algumas abordagens que utilizam conceitos de LPS para produzir software orientado a serviços e abordagens que visam utilizar SOA para produzir LPSs. Conforme foi visto nas diferentes abordagens, o desenvolvimento de uma linha de produtos com arquitetura orientada a serviços envolve a análise de muitos quesitos, alguns particulares de linhas de produtos, outros particulares de SOA e ainda alguns que surgem da combinação dessas duas técnicas.

Entre as dificuldades desse tipo de desenvolvimento destaca-se a análise de variabilidades que foi abordada nos trabalhos de: Ye et al. (2007), que trata das famílias de processos de negócios; a abordagem de Gomaa e Saleh (2005), que trata da identificação de variabilidades em serviços; e o trabalho de Chang e Kim (2007) que destaca quatro tipos de variabilidades em software orientado a serviço. Quando a análise de características ocorre, deve-se então analisar as características variantes sob diversas perspectivas: variabilidades de processos de negócio (workflow ou composição) e variabilidades de serviços (lógica ou interface). As abordagens Ye et al. (2007), Gomaa e Saleh (2005) e Chang e Kim (2007) podem ser combinadas para preencher a lacuna existente entre elas para a análise de variabilidades no desenvolvimento de uma linha de produtos com arquitetura orientada a serviços. Contudo, nenhuma dessas abordagens tratou a forma de implementação das variabilidades como serviços.

van Gurp e Savolainen (2006) apresentam uma técnica e um processo para serem usados na implementação de características variantes em arquitetura de grades de Web Services. As técnicas descritas por essa abordagem são de realização de variabilidades, e embora tenham sido pensadas inicialmente para o ambiente de grades de serviços, a maioria delas pode ser estendida para a implementação variabilidades em outros tipos de software orientado a serviço.

Este capítulo ainda apresentou os trabalhos de Zaupa (2007) e de Lee et al. (2008). O primeiro apresenta um processo de desenvolvimento de software orientado a serviços e um método de mapeamento entre o diagrama de características e o diagrama de classes. O segundo apresenta 
uma abordagem de desenvolvimento de linha de produtos baseado em serviços e um método de definição de serviços com a granularidade mais adequada . Na Tabela 3.2 apresenta-se um resumo das contribuições, relevantes para este trabalho, dessas abordagens.

Tabela 3.2: Principais contribuições das abordagens apresentadas.

\begin{tabular}{|l|l|}
\hline Autores & Contribuições \\
\hline Gomaa e Saleh (2005) & Adaptações nos diagramas UML para modelagem de serviços. \\
\hline Lee et al. (2008) & Definição de serviços com base em características. \\
\hline Ye et al. (2007) & Análise de famílias de processos de negócios. \\
\hline Chang e Kim (2007) & Modelagem de variabilidades em software orientado a serviços. \\
\hline van Gurp e Savolainen (2006) & Técnicas de implementação de variabilidades em web services. \\
\hline Zaupa (2007) & Método de mapeamento entre diagrama de características e diagrama de classes. \\
\hline
\end{tabular}

O capítulo seguinte apresenta a principal contribuição deste trabalho: uma abordagem de desenvolvimento de linha de produtos com arquitetura orientada a serviços, que utiliza algumas contribuições das abordagens apresentadas neste capítulo e tem o objetivo de fornecer um método de desenvolvimento que preencha as principais lacunas existentes. 


\section{Abordagem SoProL-WS}

\subsection{Considerações Iniciais}

O uso de SOA para flexibilizar a arquitetura de uma LPS, aumentar sua capacidade de evolução/manutenção e facilitar a derivação de seus produtos acrescenta e altera algumas atividades e artefatos comuns ao desenvolvimento de LPSs baseadas em componentes ou em frameworks, por exemplo. Neste capítulo apresenta-se uma abordagem de desenvolvimento de LPS com SOA, bem como as justificativas para a sua proposta, as contribuições desta em relação à literatura e as atividades e artefatos que a compõem.

O capítulo está organizado da seguinte forma. Na Seção 4.2, apresenta-se a abordagem proposta, chamada de SoProL-WS, suas bases e seus objetivos. Na Seção 4.3, apresenta-se uma visão geral do domínio de leilões Web, que é usado para o desenvolvimento do estudo de caso e como exemplo para os artefatos de cada atividade da abordagem SoProL-WS. Na Seção 4.4, apresentamse alguns princípios seguidos durante o desenvolvimento do estudo de caso da LPS de leilões Web. $\mathrm{Na}$ Seção 4.5, apresentam-se os pré-requisitos para serem iniciadas as atividades da abordagem. Na Seção 4.6, são apresentadas as atividades de requisitos da abordagem SoProL-WS, bem como exemplos da aplicação da abordagem direcionada a LPS de leilões Web. Na Seção 4.7, são apresentadas as atividades de análise e projeto da abordagem SoProL-WS seguida de sua aplicação no estudo de caso de leilões Web. Na Seção 4.8, apresenta-se uma avaliação dos ambientes de desenvolvimento para BPEL e os detalhes de implementações dos WS, PN e interface do usuário (GUI) da LPS de leilões Web. Na Seção 4.9 apresentam-se alguns detalhes sobre o teste de LPS. Na Seção 4.10, comenta-se sobre a utilização dos artefatos do núcleo para a composição dos mem- 
bros da LPS. Na Seção 4.11, caracteríza-se a engenharia de aplicações de LPS, e por fim, na Seção 4.12, são apresentadas as considerações finais do capítulo.

\subsection{Caracterização da Abordagem}

A adoção de uma abordagem para o desenvolvimento de linha de produtos com arquitetura orientada a serviços permite: a uniformidade do processo de desenvolvimento, uma vez que pode-se realizar o desenvolvimento seguindo os mesmos passos e realizando as mesmas atividades; uma maior agilidade no desenvolvimento, pois o uso de SOA facilita o reaproveitamento de serviços existentes; uma maior facilidade de manutenção na linha, pois SOA permite alcançar uma arquitetura flexível e adaptável; e facilidade na derivação de membros da linha, uma vez que os serviços possuem um baixo acoplamento e podem ser ligados em tempo de execução.

A elaboração de uma abordagem para o desenvolvimento de LPS com SOA proposta neste trabalho tomou como base a abordagem PLUS (Gomaa, 2004), sua extensão proposta por Gomaa e Saleh (2005), a abordagem proposta por Lee et al. (2008), além dos trabalhos de Ye et al. (2007), van Gurp e Savolainen (2006), Zaupa (2007) e Chang e Kim (2007), com a finalidade de fornecer um guia mais completo que os trabalhos anteriores e que trate alguns dos principais problemas existentes nesse tipo de desenvolvimento.

A abordagem proposta neste trabalho, denominada SoProL-WS (do inglês Software Product Line-Web Services), utiliza o processo evolucionário de linha de produtos, assim como a abordagem PLUS. Esse processo é composto pelas duas fases a seguir:

- Engenharia de domínio: Modelagem com o uso da UML adaptada para as necessidades de LPS e web services, modelagem das features (características), definição dos serviços, análise das variabilidades em processos de negócios e em serviços, definição da arquitetura da linha, implementação de web services reutilizáveis e construção de um gerador de aplicações para a derivação dos produtos da linha.

- Engenharia de aplicações: Configuração da modelagem de um membro (sistema alvo) da linha de produtos a partir da modelagem da linha. O engenheiro de aplicações seleciona as features desejadas para o membro da linha. A partir das features selecionadas, adapta-se a arquitetura da linha para o sistema alvo e determina-se quais serviços são necessários para a configuração do sistema.

O desenvolvimento de uma LPS com SOA exige algumas atividades que não fazem parte da abordagem PLUS como, por exemplo: identificação de serviços reutilizáveis e de suas variabilidades; identificação de processos de negócio e suas variabilidades; e identificação de opções para implementação de serviços. Portanto, a maior contribuição deste trabalho é apresentar uma abordagem de desenvolvimento com as atividades essenciais ao desenvolvimento de uma LPS com 
SOA, buscando fornecer um guia de desenvolvimento que contempla as principais atividades necessárias para a construção bem sucedida de uma linha de produtos com arquitetura orientada a serviços preenchendo a lacuna deixada pelas abordagens apresentadas no Capítulo 3.

Conforme discutido na Seção 2.2.1, cada uma das abordagens de desenvolvimento de LPS existentes foca em uma etapa específica, seja na engenharia de domínio, na engenharia de aplicações ou no produto final gerado pela LPS. A abordagem SoProL-WS possui um forte enfoque na engenharia de domínio, em especial na definição de serviços e processos de negócios com suas respectivas variabilidades, por acreditar que uma engenharia de domínio bem feita aumenta as chances de sucesso no desenvolvimento, facilita a derivação de produtos da linha com o uso dos artefatos reutilizáveis desenvolvidos nessa etapa e ainda permite um bom projeto de serviços, para que possam ser reutilizados em outros produtos ou outras LPS de domínios diferentes. Contudo, a abordagem SoProL-WS também investe esforços na configuração de um gerador de aplicações para facilitar a derivação dos produtos da linha de forma automatizada.

Em suma, a abordagem SoProL-WS inicia-se com a fase de engenharia de domínio. Essa fase é responsável por descrever o domínio da aplicação em desenvolvimento, utilizando os modelos UML, identificando os serviços e processos de negócios com suas respectivas variabilidades, definindo a arquitetura da LPS, implementando os serviços reutilizáveis, montando os workflows BPEL, realizando testes de unidade e configurando um gerador de aplicações. A fase seguinte é a engenharia de aplicações, na qual o engenheiro de aplicações define os requisitos do sistema alvo, cria uma instância do diagrama de casos de uso e do modelo de características para esse sistema, utiliza o gerador de aplicações com base nos requisitos desejados e testa a aplicação resultante. Cada uma dessas atividades será detalhada mais adiante com exemplos da LPS de leilões Web.

Na Figura 4.2, apresenta-se uma visão geral das atividades de SoProL-WS, dividida em suas duas fases: engenharia de domínio e engenharia de aplicações. Pode-se perceber, em alto nível, alguma semelhança com a abordagem PLUS (vide Figura 2.4), que será melhor diferenciada a medida que as fases de desenvolvimento forem detalhadas. A Figura foi feita utulizando-se a notação BPMN, para qual apresenta-se uma legenda na Figura 4.1. Observa-se que as setas representam o fluxo de dados e em alguns casos indicam realimentação do processo, ou seja, que foi encontrado algum problema nos artefatos da atividade anterior e eles precisam ser refeitos. Observe que a engenharia de domínio produz uma série de artefatos reunidos na biblioteca de reúso da LPS e que serão usados na engenharia de aplicações para obtenção do sistema alvo. Entre esses artefatos destacam-se os diagramas de casos de uso, os diagramas de características, a implementação dos serviços e os processos de negócios BPEL. Exemplos desses artefatos são apresentados ao longo deste Capítulo para a linha de produtos de leilões Web. O sistema alvo pode utilizar somente um serviço, desde que os serviços que serão selecionados para ele, por meio da escolha das características, possam ser usados em um único processo de negócio.

Durante a engenharia de aplicações, pode-se perceber a ausência de serviços que não foram modelados durante a engenharia de domínio, nesse caso a abordagem SoProL-WS permite um ponto de flexibilização, no qual os projetistas da aplicação podem: encontrar o serviço em algum 
repositório da Web, implementar o serviço localmente para o sistema alvo, ou voltar à engenharia de domínio para projeto e implementação desse serviço para a LPS.

Outra característica importante da abordagem SoProL-WS é que ela prega o desenvolvimento incremental, ou seja, na primeira iteração do desenvolvimento elabora-se o núcleo da LPS, que não precisa ser operacional (executável e utilizável por usuários). Nas próximas iterações desenvolvese um conjunto de características opcionais e alternativas que permitam a geração de um novo sistema alvo da LPS.

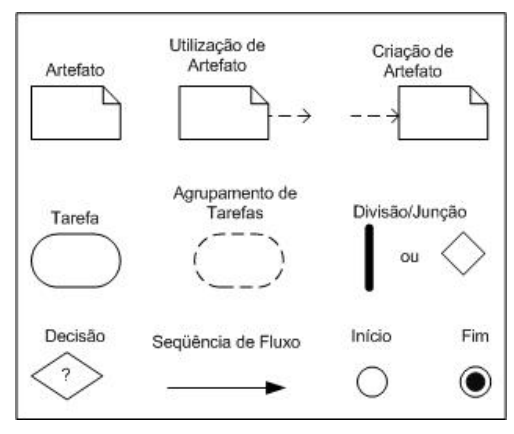

Figura 4.1: Legenda BPMN.

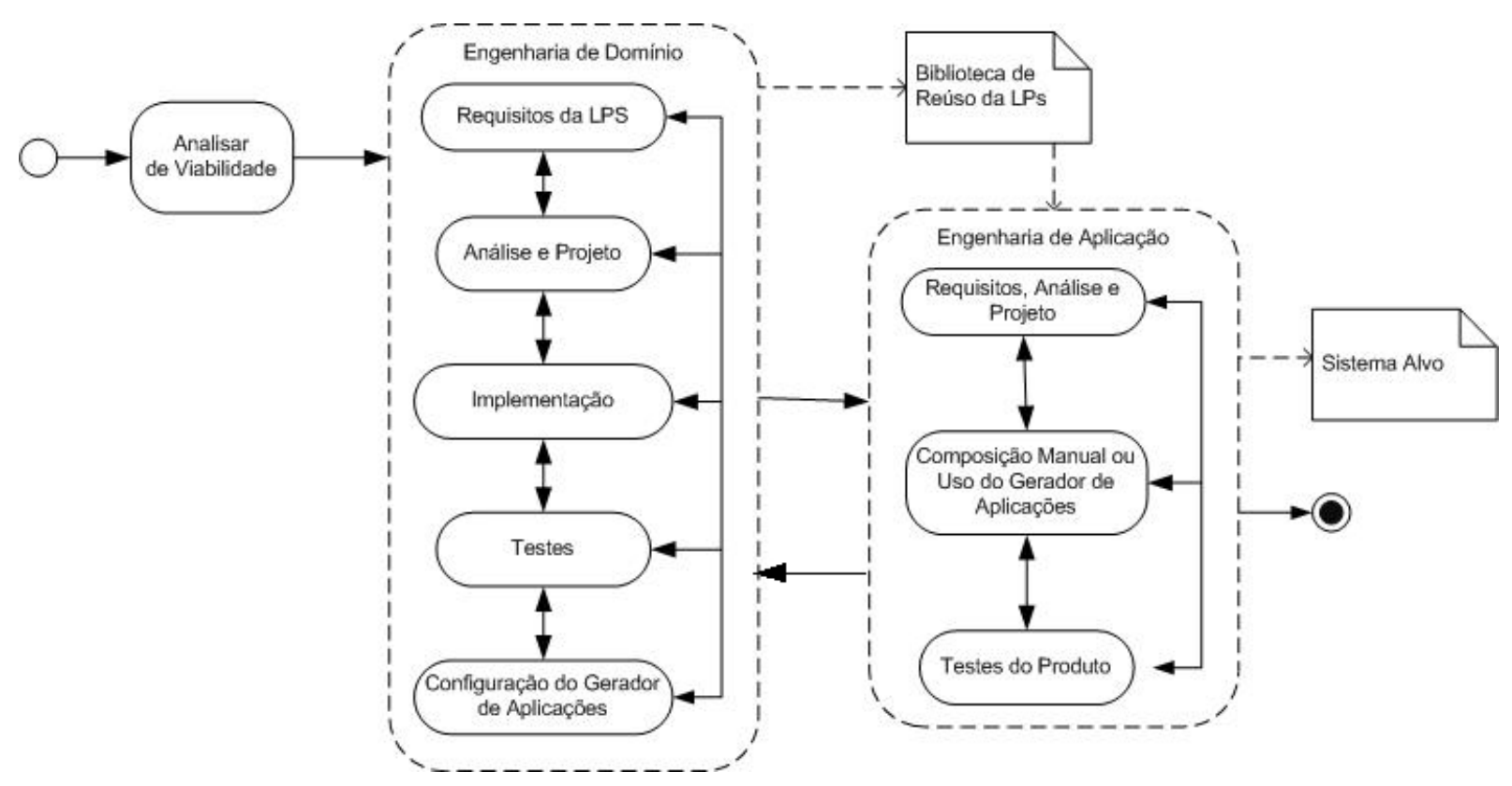

Figura 4.2: Visão Geral da Abordagem SoProL-WS.

\subsection{Visão Geral do Domínio de Leilões Web}

O domínio escolhido para o estudo de caso é o de leilões Web, também conhecido como leilões virtuais. Os leilões Web representam um tipo de comércio eletrônico que procura reunir compradores e vendedores, como se fossem mercados, com o intuito de facilitar as transações. Os leilões 
virtuais, assim como os leilões presenciais, são baseados em lances. O vencedor possui direito de adquirir um certo produto quando, ao término do leilão, o seu lance é dado como vencedor de acordo com as regras do leilão.

Os leilões Web promovem oportunidades especiais para compradores e vendedores (Aggarwal e Yu, 2009):

- Para os vendedores, os leilões representam uma oportunidade de vender produtos de forma rápida e controlada. Diversos produtos são parte de liquidações não vendidas.

- Para compradores, os relativos preços baixos dos leilões oferecem grande atração e alguma flexibilidade. Essa flexibilidade é usualmente exibida em termos de tempo e espaço físico, pois os compradores não precisam ir as lojas.

Existem diversos tipos de leilões, que podem ser classificados quanto:

- ao número de participantes;

- ao número de lances ofertados de cada lado do mercado;

- a forma dos lances;

- o número de itens comprados e vendidos por transação;

- as regras do leilão; e

- o mecanismo de ordenação e o modo da ocorrência da transação.

De acordo com esses atributos apresenta-se na Figura 4.3 uma taxonomia definida em Ré (2002). Embora exista uma grande quantidade de tipos de leilões nem todos podem ser aplicados no ambiente Web. Os principais tipos de leilões são: inglês, holandês, de lance oculto e de compra. Cada um deles realiza os lances e a definição do lance vencedor de formas distintas. Ao longo do capítulo são apresentados mais detalhes sobre o domínio de leilões Web, incluindo uma limitação do escopo da LPS.

\subsection{Princípios Adotados para o Desenvolvimento da LPS}

Gomaa (2004) apresenta duas estratégias principais para o desenvolvimento de LPSs: engenharia avante e engenharia reversa. A engenharia reversa é melhor utilizada quando o desenvolvimento de uma LPS inicia-se com a observação de sistemas existentes que são candidatos à modernização e inclusão em um projeto para desenvolver uma linha de produtos. A engenharia avante é melhor utilizada quando uma nova LPS está sendo desenvolvida sem a existência de nenhum sistema prévio para guiar o desenvolvimento. 
Número de lances/ofertas de cada lado do mercado

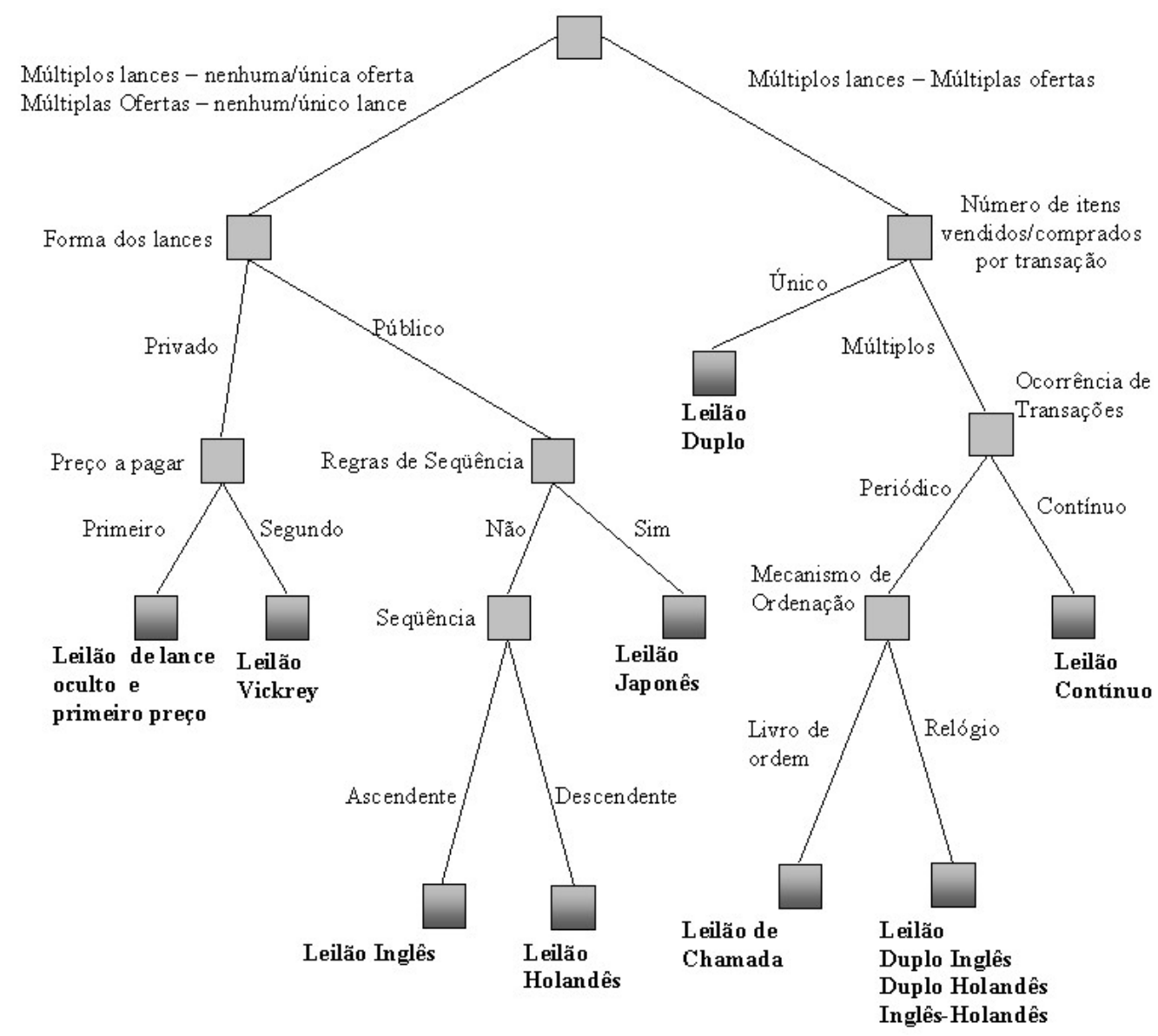

Figura 4.3: Tipos de Leilões (Ré, 2002).

A engenharia reversa exige a observação de sistemas existentes, em um domínio particular, e a identificação das características comuns e variantes entre eles. Representa a forma mais simples de identificar e desenvolver uma LPS, pois o desenvolvimento passa a ser guiado pelos sistemas existentes. A engenharia avante apresenta uma maior dificuldade, pois é necessário fazer um estudo mais aprofundado do domínio sem a existência de sistemas para guiar o estudo. Cleaveland (1988) deparou-se com esse problema enquanto investigava o desenvolvimento de geradores de aplicações, e sugere que o passo inicial para realizar esse tipo de estratégia é reconhecer padrões. Outras formas para ajudar a identificar domínios de possíveis LPSs podem ser encontradas em Cleaveland (1988). A abordagem SoProL-WS recomenda o uso da estratégia de engenharia reversa quando possível, pois pode-se obter maiores ganhos de produtividade durante as atividades de requisitos quando existem sistemas prévios para guiar essa etapa do desenvolvimento.

Visto que existem diversos sites de leilões Web, definiu-se o princípio de aplicar um processo de desenvolvimento de LPS baseado em engenharia reversa. Entre os diversos sites encontrados os três escolhidos para guiar o desenvolvimento foram: Mercado Livre http: //www . mercadolivre.com.br, Milan Leilões (http://www.milanexpress.com.br) e Ebay http: //global.ebay.com. Além da observação desses sites, foi utilizado o trabalho de Ré et 
al. (2001) e Durães (1997) para a elicitação dos requisitos e definição dos pontos de variação e variabilidades da LPS. Existem, ainda, sites com listas de diversos leilões virtuais, tais como: Leilão Virtual http://www. leilaovirtual.com.br/; e Internet Auctions http: //www. internetauctionlist.com. Esses leilões possuem muitas características comuns e ainda assim apresentam algumas variabilidades entre eles, caracterizando-se como uma LPS.

Outro princípio escolhido foi de iniciar o desenvolvimento pelo núcleo da LPS, onde optou-se por ter um núcleo operacional, ou seja, um produto pode ser derivado sem a presença de variabilidades, pois o núcleo é executável e pode ser visto como um produto da linha, desse modo foi necessário escolher uma característica alternativa como padrão para incorporar-se ao núcleo da LPS de leilões Web. A adição dessa característica ao núcleo não prejudica as propriedades de reúso da linha, uma vez que essa característica é implementada como um serviço e pode facilmente ser alterada para um novo produto da linha.

Essa decisão foi tomada pois um dos interesses de pesquisa deste trabalho é investigar a agilidade e facilidade de manutenção de uma LPS com SOA durante o seu desenvolvimento. Além disso, procurou-se investigar o projeto da LPS considerando web services e processos de negócios. Se por um lado, nem toda LPS orientada a serviço precisa de processos de negócios, um processo de negócios depois de implantado pode ser visto como um serviço. Por isso optou-se por mesclar o uso de serviços e processos de negócios na arquitetura da linha, até porque ambos podem ser usados posteriormente por outros clientes na Web.

As variabilidades são adicionadas em incrementos a cada iteração, de modo que um novo produto possa ser gerado, ou seja, se uma variabilidade depende de outra para gerar um novo produto, as duas são adicionadas à linha em um incremento único. Por se tratar de um projeto de mestrado com foco em reúso e processo de LPS, nem todas as variabilidades possíveis são implementadas e não são tratadas questões de segurança ao longo do desenvolvimento. Esses princípios foram adotados durante a pesquisa realizada no desenvolvimento da LPS de leilões Web. Alguns por serem decisões relacionadas ao contexto do projeto de mestrado e outros pelo interesse de investigação de alguns fatores relacionados ao processo de desenvolvimento de uma LPS com SOA.

\subsection{Engenharia de Domínio}

Antes de iniciar-se a engenharia de domínio, é necessário identificar uma linha de produtos que tenha garantia de retorno de investimento e escolher uma estratégia de desenvolvimento. Essa análise é feita por meio da análise de viabilidade, que gera o artefato de entrada para a engenharia de domínio.

A análise de viabilidade da linha de produtos verifica se a LPS identificada é economicamente viável. Visto que o custo de desenvolvimento de uma LPS é maior que o custo de desenvolvimento de um sistema único, é necessário vender uma certa quantidade de sistemas para que a linha de 
produtos se torne economicamente viável. Bayer et al. (1999) e Weiss e Lai (2004) apresentam mais detalhes sobre a análise de viabilidade de linha de produto.

Como artefato de saída dessa atividade tem-se o documento de viabilidade, que apresenta o domínio da linha de produto, a estratégia de desenvolvimento e uma breve análise da viabilidade do projeto. Por se tratar de um projeto de mestrado sem fins lucrativos, a análise de viabilidade não foi feita para a LPS de leilões Web.

No decorrer deste texto, ao longo de cada sub atividade da abordagem são mostrados os artefatos de saída da sub atividade para a linha de produtos de leilões Web na Subseção intitulada "Exemplo". Alguns exemplos são apresentados de forma simplificada nesta dissertação, contudo os artefatos completos estão hospedados no seguinte website: http://code.google.com/ p/Ipslw. Ao entrar na URL indicada, basta clicar na aba downloads, onde podem ser encontrados os diversos artefatos gerados durante o desenvolvimento da LPS. Na Figura 4.4, apresentam-se as atividades da engenharia de domínio da abordagem SoProL-WS e os artefatos gerados por cada atividade. 


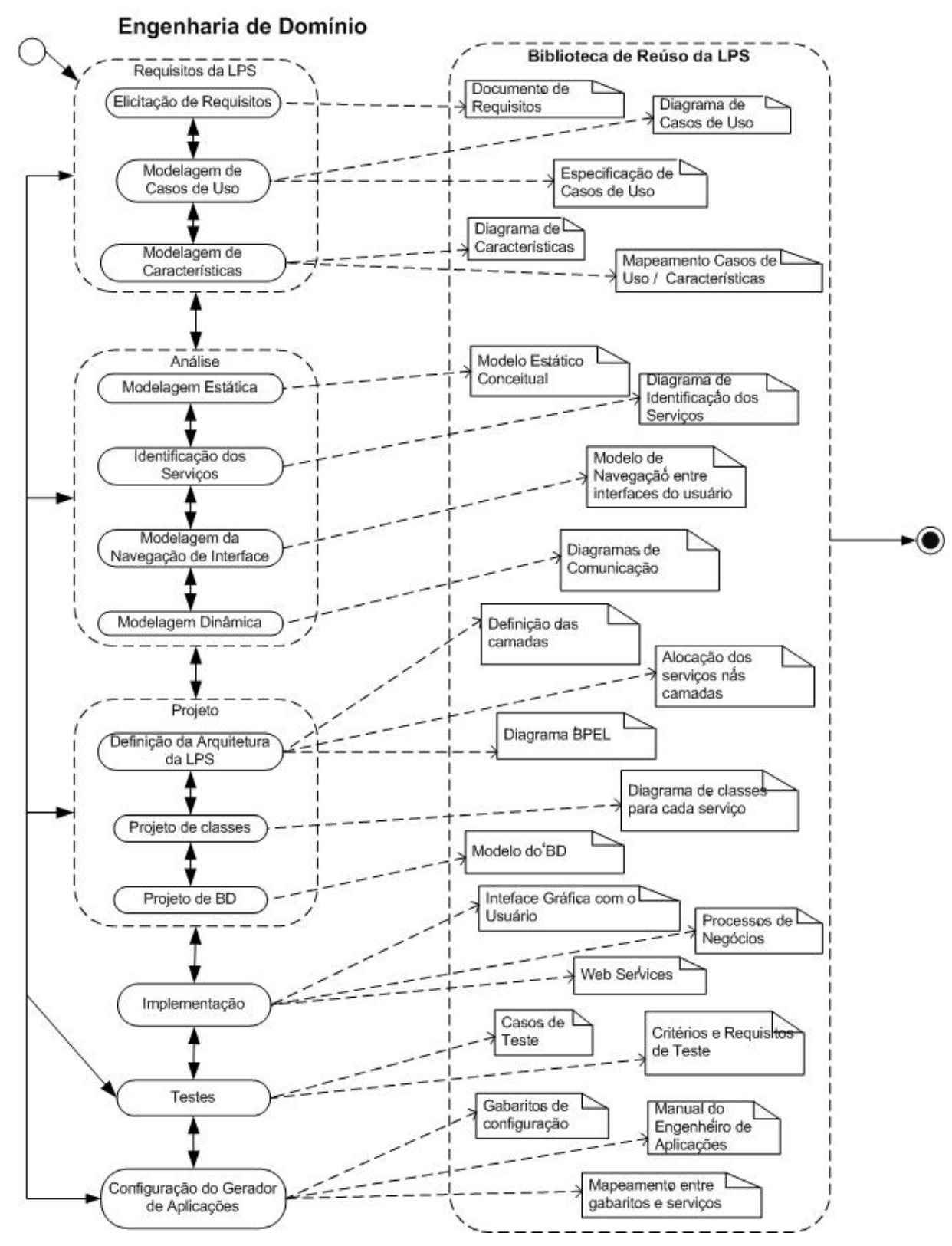

Figura 4.4: Conjunto de artefatos gerados em cada atividade da abordagem SoProL-WS.

\subsection{Atividades de Requisitos}

Após a identificação de uma LPS que possui retorno de investimento, inicia-se a engenharia de domínio com as atividades de requisitos, que correspondem a: elicitação de requisitos, identificação dos processos de negócios, elaboração do diagrama de casos de uso e elaboração do diagrama de características. Essa etapa do desenvolvimento gera como saída os documentos de elicitação de requisitos, os processos de negócios da LPS, o diagrama de casos de uso, o diagrama de características do núcleo e o diagrama de características das variabilidades da LPS, que farão parte da biblioteca de reúso da LPS. 


\subsubsection{Elicitação dos Requisitos}

A elicitação de requisitos inicia-se por meio de uma pesquisa aprofundada sobre o domínio da LPS, incluindo entrevistas com os especialistas nesse domínio, ou no caso de utilização da estratégia de engenharia reversa, inicia-se pela observação das funcionalidades de sistemas existentes no domínio para definição dos requisitos da LPS.

A etapa de elicitação de requisitos vai permitir reunir os requisitos que deverão ser cumpridos por possíveis sistemas nesse domínio. É recomendável a elaboração de documentos de requisitos para três possíveis sistemas no domínio. No caso da utilização de engenharia reversa, esses sistemas já existem. Quando utiliza-se engenharia avante, deve-se utilizar a experiência adquirida sobre o domínio para elaborar o requisito de três possíveis sistemas alvo. Por meio desses três documentos de requisitos, define-se quais requisitos são obrigatórios, opcionais ou alternativos para os membros da LPS. O artefato de saída gerado por essa atividade é o documento de requisitos da LPS, destacando-se os requisitos obrigatórios, opcionais e alternativos. Os requisitos obrigatórios estão presentes em todos os membros da LPS, os requisitos opcionais podem ou não estar presentes em algum membro da linha e os requisitos alternativos podem estar presentes com diferentes alternativas nos membros da linha. Esse documento é utilizado em seguida para ajudar na elaboração do diagrama de casos de uso. A abordagem SoProL-WS recomenda um documento de requisitos com, pelo menos, a seguinte estrutura:

- documento de requisitos de um sistema A, que contém uma visão geral do sistema, os requisitos funcionais (de armazenamento, movimentações e consultas) e os requisitos não funcionais do sistema;

- documento de requisitos de sistemas B e C seguindo o modelo feito para o sistema A;

- visão geral da linha de produtos, requisitos funcionais obrigatórios e definição dos pontos de variação, baseado nas variabilidades encontradas nos três documentos de requisitos encontrados.

A definição dos pontos de variação no documento de requisitos é feita em alto nível e deve definir se a variabilidade é opcional ou alternativa, apresentando os possíveis variantes para cada ponto de variação. Recomenda-se fazer uma tabela para resumir os requisitos do sistema e definir sua categoria de reúso (obrigatório, opcional ou alternativo).

\section{Exemplo}

A elicitação de requisitos inicia-se a partir de estudos sobre leilões e leilões virtuais, baseado em Ré (2002), Durães (1997) e na observação de alguns leilões virtuais existentes, para definir os requisitos da LPS. 
$\mathrm{Na}$ Listagem 4.1, são mostrados trechos do documento de requisitos da LPS. Observa-se que esse documento já representa a fusão de três documentos de requisitos de sistemas no domínio, por isso ele já possui a diferenciação das variabilidades da LPS. São destacadas também, as linhas 8 a 29 que apresentam os requisitos funcionais da LPS e as linhas 37 a 43 que apresentam um dos pontos de variação da LPS com as possíveis variabilidades para ele.

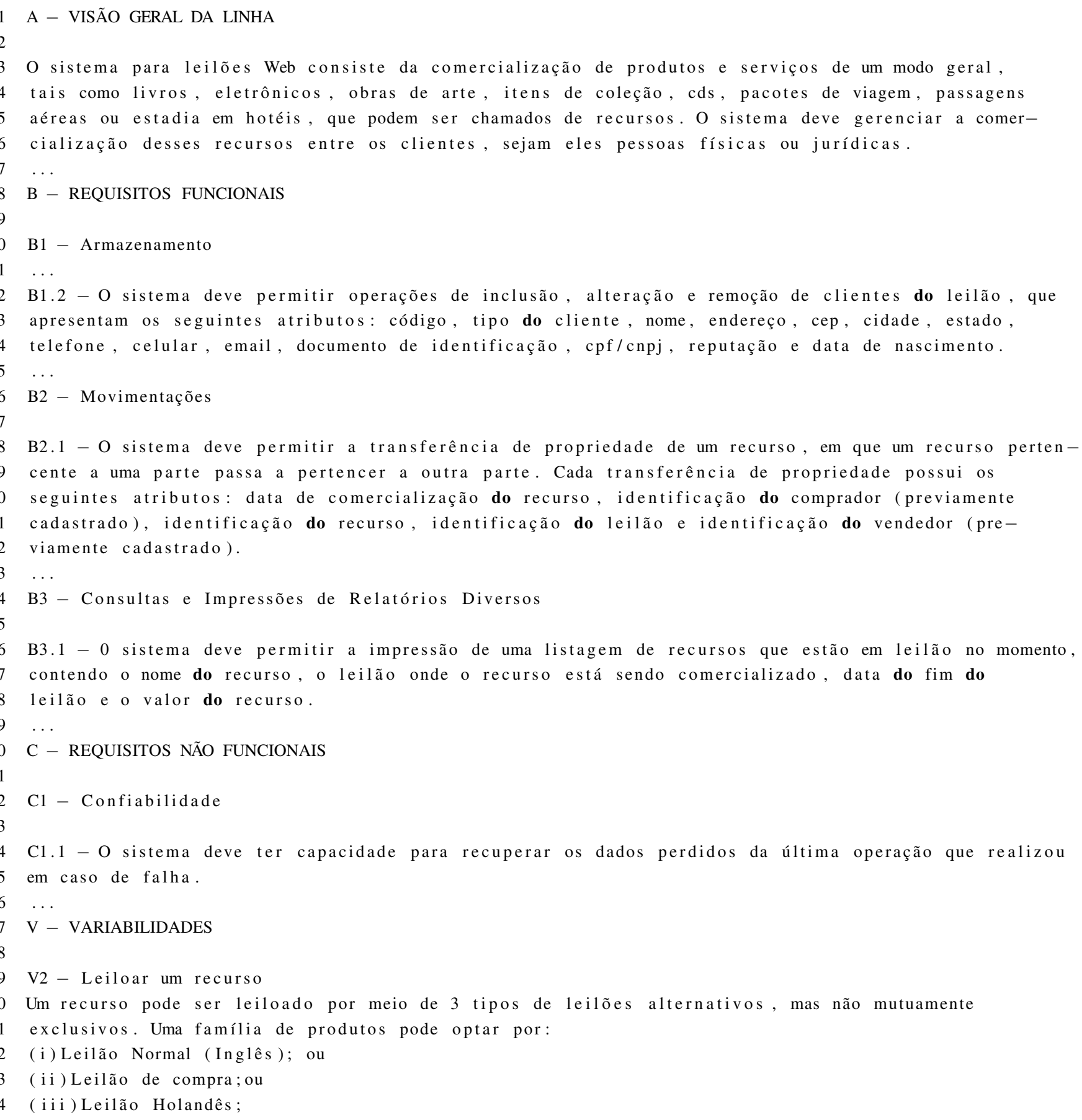

Listagem 4.1: Trechos do documento de requisitos.

Na Tabela 4.1, mostra-se um resumo dos principais requisitos da LPS de leilões Web, diferenciandose os requisitos do núcleo das variabilidades por meio da coluna Categoria de Reúso. 
Tabela 4.1: Requisitos Funcionais.

\begin{tabular}{|c|c|c|}
\hline Código & Definição do Requisito & Categoria de Reúso \\
\hline RQ01 & $\begin{array}{l}\text { O sistema deve permitir operações de inclusão, alteração e remoção de tipos de } \\
\text { clientes do leilão }\end{array}$ & Núcleo \\
\hline RQ02 & $\begin{array}{l}\text { O sistema deve permitir operações de inclusão, alteração e remoção de clientes } \\
\text { do leilão }\end{array}$ & Núcleo \\
\hline RQ03 & $\begin{array}{l}\text { O sistema deve permitir operações de inclusão, alteração e remoção de recursos } \\
\text { a serem leiloados }\end{array}$ & Núcleo \\
\hline RQ04 & $\begin{array}{l}\text { O sistema deve permitir operações de inclusão, alteração e remoção dos diver- } \\
\text { sos lances efetuados pelos clientes para um determinado recurso }\end{array}$ & Núcleo \\
\hline RQ05 & $\begin{array}{l}\text { O sistema deve permitir operações de inclusão e alteração de reputação entre } \\
\text { os participantes de uma certa transação }\end{array}$ & Núcleo \\
\hline RQ06 & $\begin{array}{l}\text { O sistema deve permitir a transferência de propriedade de um recurso, em que } \\
\text { um recurso pertencente a uma parte passa a pertencer a outra parte }\end{array}$ & Núcleo \\
\hline RQ07 & $\begin{array}{l}\text { O sistema deve permitir a impressão de uma listagem de recursos que estão em } \\
\text { leilão no momento }\end{array}$ & Núcleo \\
\hline RQ08 & O sistema deve permitir a consulta da situação de um recurso & Núcleo \\
\hline RQ09 & O sistema deve permitir a consulta da reputação de uma determinada parte & Núcleo \\
\hline VA01 & O sistema deve gerenciar recursos favoritos de um cliente & Opcional \\
\hline VA02 & $\begin{array}{l}\text { O sistema deve possibilitar a negociação entre as partes envolvidas para tirar } \\
\text { dúvidas }\end{array}$ & Opcional \\
\hline VA03 & $\begin{array}{l}\text { O sistema deve realizar leilões de ítens (inglês, com reserva, de compra, holan- } \\
\text { dês e múltiplo) }\end{array}$ & Alternativo \\
\hline VA04 & O sistema deve permitir que o lance seja marcado para futuro acompanhamento & Opcional \\
\hline VA05 & O sistema deve permitir a cobrança de taxa por uso & Opcional \\
\hline VA06 & $\begin{array}{l}\text { A cobrança por uso pode ser feita de três formas (valor fixo por período, valor } \\
\text { variável por período, taxa única) }\end{array}$ & Alternativo \\
\hline VA07 & O sistema deve permitir utilização de anúncios & Opcional \\
\hline
\end{tabular}

\subsubsection{Identificação dos Processos de Negócio e suas Variabilidades}

Existem diversas técnicas para a modelagem de processos de negócios (Castro et al., 2006), das quais destacam-se a utilização de BPMN (Business Process Modeling Notation) (Object Management Group (OMG), 2009) e o uso de diagramas de atividade da UML (Castro et al., 2006). Conforme definido na Seção 2.4.8, um processo de negócio representa um fluxo de atividades progressivas para atingir algum objetivo empresarial. No caso de um software orientado a serviços, essas atividades correspondem às operações dos serviços.

A identificação de processos de negócio pode ocorrer antes ou depois da definição dos casos de uso. Para os casos em que o software vai se basear em processos de negócios já existentes e bem definidos pela organização, pode-se usá-los para guiar a definição dos casos de uso conforme apresenta-se no trabalho de Dijkman e Joosten (2002). Durante a fase de análise de requisitos, a abordagem SoProL-WS recomenda a utilização de diagramas de atividades para a definição em alto nível dos processos de negócios. As atividades descritas no diagrama são service activities, ou seja, são atividades que representam operações de web services (Castro et al., 2006). A definição desses processos deve ser feita para cada um dos três sistemas alvo definidos no documento de requisitos da fase de elicitação de requisitos. 
Além de apresentar variabilidades em serviços, uma linha de produtos também pode apresentar variabilidades em processos de negócio. Essas variabilidades podem ser identificadas por meio da observação dos três diagramas de atividades desenvolvidos. Conforme discutido no Capítulo 3.1 as atividades do processo de negócios podem ser: atividades de negócios comuns, atividades de negócios comuns incluindo variabilidades, atividades de negócios opcionais ou atividades de negócios opcionais incluindo variabilidades. Para facilitar, utiliza-se neste trabalho a seguinte notação: as atividades de negócios comuns a todos os produtos da LPS recebem o estereótipo «kernel»; as atividades de negócios comuns a todos os membros da LPS incluindo variabilidades recebem o estereótipo «kernel-alternative»; as atividades de negócios opcionais recebem o estereótipo «optional» e as atividades de negócios opcionais incluindo variabilidades recebem os estereótipos «optional-alternative». As variações do tipo kernel-alternative e optional-alternative são variações ligadas a serviços e são melhor detalhadas em fases posteriores do desenvolvimento.

Outros tipos de variações internas às atividades de negócios discutidas no Capítulo 3.1 são: as variações de dados, variações de gateway, e variações de eventos. As variações de eventos podem ser modelados no diagrama de atividades com a utilização de caminhos alternativos e do uso do estereótipo «event». Visto que a notação gráfica de diagrama de atividade não apóia a descrição de todos esses tipos de variabilidades, SoProL-WS sugere a utilização de uma tabela em conjunto com o diagrama para descrever as variações de dados e de gateway e o seu respectivo ponto de variação no diagrama.

O refinamento da definição dos processos de negócios pode ser feito durante as atividades de projeto por meio da utilização de BPMN e de diagramas de comunicação. É importante salientar que mesmo que um processo de negócios possua apenas atividades de negócios comuns, não podese dizer que esse PN faz parte do núcleo da LPS, pois caso alguma variabilidade seja adicionada a LPS, esse PN pode ser substituido por algum outro que inclua a variabilidade escolhida.

\section{Exemplo}

Para a LPS de leilões Web foram feitos os diagramas de atividades dos três sistemas que guiam o desenvolvimento, contudo os diagramas do site do Ebay e do Mercado Livre são muito parecidos. Na Figura 4.5, são ilustrados os diagramas de atividades para os sites Mercado Livre e Milan Leilões, nos quais é possível perceber algumas diferenças. Destaca-se o uso do estereótipo «service activity» para indicar que as atividades representadas são atividades realizadas por web services. Pode-se perceber que um usuário qualquer pode se cadastrar no Mercado Livre e realizar leilões de produtos, no caso do site Milan Leilões isso não é possível, somente seus parceiros comerciais podem realizar leilões. Na Figura 4.6, ilustra-se a união desses diagramas, no qual destaca-se a utilização dos estereótipos para identificação dos tipos de variabilidades descritos nesta Seção. Ressalta-se que quando não foram utilizados estereótipos, presume-se que a atividade é do tipo kernel. 


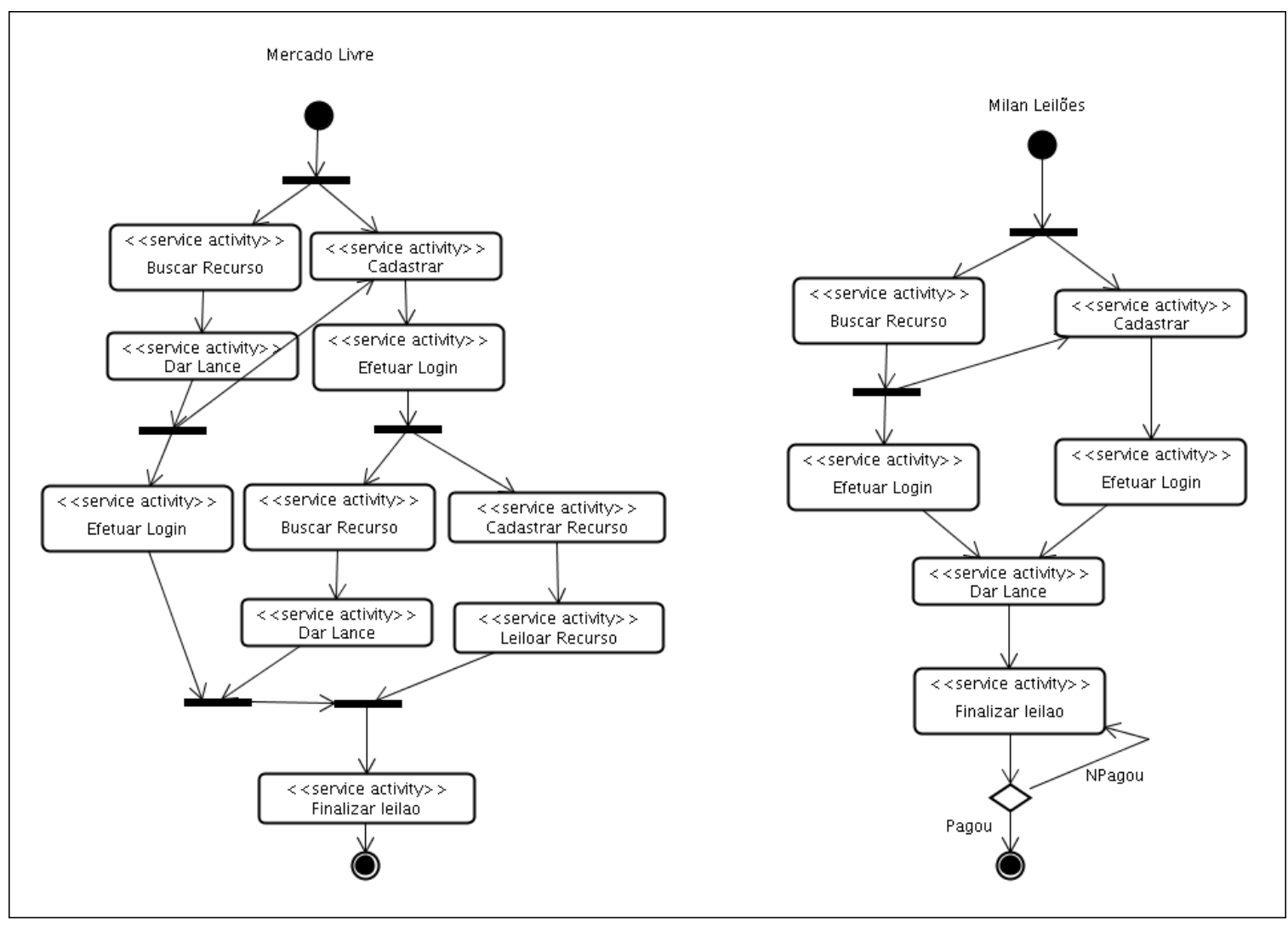

Figura 4.5: Diagrama de atividades dos sites: Mercado Livre e Milan Leilões.

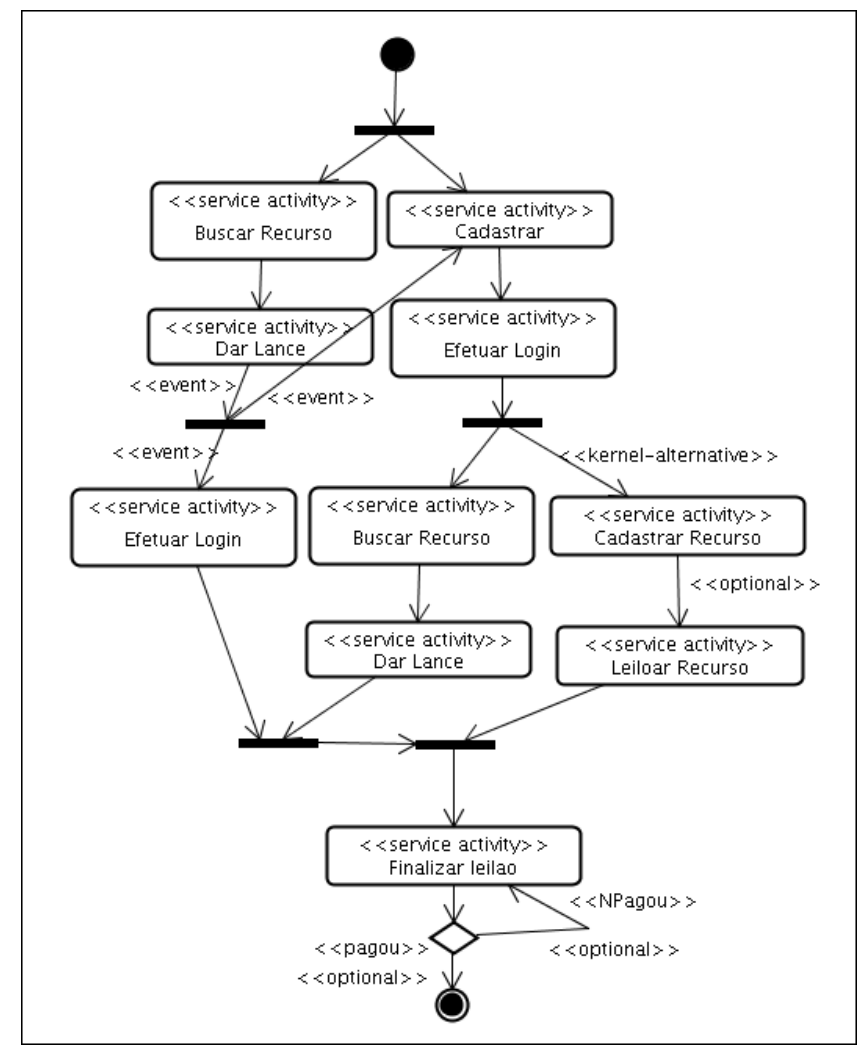

Figura 4.6: Diagrama de atividades unificado com as variabilidades. 


\subsubsection{Modelagem de Casos de Uso}

Diagramas de casos de uso (Rumbaugh et al., 2004; Fowler e Scott, 1999) são parte da notação da UML e representam uma técnica poderosa na atividade de requisitos de sistemas únicos. Em LPS eles também tem uma grande importância, pois representam o início do refinamento dos requisitos da LPS. Assim como na abordagem de Gomaa (2004), na SoProL-WS os casos de uso são divididos em três categorias de reúso:

- kernel: correspondem aos casos de uso presentes em todos os membros da linha de produto.

- optional: correspondem aos casos de uso que podem ou não estar presentes em algum membro da linha.

- alternative: correspondem aos casos de uso que possuem grupos de opções para a escolha de um deles em um certo membro da linha.

Os casos de uso opcionais e alternativos podem ser modelados com a utilização das relações extends e recebem os estereótipos optional e alternative, respectivamente. Os diagramas de casos de uso fornecem apoio à modelagem dos pontos de variação por meio dos extension points, que permitem declarar a possibilidade de uma extensão em um caso de uso. Os extension points tem um nome e uma lista de referências para um ou mais locais no fluxo de eventos do caso de uso.

O artefato de saída gerado por essa atividade é o documento de casos de uso da LPS, que é utilizado em seguida para ajudar na elaboração do diagrama de características. A abordagem SoProL-WS recomenda um documento de casos de uso com, pelo menos, a seguinte estrutura:

- o documento inicia-se com o modelo visual dos casos de uso, representado com a utilização dos casos de uso, atores e relações entre eles;

- uma tabela contendo o nome dos casos de uso, sua categoria de reúso e uma breve descrição;

- identificação dos atores da LPS, seguida de uma breve descrição;

- uma descrição de cada caso de uso contendo: nome, categoria de reúso, descrição, atores, dependências, pré-condições, fluxo principal, fluxos alternativos, descrição dos pontos de variação e pós-condições;

- uma tabela contendo o mapeamento entre os dos casos de uso e os requisitos relacionados a cada um deles. 


\section{Exemplo}

Com base na definição dos requisitos, foram utilizadas algumas técnicas descritas por Larman (2004) para identificar os casos de uso, e algumas técnicas descritas por Gomaa (2004) para definir suas categorias de reúso. Alguns dos principais casos de uso foram descritos na Tabela $4.2 \mathrm{com}$ suas respectivas categorias de reúso e os requisitos aos quais satisfazem.

Tabela 4.2: Tabela de mapeamento entre os casos de uso e os requisitos.

\begin{tabular}{|c|c|c|c|}
\hline Caso de Uso & Categoria de Reúso & Descrição & $\begin{array}{l}\text { Requisitos Relaci- } \\
\text { onados }\end{array}$ \\
\hline Gerenciar Tipos de Clientes & Núcleo & $\begin{array}{l}\text { Incluir, alterar ou retirar tipos de } \\
\text { clientes, para diferenciá-los }\end{array}$ & $\begin{array}{l}\text { RQ01 RQ02 RQ03 } \\
\text { RQ05 RQ06 }\end{array}$ \\
\hline Gerenciar Clientes & Núcleo & $\begin{array}{l}\text { Incluir, alterar ou remover clientes } \\
\text { no sistema de leilões WEB }\end{array}$ & $\begin{array}{ll}\text { RQ01 RQ02 RQ03 } \\
\text { RQ04 RQ05 RQ06 } \\
\text { RQ09 }\end{array}$ \\
\hline Gerenciar Recursos & Núcleo & $\begin{array}{l}\text { Incluir, alterar ou remover recur- } \\
\text { sos e alocá-los nas respectivas ca- } \\
\text { tegorias }\end{array}$ & $\begin{array}{l}\text { RQ01 RQ02 RQ03 } \\
\text { RQ04 RQ06 RQ07 } \\
\text { RQ08 }\end{array}$ \\
\hline Gerenciar Lances & O Núcleo & Ofertar lances & $\begin{array}{l}\text { RQ02 RQ03 RQ04 } \\
\text { RQ06 RQ08 }\end{array}$ \\
\hline Gerenciar Reputação & Núcleo & $\begin{array}{l}\text { Controlar a reputação de cada par- } \\
\text { ticipante do leilão, cotando os vo- } \\
\text { tos e sua confiabilidade }\end{array}$ & $\begin{array}{l}\text { RQ01 RQ02 RQ05 } \\
\text { RQ09 }\end{array}$ \\
\hline Finalizar Leilão & Alternativo & Define o lance vencedor & $\begin{array}{l}\text { RQ02 RQ04 RQ05 } \\
\text { RQ06 RQ08 VA03 }\end{array}$ \\
\hline Gerenciar Favoritos & Opcional & $\begin{array}{l}\text { Incluir ou remover leilões da lista } \\
\text { de favoritos dos clientes }\end{array}$ & $\begin{array}{l}\text { RQ02 RQ07 RQ08 } \\
\text { VA01 }\end{array}$ \\
\hline Gerenciar Negociação & Opcional & $\begin{array}{l}\text { Permitir que os clientes esclare- } \\
\text { çam dúvidas quanto aos recursos } \\
\text { ou quanto as informações de al- } \\
\text { gum dos leilões }\end{array}$ & $\begin{array}{l}\text { RQ01 RQ02 RQ07 } \\
\text { RQ08 VA02 }\end{array}$ \\
\hline Iniciar Leilão & Alternativo & $\begin{array}{l}\text { Abrir um leilão, selecionando os } \\
\text { recursos que participarão do leilão } \\
\text { e definindo os critérios do leilão }\end{array}$ & $\begin{array}{l}\text { RQ01 RQ03 VA03 } \\
\text { VA04 }\end{array}$ \\
\hline Acompanhar Lance & Opcional & $\begin{array}{l}\text { Marcar lances para acompanha- } \\
\text { mento por parte do cliente }\end{array}$ & $\begin{array}{l}\text { RQ03 RQ04 RQ08 } \\
\text { VA04 }\end{array}$ \\
\hline Cobrar Taxa & Alternativo & $\begin{array}{l}\text { Calcular as taxas por uso ou co- } \\
\text { mercialização de recursos }\end{array}$ & RQ01 VA05 VA06 \\
\hline Gerenciar Anúcios & Opcional & $\begin{array}{l}\text { Incluir, alterar ou retirar anúncios } \\
\text { para promover e anunciar o leilão }\end{array}$ & $\begin{array}{l}\text { RQ01 RQ03 RQ08 } \\
\text { VA07 }\end{array}$ \\
\hline
\end{tabular}

O diagrama com alguns casos de uso identificados para a linha de produto de leilões virtuais é apresentado na Figura 4.7. Os casos de uso do núcleo estão na cor branca e possuem o esteriótipo «Kernel», são eles: Gerenciar Tipos de Anúncios, Gerenciar Empresas Leiloeiras, Gerenciar Categorias, Efetuar Login, Finalizar Leilão, Criar Leilão, Gerenciar Lances, Gerenciar Clientes, Gerenciar Reputação, Gerenciar Recursos. Os casos de uso opcionais estão na cor azul e possuem o estereótipo «optional», são eles: Habilitar Mensagens, Acompanhar Lance, Gerar Lance Automático, Gerenciar Favoritos, Gerenciar Negociação, Cobrar Taxa de Uso, Cobrar Taxa de Comercialização. Por fim, os casos de uso alternativos estão na cor amarela e possuem o estereótipo «alternative», são eles: Leilão Inglês, Leilão de Compra e Leilão Holandês. Existem dois atores 
no modelo apresentado: Adm Sistema é o ator responsável por gerenciar todo o sistema e Cliente que corresponde ao usuário que usará o sistema para compras e vendas.

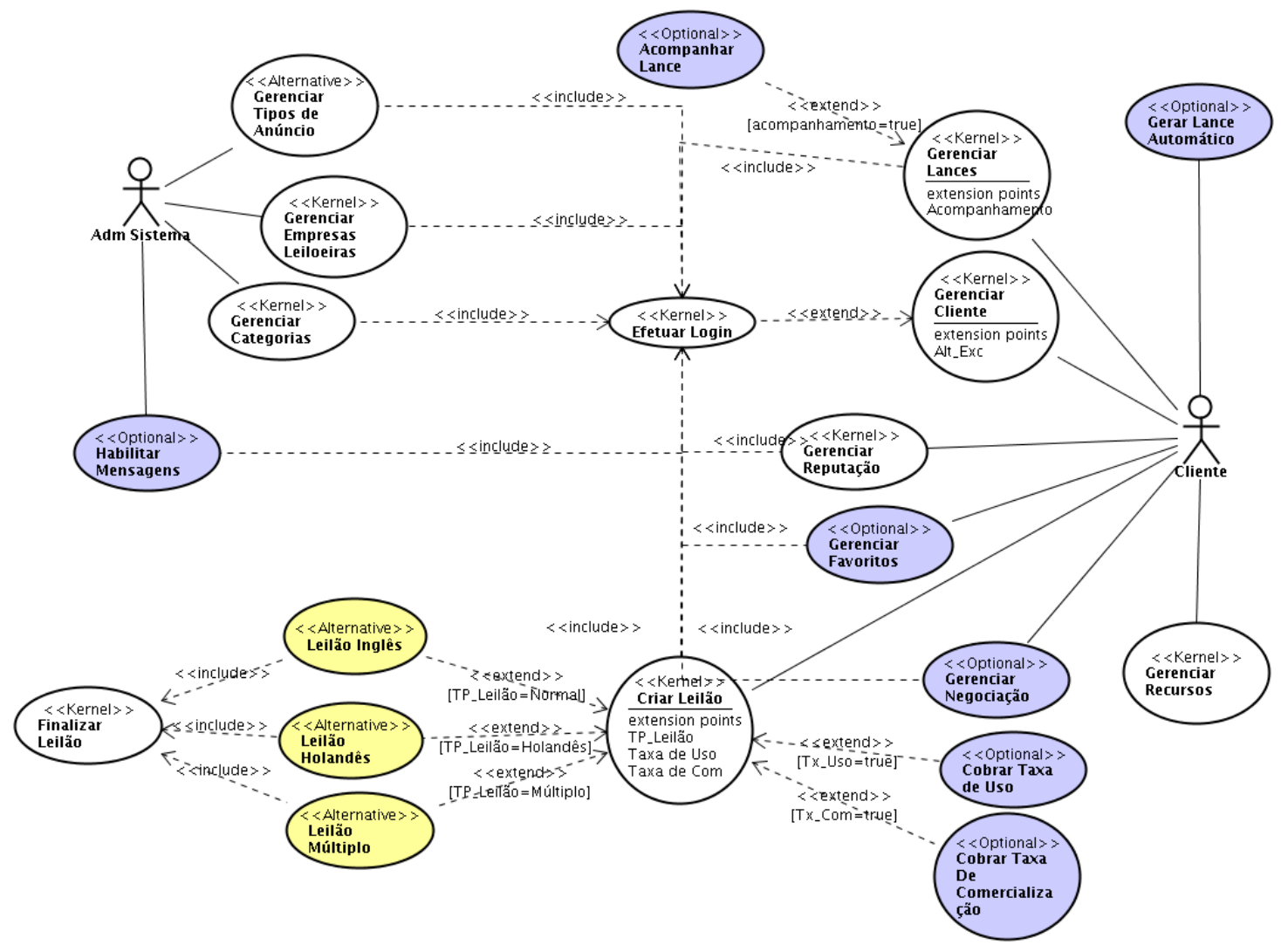

Figura 4.7: Diagrama com os principais casos de uso da LP.

$\mathrm{Na}$ Listagem 4.2, apresentam-se alguns trechos da especificação de casos de uso para a LPS de leilões Web seguindo o modelo sugerido nesta Seção.

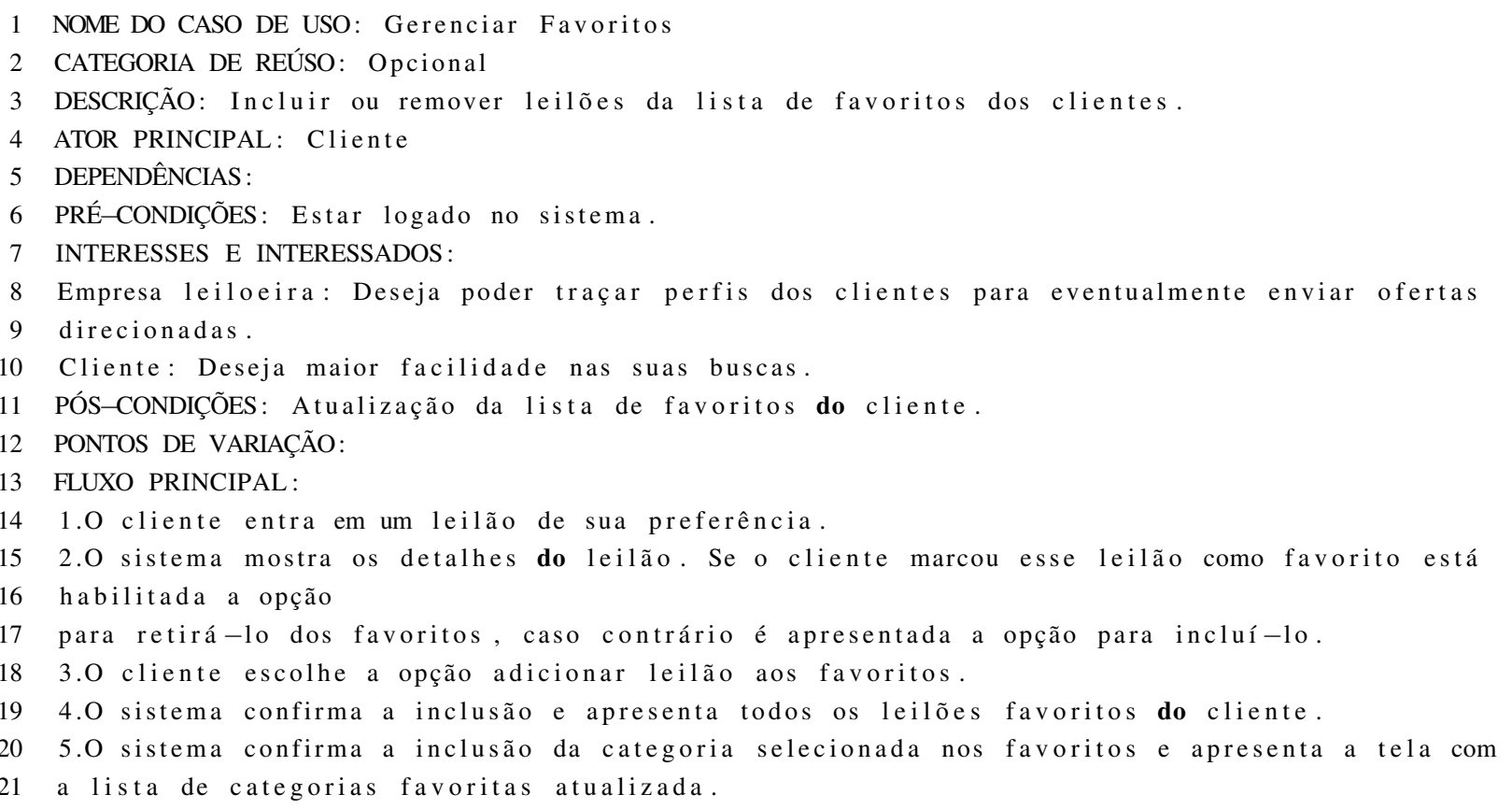




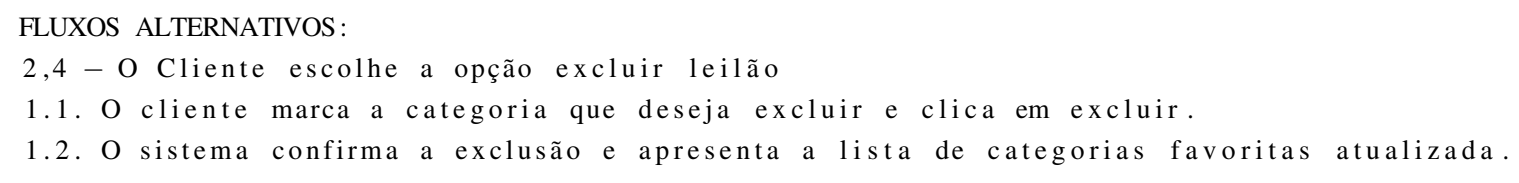

Listagem 4.2: Trecho da especificação dos casos de uso.

\subsubsection{Modelagem de Características}

O modelo de características apresentado na Seção 2.2.2 mostra uma visão do sistema em termos de funcionalidades visíveis aos usuários finais. Ele agrupa as características do sistema em forma de dependências hierárquicas. Para este trabalho, classifica-se os níveis das características da seguinte forma: o nível zero corresponde a característica que representa o sistema; o nível um corresponde as características imediatamente abaixo da categoria inicial; os outros níveis seguem a ordem crescente até as características que não possuem nenhum ("filho“), que são chamadas de folhas. Conforme é possível ver no exemplo apresentado a seguir, uma característica nível um também pode ser uma característica folha. Essas definições são usadas durante a atividade de identificação dos serviços. As características, assim como os casos de uso, são agrupadas em três categorias: common, optional e alternative. Esse modelo é de grande importância no decorrer do desenvolvimento, pois por intermédio dele é possível saber quais características estão ou não presentes nos membros da linha.

As características podem ser modeladas hierarquicamente como metaclasses, podem ser apresentadas em tabelas ou ainda modeladas em pacotes de grupos de casos de uso. Nesse último caso, as dependências entre as características também correspondem às dependências entre os casos de uso que fazem parte dessas características. A relação entre casos de uso e características é do tipo muitos para muitos, ou seja, uma característica pode englobar vários casos de uso e um caso de uso pode corresponder a várias características. Enquanto o modelo de pacotes é capaz de definir quais casos de uso estão contidos nas características, as características menores podem ser modeladas como pontos de variação em casos de uso. A abordagem SoProL-WS recomenda a construção de três modelos de características, o primeiro modelando as características como pacotes de casos de uso para encontrar mais facilmente as dependências entre elas, o segundo contendo somente as características do núcleo da LPS, e o terceiro contendo as características do núcleo como uma única característica e as características opcionais e alternativas como dependentes dela.

\section{Exemplo}

Conforme recomendado pela abordagem, foram feitos três diagramas. O primeiro apresenta-se na Figura 4.8 e modela as características da LPS de leilões Web como pacotes de casos uso. Um pacote corresponde a uma característica e dentro do pacote estão os casos de uso que correspondem a cada característica. É possível observar a relação existente entre algumas das características da LPS. O núcleo da LPS foi modelado, nesse diagrama, como uma única característica, pois foco 
dessa modelagem são as características variantes. A característica alternativa Leiloar foi destacada na coloração amarelada. As características opcionais foram pintadas com a coloração azul, e são: Taxas, Lances, Favoritos e Negociação. O núcleo apresenta-se na cor branca.

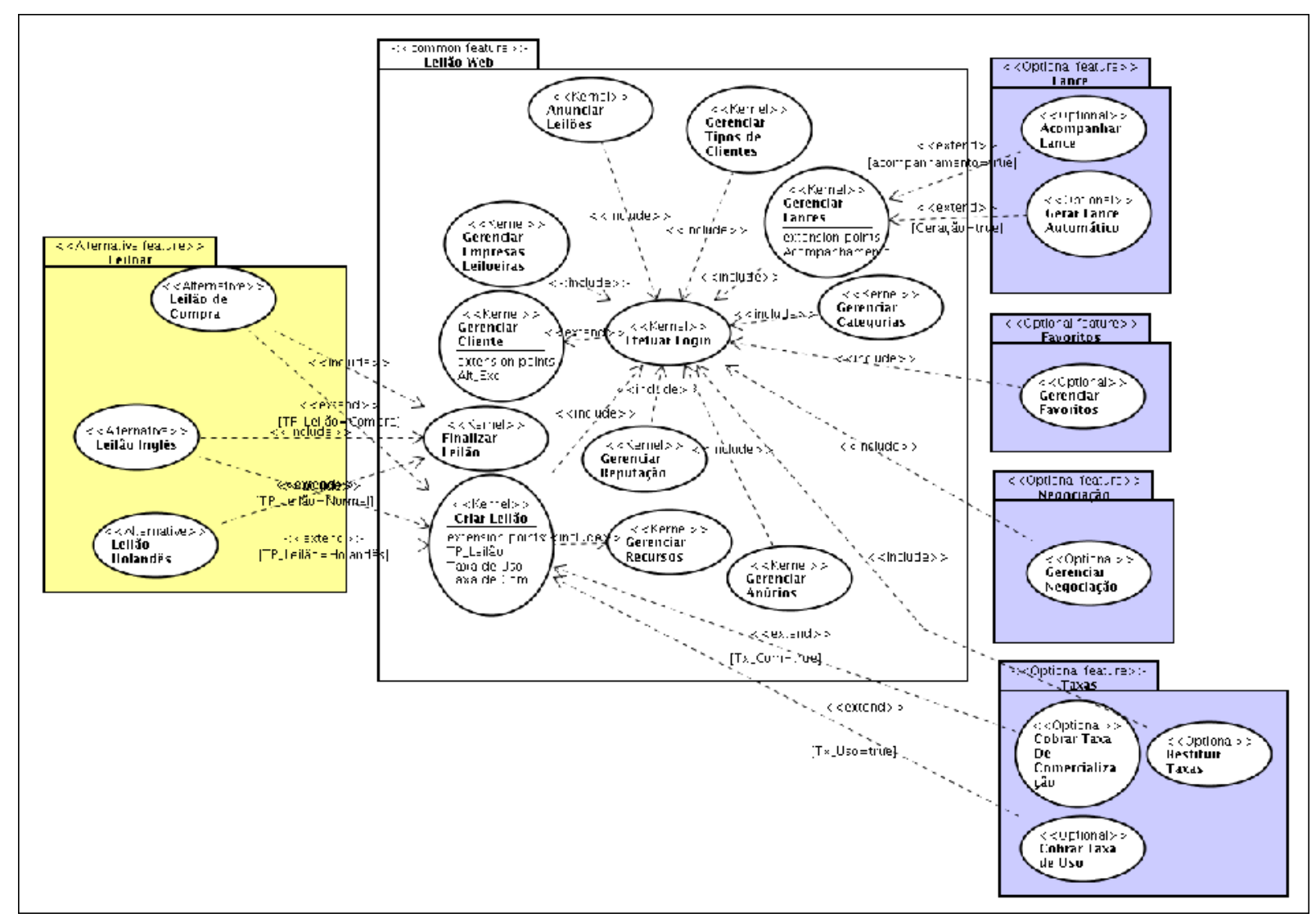

Figura 4.8: Relação entre casos de uso e características.

Apresenta-se na Figura 4.9 o segundo modelo sugerido pela abordagem, que representa um modelo de características simplificado do núcleo da LPS, essas características devem estar presentes em todos os sistemas alvo.

Na Figura 4.10, apresenta-se um modelo simplificado das características opcionais e alternativas da LPS. Nessa figura as características são mostradas como uma hierarquia de pseudoclasses com um esterótipo que indica sua categoria de reúso (opcional ou alternativa). As características alternativas estão pintadas na cor amarela e as características opcionais estão em azul. Esse é o terceiro modelo de características sugerido pela abordagem. 


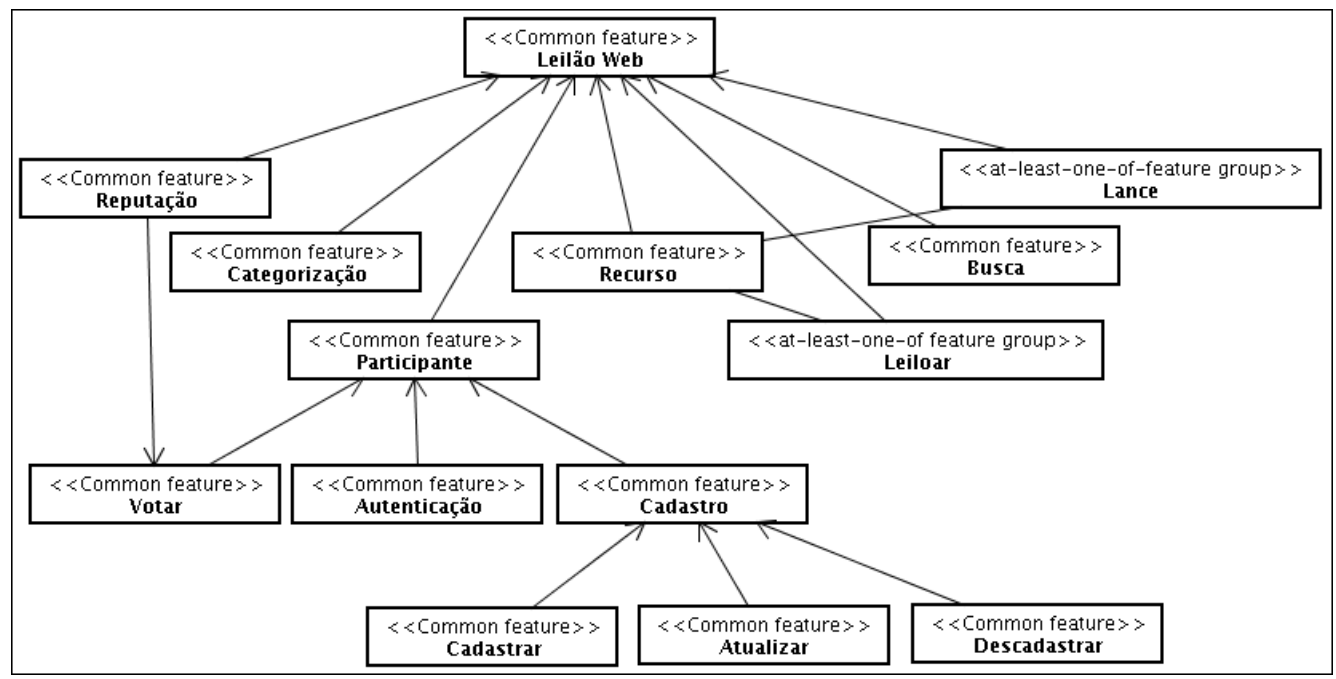

Figura 4.9: Modelo hierarquico de características do núcleo da LPS de leilões Web.

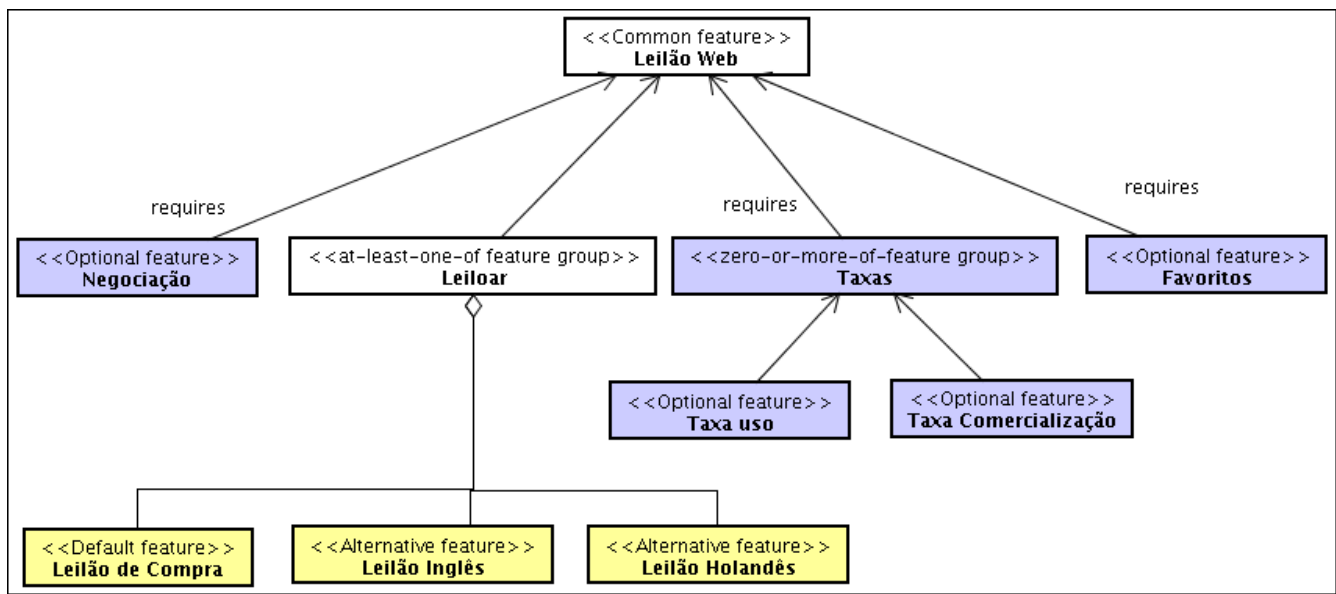

Figura 4.10: Modelo hierarquico de características das variabilidades da LPS de leilões Web.

Embora a representação hierárquica seja a mais utilizada, as características também podem ser representadas em forma de tabela.

\subsection{Atividades de Análise e Projeto}

As atividades de análise utilizam os artefatos gerados durante as atividades de requisitos e procuram definir a linha de produtos refinando seus requisitos para que um bom projeto possa ser executado sobre a LPS em estudo. Enquanto o foco da análise é criar modelos lógicos do sistema que captem as suas funcionalidades para satisfazer os requisitos, o propósito do projeto é especificar como essas funcionalidades serão implementadas (Arlow e Neustadt, 2002). A seguir apresentam-se as atividades de análise e projeto da fase de engenharia de domínio da abordagem SoProL-WS, que recomenda iniciar-se a análise e projeto pelas características que fazem parte do núcleo da LPS e depois de forma incremental revisitar essa fase do desenvolvimento para as 
características opcionais e alternativas, de tal forma que a cada iteração algum produto mínimo possa ser configurado com os artefatos da linha.

\subsubsection{Modelagem estática}

A modelagem estática é feita por meio do modelo conceitual, que apresenta os conceitos do domínio da aplicação. Em linha de produtos, o modelo conceitual representa uma notação poderosa para representar o domínio da LPS. Os conceitos que estão presentes em todos os membros da LPS são conhecidas como conceito do núcleo e recebem o estereótipo kernel. Os conceitos que estão em alguns mas não todos os membros da linha, de forma opcional, são conhecidos como conceitos opcionais e recebem o estereótipo optional. Por fim, os conceitos que possuem versões alternativas para satisfazer a diferentes membros da linha são conhecidos como conceitos variantes e recebem o estereótipo variant (Gomaa, 2004). Esses estereótipos representam as categorias de reúso dos conceitos do modelo.

O modelo conceitual é feito com base no documento de requisitos, especificação dos casos de uso e nos diagramas de características elaborados previamente durante as atividades de requisitos, e representa uma forma gráfica de entender os conceitos do domínio da LPS, bem como as relações entre eles. O artefato de saída gerado por essa atividade é um documento contendo o modelo conceitual da LPS. A abordagem SoProL-WS recomenda que além do modelo conceitual, o documento contenha uma tabela de mapeamento com o nome dos conceitos, sua categoria de reúso e uma breve descrição sobre seu papel no domínio da LPS.

\section{Exemplo}

O modelo conceitual foi feito com base nos artefatos gerados durante as atividades de requisitos e, assim como na modelagem de casos de uso, foram utilizadas técnicas descritas em Larman (2004) para identificar os conceitos e algumas técnicas descritas por Gomaa (2004) para definir suas categorias de reúso. O modelo conceitual da LPS é apresentado na Figura 4.11. Os conceitos do núcleo da LPS estão na cor branca, os conceitos opcionais estão em amarelo e os conceitos alternativos estão em azul.

\subsubsection{Identificação dos Web Services}

O modelo de características e os diagramas de atividades elaborados na atividade de análise são os artefatos principais usados para identificação dos WS da LPS e das suas operações. Em particular, três trabalhos tratam dessa identificação baseada no modelo de características, são eles:

- Zaupa (2007): os autores estabelecem que cada característica em alto nível equivale a um WS. 


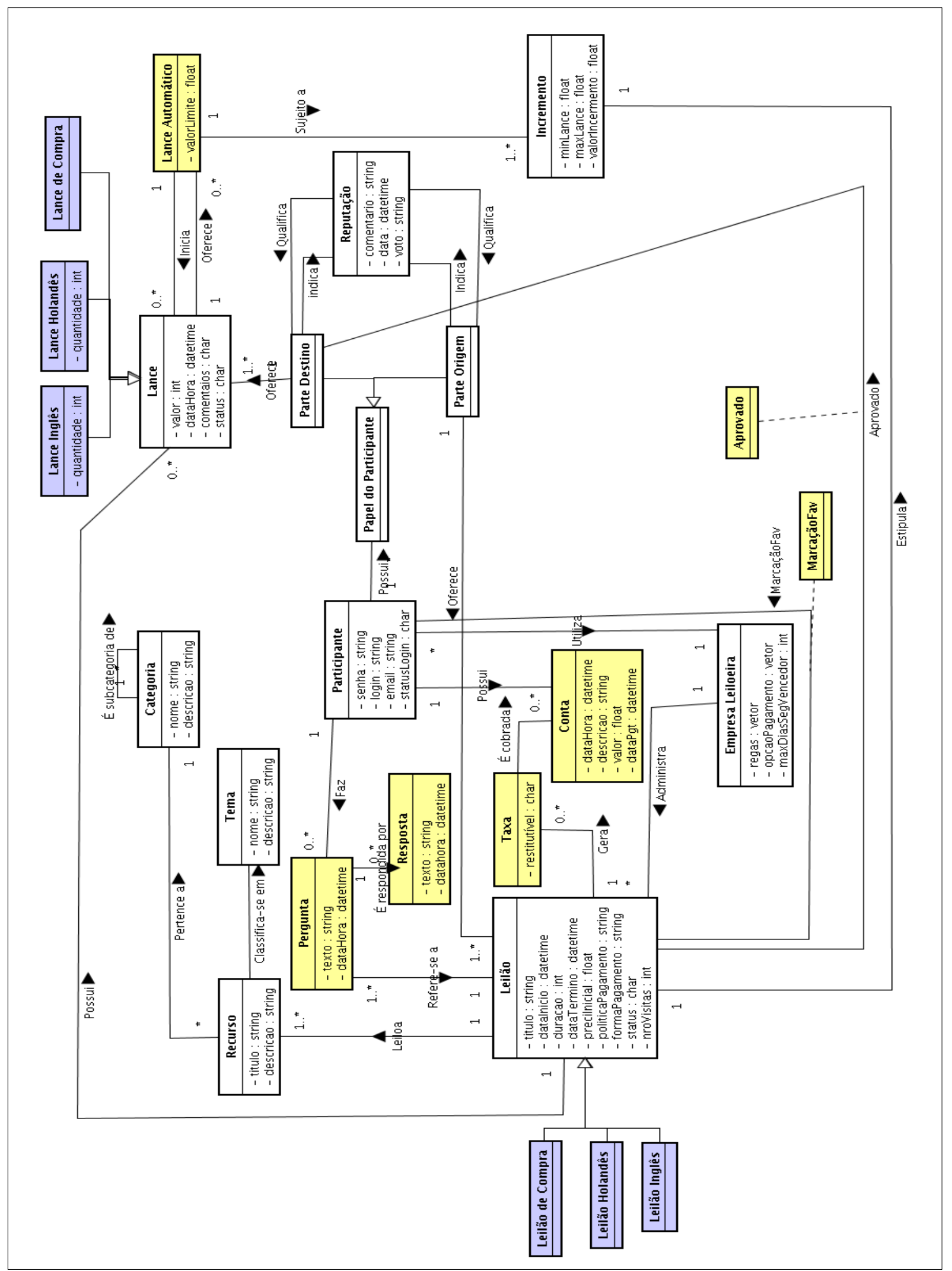

Figura 4.11: Modelo conceitual da LP. 
- Ye et al. (2007): os autores estabelecem que cada WS corresponde à implementação de uma ou mais características. Se um WS implementar mais de uma característica, cada característica que ele implementa corresponde a uma operação do serviço.

- Lee et al. (2008): os autores propõem uma análise do diagrama de características levando em consideração quatro itens:

1. os serviços devem ser auto-contidos, ou seja, cada web service é a implementação de uma funcionalidade de negócios bem definida e pode ser usada por outros serviços de forma independente.

2. os serviços não devem possuir estado do ponto de vista do usuário do serviço;

3. os serviços são fornecidos com pré e pós condições;

4. os serviços devem possuir representatividade específica no domínio.

Visto que os trabalhos divergem um pouco sobre a identificação de serviços baseada no modelo de características, a abordagem SoProL-WS considera que pela definição e características dos serviços apresentados na Seção 2.4.6, deve-se seguir as orientações de Lee et al. (2008) e Zaupa (2007) com algumas considerações extras:

1. inicia-se a identificação dos serviços pelos serviços do núcleo da LPS por meio da análise do diagrama de características que representa o seu núcleo;

2. cada característica de nível um equivale a um WS, desde que satisfaça as características de serviços apresentadas por Lee et al. (2008).

3. as operações dos WS são definidas pelas características do tipo folha que estão abaixo da característica de nível um que representa o serviço e são dependentes dela;

4. os WS modelados devem possuir todas as service activities definidas no diagrama de atividade. Caso alguma atividade não seja derivada do diagrama de características como operação de nenhum serviço, deve ser adicionada a um WS que esteja relacionado a essa atividade. Um WS relacionado a atividade é aquele WS que possui facilidades para implementar a atividade ou que faz sentido para o domínio oferecer essa operação, por exemplo: o serviço Participante possui operações para cadastrar, atualizar e descadastrar participantes, mas depois da modelagem de todos os serviços, a atividade Efetuar Login que está representada como service activity nos diagramas de atividade não foi relacionada a nenhum serviço. Nesse caso, a experiência do engenheiro de domínio deve ser usada para adicionar esse atividade ao serviço Participante, pois esse WS tem acesso aos dados dos participantes do leilão e pode fazer autenticações para o login.

5. por fim, realiza-se o mesmo procedimento para as características opcionais e alternativas por intermédio da análise do diagrama de características que as modela. 
Os serviços são representados utilizando o diagrama de classes da UML adaptado com estereótipos específicos. Cada serviço é uma pseudoclasse com o estereótipo web service. As operações dos serviços são descritas como métodos da pseudoclasse. Essa pseudoclasse funciona como uma interface para os serviços propostos. Cada serviço deve possuir estereótipos que indiquem suas características de reúso: kernel para serviços que implementam somente características do núcleo; optional para serviços que implementam somente características opcionais ou service activity do tipo optional; ou variant para serviços que implementam características variantes e possivelmente, também implementem características opcionais ou que implementem service activity do tipo kernel-alternative e optional-alternative.

A definição das operações oferecidas pelo serviço que ocorre, nessa fase, ainda é preliminar, ou seja, ainda não precisam ser decididos o tipo de retorno e os tipos de parâmetros esperados pelas operações dos WS. O artefato de saída gerado por essa atividade é um diagrama com a representação dos serviços como pseudoclasses e as operações realizadas pelos serviços como métodos da pseudoclasse.

\section{Exemplo}

A partir do diagrama de características do núcleo modelado durante a atividade de análise, foram extraídas as características de nível mais alto que são: Reputação, Autenticação, Categorização, Participante, Recurso, Leiloar e Busca. Cada uma dessas características corresponde a um WS. A característica Participante possui como características dependentes: Votar, Autenticação, Cadastro, Cadastrar, Descadastrar e Atualizar. Cada uma dessas características, que são folhas, correspondem a uma operação do serviço. Observa-se que a característica não folha Cadastro não se converte em operação do WS Participante, contudo suas características dependentes Cadastrar, Descadastrar e Atualizar são convertidas em operações do WS. Essa análise é feita para cada uma dessas características do núcleo.

Depois da definição de todos os WS do núcleo, deve ser feito o mesmo procedimento para definir os WS que implementam as características opcionais e alternativas. Ao final da definição dos WS baseado nos modelos de características, deve-se verificar se alguma service activity definida nos diagramas de atividades não se converteu em operações de nenhum WS e adicioná-la a algum WS de acordo com os conhecimentos do engenheiro de domínio da LPS. Na Figura 4.12, são apresentados alguns dos serviços modelados com essa técnica. 


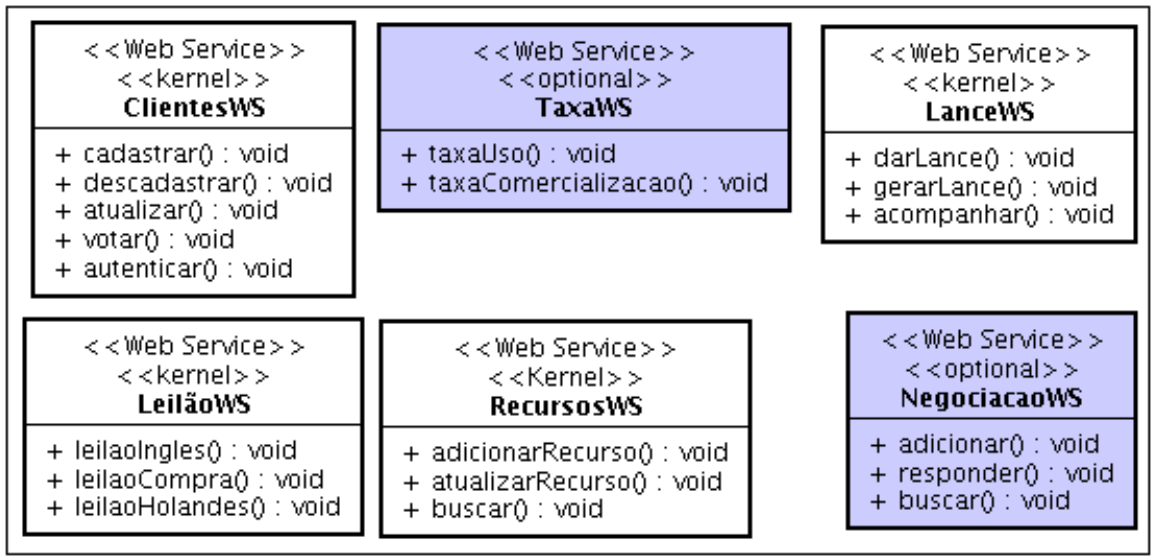

Figura 4.12: Definição de alguns serviços da LPS de leilões Web.

\subsubsection{Modelagem de Navegação de Interface}

Visto que a linha de produtos é composta por serviços e a interface gráfica com usuário (GUI) é a porta de entrada e saída de dados para os serviços, é importante modelar a navegação do usuário pelas telas da GUI e entre elas e os serviços que elas requisitam. Saleh (2005) propõem a utilização de um diagrama de navegação de interface para descrever essas interações. Esse diagrama é composto por classes sem atributos ou operações, cada classe representa uma GUI do sistema. Essas classes recebem dois estereótipos, o primeiro é «interface» e é utilizado para indicar que trata-se de uma interface com o usuário, o segundo é para indicar sua categoria de reúso.

O diagrama de navegação mostra as classes de interface que podem ser acessadas a partir de outras. De acordo com o diagrama de características instanciado para um determinado membro da LPS, todas as classes de interface do tipo kernel são selecionadas, nenhuma ou mais do tipo optional e nenhuma ou alguma alternativa do tipo alternative. As GUI do tipo optional ou alternative são aquelas que interagem ou podem vir a interagir com algum serviço opcional ou alternativo respectivamente. Isso significa que essa GUI possui elementos opcionais ou alternativos que devem ser adicionados em tempo de montagem do produto. Uma GUI ainda pode, em determinada configuração de um produto, interagir com elementos opcionais e alternativos, recebendo nesse caso o estereótipo optional-alternative. Cada uma dessas telas interagem com algum web service ou processo de negócio. Essa interação é apresentada por intermédio do diagrama de comunicação (Saleh, 2005).

Nessa fase inicia-se a elaboração do gabarito de montagem dos membros da LPS. A abordagem SoProL-WS recomenda a criação de uma tabela que contenha o nome da GUI, uma breve descrição e a característica ao qual ela está relacionada. Essa tabela será usada posteriormente na configuração do gerador de aplicações ou na montagem manual de um membro da LPS. 


\section{Exemplo}

Na Figura 4.13, são apresentadas as principais GUI da LPS de leilões Web. Destaca-se a GUI VisualizarR, que possui o estereótipo optional-alternative mesmo sendo uma GUI que obrigatoriamente deve estar em todos os produtos da linha. Contudo, caso a característica opcional Negociação seja selecionada, a tela VisualizarR deve ser alterada para mostrar as negociações em curso, ou ainda, caso a característica alternativa Leilão Holandês ou Leilão Inglês sejam escolhidas a tela também deve ser alterada, uma vez que o leilão de compra só exige que o cliente concorde em pagar o valor cobrado, ou seja, basta realizar a compra sem a necessidade de ofertar um lance, enquanto os outros dois tipos de leilões exigem que o cliente ofereça um lance.

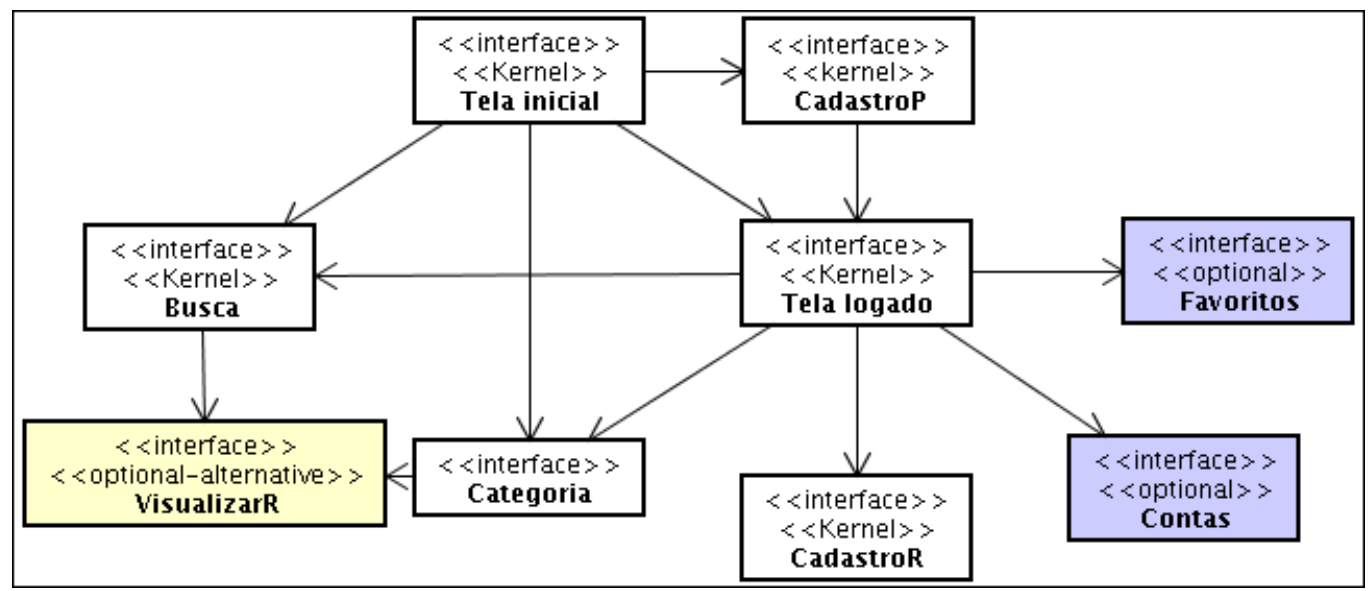

Figura 4.13: Algumas telas da LPS de leilões Web com suas interações.

$\mathrm{Na}$ Tabela 4.3, são descritas as GUIs que foram apresentadas na Figura 4.13, conforme recomendado pela abordagem SoProL-WS.

Tabela 4.3: Requisitos Funcionais.

\begin{tabular}{|l|l|l|}
\hline Nome & Descrição & Característica \\
\hline Busca & GUI que apresenta o resultado das buscas do usuário & Busca \\
\hline VisualizarR & GUI que mostra os detalhes de um recurso escolhido & Recurso \\
\hline Categoria & GUI que mostra as subcategorias de uma determinada categoria & Categorização \\
\hline CadastroC & GUI para cadastro de cliente & Cadastrar \\
\hline Tela Logado & GUI para usuário logado & Autenticação \\
\hline CadastroR & GUI para cadastro de recurso & Recurso \\
\hline Favoritos & GUI que apresenta os leilões favoritos do cliente & Favoritos \\
\hline Contas & GUI que apresenta o extrato do vendedor junto ao leilão & Taxas \\
\hline
\end{tabular}

\subsubsection{Diagrama de Comunicação}

O diagrama de comunicação é utilizado para mostrar quais web services interagem com os elementos da GUI, com isso, pode-se identificar alguns processos de negócios menores que devem 
ser implementados para a LPS. Esses processos menores podem ser unidos em um macro processo para a aplicação ou podem ser chamados em separado por cada elemento da GUI de acordo com a necessidade da LPS modelada. Quando um elemento da GUI relaciona-se com mais de um WS no diagramação de comunicação, sugere-se a utlização de PN para descrição dessas interações. Na maioria dos casos, o controlador desse elemento da GUI não acessa um WS, mas sim o PN que relaciona-se com o elemento da GUI.

\section{Exemplo}

Na Figura 4.14, apresenta-se o diagrama de comunicação iniciado pela iteração com a GUI VisualizarR. Destaca-se que para montar a GUI é necessário acessar o WS RecursoWS para obter os dados do recurso desejado, opcionalmente precisa-se acessar o WS NegociaçãoWS caso a característica negociação esteja habilitada e ainda precisa-se acessar o WS ReputaçãoWS para obter a reputação da parte origem do produto. Por meio desse diagrama de comunicação pode-se identificar dois processos de negócios menores: o primeiro consiste da invocação dos três WS e é requerido quando a característica Negociação é escolhida para fazer parte de um produto da LPS; o segundo consiste da invocação de dois WS, RecursoWS e ReputaçãoWS. Logo, conforme discutido na Seção anterior, o controlar da GUI VisualizaR deve-se ligar a um desses PN e não aos WS em separado. É importante destacar que mesmo que os dois WS presentes no segundo PN sejam WS do núcleo, o PN não pode ser classificado como pertencente ao núcleo, pois caso a característica Negociação seja escolhida, o PN que fará parte do produto será o primeiro.

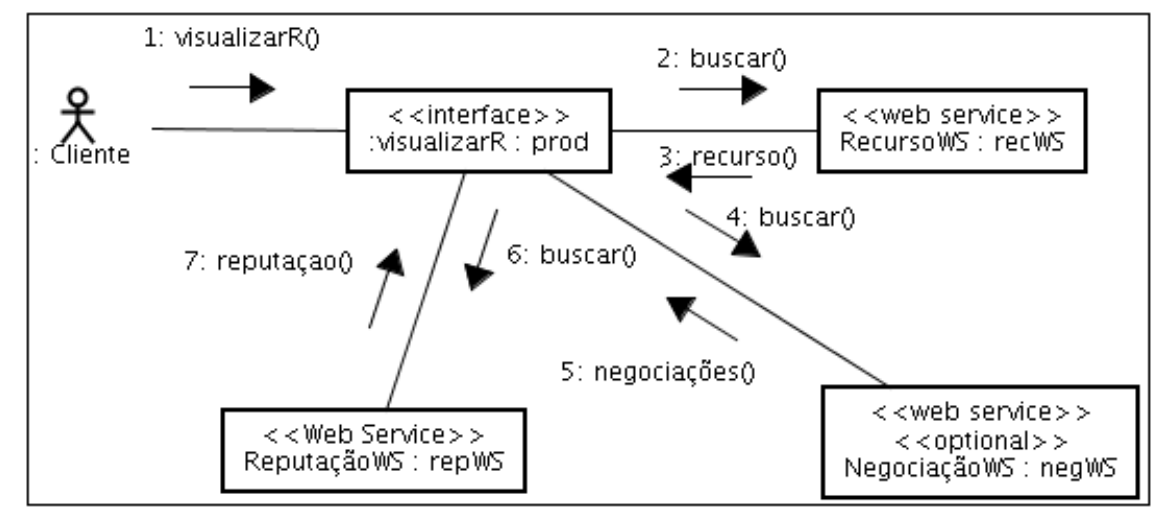

Figura 4.14: Diagrama de comunicação da GUI VisualizarR.

\subsubsection{Projeto de Classes}

O projeto de classes é feito por meio do diagrama de classes da UML, e deve ser feito para cada serviço identificado. Para definir as classes do serviço e seus respectivos métodos, utiliza-se o método de Zaupa (2007) apresentado na Seção 3.7, com um adendo: a classe principal deve 
possuir o método adicionado durante a definição do serviço que foi proveniente de alguma service activity do processo de negócio e esse método deve ter parâmetros e tipo de retorno que façam sentido para o serviço. A classe principal do diagrama representa a definição do serviço, portanto os métodos da classe são equivalentes às operações do serviço, bem como seus parâmetros e tipos de retorno. A abordagem SoProL-WS adota a seguinte notação: a classe principal do diagrama de classes que será convertida em web service recebe o estereótipo «web service». Fica como opção do projetista utilizar padrões de projeto que se encaixe no projeto de classes do WS.

Enquanto esse mapeamento é trivial para serviços do núcleo da LPS, ele deve ser adaptado para os serviços do tipo opcional e alternativos, pois devem ser criadas novas operações, atributos ou mesmo outros serviços semelhantes para tratar as suas variabilidades. Pode ser necessário criar: operações semelhantes mas que possuem parâmetro ou tipo de retorno diferentes; parâmetros para definir o comportamento do serviço; ou outros serviços com mesma interface mas com lógica de negócios diferentes entre si. As duas primeiras opções podem ser especificadas nessa fase do desenvolvimento, contudo a última deve ser tratada durante a fase de implementação.

Nessa etapa do desenvolvimento, os serviços já foram especificados de forma que pode-se realizar buscas em repositórios de serviços para encontrar serviços que atendam a essas especificações.

\section{Exemplo}

Na Figura 4.15, apresenta-se o projeto do WS Participante. As classes: Participante e Cadastro foram extraídas do diagrama de características de acordo com o método apresentado por Zaupa (2007). Adicionalmente, optou-se por utilizar dois padrões de projeto no WS: Transfer Object (TO) (Sun Microsystems, Inc., 2009a), que tem o objetivo de encapsular os dados que serão trafegados pela rede e reduzir o tráfego que seria gerado enviando os parâmetro um a um, além de ser usado para troca de dados entre a classe Participante e a classe ParticipanteDAOImp; e Data Access Object (DAO) (Sun Microsystems, Inc., 2009b), que visa a evitar que os códigos referentes ao banco de dados fiquem espalhados pelas classes do serviço. As classes adicionadas por esses padrões são: ParticipanteBeanTo, que é adicionada pelo padrão TO e ParticipanteDAO e ParticipanteDAOImp adicionadas pelo padrão DAO. A interface ParticipanteDAO foi definida para evitar o uso direto da classe ParticipanteDAOImp e reduzir o acoplamento entre as classes do WS, conseqüentemente tornando-o mais manutenível. 


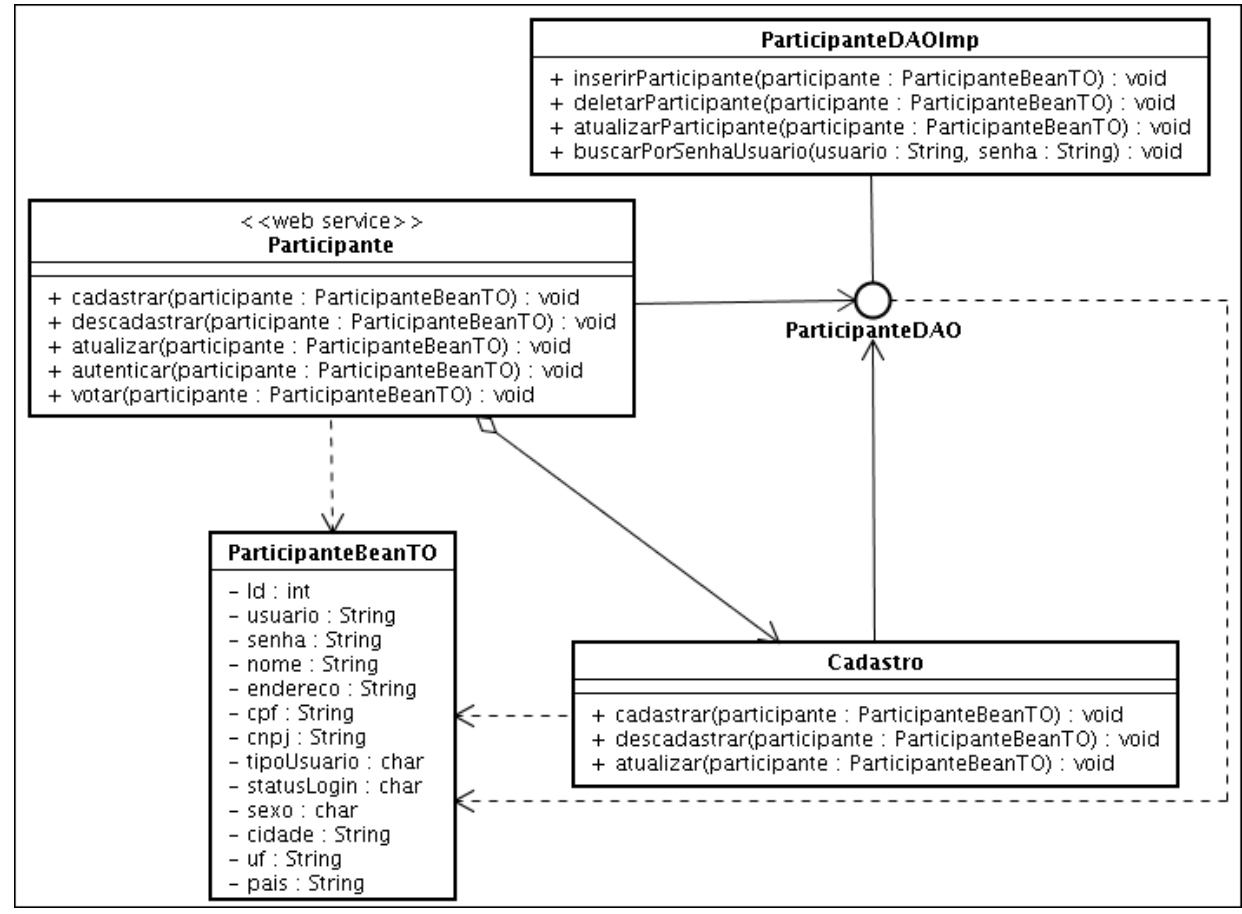

Figura 4.15: Projeto do serviço participante.

\subsubsection{Definição da Arquitetura}

Nesta etapa, é realizada a definição de uma arquitetura em alto nível, que divida os artefatos implementados em categorias/camadas. Para a definição da arquitetura pode-se recorrer aos padrões arquiteturais (Buschmann et al., 1996, 2007). A definição da arquitetura de uma LPS com SOA deve levar em conta: os artefatos produzidos, que podem ser WS, PN, telas da GUI, entre outros; a forma como os produtos serão gerados, que pode ser manualmente ou com apóio de um gerador de aplicações; e questões de flexibilidade para facilitar futuras manutenções na LPS.

\section{Exemplo}

Decidiu-se utilizar, para a linha de produto de leilões Web, uma arquitetura com quatro camadas. A arquitetura é baseada no padrão arquitetura MVC (Model View Controller) (Buschmann et al., 1996) com a adicição de uma camada para abstração do banco de dados. A camada de apresentação pode ser formada por páginas HTML, JSP, JSF, entre outros, e é responsável pela entrada e saída de dados. A camada de controle recebe as requisições da camada de apresentação e controla o fluxo de execução da aplicação, seja por meio de chamadas a serviços específicos ou pela execução de processos de negócio. A camada de aplicação corresponde aos WS e PN que implementam as funcionalidades de negócio da aplicação. A camada de dados é responsável pela persistência da aplicação. Na Figura 4.16, apresenta-se um diagrama da arquitetura lógica em alto nível. Destacase que somente os WS podem acessar diretamente os dados, todas as outras entidades, inclusive os PN só tem acesso aos dados por meio dos WS. 
Uma opção de projeto importante é a utilização da camada de controle por um controlador comum e não um PN. Mesmo que o controlador possa ser usado para simular um PN, não será utilizado dessa forma neste trabalho, pois um dos objetivos deste trabalho é estudar o reúso em LPS. Enquanto um PN pode ser reusado em qualquer outro projeto pois estará disponível na rede como um serviço, o mesmo não pode ser feito com a utilização de um controlador simulando um PN. O controlador realiza chamadas únicas a PN ou WS de acordo com a necessidade da requisição e poderá realizar algum tratamento nos dados antes de serem passados para a camada de visão.

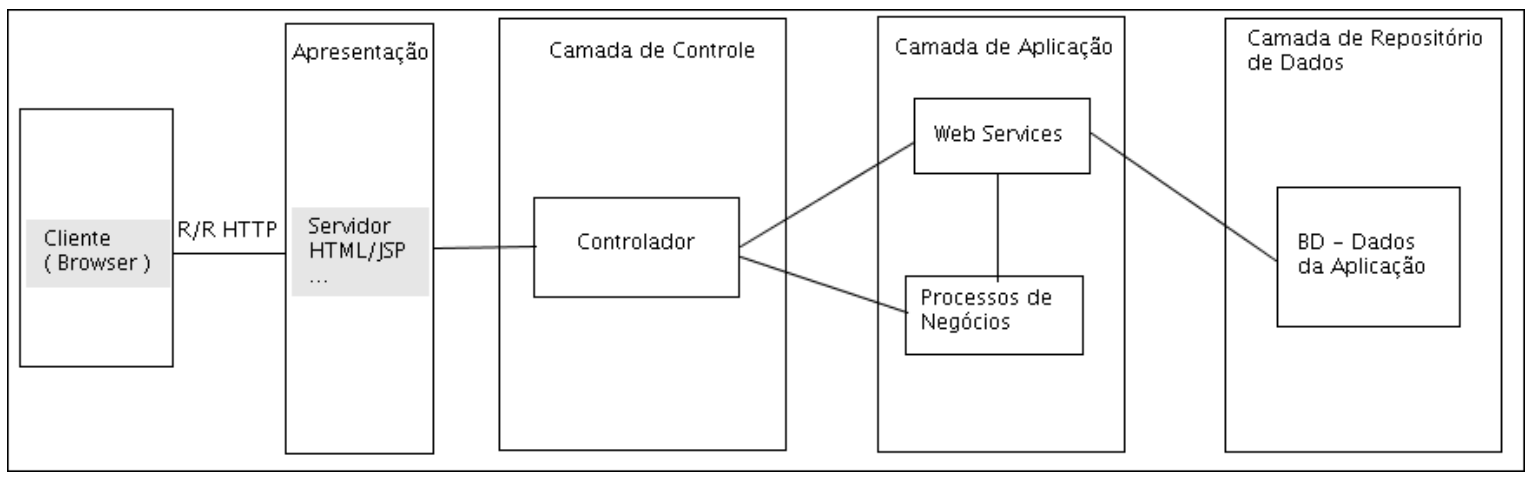

Figura 4.16: Projeto arquitetural em alto nível.

\subsubsection{Projeto de Banco de Dados}

Nessa atividade é feito o projeto do banco de dados (BD) da LPS. Essa atividade é opcional, uma vez que nem todas as LPS precisam utilizar BD para guardar os dados da aplicação, e ainda, pode ser possível elaborar uma LPS utilizando exclusivamente WS disponibilizados por terceiros, nos quais a responsabilidade dos dados fica a cargo do fornecedor do serviço. Caso seja necessário projetar um BD, deve-se levar em conta uma das principais diferenças entre serviços e componentes, sua forma de reúso. Um componente pode ser adicionado a um membro da LPS e utilizado de forma independente dos outros membros que o utilizam, dessa forma, pode-se gerar um novo BD para a LPS levando em conta as alterações causadas pela adição desse componente. No caso dos WS, existe uma instância única que é utilizada por todos os membros da LPS que precisam desse serviço, por isso o BD que gerencia esse WS é o mesmo, independente do sistema alvo da LPS. Essa característica dos WS exige que o projeto de BD seja feito de forma a dar apoio à diferenciação dos vários sistemas alvo derivados da LPS. O BD também deve ser projetado de modo a satisfazer o conjunto de todas as características da LPS, uma vez que não poderá ser alterado para satisfazer às necessidades específicas de cada membro da LPS. Por esse motivo deve-se tentar evitar misturar dados opcionais em tabelas de BD usadas por WS obrigatórios para reduzir a quantidade de nulos nas tabelas do BD, ou seja, deve-se seguir as regras de normalização de BD. 


\subsection{Implementação}

\subsubsection{Definição do Ambiente de Desenvolvimento}

Antes de iniciar-se o desenvolvimento da LPS é necessário definir o ambiente de desenvolvimento. Para a implementação dos WS, controladores e telas da GUI utiliza-se neste trabalho a IDE eclipse (The Eclipse Foundation, 2009a) com o servidor Web Tomcat (The Apache Software Foundation, 2009b) e plug-in WTP (The Eclipse Foundation, 2009b) pois já são usados há alguns anos pelo desenvolvedor deste trabalho. Para a codificação dos processos de negócio envolvidos foi feita uma avaliação de ambientes para determinar qual será utilizado na implementação nos processos de negócios da LPS de leilões Web. Um ambiente de desenvolvimento de PN deve compreender: uma IDE, que pode necessitar de plug-ins; um servidor web; e um engine BPEL. Com base nessa necessidade e na disponibilidade das ferramentas, foram avaliados três ambientes com maior uso pela comunidade:

1. Composto pela IDE Eclipse, utiliza plug-in IBM (IBM, 2009) para modelar os processos de negócio, servidor Web tomcat e engine Ode da apache (The Apache Software Foundation, 2009a).

2. Composto pela IDE Active Vos (Active endpoints, 2009) que é integrada ao engine active Bpel (Active endpoints, 2009) e utiliza o servidor Web tomcat.

3. Composto pela IDE JDeveloper (Oracle, 2009c) que é integrada ao engine da Oracle (Oracle, 2009a) e utiliza o servidor Web OC4J (Oracle, 2009d).

Foram definidas oito métricas para avaliação desses ambientes: Documentação, baseado na quantidade de documentação existente; F lexibili dade, baseado na compatibilidade das ferramentas do ambiente com outras possíveis ferramentas, como por exemplo a alteração do servidor Web; facilidade de uso ; a métrica Livre avalia se as ferramentas são liberadas para uso sem necessidade de pagamento de licença; Código Aberto, avalia se o código fonte das ferramentas é disponibilizado; Produtividade, avalia a velocidade de desenvolvimento do mesmo tipo de aplicações com os ambientes; Confiabilidade; e Escalabilidade.

Para cada métrica, foram atribuídas notas de zero a dois. A nota zero é atribuída quando um ambiente não satisfaz a métrica, a nota um é atribuída quando o ambiente satisfaz parcialmente a métrica e a nota dois é atribuída quando o ambiente satisfaz completamente a métrica proposta. Na Tabela 4.4, são apresentadas as métricas propostas, as notas dadas e o total obtido por cada ambiente. O ambiente com maior nota (Ambiente 3) foi escolhido para a implementação dos processos de negócio da LPS. 
Tabela 4.4: Avaliação das Ferramentas.

\begin{tabular}{|l|l|l|l|}
\hline & Ambiente 1 & Ambiente 2 & Ambiente 3 \\
\hline Documentação & 1 & 1 & 2 \\
\hline Flexibilidade & 2 & 1 & 1 \\
\hline Facilidade de Uso & 1 & 1 & 2 \\
\hline Livre & 2 & 1 & 2 \\
\hline Código Aberto & 2 & 0 & 0 \\
\hline Produtividade & 1 & 1 & 2 \\
\hline Confiabilidade & 1 & 1 & 2 \\
\hline Escalabilidade & 1 & 2 & 2 \\
\hline Total & 11 & 8 & 13 \\
\hline
\end{tabular}

\subsubsection{Implementação}

Optou-se por separar o desenvolvimento dos WS, da camada de visão e dos PN, para mostrar o desacoplamento entre essas partes e para mostrar os diversos pontos de vista que existem no desenvolvimento de uma LPS orientada a serviços. Depois da definição do ambiente de desenvolvimento, iniciou-se a implementação dos WS com base na programação e compilação das classes descritas nos diagramas de classes. A camada de apresentação é feita com JSP (Roth e Pelegrí-Llopart, 2003) e Struts (Holmes, 2007). Usou-se o Struts pois ele facilita a implementação de uma arquitetura MVC e fornece um controlador que recebe automaticamente requisições das páginas JSP. Com o uso do Struts, têm-se um controlador para cada página que dispara uma ação do servidor. O controlador pode fazer uma chamada a um WS ou a um PN previamente implementado.

Na Figura 4.17, mostra-se a estrutura de pacotes do projeto WSLPS que contém a implementação dos WS da LPS e o projeto LPSLWView que contém os páginas JSP e os seus respectivos controladores. Embora a estrutura seja parecida, os dois projetos são independentes e possuem diferentes conteúdos em seus pacotes. Observa-se que nos dois projetos o pacote chamado bas i co contém a implementação de artefatos do núcleo da LPS, no caso do projeto WSLPS estão o WS do núcleo da LPS e no caso do projeto LPSLWVIEW estão os controladores do núcleo da LPS. Os dois projetos possuem pacotes uti l e beans. No primeiro deles estão algumas classes utilitárias e no segundo estão os beans usados pelos WS ou controladores da LPS.

Conforme discutido na Seção 4.4, foram implementados primeiro os WS, PN, telas da GUI e controladores que representam as características que compõem o núcleo da LPS. Na Listagem 4.3, apresenta-se trechos do código da classe ParticipanteDAOImp, que é a classe que tem acesso aos dados do participante e é a única forma de acessar esses dados. Destaca-se a utilização de uma classe chamada BDUtil que controla as conexões com o BD e de uma classe chamada BaseDAO que possui as operações genéricas de manipulação do BD (inserção, remoção e atualização).

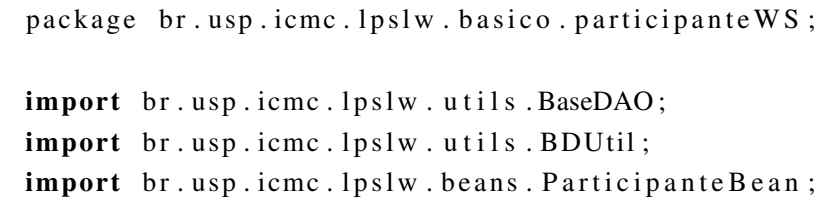



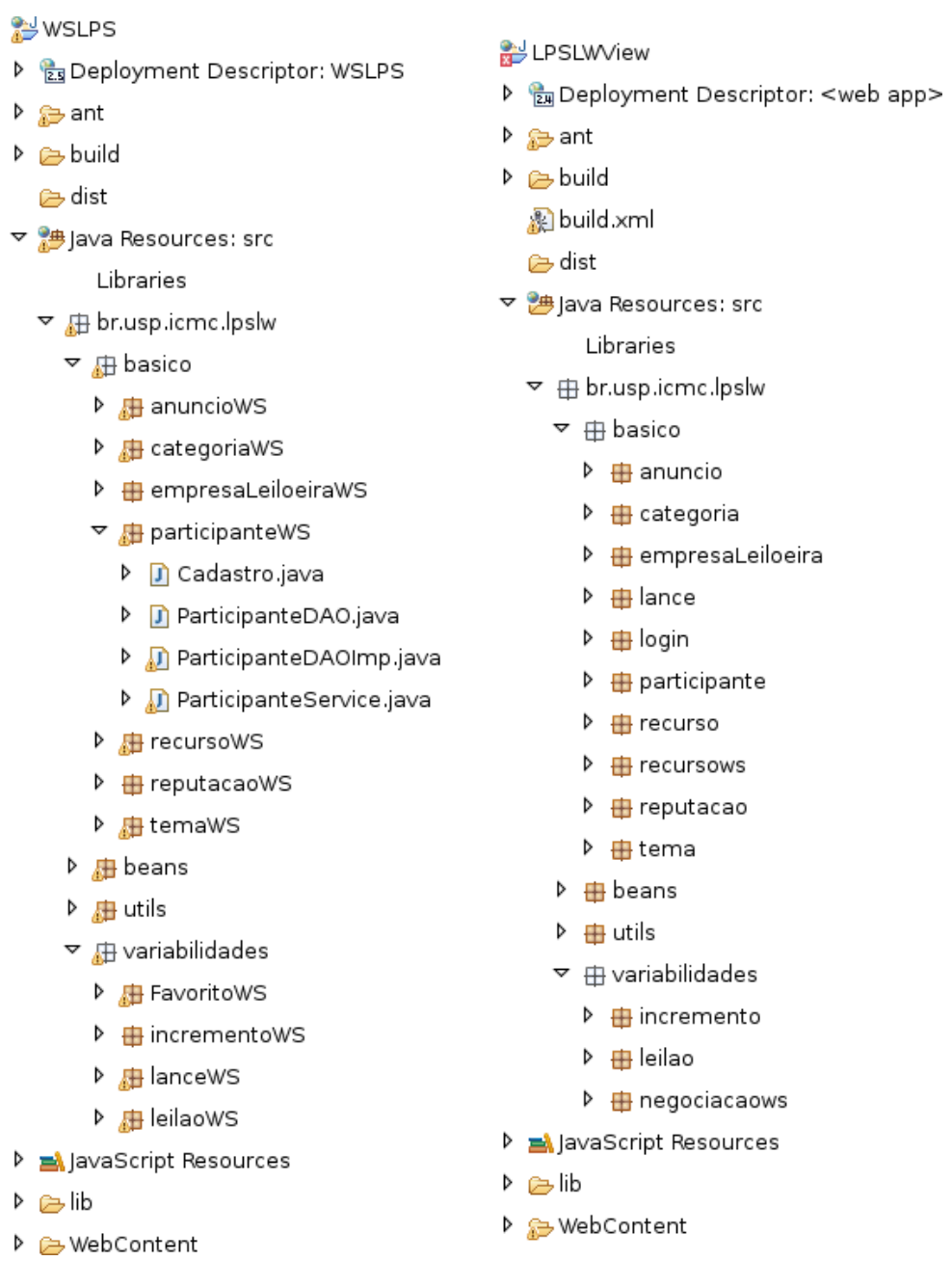

Figura 4.17: Estrutura de pacote dos WS e da camada de visão da LPS de leilões Web.

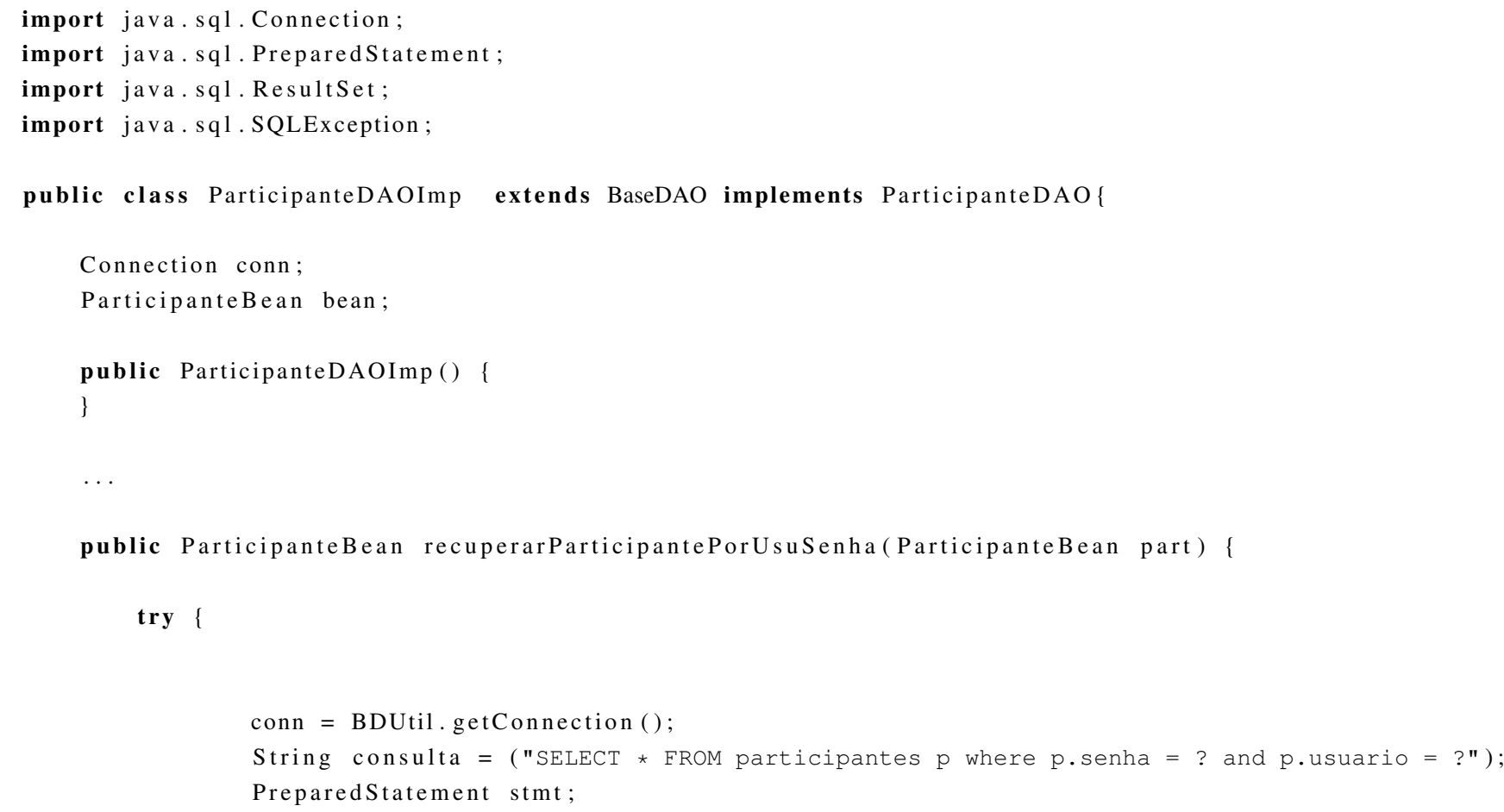




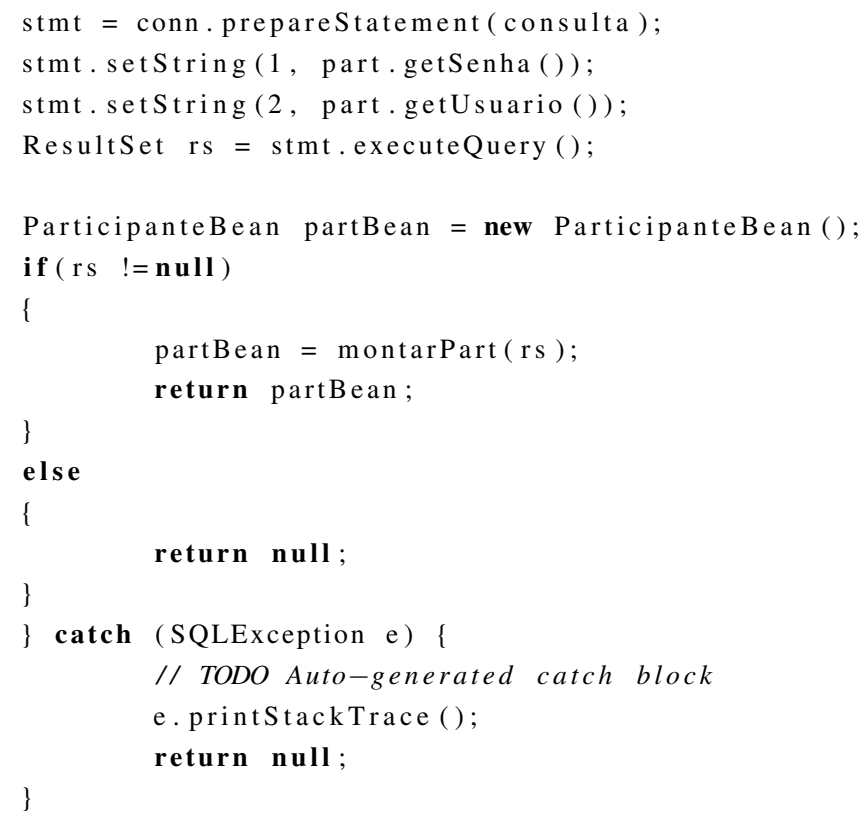

Listagem 4.3: Classe de acesso ao banco de dados.

$\mathrm{Na}$ Listagem 4.4, são apresentados trechos da classe Participante, que é a classe que é transformada em WS e portanto implementa suas operações. Destaca-se a delegação de funções para as classes ParticipanteDAO e Cadastro nas linhas 16,22 e 34.

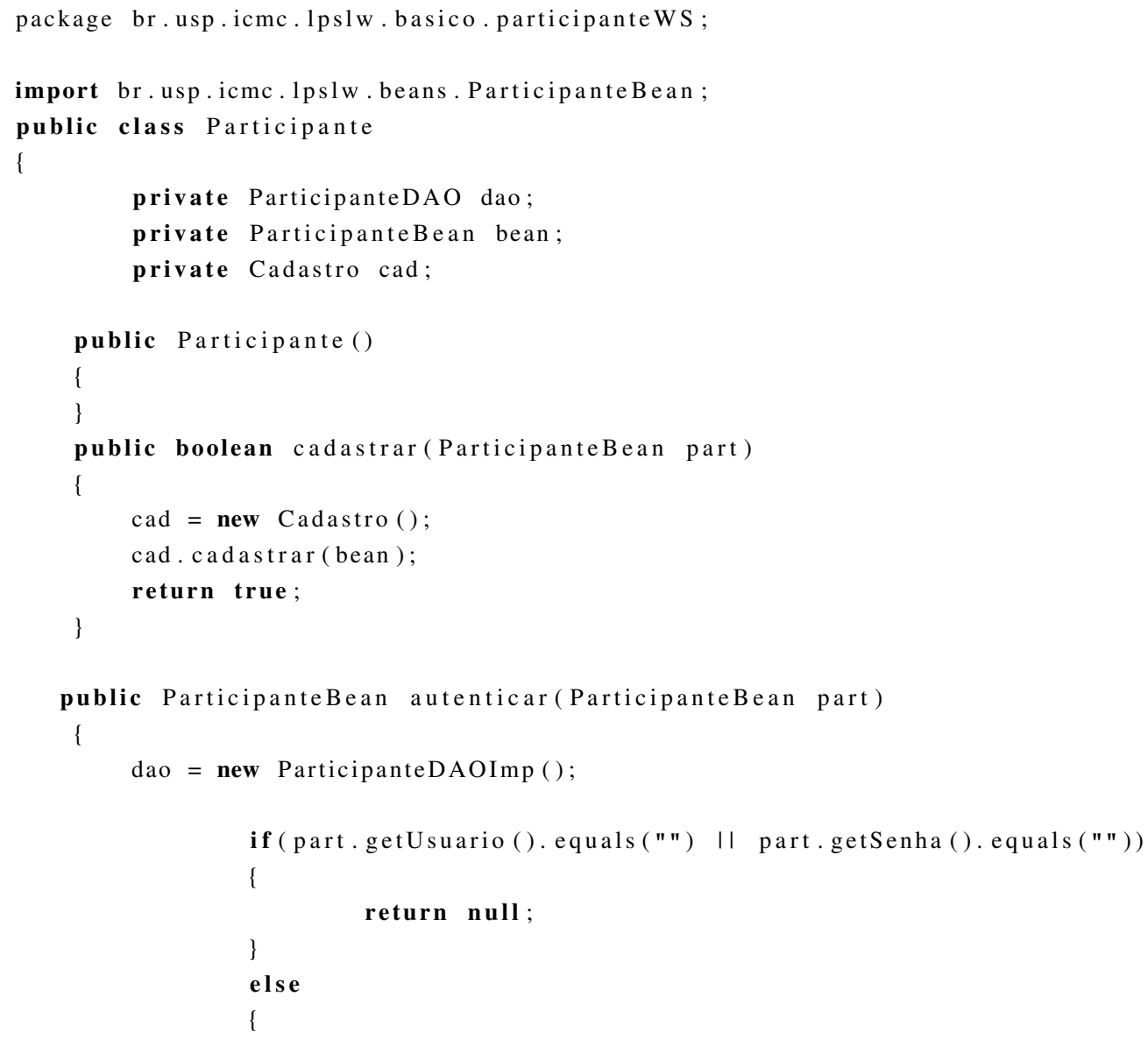




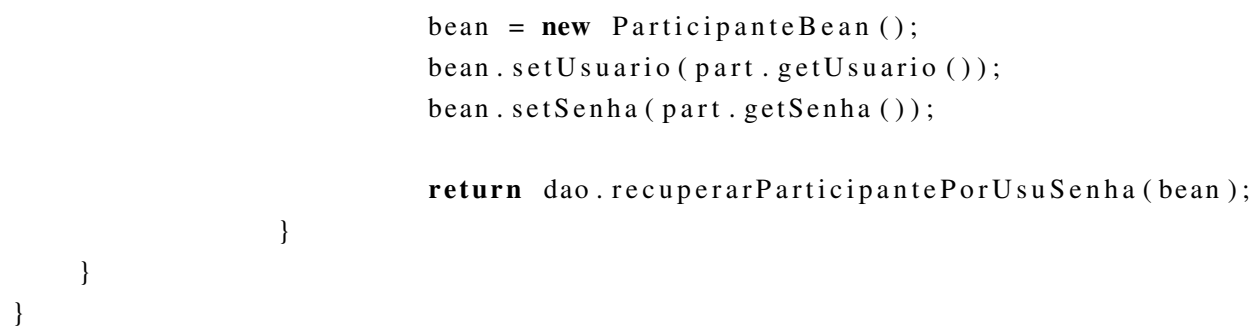

Listagem 4.4: Classe principal do serviço ParticipanteWS.

Nas Listagens 4.5 e 4.6, apresentam-se trechos de código que correspondem a programação das classes ParticipanteBeanTo e Cadastro. A classe ParticipanteBeanto implementa o padrão de projeto transfer object, conforme discutido na Seção 4.7.5, e deve estender a interface Seriali zable para que possa ser automaticamente convertida em XML e seja enviada pela rede. A classe Cadastro foi extraída do método de conversão do diagrama de características em diagrama de classes e realiza algumas operações presentes no WS.

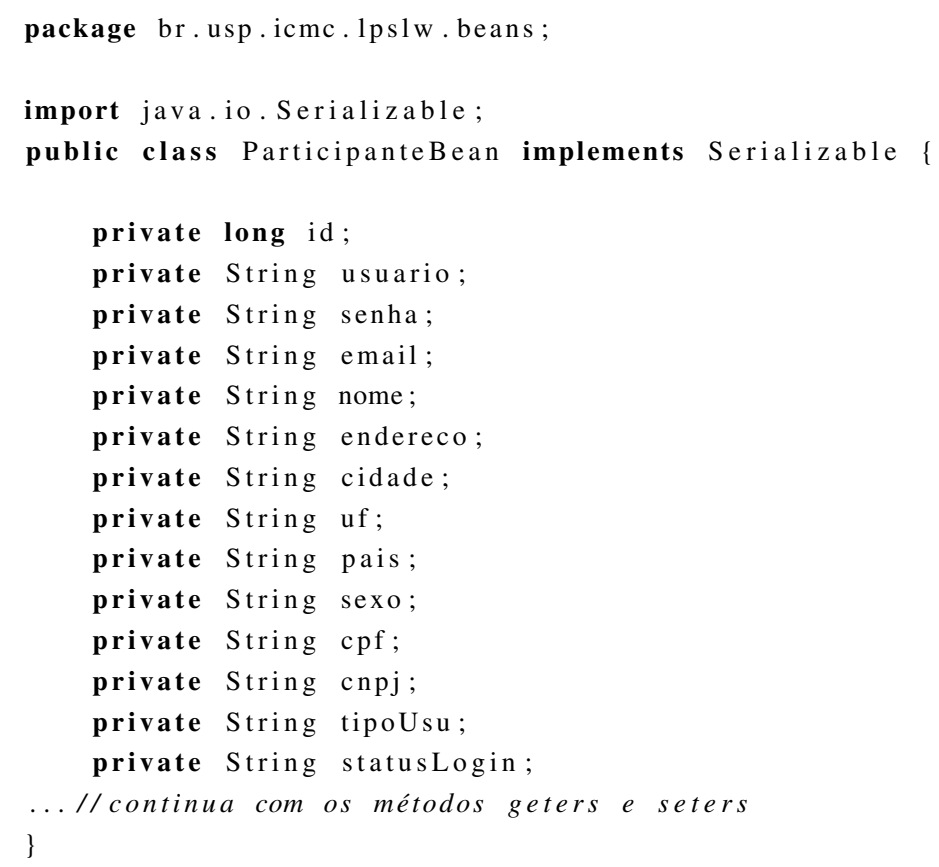

Listagem 4.5: Bean que implementa o padrão TO.

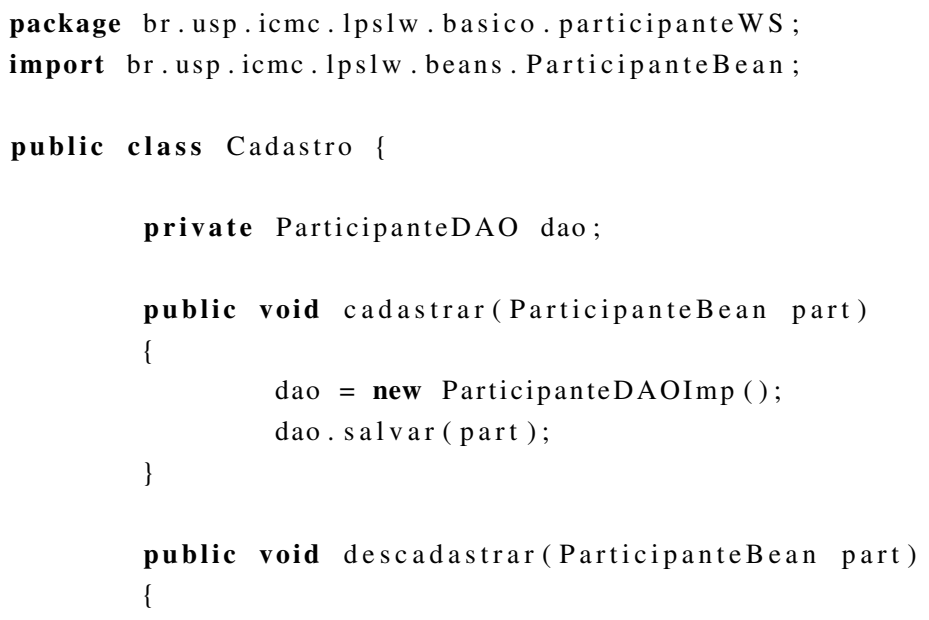




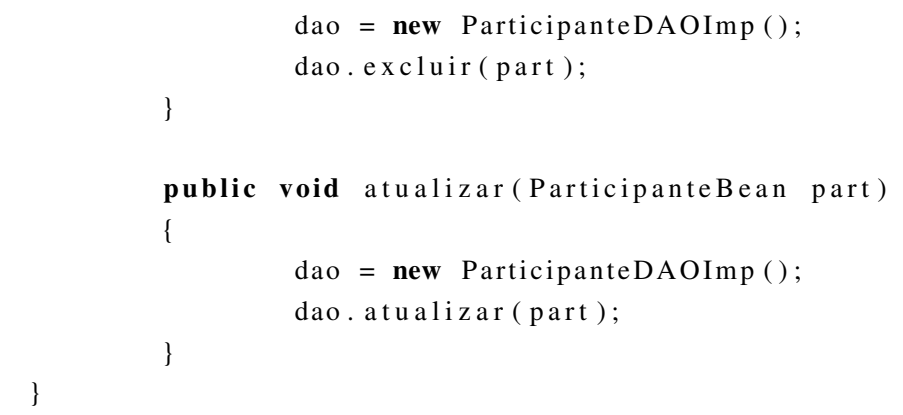

Listagem 4.6: Classe que foi extraída da análise dos diagramas de características.

A seguir, utiliza-se as ferramentas de desenvolvimento do ambiente para a conversão das classes programadas em um serviço Web. Na Figura 4.18, são apresentados esses passos para criação de um WS no ambiente de desenvolvimento Eclipse. Inicia-se escolhendo criar um web service, conforme apresenta-se em 1. A seguir, inicia-se um wizard, no qual na primeira tela é necessário informar qual classe será transformada em WS (descrito por 2) e quais as configurações do ambiente (descrito por 3). Por fim, inicia-se o servidor Web para fazer a implantação do WS (descrito por 4) e conforme pode-se observar na parte 5 da figura, é criada a estrutura do WS no pacote WebContent. Na Listagem 4.7, apresenta-se trechos do WSDL gerado para o WS.

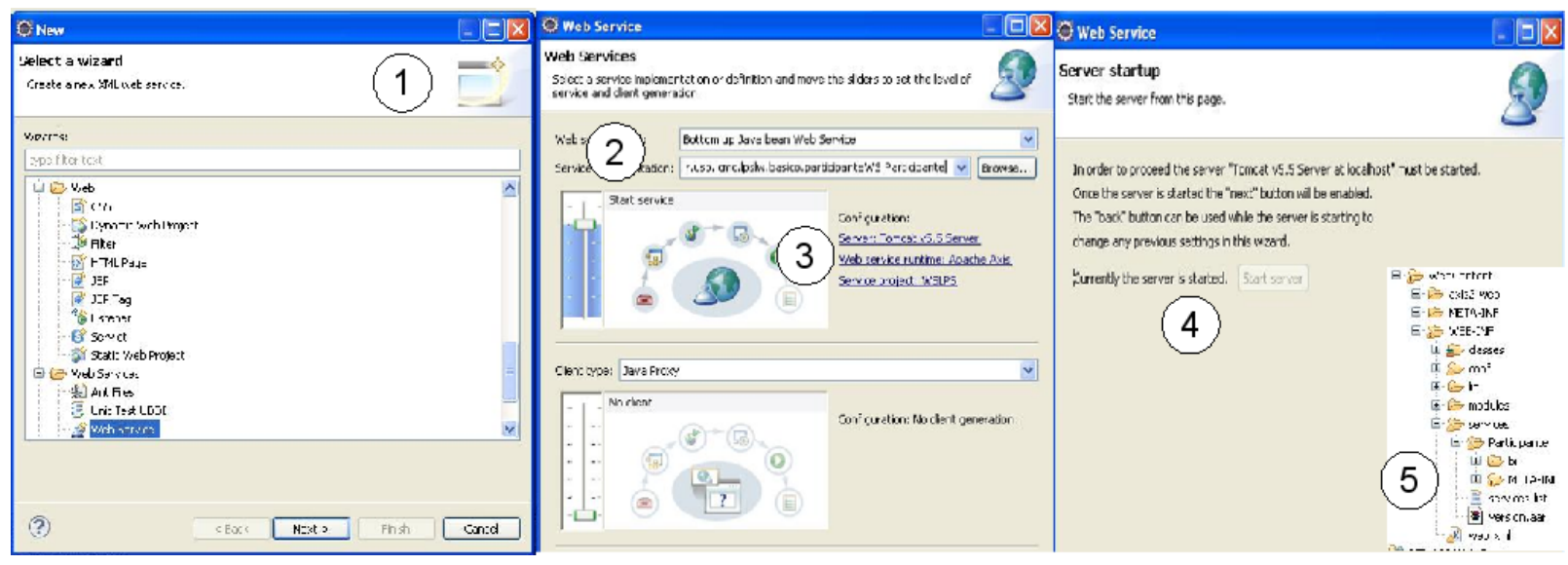

Figura 4.18: Passos para a criação do WS.

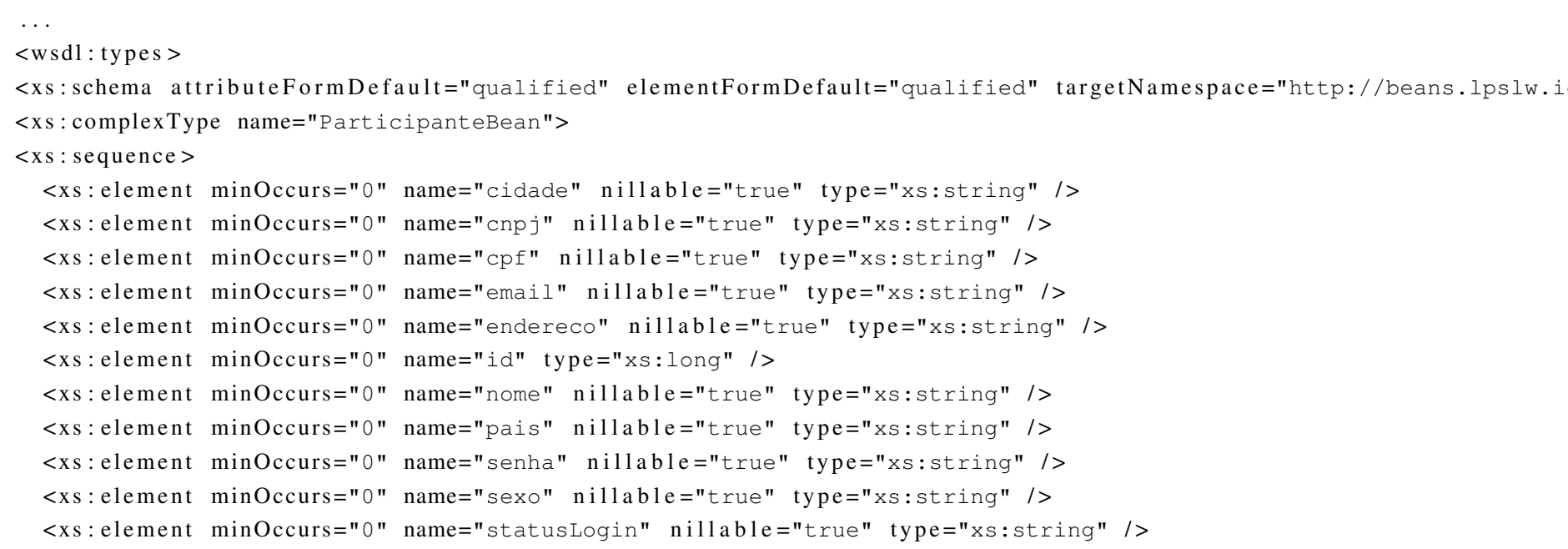




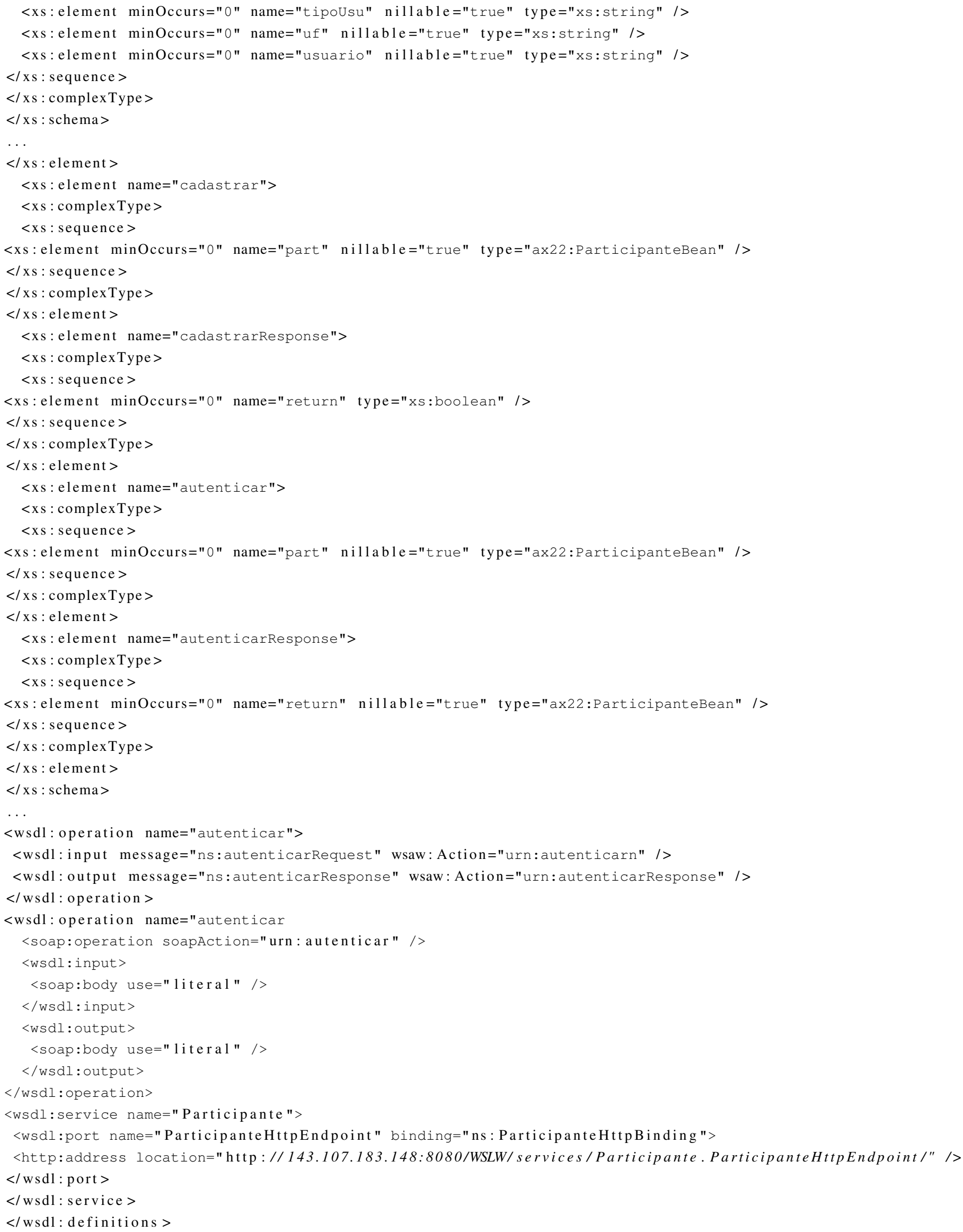

Listagem 4.7: Exemplo de documento XML. 
O Eclipse oferece apoio para a criação de clientes para os WS por meio de um wizard semelhante ao de criação dos WS. Ao fim do wizard são gerados Stubs para o acesso ao WS. Na Listagem 4.8, apresenta-se um trecho de código da classe ParticipanteAction, que representa um controlador das ações disparadas relativas aos participantes do leilão e utiliza o Stub gerado para acessar o WS Participante e chamar a sua operação para autenticação do participante. Esses Stubs foram gerados no projeto LPSLWView e sua utilização para chamada aos WS que implementam variabilidades da LPS ou PN que não são do núcleo da LPS representam o glue code responsável pela composição dos produtos da LPS. A forma de acessar um PN feito em BPEL é igual a forma de acesso aos WS, uma vez que um PN BPEL executando em um engine pode ser visto como um WS.

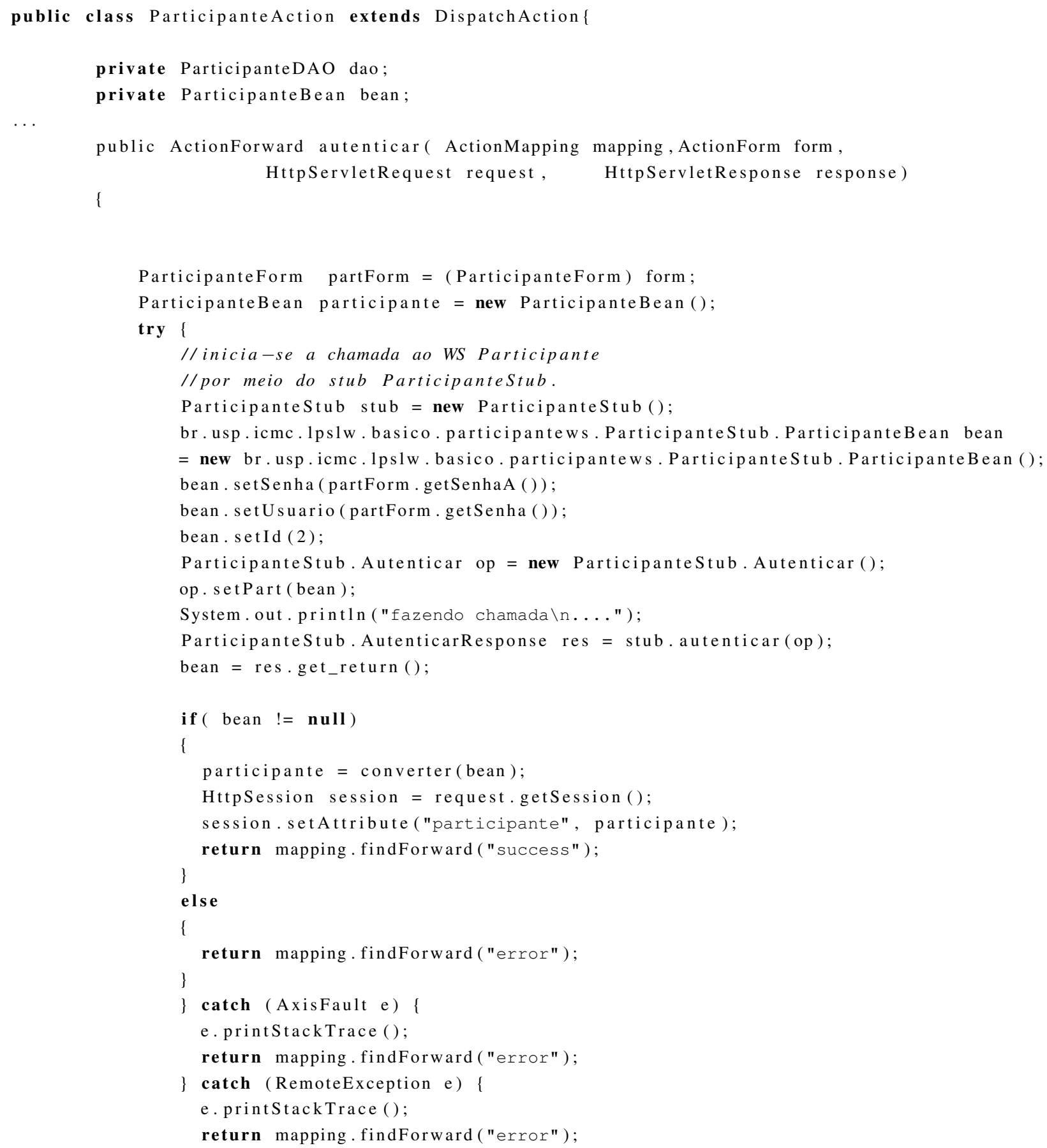


$\begin{array}{ll} & \\ \ldots & \end{array}$

Listagem 4.8: Classe principal do serviço RecursoWS.

\subsection{Testes}

Nesta etapa é feita a realização de testes de unidade com os serviços implementados e suas composições. Nesse caso, deve-se aplicar testes voltados para serviços e testes voltados para linhas de produtos. Esses tipos de testes ainda são motivo de estudo na academia. Algumas técnicas de testes de LPS podem ser encontradas nos trabalhos de Pohl e Metzger (2006) e McGregor (2001) entre outros. Os trabalhos de Endo (2007), Mei e Zhang (2005), Canfora (2005) e Canfora e Penta (2006), entre outros, apresentam técnicas para testes de WS e composições de serviços. Para o estudo de caso de leilões Web foram realizados testes de unidade de forma ad hoc com os WS e os PN.

\subsection{Manual para Geração dos Membros da LPS}

Nesta etapa do desenvolvimento já foram desenvolvidos todos os artefatos reutilizáveis da LPS, mas precisa-se elaborar um manual para que o engenheiro de aplicações saiba como implementar os códigos de ligação para gerar os membros da LPS. A abordagem SoProL-WS não utiliza esse manual. Segundo a abordagem deve-se configurar um gerador de aplicações configurável para o domínio da LPS, de modo que os produtos possam ser gerados de forma automatizada. No Capítulo 5, são apresentados os passos para a configuração do GAC Captor-AO, bem como a sua utilização na engenharia de aplicações.

\subsection{Engenheria de Aplicações}

A fase de engenharia de aplicações da LPS inicia-se com a elicitação de requisitos de um sistema. Verifica-se se o sistema pertence a LPS desenvolvida, em caso negativo, verifica-se se é viável a reconfiguração da LPS para adição das variabilidades do sistema que se deseja gerar. Caso seja viável realizam-se os passos da abordagem tomando o sistema alvo como guia para elicitar as características que precisam ser adicionadas a LPS. Caso não seja viável, inicia-se um projeto do zero, seja para uma LPS no domínio do sistema ou para o desenvolvimento do sistema como single system. Se o sistema pertence a linha de produtos configurada no gerador de aplicações, deriva-se o diagrama de características do sistema alvo para ser utilizado no gerador de aplicações para gerar o novo membro da LPS. Os passos detalhados da engenharia de aplicações com a utilização de um gerador de aplicações são apresentados no Capítulo 5. 


\subsection{Considerações Finais}

Neste capítulo foi apresentada a abordagem SoProL-WS como uma forma de desenvolver linha de produtos com arquitetura orientada a serviços. A abordagem é inspirada nos trabalhos de Gomaa (2004), Gomaa e Saleh (2005), Lee et al. (2008), Ye et al. (2007), van Gurp e Savolainen (2006), Zaupa (2007) e Chang e Kim (2007). Ela procura contemplar as principais atividades necessárias para o desenvolvimento bem sucedido de LPSs com arquitetura orientada a serviços; visa padronizar a qualidade dessas LPSs; aumentar a velocidade de desenvolvimento com o uso de serviços reutilizáveis; aumentar a manutenibilidade da linha por meio do uso de SOA; e facilitar a derivação de membros da linha por intermédio da composição de serviços. Os artefatos gerados pela abordagem foram exemplificados com o estudo de caso de leilões Web, e sempre que possível, foram apresentadas as alternativas de projeto existentes e quais foram usadas no estudo de caso seguido de uma explicação sobre sua escolha.

Na Tabela 4.5, apresenta-se um resumo com as sub atividades e artefatos produzidos para as principais atividades propostas pela abordagem SoProL-WS. No capítulo 5, apresenta-se a configuração dos artefatos de implementação gerados durante a fase de engenharia de domínio (WS, PN BPEL, JSP e Controladores) no gerador de aplicações configurável Captor-AO para geração automática de membros da LPS, além de apresentar a engenharia de aplicação com a utilização do Captor-AO.

Tabela 4.5: Requisitos Funcionais.

\begin{tabular}{|c|c|c|}
\hline Atividades & Subatividades & Artefatos \\
\hline Requisitos & $\begin{array}{l}\text { Elicitação dos requisitos } \\
\text { Modelagem de casos de uso } \\
\text { Modelagem de características }\end{array}$ & $\begin{array}{l}\text { Documento de requisitos } \\
\text { Diagrama de casos de uso } \\
\text { Especificação de casos de uso } \\
\text { Diagrama de características } \\
\text { Mapeamento casos de uso/características }\end{array}$ \\
\hline Análise & $\begin{array}{l}\text { Modelagem estática } \\
\text { Identificação dos serviços } \\
\text { Modelagem de Navegação de Interface } \\
\text { Modelagem dinâmica }\end{array}$ & $\begin{array}{l}\text { Modelo estático conceitual } \\
\text { Diagrama de identificação dos serviços } \\
\text { Modelo de navegação entre interfaces de usuário } \\
\text { Diagramas de comunicação }\end{array}$ \\
\hline Projeto & $\begin{array}{l}\text { Definição da arquitetura da LPS } \\
\text { Projeto de classes } \\
\text { Projeto de BD }\end{array}$ & $\begin{array}{l}\text { Definição das camadas } \\
\text { Alocação dos serviços nas camadas } \\
\text { Diagrama BPEL } \\
\text { Diagrama de classes para cada serviço } \\
\text { Modelo do BD }\end{array}$ \\
\hline
\end{tabular}




\section{Configuração do Captor-AO e Engenharia de Domínio}

\subsection{Considerações Iniciais}

A engenharia de domínio finaliza-se com a elaboração de um manual para geração dos membros da LPS. Na abordagem SoProL-WS, esse manual é substituído pela utilização de um gerador de aplicações que realiza a tarefa de montagem dos produtos da LPS de forma automatizada. O gerador de aplicações utilizado no estudo de caso é o Captor-AO (ver seção 2.3.1). Neste Capítulo, apresenta-se a configuração do gerador de aplicações para LPS de leilões Web e a sua utilização para derivação de membros da linha.

O capítulo está organizado da seguinte forma. Na Seção 5.2, apresenta-se a configuração do Captor-AO para a LPS de leilões Web. Na Seção 5.3, apresenta-se o uso do Captor-AO durante a fase de engenharia de aplicações da LPS de leilões Web para a derivação de produtos da linha. Na Seção 5.4, são apresentadas as considerações finais do Capítulo.

\subsection{Configuração do Captor-AO}

O Captor-AO é um gerador de aplicações que foi construído como uma extensão do Captor e foi introduzido na Seção 2.3.1. Embora neste trabalho não sejam usados os recursos adicionais do Captor-AO para composição de domínios transversais, ele é usado pois adiciona algumas melhorias ao Captor original. A configuração do Captor-AO para um novo domínio acontece em quatro eta- 
pas: Definição da LMA (Linguagem de Modelagem da Aplicação), que consiste da definição dos formulários apresentados ao engenheiro de aplicações para a configuração de um produto específico da LPS; criação dos gabaritos que são utilizados para gerar os artefatos; criação do arquivo de mapeamento de transformação de gabaritos; e criação dos arquivos de pré e pós-processamento, que são opcionais. Na Figura 5.1, são ilustrados os arquivos necessários para configuração do Captor-AO. Ao longo desta Seção são detalhadas essas etapas na configuração do Captor-AO para o domínio de leilões Web.

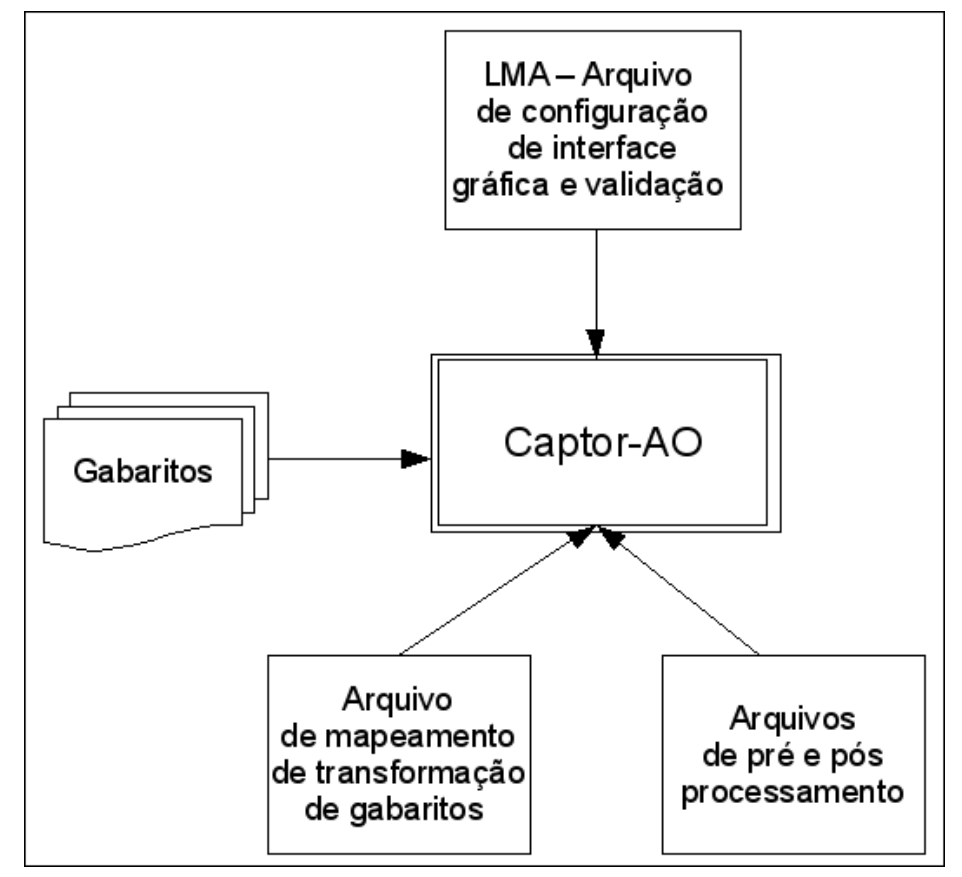

Figura 5.1: Configuração de um domínio no Captor-AO.

Conforme apresentado no Capítulo 4, foram desenvolvidos os artefatos do domínio da LPS de leilões Web. Entre eles destacam-se o modelo de características, a implementação da GUI da LPS, a implementação e implantação dos web services e a implementação e implantação dos processos de negócio BPEL. Na Figura 5.2, são ilustrados esses artefatos, a relação entre eles e o que acontece após o uso do Captor-AO para a configuração de um sistema alvo. Conforme apresenta-se na figura, inicialmente tem-se a GUI com todas as páginas JSPs implementadas, os controladores, que são servlets que recebem as requisições das páginas que requerem processamento, os stubs que são usados para acessar algum WS ou PN BPEL e as chamadas aos WS do núcleo nos controladores responsáveis. O engenheiro de aplicações elabora uma instância do modelo de características para a montagem de um sistema de leilões Web passando-a para o Captor-AO por meio do uso da LMA definida para a LPS de leilões Web. O Captor-AO utiliza os gabaritos para: adicionar nos controladores as chamadas (código de ligação) aos WS ou PN BPEL que implementam as características escolhidas; fazer alterações, se necessárias, nas telas que são adicionadas para implementar essas características; e implantar no servidor Web um subconjunto da GUI com as alterações realizadas para que possa ser usado por qualquer browser. 


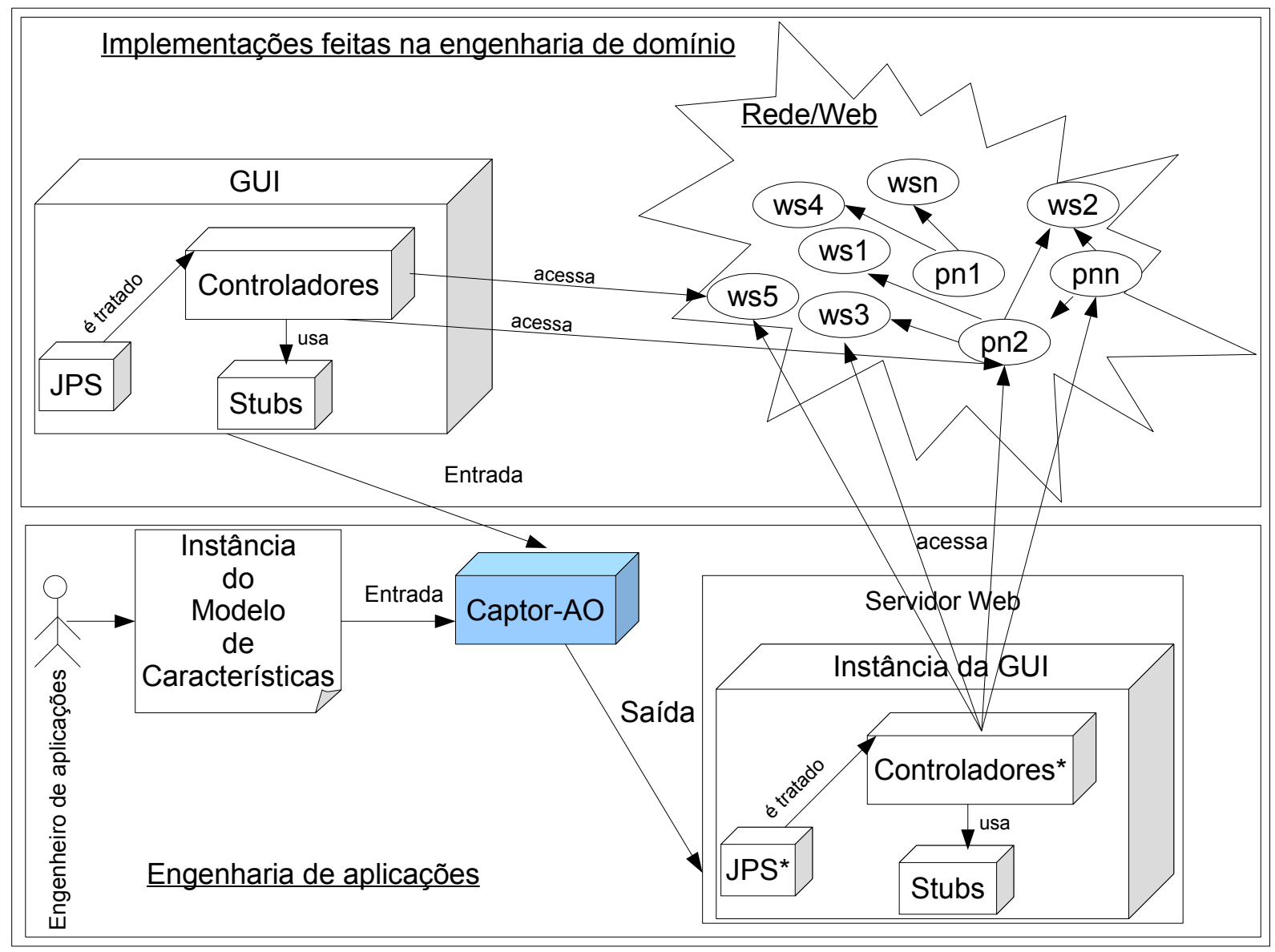

Figura 5.2: Relação entre os artefatos usados na configuração e uso do Captor-AO.

\subsubsection{Definição da LMA}

No Captor-AO, assim como no Captor, são utilizadas LMAs declarativas que são especificadas em um conjunto de formulários organizados hierarquicamente em forma de árvore (Shimabukuro Junior, 2006). Como as implementações que fazem parte do núcleo estão presentes em todos os membros da linha, elas não precisam ser representadas na LMA, que deve levar em conta apenas as variabilidades da LPS. Diversas LMAs podem ser definidas para um certo domínio e, no caso da LPS de leilões Web, a LMA foi definida com base no modelo de características que representa as características variáveis. Para cada característica de nível 1 é criado um formulário. Na Figura 5.3, mostra-se a estrutura hierárquica dos formulários definida para o domínio de leilões Web. O primeiro formulário é denominado variabilidades e é nele que o engenheiro de aplicações define o nome da aplicação alvo. A partir do primeiro formulário pode-se ir para o formulário Tipo de Leilão, Negociação ou Favoritos. 


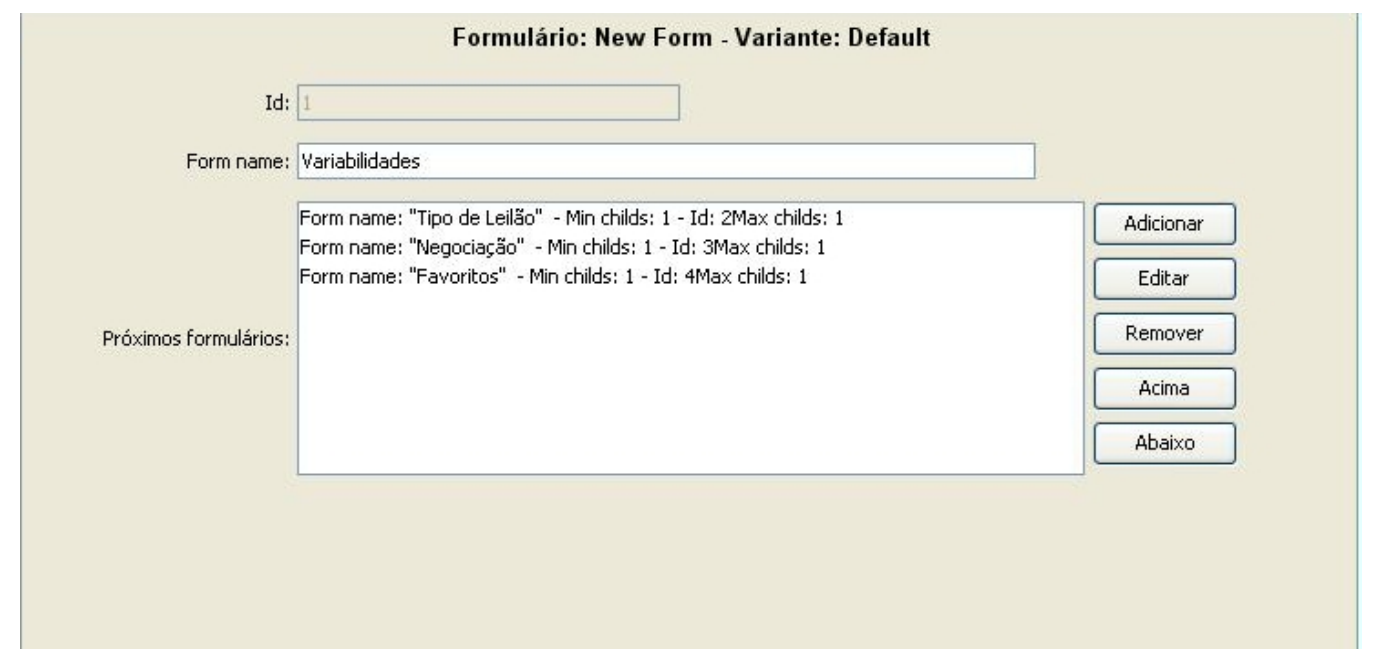

Figura 5.3: Estrutura hierárquica dos formulários.

Na Tabela 5.1, apresenta-se os pontos de variação que são modelados nos formulários e os possíveis valores para sua escolha. Na Figura 5.4, apresenta-se a configuração do Formulário com a combobox.

Tabela 5.1: Avaliação das Ferramentas.

\begin{tabular}{|l|l|l|}
\hline Nome do Formulário & Ponto de Variação & Possíveis Valores \\
\hline Variabilidades & Nome da Aplicação & Texto Livre \\
\hline Tipo de Leilão & Tipo de Leilão & Leilão Comum, Leilão Inglês, Leilão Holandes \\
\hline Negociação & Negociação & Permite, Não Permite \\
\hline Favoritos & Favoritos & Permite, Não Permite \\
\hline
\end{tabular}

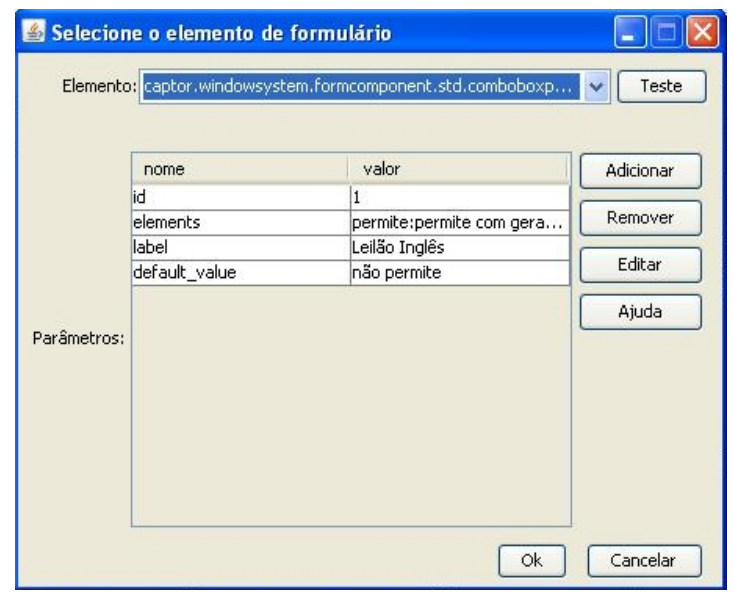

Figura 5.4: Configuração do ponto de variação Tipo de Leilão.

\subsubsection{Criação dos Gabaritos}

Quando o engenheiro de aplicações escolhe as opções apresentadas na LMA para especificar a aplicação, o Captor-AO armazena essas informações em uma representação textual no formato 
XML. A estrutura em XML que o Captor-AO utiliza para persistir a especificação possui uma parte fixa (independente de domínio) e uma parte variável (dependente de domínio) (Shimabukuro Junior, 2006). A parte variável representa as opções que o engenheiro de aplicações escolheu e pode ser acessada dentro do gabarito para que o código de ligação adicionado corresponda a opção escolhida. Na Listagem 5.1, apresentam-se trechos desse arquivo XML para uma certa configuração de aplicação. Destacam-se as partes variáveis nas linhas 11 e 15 . Na linha 11 o engenheiro de aplicações escolheu o nome da aplicação a ser gerada e na linha 15 foi selecionado o tipo de leilão do sistema alvo: Leilão Inglês.

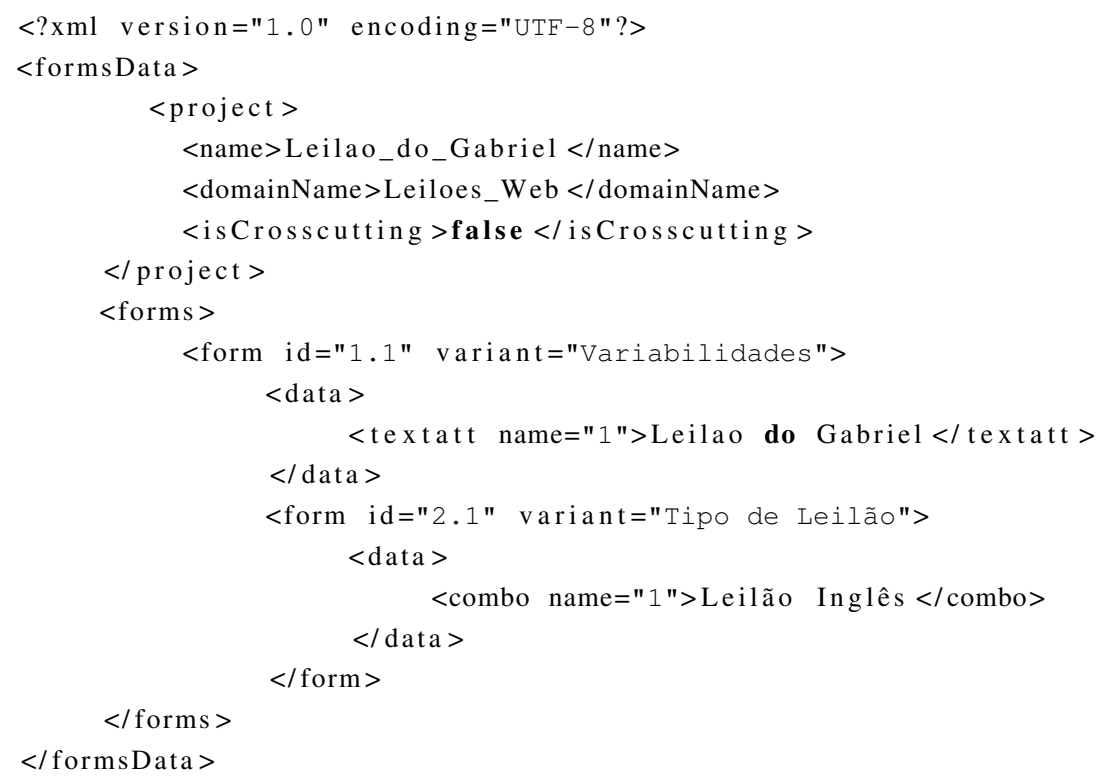

Listagem 5.1: Trechos de uma instância da LMA.

Normalmente, deve haver um gabarito para cada artefato a ser gerado (Shimabukuro Junior, 2006). Os artefatos que devem ser gerados podem ser delineados a partir: da tabela de descrição das GUIs, pois ela mostra quais elementos de interface estão relacionados com cada característica, e a partir da características sabe-se quais são os serviços que se relacionam com ela, pela inversão do algoritmo de criação de serviços; dos diagramas de comunicação, que mostram as relações das telas da GUI com os serviços ou processos de negócios, conforme foi apresentado na Seção 4.7.3 e 4.7.4. A partir desses artefatos é possível saber quais elementos de interface devem ser adicionados ou alterados quando uma certa característica é escolhida, e se esse elemento de interface for conectado com algum controlador, pode ser necessário alterar o controlador também.

Os gabaritos utilizados pela ferramenta para transformar os dados da especificação em artefatos devem ser construídos com a linguagem de gabaritos XSL, que é a linguagem de transformação utilizada pelo Captor-AO. Na Listagem 5.2, apresentam-se trechos do gabarito para o arquivo Detal heRecurso . jsp. Destaca-se na linha 15 a declaração do servlet recurso como controlador das requisições dessa página. Entre as linhas 23 e 25 estão os códigos específicos da linguagem XSL. Esse código verifica se o valor passado para o formulário Negociação é Permite, em caso positivo o comando da linha 24 é adicionado na página. No caso dessa característica, não é necessário incluir chamada a algum serviço, pois a página negociação possui um controlador fixo 
que acessa somente um WS, por esse motivo esse código, que é fixo, já foi adicionado durante a engenharia de domínio.

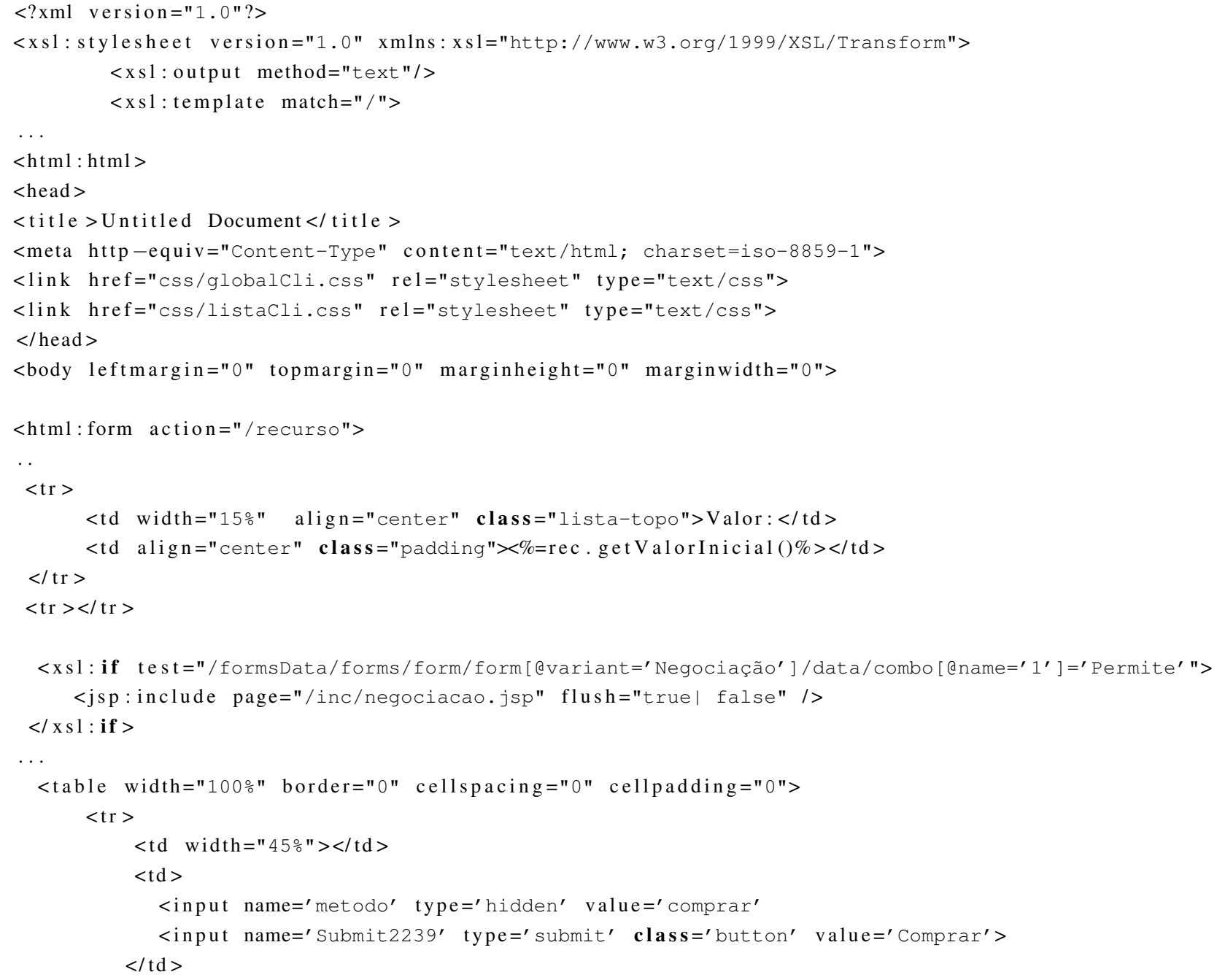

Listagem 5.2: Trechos do gabarito detalheRecurso.jsp.xsl.

\subsubsection{Definição do Arquivo de Mapeamento de Transformação de Gabaritos}

$\mathrm{O}$ arquivo de mapeamento de transformação de gabaritos é usado pelo Captor-AO para indicar quais gabaritos devem ser utilizados no processo de geração de artefatos. Esse arquivo é feito com a linguagem MTL (do inglês Mapping Transformation Language), criada especificamente para o Captor e que também é usada com o mesmo propósito no Captor-AO (Shimabukuro Junior, 2006). Na Listagem 5.3, apresenta-se o arquivo de mapeamento de transformação de gabaritos para o gabarito criado para o arquivo Detal heRecurso.jsp. Na linha 3 faz-se a chamada à tarefa detalhe, que conforme apresenta-se nas linhas 8 e 9 realiza a transformação do gabarito detalhe.jsp.xsl no arquivo detalhe.jsp que é adicionado ao pacote $\backslash$ WebContent \recursos \detalhe. jsp e posteriormente, será utilizado pelo sistema alvo. 


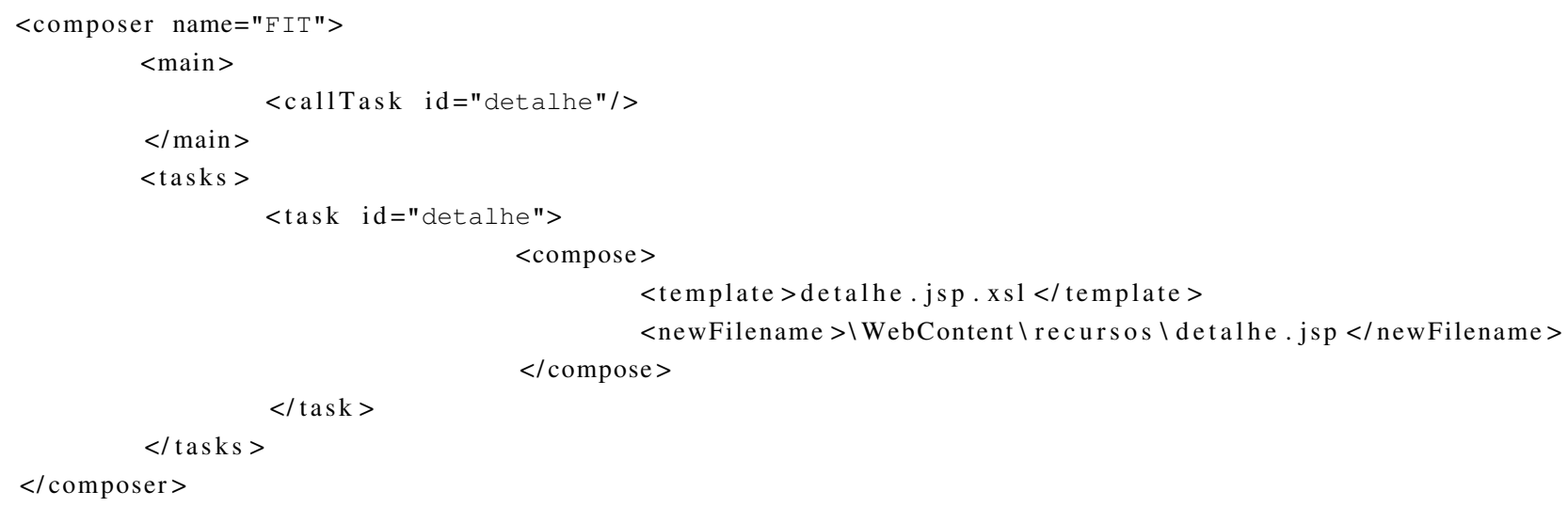

Listagem 5.3: Trechos do arquivo de mapeamento de transformação de gabaritos.

\subsubsection{Definição dos Arquivos de Pré e Pós-processamento}

Para concluir a configuração do Captor-AO para a LPS de leilões Web, elabora-se os arquivos de pré e pós-processamento, que utilizam o modelo do Ant e são opcionais. Por meio deles se faz, entre outras coisas, a montagem, compilação e implantação, no servidor Web, da aplicação gerada. Um exemplo desse arquivo será apresentado na Seção seguinte.

\subsection{Engenharia de Aplicações}

A seguir é detalhado o processo de engenharia de aplicações para o domínio de leilões Web. O engenheiro de aplicações é responsável por elicitar os requisitos da aplicação a ser obtida e verificar se ela encontra-se dentro do domínio de leilões Web. Em caso negativo, não pode-se gerar a aplicação a partir do Captor-AO. Nesse caso as alternativas são: iniciar um novo projeto para o desenvolvimento dessa aplicação ou passar os requisitos da aplicação para o engenheiro de domínio avaliar se é viável realizar manutenções na LPS de modo que ela seja capaz de gerar essa aplicação. Caso a aplicação faça parte do domínio de leilões Web, deve-se identificar as características da aplicação que se encaixam nas características variantes da LPS. Para esse exemplo, considera-se que a aplicação deve possuir a característica de realizar leilão inglês e quer permite-se negociação.

A partir das características identificadas para a aplicação, é possível configurá-la no CaptorAO. Com esse objetivo, deve-se executar o Captor-AO e criar um projeto no domínio Leilões Web. Na Figura 5.5, são mostrados os formulários preenchidos para que o sistema alvo possa ser gerado com as variabilidades Leilão Inglês e Negociação. O primeiro passo consiste em dar um nome para a aplicação. Em seguida, seleciona-se os valores dos elementos dos diversos formulários para a aplicação de acordo com as suas características, conforme apresenta-se na figura. Quando a característica não está presente na aplicação, seleciona-se a opção "Não Permite " para a variabilidade. Como exemplo, tem-se a característica Favoritos, que não existe para a aplicação, logo é marcada como 'Não Permite”. Para as características que são mutuamente exclusivas, caso 
das características Leilão Holandês, Leilão de Compra e Leilão Inglês, o formulário foi elaborado de forma que somente uma delas possa ser escolhida.

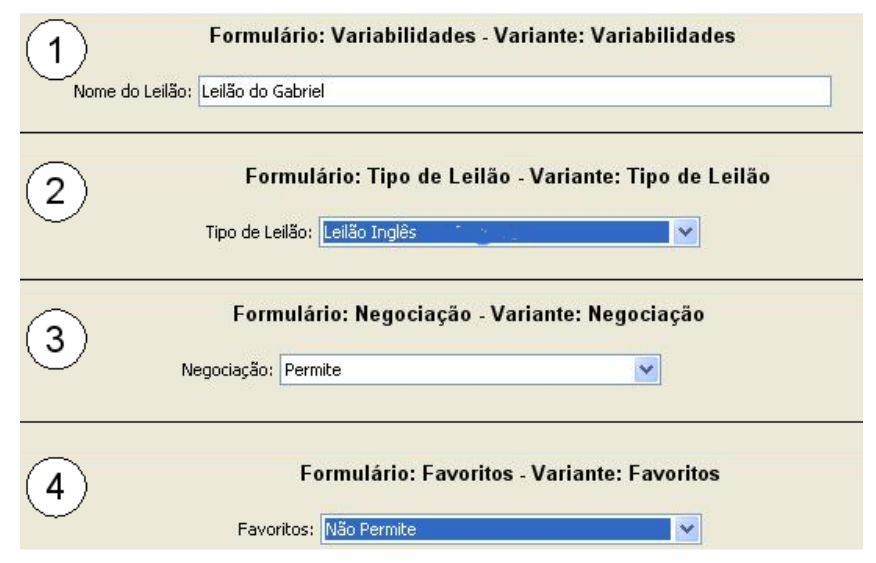

Figura 5.5: Escolha das característica para a aplicação alvo.

Para que o Captor-AO possa processar os gabaritos para gerar a aplicação, o engenheiro de aplicações deve salvar o projeto da aplicação. Nesse ponto, o Captor-AO gera o arquivo no qual estão salvos os valores selecionados pelo engenheiro para as variabilidades. Como pode ser visto na Figura 5.6, o Captor-AO apresenta no console a confirmação de geração do código XML com base nos formulários preenchidos. O código gerado pelo Captor-AO nesse momento é semelhante aos trechos mostrados na Listagem 5.1.

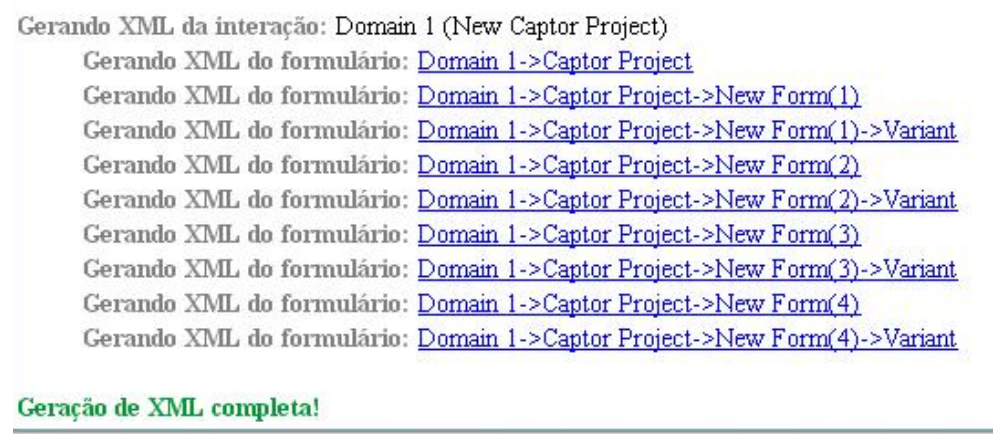

Figura 5.6: Exibição do log de geração do código XML.

Em seguida, a aplicação pode ser gerada, clicando-se no botão Gerar. O Captor-AO gera os arquivos configurados a partir dos gabaritos e do código XML que define as variabilidades escolhidas. Na Listagem 5.4 apresentam-se trechos do código do gabarito do controlador LanceAct i on, em que o Servlet é chamado sempre que um lance é dado e ele é responsável por chamar o WS LanceWS que persiste o Lance no BD. Destacam-se as linhas 26 a 41 nas quais, dependendo do tipo de leilão escolhido pelo engenheiro de aplicações, uma operação específica do WS LanceWS é chamado. Quando é escolhido no formulário o tipo de leilão, leilão de compra, executa-se as operações que estão entre as linhas 27 e 30 . Caso seja escolhida a opção leilão inglês, são executadas as operações entre as linhas 33 e 36 e caso seja escolhida a opção leilão holandês, executam-se 
os códigos entre as linhas 39 e 42. Vale ressaltar que também existem PN BPEL implantados no servidor OC4J da Oracle, e o seu acesso é feito da mesma forma que se faz com um WS, ou seja, os stubs para seu acesso fazem parte da biblioteca da GUI e podem ser utilizados por controladores da mesma forma que o exemplo apresenta para o acesso ao WS LanceWS.

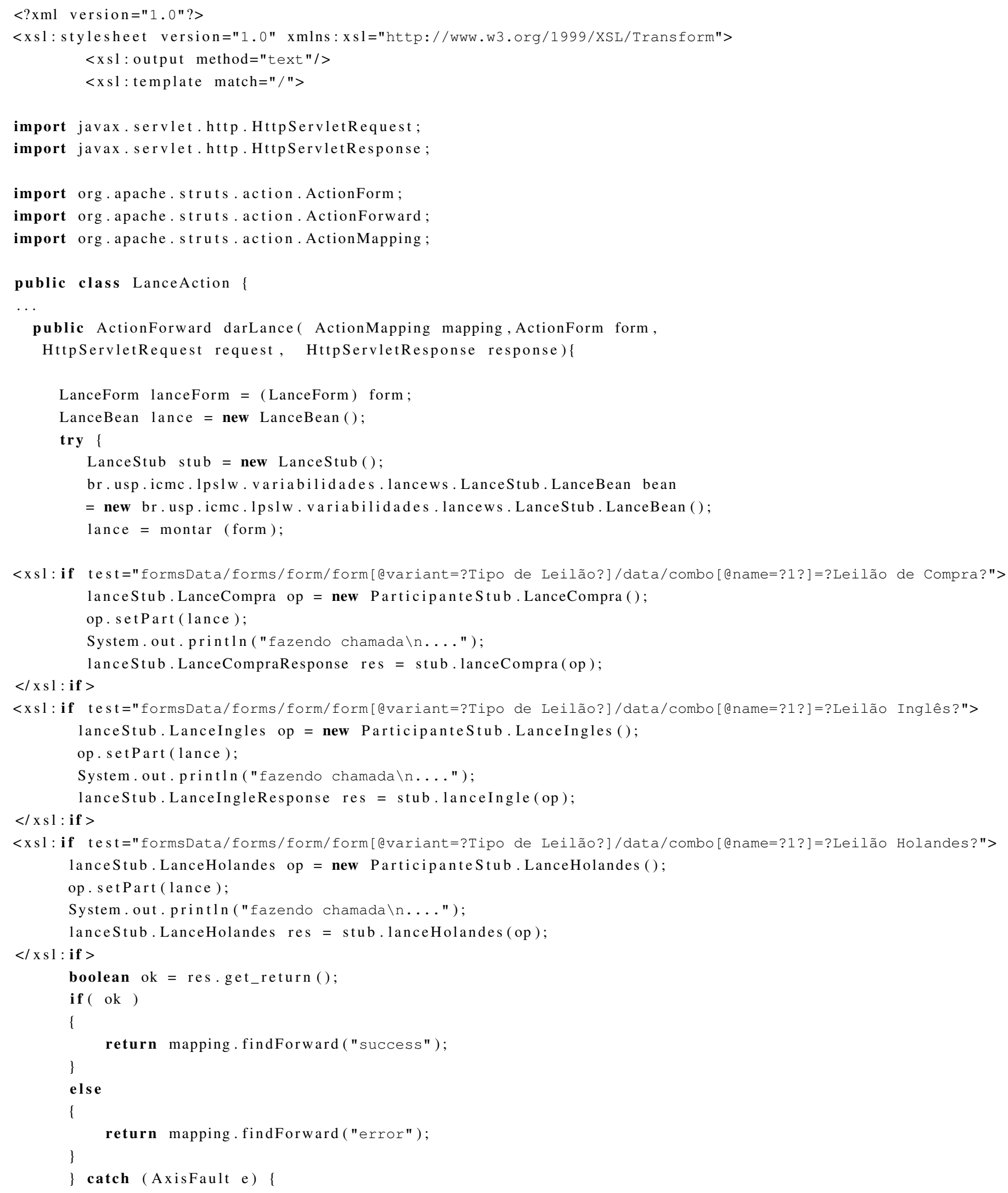




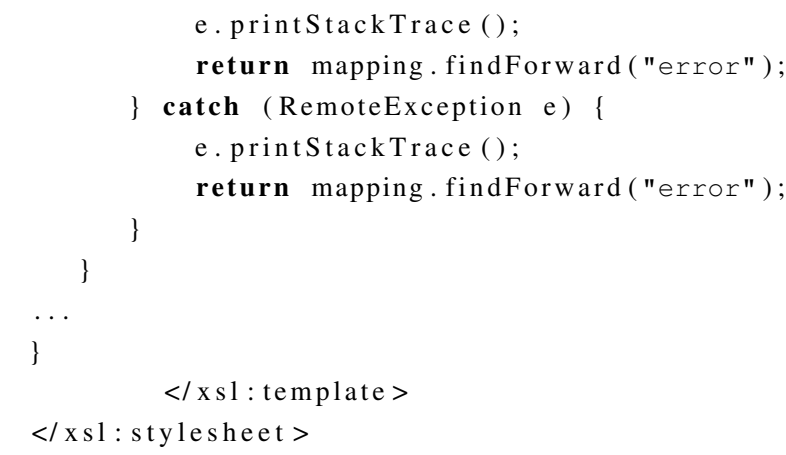

Listagem 5.4: Trechos do gabarito LanceAction.java.xsl.

Depois de gerar os artefatos configurados para as opções do sistema alvo, utiliza-se o arquivo de pós-processamento para montar a aplicação, ou seja, copiar os arquivos do núcleo, juntá-los com os arquivos gerados pelo Captor-AO, compilá-los e implantá-los no servidor de aplicações Tomcat. Na Listagem 5.5, apresentam-se trechos de código do arquivo de pós-processamento, que é responsável por realizar essa tarefa. Entre as linhas 4 e 9 definem-se algumas variáveis utilizadas ao longo do arquivo, entre as linhas 11 e 20 são adicionadas as bibliotecas ao classpath da aplicação, da linha 22 em diante são declaradas as atividades a serem realizadas para a cópia de arquivos, montagem da estrutura das pastas, compilação do código, criação do arquivo .war e, por fim, implantação do sistema resultante no servidor Web.

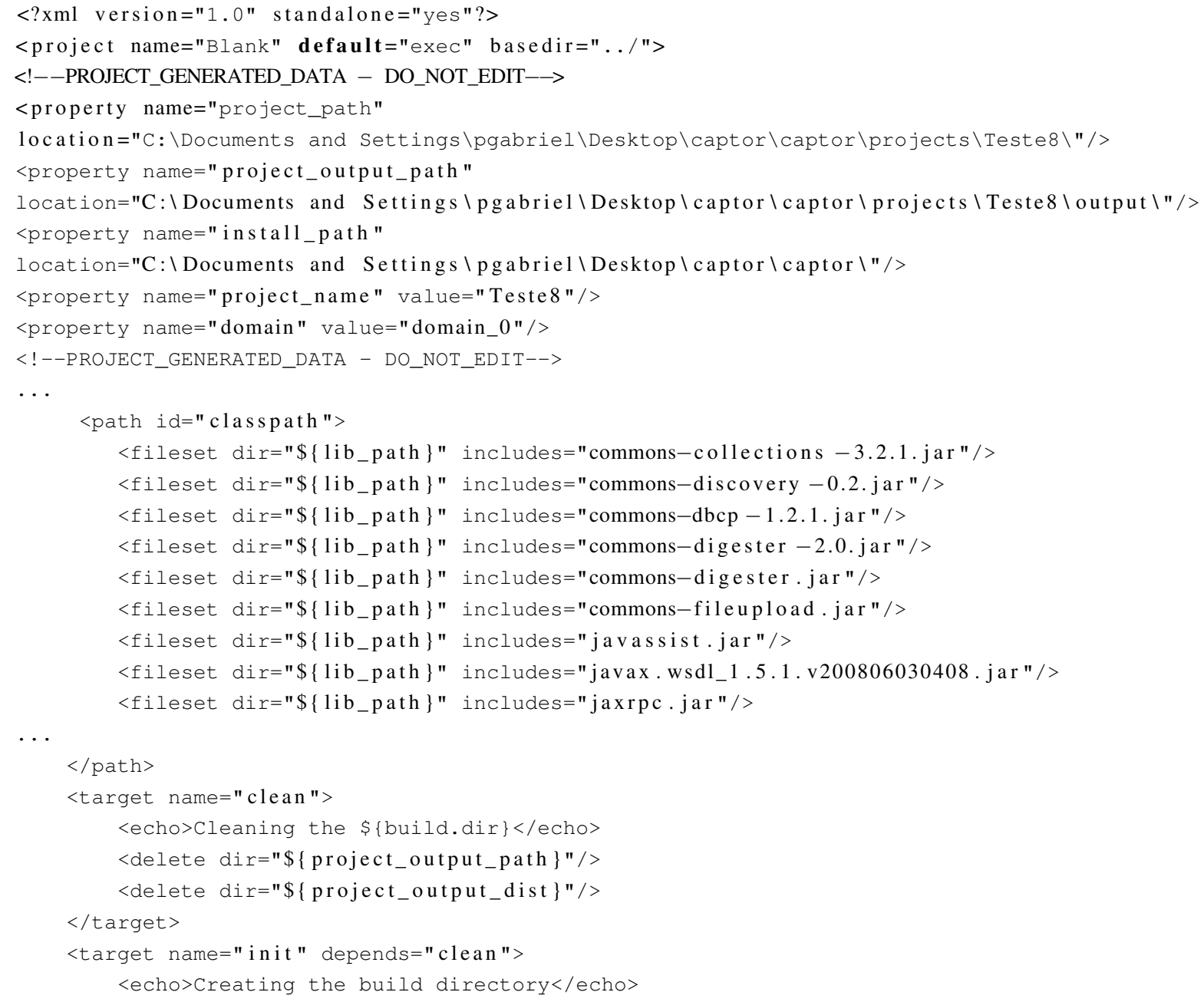




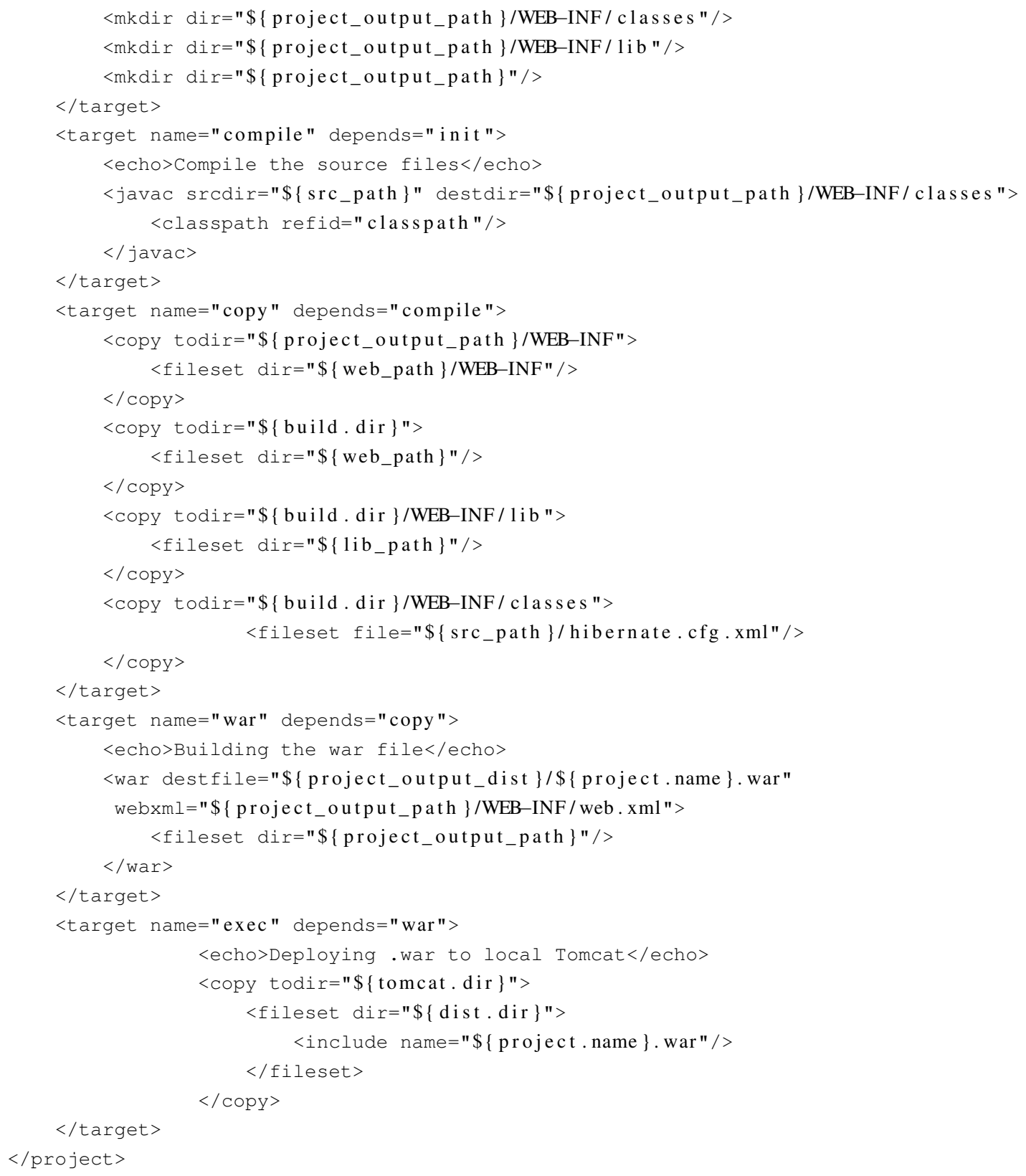

Listagem 5.5: Trechos do arquivo de pós-processamento.

Na Figura 5.7, apresentam-se as variabilidades implementadas no sistema alvo como resultado gerado pelo Captor-AO e implantado no servidor Web.

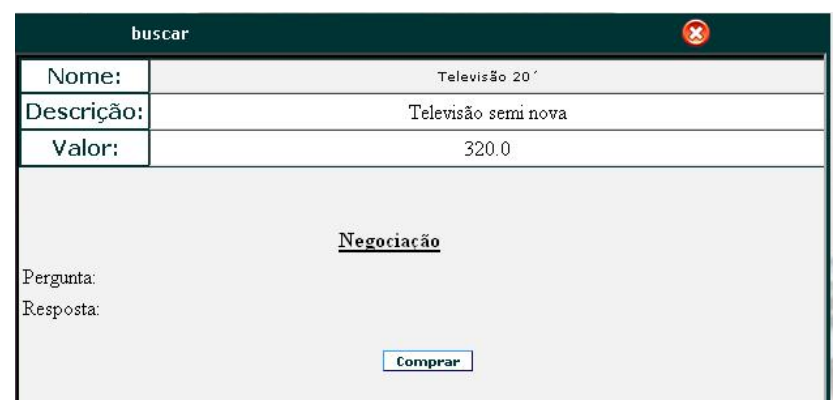

Figura 5.7: GUI gerada pela transformação dos gabaritos feita pelo Captor-AO. 


\subsection{Considerações Finais}

Este capítulo apresentou em detalhes os passos necessários para a configuração de uma LPS orientada a serviços no gerador de aplicações Captor-AO. Foi definida uma LMA para a LPS de leilões Web, criados os gabaritos para a linha, criado o arquivo de mapeamento de transformação de gabaritos e por fim, criado o arquivo de pós processamento para a compilação e implantação do sistema alvo no servidor Web.

Adicionalmente, apresentou-se um exemplo da engenharia de aplicação para um sistema específico de leilões Web com as características de realizar leilões do tipo inglês e permitir a negociação entre as partes. No Capítulo seguinte apresentam-se as conclusões deste trabalho. 
Neste trabalho foi apresentada uma abordagem para o desenvolvimento de LPS baseado em web services, denominada SoProL-WS. Nesta abordagem, a estrutura básica de construção da LPS são os serviços. Os serviços podem ser compostos ou usados de forma separada para montar o núcleo e, posteriormente, os diferentes produtos derivados. Poucos trabalhos abordam a combinação dessas duas tecnologias e os que existem, apresentam lacunas ao longo do processo de desenvolvimento. O método proposto possui duas fases. A primeira é a engenharia de domínio, fase na qual são desenvolvidos os ativos centrais da LPS. A segunda fase consiste da utilização do Captor-AO para a geração de sistemas alvo da linha. Ao longo do desenvolvimento do estudo de caso foram investigadas questões relacionadas à abordagem proposta e ao projeto baseado em web services. A abordagem SoProL-WS recomenda que o desenvolvimento seja iniciado pela implementação dos serviços do núcleo que não precisa ser operacional, a seguir recomenda a implementação dos serviços variantes seguido das composições necessárias. A realização da engenharia de aplicações de forma automatizada é feita com o uso do gerador de aplicações configurável Captor-AO, que foi configurado por meio do desenvolvimento de uma linguagem de modelagem de aplicações (LMA) para a LPS de leilões Web. Na engenharia de aplicações foram geradas diversas aplicações por meio da seleção de variabilidades com combinações válidas para a linha. A seleção de variabilidades corresponde ao fornecimento, pelo engenheiro de aplicações, de uma instância da LMA, que é utilizada como entrada para o Captor-AO, que automaticamente gera a aplicação.

\subsection{Contribuições}

Pode-se destacar como principais contribuições deste trabalho: 
- a definição de uma abordagem de desenvolvimento de LPS baseada em web services. A abordagem chamada SoProL-WS tem o objetivo de guiar o desenvolvimento de LPS com arquitetura orientada a serviços preenchendo as lacunas deixadas por outras abordagens e tornando a derivação dos membros da LPS mais rápida por meio da utilização de um gerador de aplicações para a configuração dos produtos da LPS.

- a discussão sobre questões de projeto de LPS com SOA. Durante a apresentação desta abordagem, foram delineados métodos para: identificação de serviços com o grau de granularidade adequado para que possa ser reusado em outros projetos, definição de processos de negócios menores que devem ser incorporados a LPS, além de discutir questões de projeto como a arquitetura da LPS e o projeto do banco de dados que é feito de forma bem diferente de uma LPS baseada em Componentes.

- a LPS para leilões Web. Foi apresentado um estudo de caso que realizou todas as atividades da abordagem SoProL-WS, gerando os artefatos requeridos, configurando-se o domínio de leilões Web no gerador de aplicações Captor-AO e demonstrando como se dá a derivação de membros da LPS com a utilização do Gerador.

- a análise de diversas ferramentas para desenvolvimento de aplicações que utilizam BPEL para composição de serviços, de modo a facilitar o trabalho de muitas pessoas que precisam utilizar esse tipo de tecnologia.

- a arquitetura para LPS que utiliza serviços e processos de negócios como camada de modelo e assim fica-se desacoplado da interface que pode ser configurada facilmente para utilizar os serviços modelados e implementados para a LPS.

- o conjunto de aplicações de leilões Web que pode ser utilizado para se estudar tanto as propriedades de uma LPS orientada a serviço quanto de aplicações Web orientadas a serviços.

\subsection{Dificuldades e Limitações}

A primeira dificuldade encontrada foi a escolha de um método de desenvolvimento de LPS como base para o trabalho. Os diversos métodos existentes abordam o problema de desenvolvimento de LPS por diferentes perspectivas e focam em um ponto específico do desenvolvimento. Foi necessário encontrar as lacunas desses métodos e procurar preencher com as melhores alternativas possíveis.

Outra dificuldade encontrada foi em relação a linguagem WS-BPEL e suas ferramentas de apoio. Existem diversas engines e ferramentas para o desenvolvimento de projetos BPEL, mas ainda falta padronização entre elas e principalmente documentação. A dificuldade de realizar certas operações BPEL em um conjunto engine/ferramenta pode variar de conjunto para conjunto. 
Ainda são poucos os exemplos de utilização de BPEL na literatura, o que dificulta quando se inicia seu uso.

Em relação à abordagem proposta, a principal limitação é a impossibilidade de alterar o sistema alvo em tempo de execução e não utilização de registro/repositório de serviços. Com os estudos realizados neste trabalho, acredita-se que a utilização de padrões de projeto para GUI pode reduzir muito a necessidade de alterações na GUI quando são alteradas as características da LPS.

A abordagem SoProL-WS foi avaliada com base em um estudo de caso, de leilões Web. A abordagem poderia ser aperfeiçoada com sua aplicação para construção de LPSs para outros domínios diferentes.

\subsection{Trabalhos Futuros}

Neste trabalho, considerou-se que os serviços externos são imutáveis e estão sempre funcionando da forma esperada. Um dos trabalhos futuros é prover uma verificação dos serviços, antes de montar a linha, para verificar se eles não foram alterados ou desativados.

Outro trabalho futuro é pesquisar formas de encaixar no método SoProL-WS a alteração de produtos e busca por serviços melhores em tempo de execução.

O teste de LPSs e de serviços é outra questão que precisa ser melhor estudada para encaixar técnicas de teste de LPSs com SOA na abordagem.

Seria interessante também investigar a utilização de serviços web semânticos para produzir LPSs de forma automatizada com a utilização de serviços disponíveis na rede.

Conforme foi discutido na Seção 6.2, é interessante fazer um estudo de como projetar melhor a GUI para que seja alterada o mínimo possível para as configurações de diferentes características.

Outro trabalho interessante seria estudar o comportamento do banco de dados ao longo da utilização da LPS com SOA, uma vez que as diversas aplicações com configurações diferentes compartilham o mesmo BD e isso pode resultar numa subutilização do BD, ou de forma contrária, pode-se usar esse BD compartilhado para traçar perfis de usuários.

Finalmento, o uso de aspectos na implementação de serviços deve ser investigado, considerando o que precisa ser mudado na SoProL-WS para permitir esse uso e o uso do Captor-AO, que é uma versão estendida do Captor para aspectos. 

Active endpoints ActiveVos. Programa de computador, 2009.

Disponível em: http: / / www . activevos. com/ (Acessado em 27 de novembro de 2009)

Aggarwal, C. C.; Yu, P. S. Online Auctions: There Can Be Only One. In: IEEE International Conference on E-Commerce Technology, Los Alamitos, CA, USA: IEEE Computer Society, 2009, p. 176-181.

Andrews, T.; Curbera, F.; Dholakia, H.; Goland, Y.; Klein, J.; Leymann, F.; LiU, K.; Roller, D.; Smith, D.; Thatte, S.; Trickovic, I.; Weerawarana, S. BPEL4WS, Business Process Execution Language for Web Services Version 1.1. IBM, 2003.

Disponível em: http://www.ibm.com/developerworks/library/ specification/ws-bpel/ (Acessado em 25 de junho de 2009)

ARDis, M. A.; WeISS, D. M. Defining families: the commonality analysis (tutorial). In: Proceedings of the 19th International Conference on Software Engineering (ICSE '97), New York, NY, USA: ACM, 1997, p. 649-650.

Arlow, J.; Neustadt, I. UML and the Unified Process: Practical Object-Oriented Analysis and Design. Addison-Wesley, 416 p., 2002.

Atkinson, C.; Bayer, J.; Bunse, C.; Kamsties, E.; Laitenberger, O.; Laqua, R.; Muthig, D.; PAech, B.; WÜst, J.; Zettel, J. Component-based product line engineering with UML. Addison-Wesley, 464 p., 2002.

BARAgry, J.; REED, K. Why Is It So Hard to Define Software Architecture? In: Proceedings of the Fifth Asia Pacific Software Engineering Conference (APSEC '98), Washington, DC, USA: IEEE Computer Society, 1998, p. 28.

BAResi, L.; NitTo, E. D.; GHezzI, C. Towards open-world software: Issue and challenges. In: Proceedings of the 30th Annual IEEE/NASA Software Engineering Workshop (SEW '06), Washington, DC, USA: IEEE Computer Society, 2006, p. 249-252. 
Barros, A.; Dumas, M.; OAKs, P. Standards for Web Service Choreography and Orchestration: Status and Perspectives. In: Proceedings Business Process Management Workshops, 2005, p. 61-74.

Bass, L.; Clements, P.; Kazman, R. Software architecture in practice. Boston: AddisonWesley, 452 p., 2003.

Bayer, J.; Flege, O.; Gacek, C. Creating Product Line Architectures. In: Proceedings of the International Workshop on Software Architectures for Product Families (IW-SAPF-3), London, UK: Springer-Verlag, 2000a, p. 210-216.

Bayer, J.; Flege, O.; Knauber, P.; Laqua, R.; Muthig, D.; Schmid, K.; Widen, T.; DeBAud, J.-M. PuLSE: a methodology to develop software product lines. In: Proceedings of the 1999 Symposium on Software Reusability (SSR '99), New York, NY, USA: ACM, 1999, p. 122-131.

Bayer, J.; Gacek, C.; Muthig, D.; Widen, T. PuLSE-I: Deriving Instances from a Product Line Infrastructure. In: Seventh IEEE International Conference and Workshop on the Engineering of Computer Based Systems (ECBS 2000), Los Alamitos, CA, USA: IEEE Computer Society, 2000b, p. 237-245.

Bosch, J. Design and use of software architectures: adopting and evolving a product-line approach. New York, NY, USA: ACM Press/Addison-Wesley, 368 p., 2000.

Bosch, J. On the Development of Software Product-Family Components. In: International Conference on Software Product Line (SPLC 2004), 2004, p. 146-164.

Buschmann, F.; Henney, K.; Schmidt, D. C. Pattern-Oriented Software Architecture Volume 4: A Pattern Language for Distributed Computing. Wiley, 636 p., 2007.

Buschmann, F.; Meunier, R.; Rohnert, H.; Sommerlad, P.; Stal, M.; Sommerlad, P.; Stal, M. Pattern-Oriented Software Architecture, Volume 1: A System of Patterns. Wiley, 476 p., 1996.

CAnfora, G. User-Side Testing of Web Services. In: Ninth European Conference on Software Maintenance and Reengineering, Los Alamitos, CA, USA: IEEE Computer Society, 2005, p. 301.

Canfora, G.; Penta, M. D. Testing Services and Service-Centric Systems: Challenges and Opportunities. IT Professional, v. 8, n. 2, p. 10-17, 2006.

Castro, V.; SAnZ, M. L.; Marcos, E. Business Process Development based on Web Services: a Web Information System for Medical Image Management and Processing. In: International Conference on Web Services (ICWS '06), 2006, p. 807-814. 
Chang, S. H.; KIM, S. D. A Variability Modeling Method for Adaptable Services in ServiceOriented Computing. In: Proceedings of the 11th International Software Product Line Conference (SPLC '07), Washington, DC, USA: IEEE Computer Society, 2007, p. 261-268.

Chou, W.; LI, L.; LIU, F. Web Services for Service-Oriented Communication. In: International Conference on Collaborative Computing: Networking, Applications and Worksharing (CollaborateCom 2006), 2006, p. 1-8.

Cleaveland, J. C. Building Application Generators. IEEE Software, v. 5, n. 4, p. 25-33, 1988.

Clements, P.; Northrop, L. Software Product Lines: Practices and Patterns. Boston, MA, USA: Addison-Wesley Longman, 608 p., 2001.

Czarnecki, K.; Østerbye, K.; Völter, M. Generative Programming. In: ECOOP Workshops, 2002, p. 15-29.

Davidson, D. J.; Atherton, B.; Bailliez, S.; Ensin, M. B. The Apache Ant Project. Programa de computador, 2009.

Disponível em: http: / / ant . apache. org (Acessado em 25 de novembro de 2009)

Deng, X.; Lin, Z.; Cheng, W.; XiaO, R.; FAnG, L.; LI, L. Modeling Web Service Choreography and Orchestration with Colored Petri Nets. In: Eighth ACIS International Conference on Software Engineering, Artificial Intelligence, Networking, and Parallel/Distributed Computing (SNPD 2007), Qingdao, China: IEEE Computer Society, 2007, p. 838-843.

Dijkman, R. M.; Joosten, S. M. M. An Algorithm to Derive Use Case Diagrams from Business Process Models. In: 6th International Conference on Software Engineering and Applications (SEA), Anaheim, CA, USA: ACTA Press, 2002, p. 679-684.

DikMAns, L. Transforming BPMN into BPEL: Why and How. 2008.

Disponível em: http://www.oracle.com/technology/pub/articles/ dikmans-bpm.html (Acessado em 31 de outubro de 2009)

DURÃES, M. S. D. Teoria dos Leilões: Abordagem comparativa com ênfase nos leilões de títulos do tesouro no Brasil e em outros países. Internet, 1997.

Disponível em: http://www.tesouro.fazenda.gov.br/Premio_TN/ IIpremio/divida/2afdpIVPTN/DURAES_Marisa_Socorro.pdf (Acessado em 06 de julho de 2009)

Endo, A. T. Uma estratégia de teste para composição de web services. Dissertação de Mestrado, Universidade de São Paulo, São Carlos, SP, 2007. 
Endrei, M.; Ang, J.; Arsanjani, A.; Chua, S.; Comte, P.; Krogdahl, P.; Luo, M.; Newling, T. Patterns: Service-Oriented Architecture and Web Services. IBM Redbooks, 2004.

Disponível em: http://www.redbooks.ibm.com/abstracts/sg246303.html (Acessado em 25 de junho de 2009)

ERL, T. Service-Oriented Architecture: Concepts, Technology, and Design. Upper Saddle River, NJ, USA: Prentice Hall PTR, 792 p., 2005.

Fowler, M.; Scott, K. UML Distilled: A Brief Guide to the Standard Object Modeling Language. 2 ed. Addison-Wesley Professional, 185 p., 1999.

Freitas PEREIRA JÚNIOR, C. A. Geração de aplicações para linhas de produtos orientadas a aspectos com apoio da ferramenta Captor-AO. Dissertação de Mestrado, Universidade de São Paulo, São Carlos, SP, 2006.

Gimenes, I. M. S.; Travassos, G. H. O enfoque de linha de produto para desenvolvimento de software. Minicurso da XXI Jornada de Atualização em Informática (JAI 2002), evento Integrante do XXII Congresso da SBC (SBC 2002), 2002.

GomaA, H. Designing Software Product Lines with UML: From Use Cases to Pattern-Based Software Architectures. Redwood City, CA, USA: Addison Wesley Longman, 736 p., 2004.

GomaA, H.; SAleh, M. Software product line engineering for Web services and UML. In: Proceedings of the ACS/IEEE 2005 International Conference on Computer Systems and Applications (AICCSA '05), Washington, DC, USA: IEEE Computer Society, 2005, p. 110-vii.

GREENFIELD, J.; SHORT, K. Software factories: assembling applications with patterns, models, frameworks and tools. In: 18th annual ACM SIGPLAN conference on object-oriented programming, systems, languages, and applications (OOPSLA '03), New York, NY, USA: ACM, 2003, p. 16-27.

GRISS, M. L. Implementing Product-Line Features with Component Reuse. In: Proceedings of the 6th International Conference on Software Reuse (ICSR-6), London, UK: Springer-Verlag, 2000, p. 137-152.

Gurp, J.; Savolainen, J. Service grid variability realization. In: SPLC '06: Proceedings of the 10th International on Software Product Line Conference, Washington, DC, USA: IEEE Computer Society, 2006, p. 85-94.

Gurp, J. V.; Bosch, J.; Svahnberg, M. On the Notion of Variability in Software Product Lines. In: Proceedings of the Working IEEE/IFIP Conference on Software Architecture (WICSA '01), Washington, DC, USA: IEEE Computer Society, 2001, p. 45. 
Hamadi, R.; Benatallah, B. A Petri net-based model for web service composition. In: Proceedings of the 14th Australasian database conference (ADC '03), Darlinghurst, Australia, Australia: Australian Computer Society, 2003, p. 191-200.

Holmes, J. Struts: The complete reference. 2 ed. New York, NY, USA: McGraw-Hill, 800 p., 2007.

IBM Eclipse BPEL plug-in. Programa de computador, 2009.

Disponível em: http://www.ibm.com/developerworks/opensource/ library/os-eclipse-bpel2.0/ (Acessado em 27 de novembro de 2009)

Jacobson, I.; Booch, G.; Rumbaugh, J. The Unified Software Development Process. Boston, MA, USA: Addison-Wesley Longman, 512 p., 1999.

JARZABEK, S. From reuse library experiences to application generation architectures. In: Proceedings of the 1995 Symposium on Software reusability (SSR '95), New York, NY, USA: ACM, 1995, p. 114-122.

Kang, K. C.; Cohen, S. G.; Hess, J. A.; Novak, W. E.; Peterson, A. S. Feature-Oriented Domain Analysis (FODA) Feasibility Study. Relatório Técnico, Carnegie-Mellon University Software Engineering Institute, 1990.

Disponível em: http://www.sei.cmu.edu/library/abstracts/reports/ 90tr021. cfm (Acessado em 29 de novembro de 2009)

Kang, K. C.; Kim, S.; LeE, J.; Kim, K.; Shin, E.; Huh, M. FORM: A feature-oriented reuse method with domain-specific reference architectures. Annals of Software Engineering, v. 5, p. 143-168, 1998.

Kang, K. C.; Lee, J.; Donohoe, P. Feature-Oriented Product Line Engineering. IEEE Software, v. 19, n. 4, p. 58-65, 2002.

Knauber, P.; Muthig, D.; Schmid, K.; Widen, T. Applying product line concepts in small and medium-sized companies. IEEE Software, v. 17, n. 5, p. 88-95, 2000.

Komoda, N. Service oriented architecture (SOA) in industrial systems. In: IEEE International Conference on Industrial Informatics, Singapore, 2006, p. xxiii-xxiii.

KrafzIG, D.; Banke, K.; Slama, D. Enterprise SOA : Service-Oriented Architecture Best Practices. The Coad Series. Prentice Hall, 408 p., 2004.

Krueger, C. W. Software reuse. ACM Computing Surveys, v. 24, n. 2, p. 131-183, 1992.

Laliwala, Z.; Jain, P.; Chaudhary, S. Semantic based Service-Oriented Grid Architecture for Business Processes. In: Proceedings of the IEEE International Conference on Services Computing, IEEE Computer Society, 2006, p. 423-430. 
LARman, C. Applying UML and Patterns: An Introduction to Object-Oriented Analysis and Design and Iterative Development. 3 ed. Prentice Hall, 736 p., 2004.

Lee, J.; Muthig, D.; NaAB, M. An Approach for Developing Service Oriented Product Lines. In: Proceedings of the 12th International Software Product Line Conference (SPLC '08), Washington, DC, USA: IEEE Computer Society, 2008, p. 275-284.

Lewis, G. A.; Morris, E.; Simanta, S.; Wrage, L. Common Misconceptions about Service-Oriented Architecture. In: Proceedings of the Sixth International IEEE Conference on Commercial-off-the-Shelf (COTS)-Based Software Systems (ICCBSS '07), Washington, DC, USA: IEEE Computer Society, 2007, p. 123-130.

LIEGL, P. The Strategic Impact of Service Oriented Architectures. In: Proceedings of the 14th Annual IEEE International Conference and Workshops on the Engineering of Computer-Based Systems (ECBS '07), Washington, DC, USA: IEEE Computer Society, 2007, p. 475-484.

Luo, M.; Goldshlager, B.; Zhang, L.-J. Designing and Implementing Enterprise Service Bus (ESB) and SOA Solutions. In: Proceedings of the IEEE International Conference on Web Services (ICWS’05), Washington, DC, USA: IEEE Computer Society, 2005, p. 24.

Mahmoud, H. Service-oriented architecture (SOA) and web services: The road to enterprise application integration (EAI). Sun Technical Articles, 2005.

Disponível em: http://java.sun.com/developer/technicalArticles/ WebServices/soa/ (Acessado em 29 de novembro de 2009)

Martens, A.; Moser, S.; Gerhardt, A.; Funk, K. Analyzing Compatibility of BPEL Processes. In: International Conference on Internet and Web Applications and Services/Advanced International Conference on Telecommunications (AICT-ICIW '06), IEEE Computer Society, 2006, p. 147.

MCGregor, J. D. Testing a software product line. Relatório Técnico, Software Engineering Institute (SEI), 2001.

Disponível em: http://www.sei.cmu.edu/library/abstracts/reports/ 01 tr022. cfm (Acessado em 29 de novembro 2009)

Mei, H.; Zhang, L. A Framework for Testing Web Services and Its Supporting Tool. In: IEEE International Workshop on Service-Oriented System Engineering, Los Alamitos, CA, USA: IEEE Computer Society, 2005, p. 207-214.

Merson, P. Evaluating a ServiceOriented Architecture. Relatório Técnico, Software Engineering Institute, 2007.

Disponível em: http://www.sei.cmu.edu/library/abstracts/reports/ 07tr015. cfm (Acessado em 29 de novembro de 2009) 
OASIS ebXML. Internet, 2006.

Disponível em: http: / / www . ebxml .org/ (Acessado em 12 de agosto de 2009)

OASIS WS-BPEL v 2.0. Internet, 2007.

Disponível em: http://docs.oasis-open.org/wsbpel/2.0/os/wsbpel-v2 . 0-OS . html (Acessado em 25 de junho de 2009)

OASIS UDDI SPECIFICATION TECHNICAL COMMitTEE UDDI. Internet, 2007.

Disponível em: http://uddi.xml .org/ (Acessado em 25 de fevereiro de 2008)

Object Management Group (OMG) Unified Modeling Language (UML) version 2.1.2. Internet, 2007.

Disponível em: http://www.omg.org/technology/documents/formal/uml. htm (Acessado em 26 de fev. 2008)

Object Management Group (OMG) Business Process Modeling Notation (BPMN) Version 1.2. Relatório Técnico, 2009.

Disponível em: http://www. omg . org/spec/BPMN/1 .2 / PDF (Acessado em 29 de novembro de 2009)

ORACLE BPEL Process Manager. Programa de computador, 2009a.

Disponível em: http://www.oracle.com/technology/products/ias/bpel/ index.html (Acessado em 27 de novembro de 2009)

OrACLE Getting Started: BPEL. Internet, (Acessado em 29 de novembro de 2009), 2009b.

Disponível em: http://www.oracle.com/technology/getting-started/ bpel . html (Acessado em 22 de setembro de 2009)

ORACLE JDeveloper. Programa de computador, 2009c.

Disponível em: http://www.oracle.com/technology/products/jdev/ index.html (Acessado em 27 de novembro de 2009)

ORACLE Oracle Containers for J2EE (OC4J). Programa de computador, 2009d.

Disponível em: http://www.oracle.com/technology/tech/java/oc4j/ index.html (Acessado em 27 de novembro de 2009)

Ouyang, C.; Dumas, M.; Hofstede, A. H. M.; Aalst, W. M. P. From BPMN Process Models to BPEL Web Services. In: 4th International Conference on Web Services (ICWS'06), Chicago, USA: IEEE Computer Society, 2006, p. 285-292.

Ouyang, C.; Dumas, M.; Van Der Aalst, W. M. P.; Ter Hofstede, A. H. M.; MenDLING, J. From business process models to process-oriented software systems. ACM Transactions on Software Engineering and Methodology (TOSEM), v. 19, n. 1, p. 1-37, 2009. 
PACIOS, S. F. Uma abordagem orientada a aspectos para desenvolvimento de linhas de produtos de software. Dissertação de Mestrado, Universidade de São Paulo, São Carlos, SP, 2007.

Papazoglou, M. P. Service-Oriented Computing: Concepts, Characteristics and Directions. In: Fourth International Conference on Web Information Systems Engineering (WISE'03), 2003, p. $3-12$.

Papazoglou, M. P.; Heuvel, W.-J. Service Oriented Architectures: Approaches, Technologies and Research Issues. VLDB Journal, v. 16, n. 3, p. 389-415, 2007.

Papazoglou, M. P.; Traverso, P.; Dustdar, S.; Leymann, F.; Krämer, B. J. ServiceOriented Computing: A Research Roadmap. In: Dagstuhl Seminar Proceedings, 2005, p. $1-29$.

PARNAS, D. L. Designing software for ease of extension and contraction. In: Proceedings of the 3rd international Conference on Software Engineering (ICSE '78), Piscataway, NJ, USA: IEEE Press, 1978, p. 264-277.

Pohl, K.; Metzger, A. Software product line testing. Communications of the ACM, v. 49, n. 12, p. 78-81, 2006.

Roth, M.; Pelegrí-Llopart, E. JavaServer Pages Specification 2.0. JCP Specification, 2003.

Rumbaugh, J.; Jacobson, I.; Booch, G. Unified Modeling Language Reference Manual. 2 ed. Addison-Wesley Professional, 576 p., 2004.

RÉ, R. Um Processo para Construção de Frameworks a partir da Engenharia Reversa de Sistemas de Informação Baseados na Web: Aplicação ao Domínio dos Leilões Virtuais. Dissertação de Mestrado, Universidade de São Paulo, São Carlos, SP, orientador: Paulo Cesar Masiero, 2002.

Ré, R.; Braga, R. T. V.; Masiero, P. C. A Pattern Language For Online Auctions. In: Proceedings of the 8th Annual Conference on Pattern Languages of Programs (PLoP 2001), PLoP, 2001, p. 1-18.

SAleh, M. M. A. Software product line engineering based on web services. Tese de Doutoramento, George Mason University, Fairfax, VA, USA, orientador: Hassan Gomaa, 2005.

Shimabukuro Junior, E. K. Um gerador de aplicações configurável. Dissertação de Mestrado, Universidade de São Paulo, São Carlos, SP, 2006.

Siegel, J. CORBA 3 Fundamentals and Programming. 2 ed. Wiley Computer Publishing, 928 p., 2000. 
Smaragdakis, Y.; BatOry, D. Application Generators. Software Engineering volume of the Encyclopedia of Electrical and Electronics Engineering, 2000.

Software Engineering Institute (SEI) Framework for Software Product Line Practice 5.0. Internet, 2007.

Disponível em: http://www.sei.cmu.edu/productlines/framework.html (Acessado em 27 de janeiro de 2008)

Sun Microsystems Assessing Your SOA Readiness. Internet, 2004.

Disponível em: www.sun.com/software/whitepapers/webservices/soa_ ready . pdf (Acessado em 25 de junho de 2009)

Sun Microsystems Service-Oriented Architecture and Web Services: Concepts, Technologies, and Tools. Internet, 2005.

Disponível em: http://java.sun.com/developer/technicalArticles/ WebServices/soa2/WSProtocols.html (Acessado em 25 de junho de 2009)

Sun Microsystems Java Enterprise Edition. Programa de computador, 2008.

Disponível em: http: / / java. sun. com/ javaee/ (Acessado em 26 de fevereiro de 2008)

Sun MicRosystems, INC. Core j2ee patterns - transfer object. Internet, 2009a.

Disponível em: http://java.sun.com/blueprints/corej2eepatterns/ Patterns/Transferobject.html (Acessado em 28 de nov. 2009)

Sun Microsystems, InC. Core j2ee patterns - transfer object. Internet, 2009b.

Disponível em: http://java.sun.com/blueprints/corej2eepatterns/ Patterns/DataAccessObject.html (Acessado em 28 de nov. 2009)

ThAI, T. L. Learning DCOM. Sebastopol, CA, USA: O'Reilly \& Associates, 499 p., designed By-Nancy Priest, 1999.

The Apache Software Foundation Apache ODE. Programa de computador, 2009a.

Disponível em: http: / / ode. apache. org/ (Acessado em 27 de novembro de 2009)

The Apache Software Foundation Tomcat. Programa de computador, 2009b.

Disponível em: http: / / tomcat . apache.org/ (Acessado em 27 de novembro de 2009)

The Eclipse Foundation Eclipse. Programa de computador, 2009a.

Disponível em: http: / /www. eclipse.org/ (Acessado em 27 de novembro de 2009)

The ECLIPSE Foundation Eclipse Web Tools Platform Project. Internet, 2009b.

Disponível em: http: / / www. eclipse.org/webtools/ (Acessado em 27 de novembro de 2009) 
W3C XML Path Language (XPath) 1.0. Internet, 1999.

Disponível em: http: / /www.w3 . org/TR/xpath (Acessado em 22 de setembro de 2009)

W3C Web Services Description Language (WSDL) 1.1. Internet, 2001.

Disponível em: http: / /www.w3.org/TR/wsdl20/(Acessado em 13 de agosto de 2009)

W3C Web Service Choreography Interface (WSCI) 1.0. Internet, 2002a.

Disponível em: http: / / www.w3.org/TR/wsci (Acessado em 25 de fevereiro de 2008)

W3C Web Services Activity. Internet, $2002 \mathrm{~b}$.

Disponível em: http: / /www.w3.org/2002/ws/ (Acessado em 26 de outubro de 2009)

W3C SOAP Version 1.2 Part 1: Messaging Framework. Internet, 2004.

Disponível em: http: / /www.w3 .org/TR/soap12-part1/ (Acessado em 26 de agosto de 2009)

W3C Extensible Markup Language (XML). Internet, 2008.

Disponível em: http: / / www.w3 . org/XML/ (Acessado em 25 de fevereiro de 2008)

WEISS, D. M.; LAI, C. T. R. Software product-line engineering: a family-based software development process. Boston, MA, USA: Addison-Wesley Longman, 448 p., 2004.

Xiaoqiang, Q.; Jun, W. A Decentralized Services Choreography Approach for Business Collaboration. In: Proceedings of the IEEE International Conference on Services Computing (SCC '06), Washington, DC, USA: IEEE Computer Society, 2006, p. 190-197.

Ye, E.; Moon, M.; Kim, Y.; Yeom, K. An Approach to Designing Service-Oriented ProductLine Architecture for Business Process Families. In: 9th International Conference on Advanced Communication Technology, 2007, p. 999-1002.

Zaupa, F. G. Um Processo de Desenvolvimento de Aplicações Web Baseado em Serviços. Dissertação de Mestrado, Universidade Estadual de Maringá, Maringá, PR, orientadora: I. M. S. Gimenes, 2007.

Zeng, L.; Benatallah, B.; Dumas, M.; Kalagnanam, J.; Sheng, Q. Z. Quality driven web services composition. In: Proceedings of the 12th International Conference on World Wide Web (WWW '03), New York, NY, USA: ACM Press, 2003, p. 411-421. 